\title{
The accumulation of advanced glycation endproducts in diabetes and its relation to vascular disease
}

Citation for published version (APA):

van Eupen, M. G. A. (2017). The accumulation of advanced glycation endproducts in diabetes and its relation to vascular disease. [Doctoral Thesis, Maastricht University]. Maastricht University. https://doi.org/10.26481/dis.20170907mve

Document status and date:

Published: 01/01/2017

DOI:

10.26481/dis.20170907mve

Document Version:

Publisher's PDF, also known as Version of record

\section{Please check the document version of this publication:}

- A submitted manuscript is the version of the article upon submission and before peer-review. There can be important differences between the submitted version and the official published version of record.

People interested in the research are advised to contact the author for the final version of the publication, or visit the DOI to the publisher's website.

- The final author version and the galley proof are versions of the publication after peer review.

- The final published version features the final layout of the paper including the volume, issue and page numbers.

Link to publication

\footnotetext{
General rights rights.

- You may freely distribute the URL identifying the publication in the public portal. please follow below link for the End User Agreement:

www.umlib.nl/taverne-license

Take down policy

If you believe that this document breaches copyright please contact us at:

repository@maastrichtuniversity.nl

providing details and we will investigate your claim.
}

Copyright and moral rights for the publications made accessible in the public portal are retained by the authors and/or other copyright owners and it is a condition of accessing publications that users recognise and abide by the legal requirements associated with these

- Users may download and print one copy of any publication from the public portal for the purpose of private study or research.

- You may not further distribute the material or use it for any profit-making activity or commercial gain

If the publication is distributed under the terms of Article $25 \mathrm{fa}$ of the Dutch Copyright Act, indicated by the "Taverne" license above, 


\section{THE ACCUMULATION OF ADVANCED GLYCATION ENDPRODUCTS IN DIABETES AND ITS RELATION TO VASCULAR DISEASES}


(C) Marcelle van Eupen, Maastricht 2017

No part of this book may be reproduced or transmitted in any form or by any means, without prior permission in writing by the author, or when appropriate, by the publishers of the publications.

Cover photo: Patrick van Denderen

Production: IPSKAMP PRINTING

ISBN: 978-94-028-0723-3

This research presented in this thesis was performed within the framework of CTMM, the Center for Translational Molecular Medicine (www.ctmm.nl), project PREDICCt (grant 01C-104), and supported by the Dutch Heart Foundation, Dutch Diabetes Research Foundation and Dutch Kidney Foundation. 


\title{
THE ACCUMULATION OF ADVANCED GLYCATION ENDPRODUCTS IN DIABETES AND ITS RELATION TO VASCULAR DISEASES
}

\author{
PROEFSCHRIFT \\ ter verkrijging van de graad van doctor aan de Universiteit Maastricht, \\ op gezag van de Rector Magnificus, Prof. dr. Rianne M. Letschert, \\ volgens het besluit van het College van Decanen, \\ in het openbaar te verdedigen op \\ donderdag 7 september 2017 om 10.00 uur
}

door

Marcelle G.A. van Eupen 


\section{Promotores}

Prof. dr. C.G. Schalkwijk

Prof. dr. C.D.A. Stehouwer

Copromotor

Dr. M.T. Schram

Beoordelingscommissie

Prof. dr. P.W. de Leeuw (voorzitter)

Prof. dr. I. Arts

Prof. dr. H. Bilo (Rijksuniversiteit Groningen)

Dr. E.G. Gerrits

Prof. Dr. G. Nijpels (Vrije Universiteit Amsterdam)

Financial support by Maastricht University and the Dutch Heart Foundation for the publication of this thesis is gratefully acknowledged 


\section{CONTENTS}

$\begin{array}{lll}\text { Chapter } 1 & \text { General introduction } & 7\end{array}$

Chapter 2 The methylglyoxal-derived AGE tetrahydropyrimidine is 31 increased in plasma of type 1 diabetes mellitus and in atherosclerotic lesions and is associated with sVCAM-1

Chapter 3 Plasma levels of advanced glycation endproducts are associated with type 1 diabetes and coronary artery calcification

Chapter 4 Skin autofluorescence and pentosidine are associated with aortic stiffening: The Maastricht Study

Chapter 5 Skin autofluorescence, but not plasma AGEs, is positively associated with markers of endothelial dysfunction: The Maastricht Study

Chapter 6 Higher skin autofluorescence, but not plasma AGEs, is 105 associated with lower ankle-brachial index in individuals without and with type 2 diabetes: The Maastricht Study

Chapter 7 Associations of advanced glycation endproducts with cognitive functions in individuals with and without type 2 diabetes: The Maastricht Study

Chapter 8 General discussion

Chapter 9 Valorisation addendum

Nederlandstalige samenvatting

Dankwoord

Curriculum vitae

List of publications 



\section{CHAPTER 1}

GENERAL INTRODUCTION 


\section{GENERAL INTRODUCTION}

Diabetes, or diabetes mellitus, is a group of chronic metabolic diseases which, according to the International Diabetes Federation, affected 415 million people worldwide in $2015^{1}$. In 2015, there were approximately 1,1 million individuals with diagnosed diabetes in the Netherlands ${ }^{2}$. The prevalence of diabetes is increasing rapidly, leading to the projection of The World Health Organisation (WHO) that diabetes will be the $7^{\text {th }}$ leading cause of death in $2030^{3}$. Having diabetes leads to an increased risk of micro- and macrovascular complications ${ }^{4-8}$ and subsequent mortality, illustrated by the fact that diabetes caused 5.0 million deaths worldwide in $2015^{1}$.

There are various mechanisms proposed to explain the increased risk of vascular complications in diabetes, including detrimental effects of advanced glycation endproducts (AGEs) on vascular tissues. This thesis focuses on the associations between AGEs and micro- and macrovascular disease in individuals with and without diabetes. To evaluate these associations, we used different state of the art techniques for the measurements of AGEs and large cohort studies consisting of both individuals with and without diabetes.

\subsection{Diabetes}

Diabetes is characterized by hyperglycaemia, i.e. raised blood sugar, resulting from defects in insulin secretion, insulin action or both ${ }^{9}$. There are various forms of diabetes, of which type 1 and type 2 diabetes are the most common. Type 1 diabetes (T1DM) is characterized by autoimmune destruction of $\beta$-cells in the pancreas, which leads to insufficient insulin production. Individuals with T1DM require daily administration of insulin. T1DM comprises $5-10 \%$ of individuals with diabetes around the world ${ }^{9}$. The incidence of T1DM in western countries is increasing ${ }^{10,11}$, most probably as a result of environmental triggers. However, the exact cause of T1DM is not known and so far, it is neither preventable nor curable. Type 2 diabetes (T2DM), formerly called adultonset diabetes, results from the body's ineffective use of insulin, known as insulin resistance. T2DM has a genetic component. Its incidence is markedly increasing in developing countries ${ }^{3}$, following the trend of the increasing incidence of obesity and increased ageing ${ }^{12,13}$. Obesity itself causes some degree of insulin resistance ${ }^{9}$. Therefore, besides medication to improve glycaemic control, the treatment of T2DM includes an advice for weight reduction, diet and exercise. T2DM accounts for $90-95 \%$ of people with diabetes around the world ${ }^{9}, 14$. Until recently, this type of diabetes was seen only in adults, but it is now also seen in obese children ${ }^{15-17}$.

The WHO and ADA additionally discriminate impaired glucose tolerance (IGT) and impaired fasting glycaemia (IFG) as intermediate conditions in the transition between normal glucose levels and T2DM. Individuals with IGT or IFG have shown to be at higher risk of future development of diabetes and cardiovascular disease (CVD) compared with the general population ${ }^{18-21}$.

\subsection{Micro- and macrovascular complications of diabetes}

Chronic vascular complications are the major source of morbidity and mortality in both T1DM and $\mathrm{T}_{2} \mathrm{DM}^{4-8,}$ 22. Vascular complications can be divided into microvascular complications, caused by damage to small blood vessels, and macrovascular complications, caused by damage to large arteries. Microvascular complications include diabetic nephropathy, neuropathy, and retinopathy. 
Coronary artery disease, peripheral arterial disease, and stroke are considered macrovascular complications ${ }^{22}$. Cognitive decline and dementia is a more recently described chronic complication of diabetes $23-25$.

\subsubsection{Microvascular complications}

Microvascular complications are characterized by endothelial dysfunction and pathological changes in the structure of small arterioles and capillaries, which predominantly involve thickening of the basement membrane and changes in the extracellular matrix. The risk of microvascular complications depends strongly on the duration of diabetes and the degree of glycaemic control? 8,26 .

\section{Diabetic nephropathy}

Diabetic nephropathy is characterized by proteinuria and a subsequent decline in glomerular filtration rate (GFR). Proteinuria is determined by the quantification of urinary albumin, as albumin is the major component of proteinuria. It is caused by detrimental changes of the glomerular capillary wall consisting of endothelial cells, the basement membrane and podocytes. Albuminuria can be subdivided in microalbuminuria and macroalbuminuria. Microalbuminuria, defined as an albumin excretion of 30-300 mg in 24 hours, is the earliest stage of diabetic nephropathy and can, therefore, be used as an early marker. Macroalbuminuria, defined as a urinary albumin excretion of $>300 \mathrm{mg}$ in 24 hours, can progress to end-stage renal disease. In individuals with T1DM and approximately 13 years of diabetes duration, microalbuminuria has shown to be present in $21 \%$ and macroalbuminuria in $9 \%$ of individuals. After a diabetes duration of ten years, the prevalence of microalbuminuria was $25 \%$ and of macroalbuminuria $5 \%$ in individuals with $\mathrm{T}_{2} \mathrm{DM}{ }^{28}$. Both micro and macroalbuminuria are independently associated with an increased CVD risk in individuals with T2DM ${ }^{29}$.

\section{Diabetic retinopathy}

Diabetic retinopathy is generally classified as either background or proliferative retinopathy. Background retinopathy involves small haemorrhages, lipid depositions (hard exudates), micro aneurysms and retinal oedema. Proliferative retinopathy is characterized by the formation of new blood vessels on the surface of the retina (neovascularization) and can lead to vitreous haemorrhage. A sign of impending proliferative retinopathy are the, so called, 'cotton wool spots'. If proliferation continues, blindness can occur through vitreous haemorrhage and traction retinal detachment ${ }^{22}$. In individuals with T1DM and approximately 13 years of diabetes duration, nonproliferative retinopathy was present in $36 \%$ and proliferative retinopathy in $11 \% 27$. The prevalence of diabetic retinopathy was 35\% in individuals with T2DM and approximately 8 years of diabetes duration ${ }^{30}$. The prevalence of any kind of diabetic retinopathy in white individuals with T1DM above the year of 50 is even described as high as $99 \%$ in women and $94 \%$ in men $^{31}$. In white individuals with T2DM, the prevalence of any kind of retinopathy was shown to be much lower, with an overall crude prevalence of $42 \%$ in both men and women ${ }^{32}$.

\section{Diabetic neuropathy}

Diabetic neuropathy is defined as the presence of symptoms and/or signs of peripheral nerve dysfunction in individuals with diabetes, after the exclusion of other causes ${ }^{22}$. Peripheral neuropathy in diabetes may manifest in several different forms, including sensory, focal/multifocal, 
and autonomic neuropathies ${ }^{22}$. Peripheral neuropathy is characterized by a diminished sensitivity to vibrations and thermal stimuli, especially in the legs. Peripheral neuropathy can cause a loss of sensation in response to injury which makes the individual more vulnerable to develop foot and leg ulcers. Pain is another symptom of peripheral neuropathy, which can significantly decrease the quality of life. In individuals with T1DM and approximately 26 years of diabetes duration, 30\% had clinical neuropathy ${ }^{33}$. The prevalence of diabetic peripheral neuropathy has shown to be $35 \%$ in T2DM individuals with 6 years of diabetes duration ${ }^{34}$.

\section{Glycaemic control and microvascular complications}

The association between glycaemic control and microvascular complications has been found in both individuals with T1DM and T2DM. In individuals with T1DM, the prospective Diabetes Control and Complications Trail (DCCT) and the EDIC follow-up study showed that intensive insulin therapy with either an insulin pump or three or more daily insulin injections resulted in decreased rates of retinopathy, nephropathy and neuropathy compared with one or two daily insulin injections 7,35 . Additionally, in individuals with T2DM, the United Kingdom Prospective Diabetes Study (UKPDS) demonstrated that intensive blood-glucose control by either sulphonylureas or insulin compared with conventional diet treatment substantially decreases the risk of microvascular complications ${ }^{8}$. For the risk of nephropathy and retinopathy in individuals with T2DM, these findings were recently supported by a large Cochrane meta-analysis of twenty randomized clinical trials ${ }^{36}$, that included the UKPDS and 'Action in Diabetes and Vascular Disease: Preterax and Diamicron Modified Release Controlled Evaluation' (ADVANCE) trail. However, there is heterogeneity amongst trials with respect to which types of microvascular disease are reduced; in the UKPDS, the reduction in microvascular events was primarily due to the observed reduction in retinopathy, whereas in the ADVANCE trial this was due to a reduction in nephropathy.

\subsubsection{Macrovascular complications}

Macrovascular complications of diabetes are caused by atherosclerosis and/or arteriosclerosis (i.e. arterial stiffening). Atherosclerosis is a chronic inflammatory disease of primarily the intimal layer of the large arteries, beginning with the formation of a 'fatty streak' which may progress to an advanced plaque with a fibrous cap and a necrotic core. The on-going inflammatory response, matrix degradation and cell death eventually thin the fibrous cap and increase the necrotic core content, which increases the risk of plaque rupture. A ruptured plaque in the coronary arteries can lead to myocardial infarction, whereas a ruptured plaque in the carotid artery can lead to stroke. Arterial stiffness is caused by structural and functional changes occurring primarily in the medial layer of the arterial wall and has been associated with left ventricular hypertrophy, impaired coronary perfusion, myocardial infarction and stroke ${ }^{37,38}$. Both T1DM and T2DM are known risk factor for the development of atherosclerosis ${ }^{39}, 40$, arterial stiffness ${ }^{41-43}$ and subsequent CVD, illustrated by a 4-fold increase in the risk of CVD in T1DM ${ }^{4}$ and a 2-fold increase in the risk of individuals with $\mathrm{T}_{2} \mathrm{DM}^{5,6}$. CVD is an important cause of death in individuals with $\mathrm{T}_{1 \mathrm{DM}}{ }^{44}$ or $\mathrm{T}_{2} \mathrm{DM}^{5}$, 6,45 , increasing the risk of death from vascular causes by more than 2 -fold ${ }^{6}$ compared with the general population.

\section{Glycaemic control and macrovascular complications}

The importance of good glycaemic control to decrease the risk of macrovascular disease in individuals with T1DM has also been demonstrated in the EDIC study, which was the follow-up 
study of the DCCT ${ }^{46}$. In this study, intensive insulin therapy reduced the risk of non-fatal myocardial infarction, stroke and death from CVD in individuals with T1DM by $57 \%{ }^{46}$. The protective effect of intensive glycaemic control on the development of macrovascular diseases has not been established as clearly for individuals with T2DM. Based on 10 year follow-up data, the UKPDS study suggested long-term beneficial effects of intensive glucose control on risk reduction for myocardial infarction (24-33\%) and death from any cause (13-27\%) ${ }^{47}$. However, three other randomized clinical trials, i.e. the 'Action to Control Cardiovascular Risk in Diabetes' (ACCORD) trail ${ }^{48}$, ADVANCE trail ${ }^{49}$ and Veterans Affairs Diabetes Trial $(\text { VADT })^{50}$, have shown no reduction in the risk of cardiovascular mortality when comparing an intensive glycaemic control group with a group with conventional glycaemic control. The ACCORD trail even showed an increase in cardiovascular and total mortality with intensive therapy. Meta-analyses ${ }^{51-53}$ show a small reduction in the risk of coronary heart disease and non-fatal myocardial infarction with intensive compared with conventional therapy. However, intensive therapy did not decrease the risk of stroke, cardiovascular mortality or all-cause mortality and increased the risk of severe hypoglycaemia. More double blind randomized controlled trials are needed to establish the best therapeutic approach for hyperglycaemia in individuals with T2DM ${ }^{51}$. To this day, the multifactorial reduction of cardiovascular risk factors, including hyperglycaemia, dyslipidaemia, hypertension, obesity and smoking, is considered to be the most effective approach to prevent macrovascular complication in individuals with $\mathrm{T}_{2} \mathrm{DM}^{54,55}$.

\subsubsection{Cognitive decline}

Cognition is known to decrease as a result of normal aging. Mild cognitive impairment, a state in which memory impairment can be recognized without having an effect on daily functioning, is considered as a risk state for dementia ${ }^{56}$. Dementia has two major forms: Alzheimer's disease, associated with the presence and the accumulation of neurofibrillary tangles and amyloid plaques in the brain ${ }^{57}$, and vascular dementia, also known as multi-infarct dementia, caused by recurrent small strokes in the brain. Both are characterized by progressive memory loss and a decline in cognitive function and often coexist. Several large prospective cohort studies have found that diabetes increases the risk of dementia, illustrated by an average two-fold increase in the risk of Alzheimer's disease or vascular dementia in individuals with diabetes ${ }^{58}$.

\section{Glycaemic control and cognitive decline}

Studies investigating the effect of glycaemic control in reducing the risk of dementia show conflicting results. Several studies have found an association between less tight diabetes control and greater cognitive decline 59,60 . In contrast, a substudy of the ACCORD trail showed no differences in cognitive functioning between intensive and conventional glycaemic control in T2DM ${ }^{61}$. However, mean age was 62 years with a maximum follow-up of 40 months, while it has been suggested that up to the age of 70 years there is little measurable cognitive decline in people with T2DM 61 . Additionally, it has to be noted that severe hypoglycaemic episodes have been associated with dementia, suggesting that tight glycaemic controls also has its downsides ${ }^{62}$.

\subsection{Mechanisms underlying hyperglycaemia-induced damage}

Most cells are able to reduce the influx of glucose when they are exposed to hyperglycaemia, in order to maintain a healthy intracellular glucose concentration. For example, striated muscle (e.g. cardiac muscle) relies on the glucose transporter type 4 (GLUT4) for insulin-regulated glucose 
transport into the cell. In contrast, the cells damaged by hyperglycaemia, i.e. capillary endothelial cells in the retina of the eye, mesangial cells in the renal glomerulus of the kidney, neurons and Schwann cells in peripheral nerves and the endothelial cells of the vessel wall, do not rely on insulin for the transport of glucose through their cell membrane. Consequently, they are not able to sufficiently control the influx of glucose. Therefore, in case of hyperglycaemia, their intracellular concentration of glucose becomes high as well, leading to an increase in glycolytic intermediates which has detrimental effects on cellular functioning ${ }^{63}$.

There are several pathophysiological pathways proposed to explain the hyperglycaemia-induced vascular damage in diabetes. These pathways are: 1 ) increased flux through the polyol pathway, 2) activation of the protein kinase C pathway, 3) increased hexosamine pathway flux and 4) increased formation of AGEs ${ }^{63}$. The AGE pathway will be described in more detail, as this pathway is the focus of this thesis.

\subsection{Advanced glycation endproducts (AGEs)}

AGEs are formed by a non-enzymatic reaction of the aldehydes of reduced sugars with free amino group of proteins. This reaction was first described by Louis-Camille Maillard in 1912 and gained interest of food chemists as the reaction behind the browning of cooked food. This Maillard reaction is initiated by the reversible formation of a Schiff's base which undergoes several rearrangements to become a relatively stable Amadori product. A small part of these Amadori products undergo a series of irreversible oxidative reactions to become stable advanced glycation end-products (AGE) (Figure 1.1). HbA1c is an example of a well-known Amadori product of haemoglobin. In 1969, HbA1c was found to be elevated in diabetes ${ }^{64}$ which initiated research about the role of glycated proteins in diabetes and its complications.

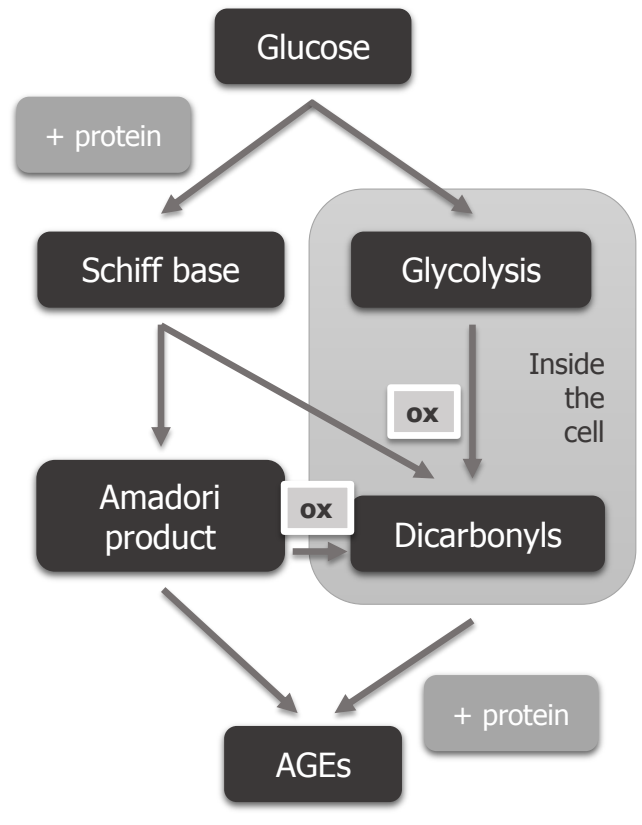

Figure 1.1. Schematic presentation of the major pathways in the formation of AGEs derived from the reaction of a reducing sugar with an amino group within a protein

Left: the classical Maillard reaction Right: intracellular AGE formation out of dicarbonyl precursors Ox, oxidation 
In addition to the classical Maillard reaction, intracellular formation of AGEs from reactive glucoseor lipid-derived dicarbonyl precursors has gained increased attention as an important and more rapid production of $A G E s^{63,65-67}$ (Figure 1.1). This process of AGE formation is more rapid since the very reactive dicarbonyl precursors are able to react with proteins and nucleic acids in a very fast fashion. The dicarbonyl product methylglyoxal (MGO) has been demonstrated to be the most important precursor in the formation of $\mathrm{AGES}^{65,67}$. MGO is a dicarbonyl compound which is mainly formed by the dephosphorylation and conversion of the trioses glyceraldehyde 3-phosphate and dihydroxyacetone phosphate. It primarily reacts with arginine residues in proteins to form three products: the non-fluorescent products 5-hydro-5-methylimidazolone (MG-H1) and tetrahydropyrimidine (THP), and the major fluorescent product, argpyrimidine ${ }^{66}$. MGO also reacts with lysine to form $\mathrm{N}^{\varepsilon}$ (carboxyethyl)lysine (CEL) and methylglyoxal lysine dimer (MOLD) ${ }^{68,69}$. MGO is detoxified to D-lactate by the glyoxalase pathway 70,71 . In addition to a glycolysis-derived dicarbonyl formation, intracellular hyperglycaemia can lead to an increase in dicarbonyl precursors through an increased superoxide $\left(\mathrm{O}_{2}{ }^{-}\right)$formation by the mitochondria. Increased superoxide formation inhibits the key glycolytic enzyme glyceraldehyde-3 phosphate dehydrogenase (GAPDH), which causes an increase in the level of all the glycolytic intermediates that are upstream of GAPDH. Amongst others, this includes glyceraldehyde-3 phosphate and DHAP, the major precursors of MGO ${ }^{63}$.

In addition to glucose, AGEs can also be formed through lipid peroxidation of polyunsaturated fatty acids. This leads to the formation of lipid peroxides, which decompose in a large variety of reactive dicarbonyl compounds, including $\mathrm{MGO}^{72-74}$ and glyoxal (GO). Reactions of these dicarbonyl compounds with amino acid residues results in the formation of, amongst others, CEL and CML, which are therefore both considered advanced lipoxidation endproducts (ALEs) and AGEs ${ }^{75}$. AGE formation can be enhanced by oxidative stress and inflammation ${ }^{76}$.

\subsubsection{AGEs in the pathogenesis of diabetic complications}

AGEs are thought to affect vascular tissue via distinct pathways. First, as depicted in Figure 1.2, certain AGEs, e.g. pentosidine, are able to form cross-links between extracellular matrix proteins such as collagen in the arterial wall, which may directly result in a decrease in vascular elasticity and an increase in arterial stiffness ${ }^{77-79}$. The age-related accumulation of AGEs on long lived proteins, e.g. collagen, is known to be accelerated in T2DM ${ }^{80-82}$. Second, other AGEs, particularly MGO-derived AGEs, are able to affect cell function via altering the structure, function or activity of these proteins ${ }^{63}$. Third, some AGEs, e.g. CML, are known to bind to the receptor for AGEs (RAGE), inducing receptor-mediated cell activation and low-grade inflammation, which in turn causes vascular dysfunction $63,83,84$. RAGE is identified in various cell systems, such as, monocytes and macrophages, T lymphocytes, fibroblasts, smooth muscle cells, endothelial cells, neurons, red cells, and mesangial cells. The binding of AGEs to RAGE on monocytes or macrophages induces the production of cytokines (e.g. interleukin $1 \beta$ and TNF- $a$ ) and growth factors, with a consequent increase in the synthesis of type IV collagen, a greater proliferation of vessel smooth muscle cells, and a stimulation of macrophage chemotaxis ${ }^{85}$. 


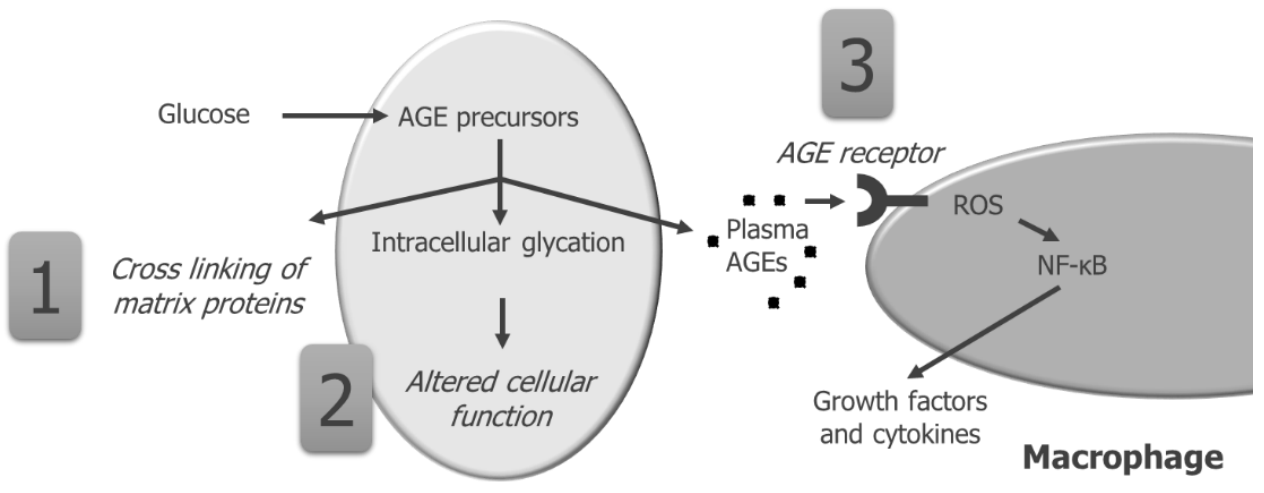

\section{Endothelial cell}

Figure 1.2. Three different mechanisms by which AGEs are thought to damage vascular tissue Figure adapted from Brownlee et al, 2001, Nature

Through a mechanism of oxidative stress, AGE-RAGE binding on endothelial cells induces the transcription factor NF-кB, which in turn increases the expression of the vascular cellular adhesion molecule (VCAM-1). The resulting VCAM-1 overexpression increases the adhesion of monocytes to endothelial cells, and vascular permeability, speeding up the trans-endothelial passage of AGE-modified proteins, e.g. AGE-LDL ${ }^{85}$.

\subsubsection{Measurement of AGE accumulation}

AGEs are thought to exert their detrimental effects by the accumulation in tissues that are vulnerable to diabetic complications, such as the eye, the kidney, nerve tissue, brain cells and blood vessels. Obviously, direct measurement in these tissues is very invasive and complex. Therefore, research on the role of AGEs in tissue damage has long been hampered by the fact that a good alternative to measure AGEs was missing. Nowadays, AGEs are measured in plasma or serum, in skin collagen or estimated by the measurement of skin autofluorescence.

\section{Circulating AGES}

AGEs can be measured in plasma or serum with ELISA techniques or even more specific by the use of state-of-the-art ultra-performance liquid chromatography (UPLC) in combination with tandem mass spectrometry or, in case of pentosidine, with high-performance liquid chromatography (HPLC) and fluorescence detection. These latter techniques are considered to be the most accurate techniques for the measurement of circulating AGEs. Circulating AGEs are thought to be higher in individuals with T1DM as compared to those without. This is, however, based on studies with relatively small patient and control groups ${ }^{86,87}$ or studies that have used less specific immunological techniques for the detection of $\mathrm{AGES}^{88,89}$. Previous studies comparing levels of circulating AGEs between individuals with and without T2DM show inconsistent findings; several studies describe higher AGE levels in T2DM ${ }^{90-95}$, whereas the other do not find any differences between groups ${ }^{94-101}$. Circulating AGEs have been associated with micro-102-104 and macrovascular complications ${ }^{105-107}$ in individuals with T1DM. In individuals with T2DM, circulating AGEs are associated with microvascular complications $92,93,108$. However, for macrovascular 
complications, most studies find no association between circulating AGEs and CVD $95,97,98$. It is speculated that in T2DM, circulating AGEs may not be an accurate reflection of the accumulation of AGEs in tissues. This is supported by the finding that plasma CML levels are lower in individuals with obesity ${ }^{109-112}$, abnormal glucoses metabolism ${ }^{113}$ and T2DM ${ }^{95}$. It has been hypothesised that the trapping of CML by the receptor for AGEs (RAGE) in adipose tissue may cause a decrease in AGE plasma levels in obese individuals with T2DM ${ }^{112}$. This may explain why the associations between circulating AGEs and T2DM and macrovascular complications in T2DM are not that evident.

\section{Accumulation of AGEs in skin collagen}

Skin collagen is an accessible long-lived protein, and its modification by AGEs may reflect cumulative AGE-mediated tissue damage elsewhere. In that context, AGE accumulation in skin collagen has been associated with the duration of diabetes, diabetes control and the presence and progression of diabetic complications ${ }^{114-117}$. As skin biopsy are obviously not generally available in the clinical setting, a non-invasive, surrogate measure of AGE accumulation in the skin, namely the measurement of skin autofluorescence (SAF), was developed as a non-invasive alternative.

\section{Skin autofluorescence}

The measurement of SAF is based on the fact that some AGEs, such as the cross-linking AGE pentosidine, have fluorescent properties ${ }^{118}$. SAF is measured with the AGE reader (Figure 1.3) using the characteristic fluorescence spectrum of AGEs (emission at 440nm upon excitation at $370 \mathrm{~nm}$ ), and is, therefore, thought to represent skin AGE accumulation. Indeed, SAF is associated with the level of pentosidine, CML and CEL in skin biopsy specimens in individuals with and without T1DM and T2DM ${ }^{118}$. Additionally, SAF has been shown to be higher in individuals with T1DM or T2DM compared with the general population ${ }^{118,119}$. As a possible reflection of tissue AGE accumulation, SAF has been associated with neuropathy, nephropathy and retinopathy in individuals with T1DM ${ }^{120-124}$ and T2DM 121, 123, 125-128 and macrovascular complications in both T1DM $121,129,130$ and T2DM121, 126, 128, 129, 131, 132. Additionally, SAF has even shown to provide additional information to the UK Prospective Diabetes Study (UKPDS) risk score for the estimation of cardiovascular prognosis in T2DM ${ }^{131}$.
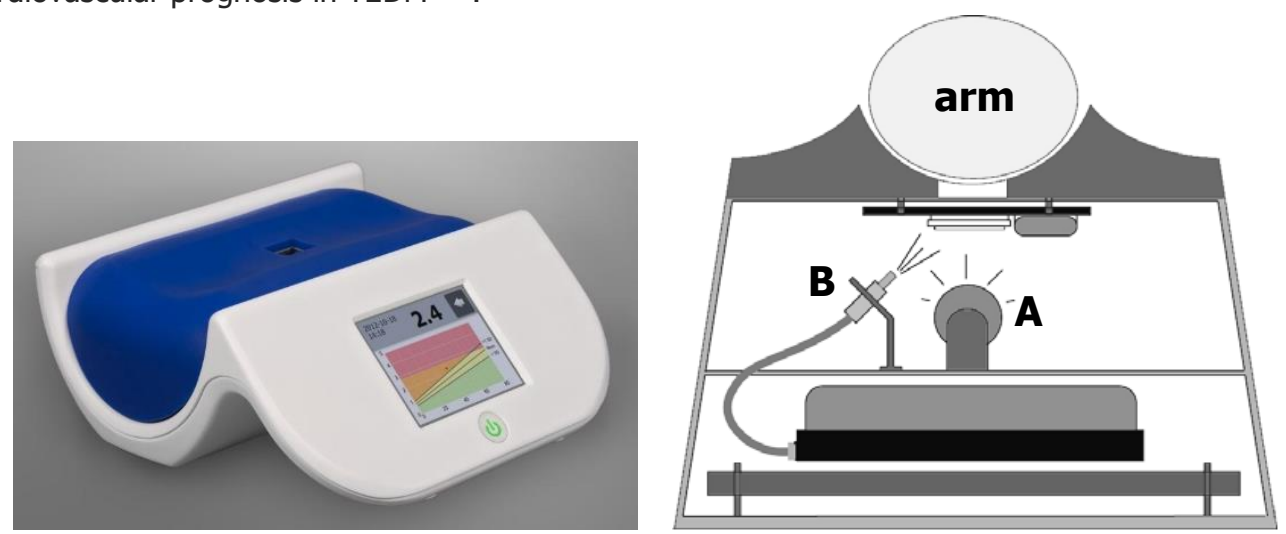

Figure 1.3. The AGE reader

Left: a picture of the AGE-reader. Right: an illustration of the inside of the AGE reader. An excitation light source (A) within the AGE reader illuminates the skin. Light that is than reflected from the skin is measured with a spectrometer (B) 


\subsubsection{Potential AGE-induced pathways leading to microvascular and macrovascular diseases}

\section{Low-grade inflammation and endothelial dysfunction}

Inflammation is our defence mechanisms against various pathogens. However, excessive or uncontrolled inflammatory responses can lead to the pathologic inflammation seen in inflammatory diseases such as atherosclerosis. Inflammation is characterized by the accumulation of leukocytes in the affected tissue, a process which is actively mediated and precisely controlled by cytokines and the vascular endothelium ${ }^{133}$. AGEs can lead to cytokine production via the activation of the RAGE receptor. Circulating AGEs may interact with the endothelial RAGE, which leads to translocation of NF-KB to the nucleus, where it activates transcription of its target genes, among them pro-inflammatory cytokines, adhesion molecules, and RAGE itself $76,134,135$. On the other hand, inflammation itself can cause increased formation of AGEs ${ }^{76}$. Therefore, AGEs could be a mechanism by which low-grade inflammation leads to atherosclerosis.

In addition to low-grade inflammation, AGEs have been shown to induce the expression of markers of endothelial dysfunction, e.g. vascular cell adhesion molecule 1 (VCAM-1) ${ }^{136-138}$, intracellular adhesion molecule 1 (ICAM-1) ${ }^{83}$ and E-selectin ${ }^{83}$. Focal expression of VCAM-1, ICAM-1 and Eselectin has been demonstrated in human atherosclerotic plaques ${ }^{139}$. Furthermore, it was shown that the modification of proteins by MGO results in increased formation of reactive oxygen species (ROS) ${ }^{140-142}$ and increased expression of adhesion molecules, e.g. VCAM-1 and ICAM-1, intra growth factors and a sensitizing of cells to the effects of pro-inflammatory cytokines ${ }^{143}$, i.e. early events in the initiation of atherosclerosis.

\section{Atherosclerosis}

Atherosclerosis is a progressive disease characterized by the accumulation of lipids and fibrous elements in the large arteries ${ }^{144}$. Rupture of an atherosclerotic plaque and subsequent thrombosis is known as the major cause of cardiovascular events such as heart attack and stroke ${ }^{145,}{ }^{146}$. AGEs are thought to lead to atherosclerosis through the binding of certain AGEs, e.g. $N \varepsilon$ (carboxymethyl)lysine (CML), to RAGE, inducing the generation of pro-inflammatory cytokines, expression of adhesion molecules and the stimulation of oxidative stress 76, 83, 84, 136, 147-150, all linked to the development of atherosclerosis 151, 152. AGEs have been localized in human atherosclerotic lesions ${ }^{153,154}$. Therapeutically lowering AGEs or blocking the receptor for AGEs in murine models has been shown to attenuate plaque formation ${ }^{155}$, ${ }^{156}$. Moreover, higher concentrations of $\mathrm{CML}$ and MG-H1 have been observed in rupture-prone compared with stable atherosclerotic plaques, suggesting that AGEs may even influence the progression of stable to rupture-prone plaques ${ }^{157}$. A number of surrogate indicators of subclinical atherosclerosis have been described, including coronary artery calcification, the ankle-brachial index and carotid intimamedia thickness. 


\section{Coronary artery calcification}

Coronary artery calcification (CAC) is a well-accepted early marker and precursor of CVD ${ }^{158,159}$. CAC can be quantified with electron beam or multidetector row computed tomography (EBCT). In 1990 , Agatson et al ${ }^{160}$ described a method for the quantification of coronary artery calcium using ultrafast computed tomography. Since then, this method is widely used to determine the amount of coronary artery calcification ${ }^{161-163}$. CAC detected by CT is highly sensitive for the presence of coronary artery disease or coronary heart disease, but only moderately specific. In a review of 16 studies, the sensitivity and specificity of EBCT were 91 and $49 \%$, respectively ${ }^{164}$. However, in asymptomatic individuals, the CAC score has shown to be of added value to predict the risk of coronary heart disease events over the single use of Framingham risk score ${ }^{165,166}$.

Both individuals with T1DM and T2DM have been shown to have more CAC ${ }^{167-169}$. In addition, experimental studies recently demonstrated that AGEs are able to induce vascular calcification ${ }^{170-}$ 174. In response to AGEs, aortic VSMCs differentiate into cells that exhibit an osteoblast-like phenotype characterized by the deposition of calcium into the extracellular matrix ${ }^{170,171}$. These findings support a direct role of AGEs in the stimulation of CAC.

\section{The ankle-brachial index}

The ankle-brachial index ( $A B I$ ) is a simple non-invasive tool that is implemented in the clinical diagnosis of peripheral arterial disease (PAD). The ABI is defined as the ratio between the systolic blood pressure at the ankle and brachial artery. Besides its use in the diagnosis of peripheral arterial disease (PAD), the ABI was shown to be an indicator of systemic atherosclerosis and it is able to predict cardiovascular events, even in absence of symptoms of PAD ${ }^{175-178}$.

SAF and plasma AGEs have been shown to associate with the ABI. Monami et al. found an association between SAF and arteriopathy of the lower limbs in individuals with T2DM ${ }^{127}$. Others observed an association between SAF and PAD in individuals with and without PAD ${ }^{179}$ or carotid artery stenosis ${ }^{180}$. Takahasi et al. found that higher serum AGEs and serum pentosidine were associated with lower $\mathrm{ABI}$ in healthy men ${ }^{181}$, whereas LaPolla et al. previously reported an association between higher plasma pentosidine and lower ABI in individuals with T2DM ${ }^{182}$.

\section{Carotid intima-media thickness}

The measurement of carotid intima-media thickness (cIMT) is a widely used, non-invasive imaging technique for the detection of atherosclerosis in the carotid artery, as an indication of systemic atherosclerosis and to serve as a risk factor for the development of CVD. However, the cIMT does not add value to the Framingham risk score in individuals with diabetes ${ }^{183}$. This suggests that its use in risk prediction in T2DM overlaps current CVD risk predictors. However, CIMT is used in many epidemiological studies as a marker of atherosclerosis because of its simple non-invasive nature, and because it is a marker of early atherosclerosis, reducing the need for a long followup.

SAF and cIMT have been associated in individuals with neither diabetes nor clinically manifest cardiovascular disease ${ }^{184}$. Furthermore, Yoshida et al. described an association between serum pentosidine and CIMT in individuals with and without T2DM ${ }^{90}$. However, Baumann et al. found no independent association between plasma CML and CIMT in the general population ${ }^{185}$. 


\section{Arterial stiffness}

Arterial stiffening is caused by structural and functional changes occurring primarily in the medial layer of the arterial wall. Arterial stiffness has been associated with left ventricular hypertrophy, impaired coronary perfusion, myocardial infarction and stroke ${ }^{37,38}$. Arterial stiffening occurs with increasing age and is known to predict CVD ${ }^{186}$ and cardiovascular and all-cause mortality ${ }^{187-189}$ in a variety of populations, including individuals with T2DM ${ }^{190}$. Moreover, the age-related increase in arterial stiffness has been shown to be steeper in individuals with T2DM compared to individuals without ${ }^{42,43}$, suggesting that T2DM accelerates the development of arterial stiffness. Carotid to femoral pulse wave velocity (cfPWV) is considered the 'gold standard' for the measurement of arterial stiffness ${ }^{191}$. Several studies have found an association between SAF ${ }^{192-194}$ or plasma AGEs 78, 90, 195 and PWV in different populations. An increase in arterial stiffness impairs the cushioning capacity of arteries leading to increases in systolic and decreases in diastolic blood pressure ${ }^{37,38}$, thereby, increasing pulse pressure (PP). Next to cfPWV, PP has also been shown to be positively associated with measures of AGE accumulation in individuals with $\mathrm{T}^{1 D \mathrm{DM}^{196}}$ and volunteers without diabetes ${ }^{121}$.

\subsubsection{AGEs and cognitive decline}

The mechanisms by which diabetes leads to an increased risk of cognitive decline and dementia are not fully understood. AGEs are thought to play a role, partially via the above mentioned detrimental effects of endothelial dysfunction and low-grade inflammation with subsequent blood brain barrier dysfunction ${ }^{197}$, but also via atherosclerosis in the brain. Moreover, long-lived proteins, including $\beta$-amyloid $(A \beta)$, have been found to be modified by AGEs and a recent study has shown that the formation of $A G E-$ modified $A \beta$ exacerbates the toxicity of $A \beta^{198}$. AGEs have been found in neurofibrillary tangles and senile plaques of patients with Alzheimer's disease (AD) ${ }^{199}$ and the receptor for AGE (RAGE) appears to be involved in the transport of amyloid peptides through the blood-brain barrier200.

\subsection{Aim and outline of this thesis}

So far, only a few studies have investigated the association of AGEs with micro- and macrovascular complications in large well-defined cohorts with the use of state-of the art analytical techniques for the detection of AGEs. Therefore, the general aim of this thesis was to obtain more insight in the associations between AGE accumulation on the one hand and micro- and macrovascular diseases on the other in individuals with and without T1DM or T2DM. In Chapter 2 and 3 we evaluate these associations in T1DM, whereas Chapter 4-7 focuses on individuals with impaired glucose metabolism (IGM) and T2DM. In Chapter 2 we describe the development and characterization of a new antibody against MGO-derived tetrahydropyrimidine (THP) and study the association between THP and T1DM, markers of ED and LGI, and micro- and macrovascular complications in two cohort studies. Furthermore, we evaluate the presence of THP in atherosclerotic plaques of human coronary arteries. In Chapter 3, we evaluate the associations between THP and other well-known AGEs, i.e. protein-bound pentosidine, CML and CEL, measured with state-of-the-art techniques, on the one hand, and T1DM and coronary artery calcification (CAC) on the other. Moreover, we address whether or not the association between plasma AGEs and CAC might be explained by ED or LGI. Chapters 4-7 are based on data from The Maastricht 
Study, an observational prospective population-based cohort study with oversampling of individuals with T2DM, which focuses on the aetiology, pathophysiology, complications and comorbidities of T2DM. In this cohort study, we measured AGE accumulation by the measurement of protein-bound plasma AGEs pentosidine, CML and CEL. Additionally, we measure skin autofluorescence (SAF) with the AGE reader. Chapter 4 describes the associations between SAF and plasma AGEs on the one hand and cfPWV, central pulse pressure and 24-hour ambulatory PP (aPP), all measures of arterial stiffness, a known and risk factor of CVD, on the other. Chapter 5 investigates of the association of AGE accumulation with markers of ED and LGI, as potential mechanisms by which AGEs could lead to CVD. In Chapter 6, we evaluate the association of SAF and plasma AGEs on the one hand and the ankle-brachial index (ABI) and carotid intima-media thickness (CIMT), as early markers of atherosclerosis on the other. As AGEs have been proposed to play a role in the development of cognitive decline, in Chapter 7, we examined the associations between SAF and plasma AGEs on the one hand and cognitive functions on the other. Finally, Chapter 8 provides a summary and discussion of the results of the studies presented in this thesis. Furthermore, it addresses their methodological considerations, clinical implications and implications for future research. 


\section{REFERENCES}

1. International Diabetes Federation. Idf diabetes atlas, 7th edition. Brussels, Belgium: International Diabetes Federation. 2015

2. $\quad$ NIVEL Zorgregistraties eerste lijn, NIVEL Zorgregistraties, zorggegevens.nl

3. Alwan A. Global status report on noncommunicable diseases 2010. World Health Organization. 2011

4. Soedamah-Muthu SS, Fuller JH, Mulnier HE, Raleigh VS, Lawrenson RA, Colhoun HM. High risk of cardiovascular disease in patients with type 1 diabetes in the U.K.: A cohort study using the general practice research database. Diabetes Care. 2006;29:798-804

5. Sarwar N, Gao P, Seshasai SR, Gobin R, Kaptoge S, Di Angelantonio E, Ingelsson E, Lawlor DA, Selvin E, Stampfer M, Stehouwer CD, Lewington S, Pennells L, Thompson A, Sattar N, White IR, Ray KK, Danesh J. Diabetes mellitus, fasting blood glucose concentration, and risk of vascular disease: A collaborative meta-analysis of 102 prospective studies. Lancet. 2010;375:2215-2222

6. Seshasai SR, Kaptoge S, Thompson A, Di Angelantonio E, Gao P, Sarwar N, Whincup PH, Mukamal KJ, Gillum RF, Holme I, Njolstad I, Fletcher A, Nilsson P, Lewington S, Collins R, Gudnason V, Thompson SG, Sattar N, Selvin E, Hu FB, Danesh J. Diabetes mellitus, fasting glucose, and risk of cause-specific death. N Engl J Med. 2011;364:829-841

7. The effect of intensive treatment of diabetes on the development and progression of long-term complications in insulindependent diabetes mellitus. The diabetes control and complications trial research group. N Engl J Med. 1993;329:977986

8. Intensive blood-glucose control with sulphonylureas or insulin compared with conventional treatment and risk of complications in patients with type 2 diabetes (ukpds 33). Uk prospective diabetes study (ukpds) group. Lancet. 1998;352:837-853

9. Diagnosis and classification of diabetes mellitus. Diabetes Care. 2013;36 Suppl 1:S67-74

10. Harjutsalo V, Sjoberg L, Tuomilehto J. Time trends in the incidence of type 1 diabetes in finnish children: A cohort study. Lancet. 2008;371:1777-1782

11. Taplin CE, Craig ME, Lloyd M, Taylor C, Crock P, Silink M, Howard NJ. The rising incidence of childhood type 1 diabetes in new south wales, 1990-2002. Med J Aust. 2005;183:243-246

12. Forbes JM, Cooper ME. Mechanisms of diabetic complications. Physiol Rev. 2013;93:137-188

13. Danaei G, Finucane MM, Lu Y, Singh GM, Cowan MJ, Paciorek CJ, Lin JK, Farzadfar F, Khang YH, Stevens GA, Rao M, Ali MK, Riley LM, Robinson CA, Ezzati M. National, regional, and global trends in fasting plasma glucose and diabetes prevalence since 1980: Systematic analysis of health examination surveys and epidemiological studies with 370 countryyears and 2.7 million participants. Lancet. 2011;378:31-40

14. Definition, diagnosis and classification of diabetes mellitus and its complications. Part 1: Diagnosis and classification of diabetes mellitus. World Health Organization. 1999

15. Rosenbloom AL, Joe JR, Young RS, Winter WE. Emerging epidemic of type 2 diabetes in youth. Diabetes Care. 1999;22:345-354

16. Ehtisham S, Barrett TG, Shaw NJ. Type 2 diabetes mellitus in uk children--an emerging problem. Diabet Med. 2000; $17: 867-871$

17. Goran MI, Ball GD, Cruz ML. Obesity and risk of type 2 diabetes and cardiovascular disease in children and adolescents. J Clin Endocrinol Metab. 2003;88:1417-1427

18. Blake DR, Meigs JB, Muller DC, Najjar SS, Andres R, Nathan DM. Impaired glucose tolerance, but not impaired fasting glucose, is associated with increased levels of coronary heart disease risk factors: Results from the baltimore longitudinal study on aging. Diabetes. 2004;53:2095-2100

19. Levitan EB, Song Y, Ford ES, Liu S. Is nondiabetic hyperglycemia a risk factor for cardiovascular disease? A metaanalysis of prospective studies. Arch Intern Med. 2004;164:2147-2155

20. Henry RM, Kostense PJ, Spijkerman AM, Dekker JM, Nijpels G, Heine RJ, Kamp O, Westerhof N, Bouter LM, Stehouwer CD. Arterial stiffness increases with deteriorating glucose tolerance status: The hoorn study. Circulation. 2003;107:2089-2095

21. Schram MT, Henry RM, van Dijk RA, Kostense PJ, Dekker JM, Nijpels G, Heine RJ, Bouter LM, Westerhof N, Stehouwer $\mathrm{CD}$. Increased central artery stiffness in impaired glucose metabolism and type 2 diabetes: The hoorn study. Hypertension. 2004;43:176-181

22. Fowler MJ. Microvascular and macrovascular complications of diabetes. Clinical diabetes. 2008;26:77-82

23. Spauwen PJ, Kohler S, Verhey FR, Stehouwer CD, van Boxtel MP. Effects of type 2 diabetes on 12-year cognitive change: Results from the maastricht aging study. Diabetes Care. 2013;36:1554-1561

24. Cukierman T, Gerstein HC, Williamson JD. Cognitive decline and dementia in diabetes--systematic overview of prospective observational studies. Diabetologia. 2005;48:2460-2469

25. Strachan MW, Reynolds RM, Marioni RE, Price JF. Cognitive function, dementia and type 2 diabetes mellitus in the elderly. Nat Rev Endocrinol. 2011;7:108-114

26. Gabir MM, Hanson RL, Dabelea D, Imperatore G, Roumain J, Bennett PH, Knowler WC. Plasma glucose and prediction of microvascular disease and mortality: Evaluation of 1997 american diabetes association and 1999 world health organization criteria for diagnosis of diabetes. Diabetes Care. 2000;23:1113-1118

27. Schram MT, Chaturvedi N, Fuller JH, Stehouwer CD. Pulse pressure is associated with age and cardiovascular disease in type 1 diabetes: The eurodiab prospective complications study. J Hypertens. 2003;21:2035-2044

28. Adler AI, Stevens RJ, Manley SE, Bilous RW, Cull CA, Holman RR. Development and progression of nephropathy in type 2 diabetes: The united kingdom prospective diabetes study (ukpds 64). Kidney international. 2003;63:225-232 
29. Rosenson RS, Fioretto P, Dodson PM. Does microvascular disease predict macrovascular events in type 2 diabetes? Atherosclerosis. 2011;218:13-18

30. Yau JW, Rogers SL, Kawasaki R, Lamoureux EL, Kowalski JW, Bek T, Chen SJ, Dekker JM, Fletcher A, Grauslund J, Haffner S, Hamman RF, Ikram MK, Kayama T, Klein BE, Klein R, Krishnaiah S, Mayurasakorn K, O'Hare JP, Orchard TJ, Porta M, Rema M, Roy MS, Sharma T, Shaw J, Taylor H, Tielsch JM, Varma R, Wang JJ, Wang N, West S, Xu L, Yasuda M, Zhang X, Mitchell P, Wong TY. Global prevalence and major risk factors of diabetic retinopathy. Diabetes Care. 2012;35:556-564

31. Roy MS, Klein R, O'Colmain BJ, Klein BE, Moss SE, Kempen JH. The prevalence of diabetic retinopathy among adult type 1 diabetic persons in the united states. Arch Ophthalmol. 2004;122:546-551

32. Kempen JH, O'Colmain BJ, Leske MC, Haffner SM, Klein R, Moss SE, Taylor HR, Hamman RF. The prevalence of diabetic retinopathy among adults in the united states. Arch Ophthalmol. 2004;122:552-563

33. Herman WH, Pop-Busui R, Braffett BH, Martin CL, Cleary PA, Albers JW, Feldman EL. Use of the michigan neuropathy screening instrument as a measure of distal symmetrical peripheral neuropathy in type 1 diabetes: Results from the diabetes control and complications trial/epidemiology of diabetes interventions and complications. Diabet Med. 2012;29:937-944

34. Charles M, Ejskjaer N, Witte DR, Borch-Johnsen K, Lauritzen T, Sandbaek A. Prevalence of neuropathy and peripheral arterial disease and the impact of treatment in people with screen-detected type 2 diabetes: The addition-denmark study. Diabetes Care. 2011;34:2244-2249

35. Retinopathy and nephropathy in patients with type 1 diabetes four years after a trial of intensive therapy. The diabetes control and complications trial/epidemiology of diabetes interventions and complications research group. N Engl J Med. 2000;342:381-389

36. Hemmingsen B, Lund SS, Gluud C, Vaag A, Almdal T, Hemmingsen C, Wetterslev J. Targeting intensive glycaemic control versus targeting conventional glycaemic control for type 2 diabetes mellitus. Cochrane Database Syst Rev. 2011:CD008143

37. O'Rourke MF, Hashimoto J. Mechanical factors in arterial aging: A clinical perspective. J Am Coll Cardiol. 2007;50:1-13

38. Stehouwer CD, Henry RM, Ferreira I. Arterial stiffness in diabetes and the metabolic syndrome: A pathway to cardiovascular disease. Diabetologia. 2008;51:527-539

39. Stout RW. Blood glucose and atherosclerosis. Arteriosclerosis. 1981;1:227-234

40. Beckman JA, Creager MA, Libby P. Diabetes and atherosclerosis: Epidemiology, pathophysiology, and management. Jama. 2002;287:2570-2581

41. Ronnback M, Fagerudd J, Forsblom C, Pettersson-Fernholm K, Reunanen A, Groop PH. Altered age-related blood pressure pattern in type 1 diabetes. Circulation. 2004;110:1076-1082

42. Cameron JD, Bulpitt CJ, Pinto ES, Rajkumar C. The aging of elastic and muscular arteries: A comparison of diabetic and nondiabetic subjects. Diabetes Care. 2003;26:2133-2138

43. Schram MT, Kostense PJ, Van Dijk RA, Dekker JM, Nijpels G, Bouter LM, Heine RJ, Stehouwer CD. Diabetes, pulse pressure and cardiovascular mortality: The hoorn study. J Hypertens. 2002;20:1743-1751

44. Laing SP, Swerdlow AJ, Slater SD, Burden AC, Morris A, Waugh NR, Gatling W, Bingley PJ, Patterson CC. Mortality from heart disease in a cohort of 23,000 patients with insulin-treated diabetes. Diabetologia. 2003;46:760-765

45. Kramer CK, Zinman B, Gross JL, Canani LH, Rodrigues TC, Azevedo MJ, Retnakaran R. Coronary artery calcium score prediction of all cause mortality and cardiovascular events in people with type 2 diabetes: Systematic review and metaanalysis. Bmj. 2013;346:f1654

46. Nathan DM, Cleary PA, Backlund JY, Genuth SM, Lachin JM, Orchard TJ, Raskin P, Zinman B. Intensive diabetes treatment and cardiovascular disease in patients with type 1 diabetes. N Engl J Med. 2005;353:2643-2653

47. Holman RR, Paul SK, Bethel MA, Matthews DR, Neil HA. 10-year follow-up of intensive glucose control in type 2 diabetes. N Engl J Med. 2008;359:1577-1589

48. Gerstein HC, Miller ME, Genuth S, Ismail-Beigi F, Buse JB, Goff DC, Jr., Probstfield JL, Cushman WC, Ginsberg HN, Bigger JT, Grimm RH, Jr., Byington RP, Rosenberg YD, Friedewald WT. Long-term effects of intensive glucose lowering on cardiovascular outcomes. N Engl J Med. 2011;364:818-828

49. Patel A, MacMahon S, Chalmers J, Neal B, Billot L, Woodward M, Marre M, Cooper M, Glasziou P, Grobbee D, Hamet $P$, Harrap S, Heller S, Liu L, Mancia G, Mogensen CE, Pan C, Poulter N, Rodgers A, Williams B, Bompoint S, de Galan BE, Joshi R, Travert F. Intensive blood glucose control and vascular outcomes in patients with type 2 diabetes. $\mathrm{N}$ Engl J Med. 2008;358:2560-2572

50. Duckworth W, Abraira C, Moritz T, Reda D, Emanuele N, Reaven PD, Zieve FJ, Marks J, Davis SN, Hayward R, Warren SR, Goldman S, McCarren M, Vitek ME, Henderson WG, Huang GD. Glucose control and vascular complications in veterans with type 2 diabetes. N Engl J Med. 2009;360:129-139

51. Boussageon R, Bejan-Angoulvant T, Saadatian-Elahi M, Lafont S, Bergeonneau C, Kassai B, Erpeldinger S, Wright JM, Gueyffier F, Cornu C. Effect of intensive glucose lowering treatment on all cause mortality, cardiovascular death, and microvascular events in type 2 diabetes: Meta-analysis of randomised controlled trials. Bmj. 2011;343:d4169

52. Kelly TN, Bazzano LA, Fonseca VA, Thethi TK, Reynolds K, He J. Systematic review: Glucose control and cardiovascular disease in type 2 diabetes. Ann Intern Med. 2009;151:394-403

53. Ray KK, Seshasai SR, Wijesuriya S, Sivakumaran R, Nethercott S, Preiss D, Erqou S, Sattar N. Effect of intensive control of glucose on cardiovascular outcomes and death in patients with diabetes mellitus: A meta-analysis of randomised controlled trials. Lancet. 2009;373:1765-1772

54. Gaede $\mathrm{P}$, Vedel $\mathrm{P}$, Larsen N, Jensen GV, Parving HH, Pedersen O. Multifactorial intervention and cardiovascular disease in patients with type 2 diabetes. N Engl J Med. 2003;348:383-393 
55. Gaede $\mathrm{P}$, Lund-Andersen $\mathrm{H}$, Parving $\mathrm{HH}$, Pedersen O. Effect of a multifactorial intervention on mortality in type 2 diabetes. N Engl J Med. 2008;358:580-591

56. Gauthier S, Reisberg B, Zaudig M, Petersen RC, Ritchie K, Broich K, Belleville S, Brodaty H, Bennett D, Chertkow $H$, Cummings JL, de Leon M, Feldman H, Ganguli M, Hampel H, Scheltens P, Tierney MC, Whitehouse P, Winblad B. Mild cognitive impairment. Lancet. 2006;367:1262-1270

57. LaFerla FM, Oddo S. Alzheimer's disease: Abeta, tau and synaptic dysfunction. Trends Mol Med. 2005;11:170-176

58. Biessels GJ, Staekenborg S, Brunner E, Brayne C, Scheltens P. Risk of dementia in diabetes mellitus: A systematic review. Lancet Neurol. 2006;5:64-74

59. Abbatecola AM, Rizzo MR, Barbieri M, Grella R, Arciello A, Laieta MT, Acampora R, Passariello N, Cacciapuoti F, Paolisso G. Postprandial plasma glucose excursions and cognitive functioning in aged type 2 diabetics. Neurology. 2006;67:235240

60. Munshi M, Grande L, Hayes M, Ayres D, Suhl E, Capelson R, Lin S, Milberg W, Weinger K. Cognitive dysfunction is associated with poor diabetes control in older adults. Diabetes Care. 2006;29:1794-1799

61. Launer L], Miller ME, Williamson JD, Lazar RM, Gerstein HC, Murray AM, Sullivan M, Horowitz KR, Ding J, Marcovina S, Lovato LC, Lovato J, Margolis KL, O'Connor P, Lipkin EW, Hirsch J, Coker L, Maldjian J, Sunshine JL, Truwit C, Davatzikos C, Bryan RN. Effects of intensive glucose lowering on brain structure and function in people with type 2 diabetes (accord mind): A randomised open-label substudy. Lancet Neurol. 2011;10:969-977

62. Whitmer RA, Karter AJ, Yaffe K, Quesenberry CP, Jr., Selby JV. Hypoglycemic episodes and risk of dementia in older patients with type 2 diabetes mellitus. Jama. 2009;301:1565-1572

63. Brownlee M. Biochemistry and molecular cell biology of diabetic complications. Nature. 2001;414:813-820

64. Rahbar S, Blumenfeld O, Ranney HM. Studies of an unusual hemoglobin in patients with diabetes mellitus. Biochem Biophys Res Commun. 1969;36:838-843

65. Brouwers O, Niessen PM, Ferreira I, Miyata T, Scheffer PG, Teerlink T, Schrauwen P, Brownlee M, Stehouwer CD, Schalkwijk CG. Overexpression of glyoxalase-i reduces hyperglycemia-induced levels of advanced glycation end products and oxidative stress in diabetic rats. J Biol Chem. 2011;286:1374-1380

66. Oya T, Hattori N, Mizuno Y, Miyata S, Maeda S, Osawa T, Uchida K. Methylglyoxal modification of protein. Chemical and immunochemical characterization of methylglyoxal-arginine adducts. J Biol Chem. 1999;274:18492-18502

67. Shinohara M, Thornalley PJ, Giardino I, Beisswenger P, Thorpe SR, Onorato J, Brownlee M. Overexpression of glyoxalase-i in bovine endothelial cells inhibits intracellular advanced glycation endproduct formation and prevents hyperglycemia-induced increases in macromolecular endocytosis. J Clin Invest. 1998;101:1142-1147

68. Oya T, Hattori N, Mizuno Y, Miyata S, Maeda S, Osawa T, Uchida K. Methylglyoxal modification of protein. Chemical and immunochemical characterization of methylglyoxal-arginine adducts. J Biol Chem. 1999;274:18492-18502

69. Thornalley PJ. Protein and nucleotide damage by glyoxal and methylglyoxal in physiological systems--role in ageing and disease. Drug metabolism and drug interactions. 2008;23:125-150

70. Thornalley PJ. The glyoxalase system in health and disease. Mol Aspects Med. 1993;14:287-371

71. Rabbani N, Thornalley PJ. Glyoxalase in diabetes, obesity and related disorders. Semin Cell Dev Biol. 2011;22:309-317

72. Esterbauer H, Gebicki J, Puhl H, Jurgens G. The role of lipid peroxidation and antioxidants in oxidative modification of Idl. Free Radic Biol Med. 1992;13:341-390

73. Baynes JW, Thorpe SR. Glycoxidation and lipoxidation in atherogenesis. Free Radic Biol Med. 2000;28:1708-1716

74. Januszewski AS, Alderson NL, Jenkins AJ, Thorpe SR, Baynes JW. Chemical modification of proteins during peroxidation of phospholipids. J Lipid Res. 2005;46:1440-1449

75. Fu MX, Requena JR, Jenkins AJ, Lyons TJ, Baynes JW, Thorpe SR. The advanced glycation end product, nepsilon(carboxymethyl)lysine, is a product of both lipid peroxidation and glycoxidation reactions. J Biol Chem. 1996;271:99829986

76. Goldin A, Beckman JA, Schmidt AM, Creager MA. Advanced glycation end products: Sparking the development of diabetic vascular injury. Circulation. 2006;114:597-605

77. Aronson D. Cross-linking of glycated collagen in the pathogenesis of arterial and myocardial stiffening of aging and diabetes. J Hypertens. 2003;21:3-12

78. McNulty M, Mahmud A, Feely J. Advanced glycation end-products and arterial stiffness in hypertension. American journal of hypertension. 2007;20:242-247

79. Sell DR, Monnier VM. Molecular basis of arterial stiffening: Role of glycation - a mini-review. Gerontology. 2012;58:227237

80. Vlassara H, Bucala R, Striker L. Pathogenic effects of advanced glycosylation: Biochemical, biologic, and clinical implications for diabetes and aging. Lab Invest. 1994;70:138-151

81. McCance DR, Dyer DG, Dunn JA, Bailie KE, Thorpe SR, Baynes JW, Lyons TJ. Maillard reaction products and their relation to complications in insulin-dependent diabetes mellitus. J Clin Invest. 1993;91:2470-2478

82. Verzijl N, DeGroot J, Oldehinkel E, Bank RA, Thorpe SR, Baynes JW, Bayliss MT, Bijlsma JW, Lafeber FP, Tekoppele JM. Age-related accumulation of maillard reaction products in human articular cartilage collagen. Biochem J. 2000;350 Pt 2:381-387

83. Basta G, Lazzerini G, Massaro M, Simoncini T, Tanganelli P, Fu C, Kislinger T, Stern DM, Schmidt AM, De Caterina R. Advanced glycation end products activate endothelium through signal-transduction receptor rage: A mechanism for amplification of inflammatory responses. Circulation. 2002;105:816-822

84. Bierhaus A, Humpert PM, Stern DM, Arnold B, Nawroth PP. Advanced glycation end product receptor-mediated cellular dysfunction. Ann N Y Acad Sci. 2005;1043:676-680

85. Piarulli F, Sartore G, Lapolla A. Glyco-oxidation and cardiovascular complications in type 2 diabetes: A clinical update. Acta Diabetol. 2013;50:101-110 
86. Ahmed N, Babaei-Jadidi R, Howell SK, Beisswenger PJ, Thornalley PJ. Degradation products of proteins damaged by glycation, oxidation and nitration in clinical type 1 diabetes. Diabetologia. 2005;48:1590-1603

87. Hwang JS, Shin $\mathrm{CH}$, Yang SW. Clinical implications of $\mathrm{n}$ epsilon-(carboxymethyl)lysine, advanced glycation end product, in children and adolescents with type 1 diabetes. Diabetes Obes Metab. 2005;7:263-267

88. Galler A, Muller G, Schinzel R, Kratzsch J, Kiess W, Munch G. Impact of metabolic control and serum lipids on the concentration of advanced glycation end products in the serum of children and adolescents with type 1 diabetes, as determined by fluorescence spectroscopy and nepsilon-(carboxymethyl)lysine elisa. Diabetes Care. 2003;26:2609-2615

89. Berg TJ, Dahl-Jorgensen K, Torjesen PA, Hanssen KF. Increased serum levels of advanced glycation end products (ages) in children and adolescents with iddm. Diabetes Care. 1997;20:1006-1008

90. Yoshida N, Okumura K, Aso Y. High serum pentosidine concentrations are associated with increased arterial stiffness and thickness in patients with type 2 diabetes. Metabolism. 2005;54:345-350

91. Kilhovd BK, Berg TJ, Birkeland KI, Thorsby P, Hanssen KF. Serum levels of advanced glycation end products are increased in patients with type 2 diabetes and coronary heart disease. Diabetes Care. 1999;22:1543-1548

92. Wautier MP, Massin P, Guillausseau PJ, Huijberts M, Levy B, Boulanger E, Laloi-Michelin M, Wautier JL. $\mathrm{N}$ (carboxymethyl)lysine as a biomarker for microvascular complications in type 2 diabetic patients. Diabetes Metab. 2003;29:44-52

93. Boehm BO, Schilling S, Rosinger S, Lang GE, Lang GK, Kientsch-Engel R, Stahl P. Elevated serum levels of n(epsilon)carboxymethyl-lysine, an advanced glycation end product, are associated with proliferative diabetic retinopathy and macular oedema. Diabetologia. 2004;47:1376-1379

94. Daimon M, Ono Y, Saito T, Yamaguchi H, Hirata A, Ohnuma H, Igarashi M, Eguchi H, Manaka H, Kato T. Increased serum levels of pentosidine, but not carboxymethyl lysine, in type 2 diabetes without obvious diabetic nephropathy. Diabetes Care. 1999;22:877-878

95. Hanssen NM, Engelen L, Ferreira I, Scheijen JL, Huijberts MS, van Greevenbroek MM, van der Kallen CJ, Dekker JM, Nijpels G, Stehouwer CD, Schalkwijk CG. Plasma levels of advanced glycation endproducts n\{epsilon\}(carboxymethyl)lysine, n\{epsilon\}-(carboxyethyl)lysine, and pentosidine are not independently associated with cardiovascular disease in individuals with or without type 2 diabetes: The hoorn and codam studies. J Clin Endocrinol Metab. 2013;98:E1369-1373

96. Sugiyama S, Miyata T, Ueda Y, Tanaka H, Maeda K, Kawashima S, Van Ypersele de Strihou C, Kurokawa K. Plasma levels of pentosidine in diabetic patients: An advanced glycation end product. J Am Soc Nephrol. 1998;9:1681-1688

97. Busch M, Franke S, Wolf G, Brandstadt A, Ott U, Gerth J, Hunsicker LG, Stein G. The advanced glycation end product $\mathrm{n}$ (epsilon)-carboxymethyllysine is not a predictor of cardiovascular events and renal outcomes in patients with type 2 diabetic kidney disease and hypertension. Am J Kidney Dis. 2006;48:571-579

98. Kilhovd BK, Juutilainen A, Lehto S, Ronnemaa T, Torjesen PA, Hanssen KF, Laakso M. Increased serum levels of methylglyoxal-derived hydroimidazolone-age are associated with increased cardiovascular disease mortality in nondiabetic women. Atherosclerosis. 2009;205:590-594

99. Semba RD, Ferrucci L, Sun K, Beck J, Dalal M, Varadhan R, Walston J, Guralnik JM, Fried LP. Advanced glycation end products and their circulating receptors predict cardiovascular disease mortality in older community-dwelling women. Aging Clin Exp Res. 2009;21:182-190

100. Endo M, Yanagisawa K, Tsuchida K, Okamoto T, Matsushita T, Higuchi M, Matsuda A, Takeuchi M, Makita Z, Koike T. Increased levels of vascular endothelial growth factor and advanced glycation end products in aqueous humor of patients with diabetic retinopathy. Horm Metab Res. 2001;33:317-322

101. Wagner Z, Wittmann I, Mazak I, Schinzel R, Heidland A, Kientsch-Engel R, Nagy J. N(epsilon)-(carboxymethyl)lysine levels in patients with type 2 diabetes: Role of renal function. Am J Kidney Dis. 2001;38:785-791

102. Chiarelli F, Catino M, Tumini S, Cipollone F, Mezzetti A, Vanelli M, Verrotti A. Advanced glycation end products in adolescents and young adults with diabetic angiopathy. Pediatr Nephrol. 2000;14:841-846

103. Fosmark DS, Berg JP, Jensen AB, Sandvik L, Agardh E, Agardh CD, Hanssen KF. Increased retinopathy occurrence in type 1 diabetes patients with increased serum levels of the advanced glycation endproduct hydroimidazolone. Acta Ophthalmol. 2009;87:498-500

104. Miura J, Yamagishi S, Uchigata Y, Takeuchi M, Yamamoto H, Makita Z, Iwamoto Y. Serum levels of noncarboxymethyllysine advanced glycation endproducts are correlated to severity of microvascular complications in patients with type 1 diabetes. J Diabetes Complications. 2003;17:16-21

105. Berg TJ, Snorgaard O, Faber J, Torjesen PA, Hildebrandt P, Mehlsen J, Hanssen KF. Serum levels of advanced glycation end products are associated with left ventricular diastolic function in patients with type 1 diabetes. Diabetes Care. $1999 ; 22: 1186-1190$

106. Steine K, Larsen JR, Stugaard M, Berg TJ, Brekke M, Dahl-Jorgensen K. Lv systolic impairment in patients with asymptomatic coronary heart disease and type 1 diabetes is related to coronary atherosclerosis, glycaemic control and advanced glycation endproducts. Eur J Heart Fail. 2007;9:1044-1050

107. Nin JW, Jorsal A, Ferreira I, Schalkwijk CG, Prins MH, Parving HH, Tarnow L, Rossing P, Stehouwer CD. Higher plasma levels of advanced glycation end products are associated with incident cardiovascular disease and all-cause mortality in type 1 diabetes: A 12-year follow-up study. Diabetes Care. 2011;34:442-447

108. Ono Y, Aoki S, Ohnishi K, Yasuda T, Kawano K, Tsukada Y. Increased serum levels of advanced glycation end-products and diabetic complications. Diabetes Res Clin Pract. 1998;41:131-137

109. Semba RD, Arab L, Sun K, Nicklett EJ, Ferrucci L. Fat mass is inversely associated with serum carboxymethyl-lysine, an advanced glycation end product, in adults. J Nutr. 2011;141:1726-1730

110. Grote VA, Nieters A, Kaaks R, Tjonneland A, Roswall N, Overvad K, Nielsen MR, Clavel-Chapelon F, Boutron-Ruault MC, Racine A, Teucher B, Lukanova A, Boeing H, Drogan D, Trichopoulou A, Trichopoulos D, Lagiou P, Palli D, Sieri S, 
Tumino R, Vineis P, Mattiello A, Arguelles Suarez MV, Duell EJ, Sanchez MJ, Dorronsoro M, Huerta Castano JM, Barricarte A, Jeurnink SM, Peeters PH, Sund M, Ye W, Regner S, Lindkvist B, Khaw KT, Wareham N, Allen NE, Crowe FL, Fedirko V, Jenab M, Romaguera D, Siddiq A, Bueno-de-Mesquita HB, Rohrmann S. The associations of advanced glycation end products and its soluble receptor with pancreatic cancer risk: A case-control study within the prospective epic cohort. Cancer Epidemiol Biomarkers Prev. 2012;21:619-628

111. Sebekova K, Somoza V, Jarcuskova M, Heidland A, Podracka L. Plasma advanced glycation end products are decreased in obese children compared with lean controls. Int J Pediatr Obes. 2009;4:112-118

112. Gaens KH, Stehouwer CD, Schalkwijk CG. Advanced glycation endproducts and its receptor for advanced glycation endproducts in obesity. Curr Opin Lipidol. 2013;24:4-11

113. Semba RD, Beck J, Sun K, Egan JM, Carlson OD, Varadhan R, Ferrucci L. Relationship of a dominant advanced glycation end product, serum carboxymethyl-lysine, and abnormal glucose metabolism in adults: The baltimore longitudinal study of aging. J Nutr Health Aging. 2010;14:507-513

114. Monnier VM, Vishwanath V, Frank KE, Elmets CA, Dauchot P, Kohn RR. Relation between complications of type i diabetes mellitus and collagen-linked fluorescence. N Engl J Med. 1986;314:403-408

115. Monnier VM, Bautista O, Kenny D, Sell DR, Fogarty J, Dahms W, Cleary PA, Lachin J, Genuth S. Skin collagen glycation, glycoxidation, and crosslinking are lower in subjects with long-term intensive versus conventional therapy of type 1 diabetes: Relevance of glycated collagen products versus hba1c as markers of diabetic complications. Dcct skin collagen ancillary study group. Diabetes control and complications trial. Diabetes. 1999;48:870-880

116. Monnier VM, Sell DR, Genuth S. Glycation products as markers and predictors of the progression of diabetic complications. Ann N Y Acad Sci. 2005;1043:567-581

117. Genuth S, Sun W, Cleary P, Gao X, Sell DR, Lachin J, Monnier VM. Skin advanced glycation end products glucosepane and methylglyoxal hydroimidazolone are independently associated with long-term microvascular complication progression of type 1 diabetes. Diabetes. 2015;64:266-278

118. Meerwaldt R, Graaff R, Oomen PH, Links TP, Jager JJ, Alderson NL, Thorpe SR, Baynes JW, Gans RO, Smit AJ. Simple non-invasive assessment of advanced glycation endproduct accumulation. Diabetologia. 2004;47:1324-1330

119. Koetsier M, Lutgers H, Smit AJ, Links TP, Vries RD, Gans RO, Rakhorst G, Graaff R. Skin autofluorescence for the risk assessment of chronic complications in diabetes: A broad excitation range is sufficient. Opt Express. 2009;17:509-519

120. Araszkiewicz A, Naskret D, Niedzwiecki $P$, Samborski $P$, Wierusz-Wysocka B, Zozulinska-Ziolkiewicz D. Increased accumulation of skin advanced glycation end products is associated with microvascular complications in type 1 diabetes. Diabetes Technol Ther. 2011;13:837-842

121. Bos DC, de Ranitz-Greven WL, de Valk HW. Advanced glycation end products, measured as skin autofluorescence and diabetes complications: A systematic review. Diabetes Technol Ther. 2011;13:773-779

122. Chabroux S, Canoui-Poitrine F, Reffet S, Mills-Joncour G, Morelon E, Colin C, Thivolet C. Advanced glycation end products assessed by skin autofluorescence in type 1 diabetics are associated with nephropathy, but not retinopathy. Diabetes Metab. 2010;36:152-157

123. Meerwaldt R, Links TP, Graaff R, Hoogenberg K, Lefrandt JD, Baynes JW, Gans RO, Smit AJ. Increased accumulation of skin advanced glycation end-products precedes and correlates with clinical manifestation of diabetic neuropathy. Diabetologia. 2005;48:1637-1644

124. Orchard TJ, Lyons TJ, Cleary PA, Braffett BH, Maynard J, Cowie C, Gubitosi-Klug RA, Way J, Anderson K, Barnie A, Villavicencio S. The association of skin intrinsic fluorescence with type 1 diabetes complications in the dcct/edic study. Diabetes Care. 2013;36:3146-3153

125. Gerrits EG, Lutgers HL, Kleefstra N, Graaff R, Groenier KH, Smit AJ, Gans RO, Bilo HJ. Skin autofluorescence: A tool to identify type 2 diabetic patients at risk for developing microvascular complications. Diabetes Care. 2008;31:517-521

126. Lutgers HL, Graaff R, Links TP, Ubink-Veltmaat $\mathrm{U}$, Bilo HJ, Gans RO, Smit AJ. Skin autofluorescence as a noninvasive marker of vascular damage in patients with type 2 diabetes. Diabetes Care. 2006;29:2654-2659

127. Monami M, Lamanna C, Gori F, Bartalucci F, Marchionni N, Mannucci E. Skin autofluorescence in type 2 diabetes: Beyond blood glucose. Diabetes Res Clin Pract. 2008;79:56-60

128. Tanaka K, Tani Y, Asai J, Nemoto F, Kusano Y, Suzuki H, Hayashi Y, Asahi K, Nakayama M, Miyata T, Watanabe T. Skin autofluorescence is associated with severity of vascular complications in japanese patients with type 2 diabetes. Diabet Med. 2012;29:492-500

129. Meerwaldt R, Lutgers HL, Links TP, Graaff R, Baynes JW, Gans RO, Smit AJ. Skin autofluorescence is a strong predictor of cardiac mortality in diabetes. Diabetes Care. 2007;30:107-112

130. Conway B, Edmundowicz D, Matter N, Maynard J, Orchard T. Skin fluorescence correlates strongly with coronary artery calcification severity in type 1 diabetes. Diabetes Technol Ther. 2010;12:339-345

131. Lutgers HL, Gerrits EG, Graaff R, Links TP, Sluiter WJ, Gans RO, Bilo HJ, Smit AJ. Skin autofluorescence provides additional information to the uk prospective diabetes study (ukpds) risk score for the estimation of cardiovascular prognosis in type 2 diabetes mellitus. Diabetologia. 2009;52:789-797

132. Noordzij MJ, Mulder DJ, Oomen PH, Brouwer T, Jager J, Castro Cabezas M, Lefrandt JD, Smit AJ. Skin autofluorescence and risk of micro- and macrovascular complications in patients with type 2 diabetes mellitus-a multi-centre study. Diabet Med. 2012;29:1556-1561

133. Zarbock A, Ley K. Mechanisms and consequences of neutrophil interaction with the endothelium. Am J Pathol. 2008;172:1-7

134. Li J, Schmidt AM. Characterization and functional analysis of the promoter of rage, the receptor for advanced glycation end products. J Biol Chem. 1997;272:16498-16506

135. Bierhaus A, Humpert PM, Morcos M, Wendt T, Chavakis T, Arnold B, Stern DM, Nawroth PP. Understanding rage, the receptor for advanced glycation end products. J Mol Med (Berl). 2005;83:876-886 
136. Schmidt AM, Hori O, Chen JX, Li JF, Crandall J, Zhang J, Cao R, Yan SD, Brett J, Stern D. Advanced glycation endproducts interacting with their endothelial receptor induce expression of vascular cell adhesion molecule-1 (vcam1 ) in cultured human endothelial cells and in mice. A potential mechanism for the accelerated vasculopathy of diabetes. J Clin Invest. 1995; $96: 1395-1403$

137. Vlassara H, Fuh H, Donnelly T, Cybulsky M. Advanced glycation endproducts promote adhesion molecule (vcam-1, icam-1) expression and atheroma formation in normal rabbits. Mol Med. 1995;1:447-456

138. Harja E, Bu DX, Hudson BI, Chang JS, Shen X, Hallam K, Kalea AZ, Lu Y, Rosario RH, Oruganti S, Nikolla Z, Belov D, Lalla E, Ramasamy R, Yan SF, Schmidt AM. Vascular and inflammatory stresses mediate atherosclerosis via rage and its ligands in apoe-/- mice. J Clin Invest. 2008;118:183-194

139. Davies MJ, Gordon JL, Gearing AJ, Pigott R, Woolf N, Katz D, Kyriakopoulos A. The expression of the adhesion molecules icam-1, vcam-1, pecam, and e-selectin in human atherosclerosis. J Pathol. 1993;171:223-229

140. Wang H, Liu J, Wu L. Methylglyoxal-induced mitochondrial dysfunction in vascular smooth muscle cells. Biochem Pharmacol. 2009;77:1709-1716

141. Rosca MG, Mustata TG, Kinter MT, Ozdemir AM, Kern TS, Szweda LI, Brownlee M, Monnier VM, Weiss MF. Glycation of mitochondrial proteins from diabetic rat kidney is associated with excess superoxide formation. Am J Physiol Renal Physiol. 2005;289:F420-430

142. Rabbani N, Thornalley PJ. Dicarbonyls linked to damage in the powerhouse: Glycation of mitochondrial proteins and oxidative stress. Biochem Soc Trans. 2008;36:1045-1050

143. Yao D, Taguchi T, Matsumura T, Pestell R, Edelstein D, Giardino I, Suske G, Rabbani N, Thornalley PJ, Sarthy VP, Hammes HP, Brownlee M. High glucose increases angiopoietin-2 transcription in microvascular endothelial cells through methylglyoxal modification of msin3a. J Biol Chem. 2007;282:31038-31045

144. Libby P. Inflammation in atherosclerosis. Nature. 2002;420:868-874

145. Burke AP, Farb A, Malcom GT, Liang YH, Smialek J, Virmani R. Coronary risk factors and plaque morphology in men with coronary disease who died suddenly. N Engl J Med. 1997;336:1276-1282

146. Farb A, Tang AL, Burke AP, Sessums L, Liang Y, Virmani R. Sudden coronary death. Frequency of active coronary lesions, inactive coronary lesions, and myocardial infarction. Circulation. 1995;92:1701-1709

147. Rashid G, Benchetrit S, Fishman D, Bernheim J. Effect of advanced glycation end-products on gene expression and synthesis of tnf-alpha and endothelial nitric oxide synthase by endothelial cells. Kidney international. 2004;66:10991106

148. Uchida Y, Ohba K, Yoshioka T, Irie K, Muraki T, Maru Y. Cellular carbonyl stress enhances the expression of plasminogen activator inhibitor-1 in rat white adipocytes via reactive oxygen species-dependent pathway. J Biol Chem. 2004;279:4075-4083

149. Ramasamy R, Yan SF, Schmidt AM. The diverse ligand repertoire of the receptor for advanced glycation endproducts and pathways to the complications of diabetes. Vascul Pharmacol. 2012;57:160-167

150. Basta G, Schmidt AM, De Caterina R. Advanced glycation end products and vascular inflammation: Implications for accelerated atherosclerosis in diabetes. Cardiovasc Res. 2004;63:582-592

151. Ross R. Atherosclerosis--an inflammatory disease. N Engl J Med. 1999;340:115-126

152. Son SM, Whalin MK, Harrison DG, Taylor WR, Griendling KK. Oxidative stress and diabetic vascular complications. Curr Diab Rep. 2004;4:247-252

153. van Eupen MG, Schram MT, Colhoun HM, Hanssen NM, Niessen HW, Tarnow L, Parving HH, Rossing P, Stehouwer CD, Schalkwijk CG. The methylglyoxal-derived age tetrahydropyrimidine is increased in plasma of individuals with type 1 diabetes mellitus and in atherosclerotic lesions and is associated with svcam-1. Diabetologia. 2013

154. Kume S, Takeya M, Mori T, Araki N, Suzuki H, Horiuchi S, Kodama T, Miyauchi Y, Takahashi K. Immunohistochemical and ultrastructural detection of advanced glycation end products in atherosclerotic lesions of human aorta with a novel specific monoclonal antibody. Am J Pathol. 1995;147:654-667

155. Park L, Raman KG, Lee KJ, Lu Y, Ferran LJ, Jr., Chow WS, Stern D, Schmidt AM. Suppression of accelerated diabetic atherosclerosis by the soluble receptor for advanced glycation endproducts. Nat Med. 1998:4:1025-1031

156. Forbes JM, Yee LT, Thallas V, Lassila M, Candido R, Jandeleit-Dahm KA, Thomas MC, Burns WC, Deemer EK, Thorpe $\mathrm{SR}$, Cooper ME, Allen TJ. Advanced glycation end product interventions reduce diabetes-accelerated atherosclerosis. Diabetes. 2004;53:1813-1823

157. Hanssen NM, Wouters K, Huijberts MS, Gijbels MJ, Sluimer JC, Scheijen JL, Heeneman S, Biessen EA, Daemen MJ, Brownlee M, de Kleijn DP, Stehouwer CD, Pasterkamp G, Schalkwijk CG. Higher levels of advanced glycation endproducts in human carotid atherosclerotic plaques are associated with a rupture-prone phenotype. European heart journal. 2014;35:1137-1146

158. Taki K, Takayama F, Tsuruta Y, Niwa T. Oxidative stress, advanced glycation end product, and coronary artery calcification in hemodialysis patients. Kidney international. 2006;70:218-224

159. Peters SA, Bakker M, den Ruijter HM, Bots ML. Added value of cac in risk stratification for cardiovascular events: A systematic review. Eur J Clin Invest. 2012;42:110-116

160. Agatston AS, Janowitz WR, Hildner FJ, Zusmer NR, Viamonte M, Jr., Detrano R. Quantification of coronary artery calcium using ultrafast computed tomography. J Am Coll Cardiol. 1990;15:827-832

161. Achenbach S, Ropers D, Pohle K, Leber A, Thilo C, Knez A, Menendez T, Maeffert R, Kusus M, Regenfus M, Bickel A, Haberl R, Steinbeck G, Moshage W, Daniel WG. Influence of lipid-lowering therapy on the progression of coronary artery calcification: A prospective evaluation. Circulation. 2002;106:1077-1082

162. Block GA, Spiegel DM, Ehrlich J, Mehta R, Lindbergh J, Dreisbach A, Raggi P. Effects of sevelamer and calcium on coronary artery calcification in patients new to hemodialysis. Kidney international. 2005;68:1815-1824 
163. Goodman WG, Goldin J, Kuizon BD, Yoon C, Gales B, Sider D, Wang Y, Chung J, Emerick A, Greaser L, Elashoff RM, Salusky IB. Coronary-artery calcification in young adults with end-stage renal disease who are undergoing dialysis. $\mathrm{N}$ Engl J Med. 2000;342:1478-1483

164. O'Rourke RA, Brundage BH, Froelicher VF, Greenland P, Grundy SM, Hachamovitch R, Pohost GM, Shaw L, Weintraub WS, Winters WL, Jr., Forrester JS, Douglas PS, Faxon DP, Fisher JD, Gregoratos G, Hochman JS, Hutter AM, Jr., Kaul $\mathrm{S}$, Wolk MJ. American college of cardiology/american heart association expert consensus document on electron-beam computed tomography for the diagnosis and prognosis of coronary artery disease. Circulation. 2000;102:126-140

165. Greenland P, LaBree L, Azen SP, Doherty TM, Detrano RC. Coronary artery calcium score combined with framingham score for risk prediction in asymptomatic individuals. Jama. 2004;291:210-215

166. Arad Y, Goodman KJ, Roth M, Newstein D, Guerci AD. Coronary calcification, coronary disease risk factors, c-reactive protein, and atherosclerotic cardiovascular disease events: The st. Francis heart study. J Am Coll Cardiol. 2005;46:158165

167. Colhoun HM, Rubens MB, Underwood SR, Fuller JH. The effect of type 1 diabetes mellitus on the gender difference in coronary artery calcification. J Am Coll Cardiol. 2000;36:2160-2167

168. Dabelea D, Kinney G, Snell-Bergeon JK, Hokanson JE, Eckel RH, Ehrlich J, Garg S, Hamman RF, Rewers M. Effect of type 1 diabetes on the gender difference in coronary artery calcification: A role for insulin resistance? The coronary artery calcification in type 1 diabetes (cacti) study. Diabetes. 2003;52:2833-2839

169. Meigs JB, Larson MG, D'Agostino RB, Levy D, Clouse ME, Nathan DM, Wilson PW, O'Donnell CJ. Coronary artery calcification in type 2 diabetes and insulin resistance: The framingham offspring study. Diabetes Care. 2002;25:13131319

170. Tanikawa T, Okada Y, Tanikawa R, Tanaka Y. Advanced glycation end products induce calcification of vascular smooth muscle cells through rage/p38 mapk. J Vasc Res. 2009;46:572-580

171. Ren X, Shao H, Wei Q, Sun Z, Liu N. Advanced glycation end-products enhance calcification in vascular smooth muscle cells. J Int Med Res. 2009;37:847-854

172. Wang Z, Jiang Y, Liu N, Ren L, Zhu Y, An Y, Chen D. Advanced glycation end-product nepsilon-carboxymethyl-lysine accelerates progression of atherosclerotic calcification in diabetes. Atherosclerosis. 2012;221:387-396

173. Gawdzik J, Mathew L, Kim G, Puri TS, Hofmann Bowman MA. Vascular remodeling and arterial calcification are directly mediated by s100a12 (en-rage) in chronic kidney disease. Am J Nephrol. 2011;33:250-259

174. Cecil DL, Terkeltaub RA. Arterial calcification is driven by rage in enpp1-/- mice. J Vasc Res. 2011;48:227-235

175. Aboyans V, Criqui MH, Abraham P, Allison MA, Creager MA, Diehm C, Fowkes FG, Hiatt WR, Jonsson B, Lacroix P, Marin $B$, McDermott MM, Norgren L, Pande RL, Preux PM, Stoffers HE, Treat-Jacobson D. Measurement and interpretation of the ankle-brachial index: A scientific statement from the american heart association. Circulation. 2012;126:2890-2909

176. Criqui MH, Langer RD, Fronek A, Feigelson HS, Klauber MR, McCann TJ, Browner D. Mortality over a period of 10 years in patients with peripheral arterial disease. N Engl J Med. 1992;326:381-386

177. Fowkes FG, Murray GD, Butcher I, Heald CL, Lee RJ, Chambless LE, Folsom AR, Hirsch AT, Dramaix M, deBacker G, Wautrecht JC, Kornitzer M, Newman AB, Cushman M, Sutton-Tyrrell K, Lee AJ, Price JF, d'Agostino RB, Murabito JM, Norman PE, Jamrozik K, Curb JD, Masaki KH, Rodriguez BL, Dekker JM, Bouter LM, Heine RJ, Nijpels G, Stehouwer CD, Ferrucci L, McDermott MM, Stoffers HE, Hooi JD, Knottnerus JA, Ogren M, Hedblad B, Witteman JC, Breteler MM, Hunink MG, Hofman A, Criqui MH, Langer RD, Fronek A, Hiatt WR, Hamman R, Resnick HE, Guralnik J. Ankle brachial index combined with framingham risk score to predict cardiovascular events and mortality: A meta-analysis. Jama. 2008;300:197-208

178. McDermott MM, Guralnik JM, Tian L, Liu K, Ferrucci L, Liao Y, Sharma L, Criqui MH. Associations of borderline and low normal ankle-brachial index values with functional decline at 5-year follow-up: The walcs (walking and leg circulation study). J Am Coll Cardiol. 2009;53:1056-1062

179. de Vos LC, Noordzij MJ, Mulder DJ, Smit AJ, Lutgers HL, Dullaart RP, Kamphuisen PW, Zeebregts CJ, Lefrandt JD. Skin autofluorescence as a measure of advanced glycation end products deposition is elevated in peripheral artery disease. Arterioscler Thromb Vasc Biol. 2013;33:131-138

180. Noordzij MJ, Lefrandt JD, Loeffen EA, Saleem BR, Meerwaldt R, Lutgers HL, Smit AJ, Zeebregts CJ. Skin autofluorescence is increased in patients with carotid artery stenosis and peripheral artery disease. Int J Cardiovasc Imaging. 2012;28:431-438

181. Takahashi R, Imamura A, Yoshikane M, Suzuki M, Murakami R, Cheng XW, Numaguchi Y, Ikeda N, Murohara T, Okumura K. High serum concentrations of pentosidine, an advanced glycation end product, are associated with low normal value of ankle-brachial index in apparently healthy men. Metabolism. 2011;60:649-654

182. Lapolla A, Piarulli F, Sartore G, Ceriello A, Ragazzi E, Reitano R, Baccarin L, Laverda B, Fedele D. Advanced glycation end products and antioxidant status in type 2 diabetic patients with and without peripheral artery disease. Diabetes Care. 2007;30:670-676

183. den Ruijter HM, Peters SA, Groenewegen KA, Anderson TJ, Britton AR, Dekker JM, Engstrom G, Eijkemans MJ, Evans GW, de Graaf J, Grobbee DE, Hedblad B, Hofman A, Holewijn S, Ikeda A, Kavousi M, Kitagawa K, Kitamura A, Koffijberg H, Ikram MA, Lonn EM, Lorenz MW, Mathiesen EB, Nijpels G, Okazaki S, O'Leary DH, Polak JF, Price JF, Robertson C, Rembold CM, Rosvall M, Rundek T, Salonen JT, Sitzer M, Stehouwer CD, Witteman JC, Moons KG, Bots ML. Common carotid intima-media thickness does not add to framingham risk score in individuals with diabetes mellitus: The useimt initiative. Diabetologia. 2013;56:1494-1502

184. Lutgers HL, Graaff R, de Vries R, Smit AJ, Dullaart RP. Carotid artery intima media thickness associates with skin autofluoresence in non-diabetic subjects without clinically manifest cardiovascular disease. Eur J Clin Invest. 2010;40:812-817 
185. Baumann M, Richart $T$, Sollinger $D$, Pelisek J, Roos M, Kouznetsova $T$, Eckstein HH, Heemann $U$, Staessen JA. Association between carotid diameter and the advanced glycation end product $\mathrm{n}$-epsilon-carboxymethyllysine (cml). Cardiovasc Diabetol. 2009;8:45

186. Vlachopoulos C, Aznaouridis K, Stefanadis C. Prediction of cardiovascular events and all-cause mortality with arterial stiffness: A systematic review and meta-analysis. J Am Coll Cardiol. 2010;55:1318-1327

187. Laurent S, Boutouyrie P, Asmar R, Gautier I, Laloux B, Guize L, Ducimetiere P, Benetos A. Aortic stiffness is an independent predictor of all-cause and cardiovascular mortality in hypertensive patients. Hypertension. 2001;37:12361241

188. Sutton-Tyrrell K, Najjar SS, Boudreau RM, Venkitachalam L, Kupelian V, Simonsick EM, Havlik R, Lakatta EG, Spurgeon $\mathrm{H}$, Kritchevsky S, Pahor M, Bauer D, Newman A. Elevated aortic pulse wave velocity, a marker of arterial stiffness, predicts cardiovascular events in well-functioning older adults. Circulation. 2005;111:3384-3390

189. Willum-Hansen T, Staessen JA, Torp-Pedersen C, Rasmussen S, Thijs L, Ibsen H, Jeppesen J. Prognostic value of aortic pulse wave velocity as index of arterial stiffness in the general population. Circulation. 2006;113:664-670

190. Cruickshank K, Riste L, Anderson SG, Wright JS, Dunn G, Gosling RG. Aortic pulse-wave velocity and its relationship to mortality in diabetes and glucose intolerance: An integrated index of vascular function? Circulation. 2002;106:20852090

191. Laurent S, Cockcroft J, Van Bortel L, Boutouyrie P, Giannattasio C, Hayoz D, Pannier B, Vlachopoulos C, Wilkinson I, Struijker-Boudier H. Expert consensus document on arterial stiffness: Methodological issues and clinical applications. European heart journal. 2006;27:2588-2605

192. Hofmann B, Adam AC, Jacobs K, Riemer M, Erbs C, Bushnaq H, Simm A, Silber RE, Santos AN. Advanced glycation end product associated skin autofluorescence: A mirror of vascular function? Exp Gerontol. 2013;48:38-44

193. Ueno H, Koyama H, Tanaka S, Fukumoto S, Shinohara K, Shoji T, Emoto M, Tahara H, Kakiya R, Tabata T, Miyata T, Nishizawa Y. Skin autofluorescence, a marker for advanced glycation end product accumulation, is associated with arterial stiffness in patients with end-stage renal disease. Metabolism. 2008;57:1452-1457

194. Watfa G, Soulis G, Tartagni E, Kearney-Schwartz A, Borghi C, Salvi P, Benetos A. Relationship between tissue glycation measured by autofluorescence and pulse wave velocity in young and elderly non-diabetic populations. Diabetes Metab. 2012;38:413-419

195. Semba RD, Najjar SS, Sun K, Lakatta EG, Ferrucci L. Serum carboxymethyl-lysine, an advanced glycation end product, is associated with increased aortic pulse wave velocity in adults. American journal of hypertension. 2009;22:74-79

196. Schram MT, Schalkwijk CG, Bootsma AH, Fuller JH, Chaturvedi N, Stehouwer CD. Advanced glycation end products are associated with pulse pressure in type 1 diabetes: The eurodiab prospective complications study. Hypertension. 2005;46:232-237

197. Farrall AJ, Wardlaw JM. Blood-brain barrier: Ageing and microvascular disease--systematic review and meta-analysis. Neurobiol Aging. 2009;30:337-352

198. Li XH, Du LL, Cheng XS, Jiang X, Zhang Y, Lv BL, Liu R, Wang JZ, Zhou XW. Glycation exacerbates the neuronal toxicity of beta-amyloid. Cell Death Dis. 2013;4:e673

199. Coker LH, Wagenknecht LE. Advanced glycation end products, diabetes, and the brain. Neurology. 2011;77:1326-1327

200. Candela P, Gosselet F, Saint-Pol J, Sevin E, Boucau MC, Boulanger E, Cecchelli R, Fenart L. Apical-to-basolateral transport of amyloid-beta peptides through blood-brain barrier cells is mediated by the receptor for advanced glycation end-products and is restricted by p-glycoprotein. J Alzheimers Dis. 2010;22:849-85 



\section{CHAPTER 2}

The methylglyoxal-derived AGE tetrahydropyrimidine is increased in plasma of type 1 diabetes mellitus and in atherosclerotic lesions and is associated with SVCAM-1

The Coronary Artery Calcification Study and the LEACE study

Marcelle G.A. van Eupen, Miranda T. Schram, Helen M. Colhoun, Nordin M.J. Hanssen, Hans W.M. Niessen, Lise Tarnow, Hans-Henrik Parving, Peter Rossing, C.D.A. Stehouwer, C.G. Schalkwijk Diabetologia. 2013 Aug;56(8):1845-55 


\section{ABSTRACT}

\section{Background}

Methylglyoxal (MGO) is a major precursor for advanced glycation endproducts (AGEs), which are thought to play a role in vascular complications in diabetes. MGO-arginine-derived AGEs are 5hydro-5-methylimidazolone (MG-H1), argpyrimidine and tetrahydropyrimidine (THP). We studied THP in relation to type 1 diabetes, endothelial dysfunction, low-grade inflammation, vascular complications and atherosclerosis.

\section{Methods}

We raised and characterized a monoclonal antibody against MGO-derived THP. We measured plasma THP with a competitive ELISA in two cohort studies: study A (198 individuals with type 1 diabetes and 197 controls), and study B (individuals with type 1 diabetes, 175 with normoalbuminuria and 198 with macroalbuminuria (>300 mg/24h)). We measured plasma markers of endothelial dysfunction and low-grade inflammation, and evaluated the presence of THP and $\mathrm{N}-\varepsilon$ (Carboxymethyl)lysine (CML) in atherosclerotic arteries.

\section{Results}

THP was higher in individuals with compared to without type 1 diabetes with median [IQR] of $115.5 \mathrm{U} / \mu \mathrm{l}$ [102.4-133.2] and 109.8 $\mathrm{U} / \mu \mathrm{l}$ [91.8-122.3], respectively $(\mathrm{p}=0.03)$. THP was associated with plasma soluble vascular cell adhesion molecule 1 , in both study $A$ ( $s \beta=0.48$ [95\%-CI 0.38 , $0.58], p<0.001)$ and study $B(s \beta=0.31$ [95\%-CI 0.23, 0.40], $p<0.001)$, and with secreted phospholipase $A 2(s \beta=0.26$ [95\%-CI $0.17,0.36], p<0.001)$ in study $B$. We found no association of THP with micro- or macrovascular complications. Both THP and CML were detected in atherosclerotic arteries.

\section{Conclusions}

Our results suggest that MGO-derived THP may reflect endothelial dysfunction among individuals with and without type 1 diabetes, and therefore may potentially play a role in the development of atherosclerosis and vascular disease. 


\section{INTRODUCTION}

The pathogenesis of vascular complications in type 1 diabetes is thought to involve damaging effects of advanced glycation endproducts (AGEs) on vascular tissues ${ }^{1,2}$. Methylglyoxal (MGO), which accumulates rapidly under hyperglycaemic conditions, has been demonstrated to be the most important precursor in the formation of AGEs 3, 4. MGO is mainly formed by dephosphorylation and conversion of glyceraldehyde-3-phosphate and dihydroxyacetonephosphate. MGO is detoxified into D-lactate by the glyoxalase pathway ${ }^{5,6}$. MGO primarily reacts with arginine residues in proteins to form three products: the non-fluorescent products 5-hydro5-methylimidazolone (MG-H1), tetrahydropyrimidine (THP), and the major fluorescent product argpyrimidine ${ }^{7}$. Plasma concentrations of $\mathrm{MGO}^{8}$ as well as MG-H1 ${ }^{9}$ and argpyrimidine ${ }^{10}$ are elevated in individuals with diabetes, and are associated with complications of diabetes ${ }^{7,11}$. So far, such data about THP are lacking. THP is formed rapidly after incubation of MGO with arginine, following a similar pattern as MG-H1 ${ }^{12,13}$. Since different MGO-derived AGEs could have different pathophysiological consequences, it is important to study the potential role of THP in type 1 diabetes and its complications.

MGO may exert detrimental effects on cellular function via intracellular modifications of proteins and changes in protein structure, function or activity ${ }^{1}$. We recently demonstrated that MGO reduces endothelium-dependent vasodilatation in isolated arteries ${ }^{14}$, providing a new mechanistic link between MGO and endothelial dysfunction. It has been demonstrated that the modification of proteins by MGO results in increased formation of reactive oxygen species (ROS) ${ }^{15-17}$ and increased expression of adhesion molecules, e.g. vascular cell adhesion molecule 1 (VCAM-1) and intracellular adhesion molecule 1 (ICAM-1), intra growth factors and a sensitizing of cells to the effects of pro-inflammatory cytokines ${ }^{18}$, i.e. early events in the initiation of atherosclerosis.

Although these studies $1,3,4,7-10,14-18$ indicate that MGO is involved in the pathophysiology of vascular complications, the formation of MGO-modified proteins and their relationship in the development of complications require further investigation. Therefore, we raised and characterized an antibody against MGO-derived AGEs which preferentially binds THP above MG$\mathrm{H} 1$ and argpyrimidine. Using the antibody, we first examined whether plasma levels of THP are elevated in type 1 diabetes. Second, we evaluated the association of plasma THP with markers of endothelial dysfunction and low-grade inflammation. Third, we examined if there was an association of THP with micro- and macrovascular complications in type 1 diabetes. Fourth, we used this antibody to evaluate the presence of THP in human coronary arteries. 


\section{METHODS}

\section{Preparation of anti-methylglyoxal antibodies}

MGO-modified keyhole limpet hemocyanin (MGO-KLH) was prepared by the reaction of MGO (10 $\mathrm{mM}$ ) with $\mathrm{KLH}$ for 7 days at $37^{\circ} \mathrm{C}$ and used as antigen for the immunization of mice. MGO-KLH was emulsified in an equal volume of Freund's complete adjuvant; three mice were intradermally injected at multiple sites. These mice were boosted with the same amount of MGO-KLH emulsified in Freund's incomplete adjuvant 21 days later and antisera obtained 14 days after the booster were tested. The booster was repeated twice. Ten days after the final booster, antisera were tested with MGO-albumin and the mouse with the highest titer was used for fusion. We obtained 40 positive clones as tested with MGO-albumin, one of them was further characterized. For the characterization of the recognition-epitope of the antibody, argpyrimidine, MG-H1 and THP were synthesized as described 7,19 .

\section{Preparation of MGO-albumin}

Human serum albumin (HSA) glycated by MGO was prepared by an incubation of HSA $(6.8 \mathrm{mg} / \mathrm{ml})$ with MGO (0.5M) in PBS at $37^{\circ} \mathrm{C}$ for $0-8$ days. After the incubations, the reaction mixtures were extensively dialyzed against PBS at $4^{\circ} \mathrm{C}$ with three changes of solution. The reagents were divided in aliquots and stored at $-20^{\circ} \mathrm{C}$.

\section{MGO-albumin ELISA}

In a competitive ELISA, performed at room temperature, each well was coated with $1 \mu \mathrm{g}$ minimally-modified MGO-albumin in PBS for 1 hour at room temperature. Minimally-modified MGOalbumin was prepared by an incubation of HSA $(6.8 \mathrm{mg} / \mathrm{ml})$ with $\mathrm{MGO}(0.5 \mathrm{M})$ in PBS at $37^{\circ} \mathrm{C}$ for 2 days. The wells were washed twice with PBS. Each well was then blocked with $150 \mu \mathrm{l} 1 \%$ bovine serum albumin in PBS for 1 hour. Wells were then washed three times with PBS containing $0.05 \%$ Tween 20 (PBS-Tween). To each well were added $50 \mu$ of the anti-MGO antibody conjugated with biotin (1:2000) and $50 \mu \mathrm{l}$ of standard minimally-modified MGO-albumin or a plasma sample to be tested diluted and incubated for 2 hours. After three washes with PBS-Tween, the wells were incubated with streptavidine-peroxidase (CLB, Amsterdam, the Netherlands) for 1 hour. Finally, the wells were washed five times with PBS-Tween and the substrate was developed with $100 \mu \mathrm{l}$ of tetramethylbenzidine. The extinction at $450 \mathrm{~nm}$ was measured with a multichannel spectrophotometer (SLT Microplate reader, Wilten Bioteknika, Etten-Leur, the Netherlands). Plasma levels were expressed as MGO-albumin units $(\mathrm{U} / \mathrm{ml})$, and one $\mathrm{U}$ was defined as the antibody-reactive material equivalent to $1 \mu \mathrm{g}$ of the MGO-albumin standard. The intra- and inter assay variations were $5 \%$ and $8 \%$, respectively.

\section{Cohort Study A}

In 1998, a random sample of 199 men and women with type 1 diabetes aged 30 to 55 years was taken from the diabetes registers of five London hospitals. Type 1 diabetes was defined by age of onset $<25$ years and insulin treatment within one year of diagnosis. A random sample of 201 individuals from the general population, stratified to have a similar age and sex distribution to the individuals with diabetes, was drawn from the lists of two London general practices. It was confirmed that these controls had no clinical history of diabetes and were not on any treatment for diabetes. Individuals were included regardless of any history of heart disease. One participant 
(a woman with diabetes) had a history of angina; none had had a myocardial infarction. Pregnant women and patients on renal replacement therapy were excluded. Retinopathy and neuropathy were self-reported via a standardized questionnaire. Details of this study have been described previously ${ }^{20}$.

Laboratory methods. Urinary albumin was measured with an immunoturbidimetric method (intraassay CV 2.3\%). Normoalbuminuria was defined as a urinary albumin excretion rate (AER) of $<20$ $\mu \mathrm{g} / \mathrm{min}$, microalbuminuria as an AER of $20-200 \mu \mathrm{g} / \mathrm{min}$ and macroalbuminuria as an AER of $>200$ $\mu \mathrm{g} / \mathrm{min}$, in two 24-h urine collections. Glomerular filtration rate (eGFR) was estimated according to the short Modification of Diet in Renal Disease equation (MDRD) $=186 *$ [serum creatinine $(\mathrm{mg} / \mathrm{dL})]-1.154 *$ [age]-0.203* [0.742 if patient is female] ${ }^{21}$. High-sensitivity C-reactive protein (hSCRP), a marker of low-grade inflammation, was measured with a highly sensitive in-house ELISA, as described previously ${ }^{22}$. A commercially available ELISA kit was used to measure plasma sVCAM-1 (R\&D Systems). Von Willebrand factor (VWF) activity, a marker of endothelial dysfunction, was measured in heparin plasma by Shield vWF activity ELISA kit (Shield Diagnostics Ltd, Dundee, Scotland) using IgG monoclonal antibodies, and expressed as percentage of vWF in pooled plasma of healthy volunteers. Levels of MGO-derived THP were measured in 198 individuals with and 197 without type 1 diabetes.

\section{Cohort Study B}

In 1993, 199 individuals with type 1 diabetes and diabetic nephropathy, defined according to clinical criteria (i.e. persistent macroalbuminuria [ $>300 \mathrm{mg} / 24 \mathrm{~h}$ ] in at least two out of three previous consecutive 24-h urine collections, in the presence of diabetic retinopathy, and in the absence of other kidney or urinary tract disease), and 192 individuals with type 1 diabetes and persistent normoalbuminuria (i.e., urinary albumin excretion rate $<30 \mathrm{mg} / 24 \mathrm{~h}$ ) were recruited from the outpatient clinic at Steno Diabetes Center for a prospective observational follow-up study. Details of the inclusion criteria and selection procedures have been described elsewhere ${ }^{23}$.

Examination. Diabetic retinopathy was assessed in all patients at baseline by fundus photography after pupillary dilatation and graded as nil, simplex, or proliferative retinopathy. Any history of acute myocardial infarction (AMI) or stroke was considered as cardiovascular disease (CVD) at baseline.

Laboratory methods. Urinary albumin concentration was measured by an enzyme immunoassay from 24-hour urine collections. Glomerular filtration rate (eGFR) was estimated according to the MDRD equation ${ }^{21}$. Levels of hsCRP were determined by enzyme immunoassays (normal range $0.13-3.0 \mathrm{mg} / \mathrm{l}$ ) as described previously ${ }^{24}$. Commercially available ELISA kits were used to measure markers of endothelial dysfunction: plasma SVCAM-1 (range for assay 538-1,286 ng/ml), sICAM1 (range 98-647 ng/ml), and low-grade inflammation: interleukin- 6 (IL-6), secreted phospholipase A2 (sPLA2), and total transforming growth factor beta 1 (TGF- $\beta 1$ ) (R\&D Systems). The AGEs CEL and CML were measured with ultra-performance liquid chromatography tandem mass spectrometry (UPLC-MS/MS), pentosidine was measured with high performance liquid chromatography (HPLC) with fluorescence detection, as described previously ${ }^{2}$. Levels of MGOderived AGE THP were measured in 175 individuals with normoalbuminuria and 198 individuals with macroalbuminuria and retinopathy. All measurements were performed on blood and urine samples collected at baseline. 


\section{Immunohistochemistry}

Materials and processing of tissue specimens. Histological specimens of coronary arteries were obtained from human autopsies of individuals who died of non-cardiovascular causes in a hospital based setting. We included 12 controls, 3 individuals with type 1 diabetes and 10 with type 2 diabetes. The specimens were routinely fixed with $4 \%$ formalin and subsequently embedded in paraffin. Serial paraffin-embedded vascular tissue sections $(4 \mu \mathrm{m})$ were mounted on microscope slides and were deparaffinised for 10 minutes in xylene at room temperature and rehydrated through descending concentrations of ethanol.

Immunohistochemical detection of THP, CML and CD68 in serial sections. For staining with THP antibody, the sections were preincubated in $0.01 \mathrm{M}$ citrate, $\mathrm{pH}=6$, at $37^{\circ} \mathrm{C}$ during 10 minutes. For CML and CD68 staining, the sections were preincubated in $0.1 \%$ pepsin with hydrochloric acid $(\mathrm{HCl})$. Thereafter, sections were incubated for 40 minutes with anti-THP antibody (1:12.5), antiCML antibody 25 (1:4000) and anti-CD68 antibody specific for macrophages (dilution 1:1000, DAKO) at room temperature. After washing in PBS, sections were incubated for 40 minutes with labelled Polymer (Envision system K4007 DAKO) at room temperature and subsequently washed in PBS. Sections were then incubated for 5 minutes with liquid DAB+substrate-chromogen solution. Finally the sections were stained with hematoxylin, to visualize the nuclei of cells.

Quantification of staining. To quantify the amount of staining of THP and CML, two independent observers scored each specimen from $0-4$; ' 0 ' when there was no staining in the plaque or thickened intima, ' 4 ' when staining was abundant. The mean score of the two observers per specimen was used for analyses.

All studies were approved by the local ethics committee and all participants gave their written informed consent 20,23 .

\section{Statistical methods}

Analyses were carried out with SPSS version 17 for Windows. Variables with a skewed distribution were log-transformed before further analyses. Comparisons of baseline characteristics between groups were performed with Student's t or $\mathrm{X} 2$ tests. All biomarkers were analyzed by use of zscores [i.e., (individual values - sample's mean) / sample's standard deviation (SD))]. We used multiple linear regression analyses to evaluate the associations of THP and other AGEs with type 1 diabetes or markers of endothelial function and low-grade inflammation. Multiple logistic regression analysis was used to evaluate the associations of THP with microvascular complications, i.e. nephropathy, neuropathy, retinopathy, and macrovascular complications. For analyses based on the immunohistochemical data, we used Pearson's Chi-Square test to evaluate possible differences in percentage of stenosis between groups. We used the independent samples KruskallWallis test to evaluate possible differences in THP or CML staining between groups. A p-value of $<0.05$ was considered statistically significant. 


\section{RESULTS}

\section{Characterization of anti-MGO-derived AGEs}

MGO-KLH was used as antigen for the immunization of mice. We obtained 40 positive clones as tested with MGO-albumin and one of them, a monoclonal antibody from the IgG1 subclass, was further characterized. This antibody reacted with MGO-modified albumin but not with GO-modified albumin, 3DG-modified albumin or well-known AGEs such as CML and pentosidine (Figure 2.1a). The epitope of the anti-MGO antibody was studied using a competitive ELISA. Figure 2.1b shows the reactivity of the monoclonal anti-MGO antibody with THP with an at least 1000 -fold preference for THP as compared with argpyrimidine or MG-H1. For further validation of our test system, comparable competition experiments were performed with two well-known specific monoclonal antibodies against argpyrimidine ${ }^{7}$ and MG- ${ }_{1}{ }^{9}$, which demonstrated that the epitopes of these monoclonal antibodies were indeed argpyrimidine (Figure 2.1c) and MG-H1 (Figure 2.1d), respectively, confirming the specificity of our test system. Our antibody was further characterized by immunoblotting. Analysis of MGO-derived arginine residues in minimally-modified MGO-albumin demonstrated that the THP epitope was detectable after 1 day, reached an apparent optimum at two days and declined steadily afterwards, suggesting further chemical rearrangements that are less well recognized by our antibody (Figure 2.1e). In the minimally-modified MGO-albumin preparation, the argpyrimidine epitope was formed only after $12 \mathrm{~h}$ of incubation and further increased in time (Figure 2.1e). MG-H1 formation occurred rapidly in the initial hours and attained a maximum value in the subsequent 18 hours (Figure $2.1 \mathrm{~g}$ ). Over the next 8 days, however, there was a further slow increase in MG-H1 concentration.

\section{The association of type 1 diabetes with THP}

Table 2.1 shows the general characteristics of cohort study $A$ and $B$. In study $A$, type 1 diabetes was positively associated with THP (crude $\beta=0.23$ SD [95\%-CI $0.03,0.43$ ]; $p=0.03$ ). THP was associated with pack years of smoking and triacylglycerols, but not with age, sex, body mass index (BMI), waist-to-hip ratio, LDL-cholesterol, HDL-cholesterol, AER, eGFR, HbA1c, and systolic or diastolic blood pressure. Additional adjustment for age, sex, pack years of smoking and triacylglycerols slightly weakened the association of THP with type 1 diabetes ( $\beta=0.20$ SD [95\%CI $0.00,0.40], p=0.05)$. In study $B$, we found no significant association of THP with age, sex, macroalbuminuria, smoking, duration of diabetes, BMI, systolic or diastolic blood pressure, $\mathrm{HbA1C}$, AER, eGFR, LDL-cholesterol, HDL-cholesterol and triacylglycerols.

\section{The association of THP with markers of endothelial dysfunction}

THP was positively associated with SVCAM-1 in both cohort studies. Per SD increase in THP, sVCAM-1 increased by 0.51 SD in study A (table 2.2, crude analysis) and by 0.29 SD in study B (table 2.3, crude analysis). In both studies, additional adjustment for possible confounders did not materially change this association (table 2.2 and 2.3). We additionally investigated the association of the AGEs CML, CEL and pentosidine with SVCAM-1, which were available in cohort study $B$, and found that these AGEs were not independently associated with SVCAM-1 (table 2.3). THP was not associated with vWf (study $A$ : $s \beta=-0.07$ [95\%-CI $-0.17,0.03], p=0.19]$ ), nor with sICAM-1 (study $B$ : $s \beta=0.04[95 \%-C I-0.06,0.14], p=0.47)$, in analyses adjusted for age and sex. 
Table 2.1. Baseline characteristics of the study population of the two cohort studies

\begin{tabular}{|c|c|c|c|c|c|c|}
\hline & \multicolumn{3}{|c|}{ Cohort study A } & \multicolumn{3}{|c|}{ Cohort study B } \\
\hline & Controls & T1DM & $\begin{array}{c}\mathrm{P}- \\
\text { value }\end{array}$ & $\begin{array}{c}\text { T1DM } \\
\text { normoalbum } \\
\text { inuria }\end{array}$ & $\begin{array}{c}\text { T1DM } \\
\text { macroalbu } \\
\text { minuria \& } \\
\text { retinopathy }\end{array}$ & $\begin{array}{c}\text { P- } \\
\text { value }\end{array}$ \\
\hline \multicolumn{7}{|l|}{ General } \\
\hline $\mathrm{n}$ & 197 & 198 & & 175 & 198 & \\
\hline Age (years) & $37.8 \pm 3.7$ & $37.9 \pm 4.3$ & 0.92 & $42.7 \pm 9.7$ & $40.9 \pm 9.5$ & 0.07 \\
\hline $\begin{array}{l}\text { Sex (number of } \\
\text { males/females) }\end{array}$ & $91 / 106$ & $103 / 95$ & 0.25 & $104 / 71$ & $121 / 77$ & 0.74 \\
\hline Diabetes duration $(\mathrm{y})$ & - & $23.4 \pm 7.7$ & - & $27.7 \pm 8.2$ & $27.9 \pm 7.8$ & 0.84 \\
\hline HbA1c (\%) & $5.31 \pm 0.41$ & $8.79 \pm 1.54$ & $<0.01$ & $8.5 \pm 1.1$ & $9.6 \pm 1.5$ & $<0.001$ \\
\hline $\mathrm{HbA} 1 \mathrm{c}(\mathrm{mmol} / \mathrm{mol})$ & $34.5 \pm 4.4$ & $72.5 \pm 16.9$ & $<0.01$ & $69.8 \pm 12.1$ & $80.9 \pm 16.8$ & $<0.001$ \\
\hline $\begin{array}{l}\text { Smoking, former or } \\
\text { current }\end{array}$ & $96(49)$ & $88(44)$ & 0.39 & $62(109)$ & $68(135)$ & 0.23 \\
\hline $\begin{array}{l}\text { Pack years of smoking } \\
\text { for former or current } \\
\text { smokers }\end{array}$ & $\begin{array}{c}9.3 \\
{[4.0-19.1]}\end{array}$ & $\begin{array}{c}9.5 \\
{[4.5-17.9]}\end{array}$ & 0.85 & - & - & - \\
\hline BMI $\left(\mathrm{kg} / \mathrm{m}^{2}\right)$ & $25.3 \pm 4.7$ & $25.4 \pm 3.5$ & 0.83 & $23.7 \pm 2.5$ & $24.0 \pm 3.3$ & 0.32 \\
\hline Waist-to-hip ratio & $0.86 \pm 0.08$ & $0.87 \pm 0.08$ & 0.35 & - & - & - \\
\hline $\begin{array}{l}\text { Total cholesterol } \\
(\mathrm{mmol} / \mathrm{l})\end{array}$ & $5.49 \pm 1.21$ & $5.33 \pm 1.08$ & 0.17 & $4.8 \pm 1.0$ & $5.6 \pm 1.2$ & $<0.001$ \\
\hline $\begin{array}{l}\text { HDL cholesterol } \\
(\mathrm{mmol} / \mathrm{l})\end{array}$ & $1.70 \pm 0.41$ & $1.83 \pm 0.46$ & $<0.01$ & $1.6 \pm 0.5$ & $1.5 \pm 0.5$ & 0.09 \\
\hline $\begin{array}{l}\text { LDL cholesterol } \\
(\mathrm{mmol} / \mathrm{l})\end{array}$ & $3.11 \pm 0.94$ & $2.93 \pm 0.91$ & 0.06 & $2.8 \pm 0.9$ & $3.5 \pm 1.1$ & $<0.001$ \\
\hline $\begin{array}{l}\text { Triacylglycerols } \\
(\mathrm{mmol} / \mathrm{l})\end{array}$ & $\begin{array}{c}1.08 \\
{[0.77-1.52]}\end{array}$ & $\begin{array}{c}1.01 \\
{[0.77-1.35]}\end{array}$ & 0.08 & $\begin{array}{c}0.77 \\
{[0.57-0.96]}\end{array}$ & $\begin{array}{c}1.22 \\
{[0.88-1.66]}\end{array}$ & $<0.001$ \\
\hline Systolic BP (mm Hg) & $117 \pm 14$ & $124 \pm 14$ & $<0.01$ & $132 \pm 18$ & $151 \pm 23$ & $<0.001$ \\
\hline Diastolic BP $(\mathrm{mm} \mathrm{Hg})$ & $73 \pm 10$ & $74 \pm 9$ & 0.33 & $76 \pm 10$ & $86 \pm 13$ & $<0.001$ \\
\hline $\begin{array}{l}\text { eGFRMDRD } \\
\left(\mathrm{ml} / \mathrm{min} / 1.73 \mathrm{~m}^{2}\right)\end{array}$ & $90.1 \pm 17.2$ & $98.8 \pm 16.6$ & $<0.001$ & $93.1 \pm 14.9$ & $66.5 \pm 28.1$ & $<0.001$ \\
\hline \multicolumn{7}{|c|}{ Advanced glycation endproducts } \\
\hline THP (U/ml) & $\begin{array}{c}109.8 \\
{[91.8-122.3]}\end{array}$ & $\begin{array}{c}115.5 \\
{[102.4-133.2]}\end{array}$ & 0.03 & $\begin{array}{c}116.2 \\
{[92.8-142.4]}\end{array}$ & $\begin{array}{c}109.9 \\
{[87.1-137.4]}\end{array}$ & 0.62 \\
\hline $\mathrm{CML}(\mu \mathrm{mol} / \mathrm{l})$ & - & - & - & $\begin{array}{c}3.73 \\
{[3.28-4.10]}\end{array}$ & $\begin{array}{c}3.27 \\
{[2.83-3.85]}\end{array}$ & $<0.001$ \\
\hline $\operatorname{CEL}(\mu \mathrm{mol} / \mathrm{l})$ & - & - & - & $\begin{array}{c}0.93 \\
{[0.82-1.05]}\end{array}$ & $\begin{array}{c}0.94 \\
{[0.79-1.14]}\end{array}$ & 0.19 \\
\hline Pentosidine $(\mathrm{pmol} / \mathrm{mg})$ & - & - & - & $\begin{array}{c}42.4 \\
{[36.6-49.9]}\end{array}$ & $\begin{array}{c}45.2 \\
32.6-62.6]\end{array}$ & 0.05 \\
\hline
\end{tabular}


Table 2.1. Baseline characteristics of the study population of the two cohort studies (continued)

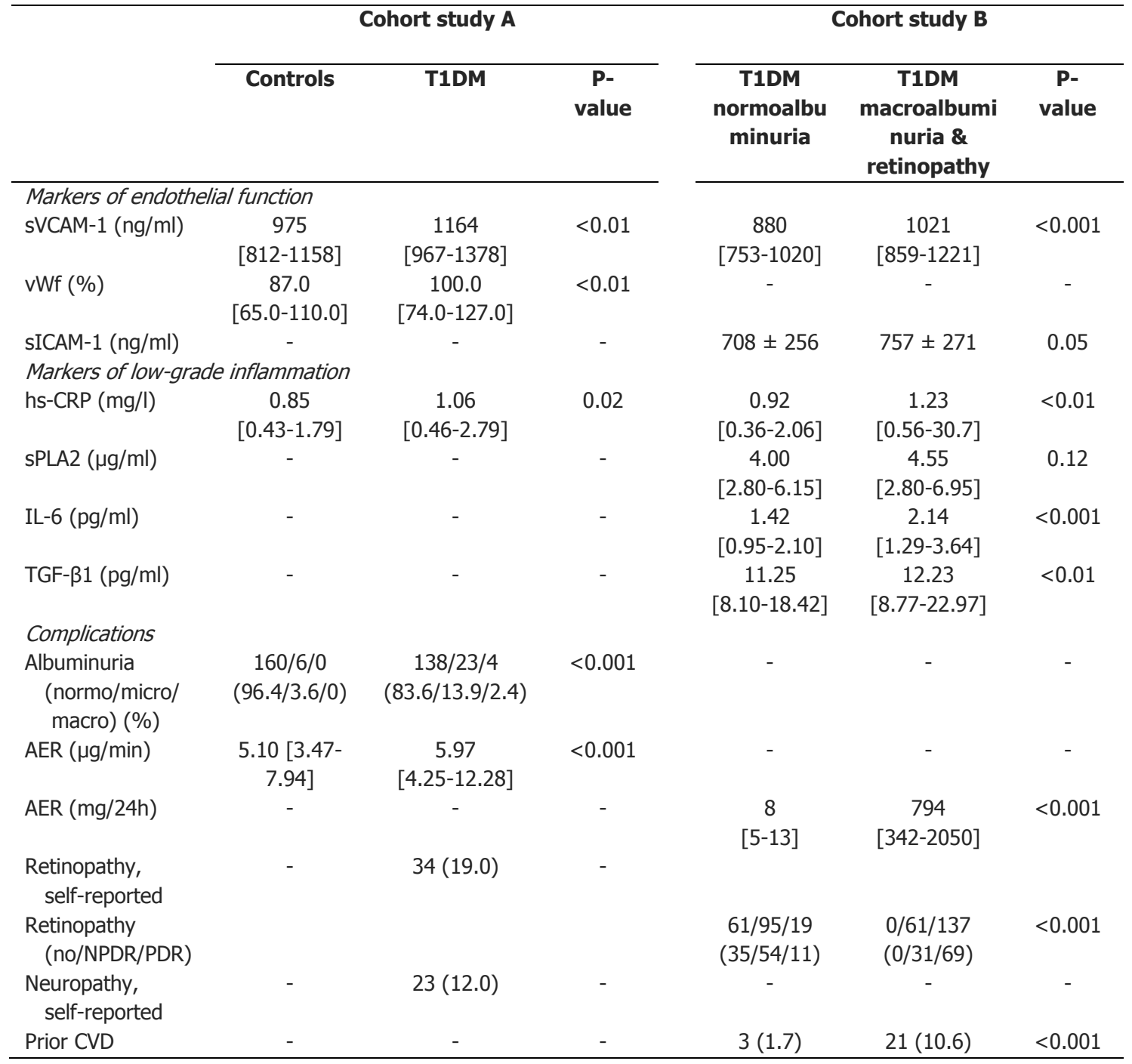

Data are presented as mean \pm standard deviation (SD), median [inter quartile range (IQR)] or number (percentage) unless otherwise indicated.

T1DM, type 1 diabetes mellitus; HbA1c, glycated hemoglobin; BMI, body mass index; HDL, high-density lipoprotein; LDL, lowdensity lipoprotein; BP, blood pressure; eGFRMDRD, estimated Glomerular Filtration Rate by abbreviated Modification of Diet in Renal Disease equation; AGE, advanced glycation endproduct; THP, tetrahydropyrimidine; sVCAM-1: soluble vascular cell adhesion molecule 1; vWf, Von Willebrand factor; sICAM-1, intercellular adhesion molecule-1; hs-CRP, high-sensitivity C-reactive protein; SPLA2, secreted phospholipases A2; IL-6, interleukin-6; TGF- $\beta 1$, transforming growth factor beta 1 ; AER, urinary albumin excretion rate; NPDR, non-proliferative diabetic retinopathy; PDR, proliferative diabetic retinopathy; CVD, cardiovascular disease. 


\section{The association of THP with markers of low-grade inflammation}

We found a significant positive association of THP with sPLA2 (study B: $s \beta=0.26$ [95\%-CI 0.17, $0.36], p<0.001])$. Additional adjustments for age, sex, macroalbuminuria, smoking, diabetes duration, HbA1c, LDL-cholesterol, HDL-cholesterol, triacylglycerols, urinary albumin excretion rate (AER), systolic and diastolic blood pressure, BMI and eGFR did not materially change this association. THP was not associated with hsCRP (study A:s $\beta=-0.004[95 \%-C I-0.10,0.10]$, $p=0.94$; study $B: s \beta=0.02$ [95\%-CI $-0.08,0.12], p=0.65$ ), IL-6 (study $B: s \beta=-0.01$ [95\%-CI -0.10 , $0.10], p=0.93$ ) and TGF- $\beta 1$ (study $B: s \beta=0.04[95 \%-C I-0.06,0.15], p=0.41$ ), in analyses adjusted for age and sex.

\section{The association of THP with micro- and macrovascular complications in type 1 diabetes}

In study A, THP was neither associated with micro- or macroalbuminuria nor with self-reported history of neuropathy or retinopathy in individuals with type 1 diabetes (table 2.4). In study B, THP was not associated with macroalbuminuria, retinopathy or with CVD at baseline (table 2.4).

\section{THP is present in atherosclerotic lesions}

We determined whether THP is present in the atherosclerotic plaque of coronary arteries. Specimens were available in 12 controls, 3 individuals with type 1 and 10 with type 2 diabetes. Respectively, 5, 2 and 4 individuals were male and mean age at time of death was 67, 65 and 66 . None of the individuals died of an acute myocardial infarction, but 3 had a previous myocardial infarction, 1 in each group. The level of stenosis in the respective atherosclerotic coronary arteries was not significantly different between controls and individuals with type 1 or type 2 diabetes $(p=0.55)$. In 7 of the 12 controls, 3 of the 3 individuals with type 1 diabetes and 4 of the 10 individuals with type 2 diabetes, coronary artery specimens showed $>50 \%$ stenosis. In coronary arteries, staining for THP and CML was observed in atherosclerotic lesions (figure 2.2). In consecutive sections, THP and CML co-localized predominantly with macrophages (CD68-positive cells) (figure 2.2).

The amount of staining of THP and CML was not significantly different between controls, individuals with type 1 and type 2 diabetes. Median (range) score for THP staining was 2.3 (0.03.5) for controls, and $3.3(2.0-3.5)$ and $0.5(0.0-3.5)$ for individuals with type 1 and type 2 diabetes, respectively $(p=0.12)$. Median (range) score for CML staining was $1.7(0.0-3.0)$ for controls, and $3.0(1.0-3.5)$ and $1.0(0.0-2.5)$ for individuals with type 1 and type 2 diabetes, respectively $(p=0.22)$. 
Table 2.2. Association of THP with SVCAM-1 in individuals with and without type 1 diabetes (cohort study A)

\begin{tabular}{llcc}
\hline $\mathbf{M}$ & Adjustments & $\boldsymbol{s} \boldsymbol{\beta}$ & $\boldsymbol{p}$-value \\
& & $(\mathbf{9 5 \%} \boldsymbol{- C I})$ & \\
\hline C & Crude & 0.51 & $<0.001$ \\
& & $(0.41-0.60)$ & $<0.001$ \\
1 & Age, sex and diabetes & 0.49 & \\
& & $(0.39-0.58)$ & $<0.001$ \\
2 & Model 1 + additional adjustments & 0.48 & \\
\hline
\end{tabular}

Standardized $\beta$, the standardized regression coefficient obtained with linear regression analyses, indicates the change in sVCAM-1 (in SD) per 1 SD higher level in THP. M, Model.

a Model 2 is additionally adjusted for pack years of smoking, HbA1c, LDL-cholesterol, HDL-cholesterol, triacylglycerols, estimated glomerular filtration rate (eGFR), urinary albumin excretion rate (AER), systolic and diastolic blood pressure, BMI and waist-hip-ratio (WHR).

Table 2.3. Association of THP, CEL, CML and pentosidine with sVCAM-1 in individuals with type 1 diabetes with and without macroalbuminuria (cohort study B)

\begin{tabular}{|c|c|c|c|c|c|c|c|c|}
\hline & \multicolumn{2}{|c|}{ THP } & \multicolumn{2}{|l|}{ CML } & \multicolumn{2}{|l|}{ CEL } & \multicolumn{2}{|c|}{ Pentosidine } \\
\hline $\mathbf{M}$ & $\begin{array}{c}s \beta \\
(95 \%-C I)\end{array}$ & p-value & $\begin{array}{c}s \beta \\
(95 \%-C I)\end{array}$ & $\begin{array}{c}p- \\
\text { valu } \\
e\end{array}$ & $\begin{array}{c}s \beta \\
(95 \%-C I)\end{array}$ & $\begin{array}{c}p- \\
\text { valu } \\
e\end{array}$ & $\begin{array}{c}S \beta \\
(95 \%-C I)\end{array}$ & $\begin{array}{c}p- \\
\text { value }\end{array}$ \\
\hline $\mathrm{C}$ & $\begin{array}{c}0.29 \\
(0.19-0.38)\end{array}$ & $<0.001$ & $\begin{array}{c}<0.01 \\
(-0.10-0.10)\end{array}$ & 0.99 & $\begin{array}{c}0.08 \\
(-0.02-0.19)\end{array}$ & 0.11 & $\begin{array}{c}0.16 \\
(0.06-0.26)\end{array}$ & $<0.01$ \\
\hline 1 & $\begin{array}{c}0.30 \\
(0.21-0.39)\end{array}$ & $<0.001$ & $\begin{array}{c}0.06 \\
(-0.05-0.16)\end{array}$ & 0.28 & $\begin{array}{c}0.04 \\
(-0.07-0.13)\end{array}$ & 0.50 & $\begin{array}{c}0.12 \\
(0.02-0.23)\end{array}$ & 0.02 \\
\hline 2 & $\begin{array}{c}0.31 \\
(0.23-0.40)\end{array}$ & $<0.001$ & $\begin{array}{c}-0.02 \\
(-0.13-0.08)\end{array}$ & 0.68 & $\begin{array}{c}-0.09 \\
(-0.19-0.02)\end{array}$ & 0.10 & $\begin{array}{c}-0.02 \\
(-0.14-0.10)\end{array}$ & 0.73 \\
\hline
\end{tabular}

Standardized $\beta$, the standardized regression coefficient obtained with linear regression analyses, indicates the change in sVCAM-1 (in SD) per 1 SD higher level in AGE.

C, crude analyses; M, Model. Model 1 is adjusted for age, sex and macroalbuminuria. Model 2 is additionally adjusted for former or current smoking, diabetes duration, HbA1c, LDL-cholesterol, HDL-cholesterol, triacylglycerols, urinary albumin excretion rate (AER), systolic and diastolic blood pressure, BMI and estimated glomerular filtration rate (eGFR). 
Figure 2.1. Immunoreactivity and specificity of the monoclonal anti-MGO-albumin antibody

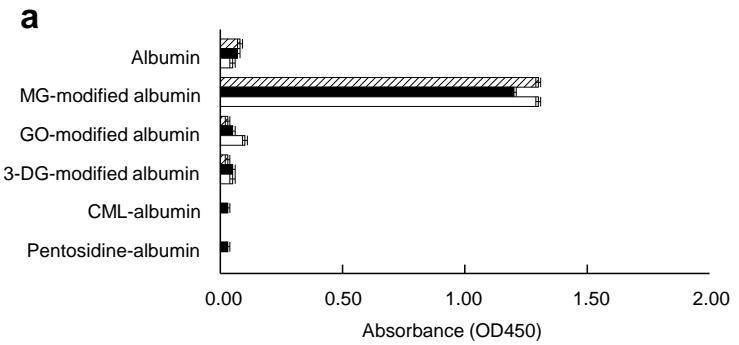

b

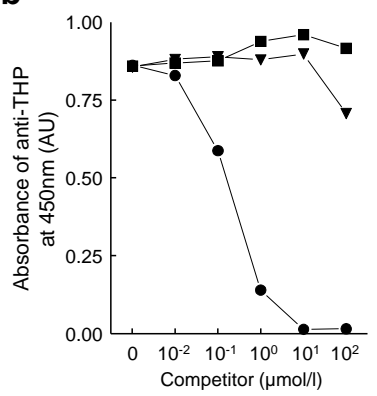

e

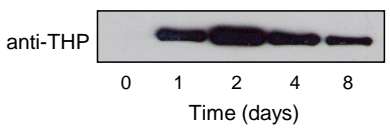

C
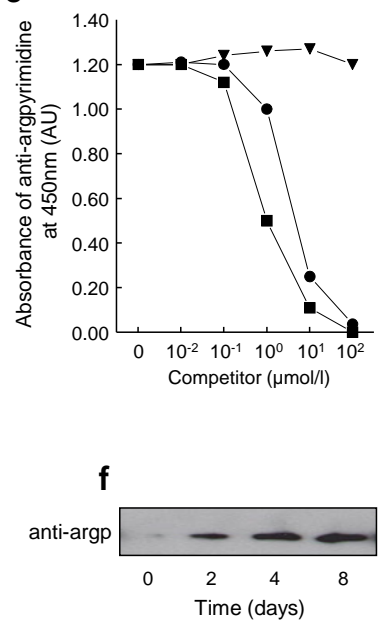

d

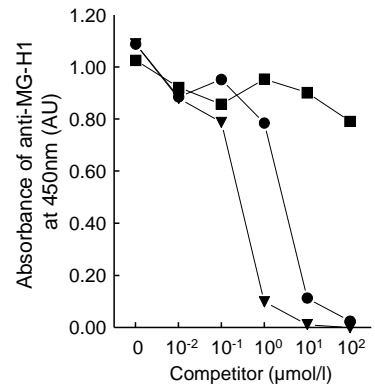

g

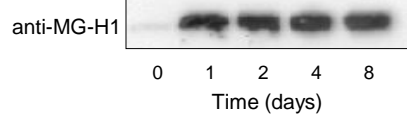

a. Microplate wells were coated with $1 \mu \mathrm{g}$ of non-modified albumin, MGO-modified albumin, glyoxal (GO)-modified albumin, 3-deoxyglucosone (3DG)-modified albumin, CML-albumin or pentosidine-albumin. MGO-modified albumin, GO-modified albumin and 3DG-modified albumin were prepared by an incubation of albumin with $10 \mathrm{mmol} / \mathrm{l}$ of MGO, GO and 3-DG, respectively for 1 day (hatched bars), 3 days (black bars) and 6 days (white bars). Detection was performed with the monoclonal anti-MGO-albumin. b-d. Competitive ELISA demonstrating the specificity of the monoclonal anti-MGO antibody for THP. MGO-modified albumin was used as the absorbed antigen, and the competition was performed with anti-THP (b) anti-argpyrimidine [7] (c) and with anti-MG-H1 [9] (d) with the competitors THP (circles), argpyrimidine (squares) or MG-H1 (triangles). e-g. Albumin was exposed to methylglyoxal $(0.5 \mathrm{mmol} / \mathrm{l})$ for different time points (0-8 days). Detection of THP (e) argpyrimidine (f) and MG-H1 (g) was performed by immunoblotting. This is a representative experiment from a series of three experiments with similar results. 
Table 2.4. Association of THP with micro- and macrovascular complications in individuals with type 1 diabetes

\begin{tabular}{llccc}
\hline & Complications & OR $^{\mathbf{a}}$ & $\mathbf{9 5 \%}$-CI & p-value \\
\hline Cohort & Micro- or macroalbuminuria & 0.92 & $0.52,1.62$ & 0.76 \\
study A & Neuropathy (self-reported) & 1.42 & $0.93,2.16$ & 0.10 \\
& Retinopathy (self-reported) & 1.25 & $0.87,1.81$ & 0.23 \\
Cohort & Macroalbuminuria & 0.95 & $0.77,1.17$ & 0.62 \\
study B & Retinopathy & 1.04 & $0.78,1.39$ & 0.78 \\
& CVD & 0.96 & $0.62,1.49$ & 0.87 \\
\hline
\end{tabular}

a Odds ratio (OR) per SD increase in THP with 95\% confidence interval (95\%-CI) obtained with logistic regression analyses, adjusted for age, sex and pack years of smoking/former or current smoking in both cohorts, and triacylglycerols in study A, and macroalbuminuria, in case of cardiovascular disease (CVD), in study B.

Figure 2.2. Co-localization of THP and CML with macrophages (CD68) in plaques of coronary arteries.
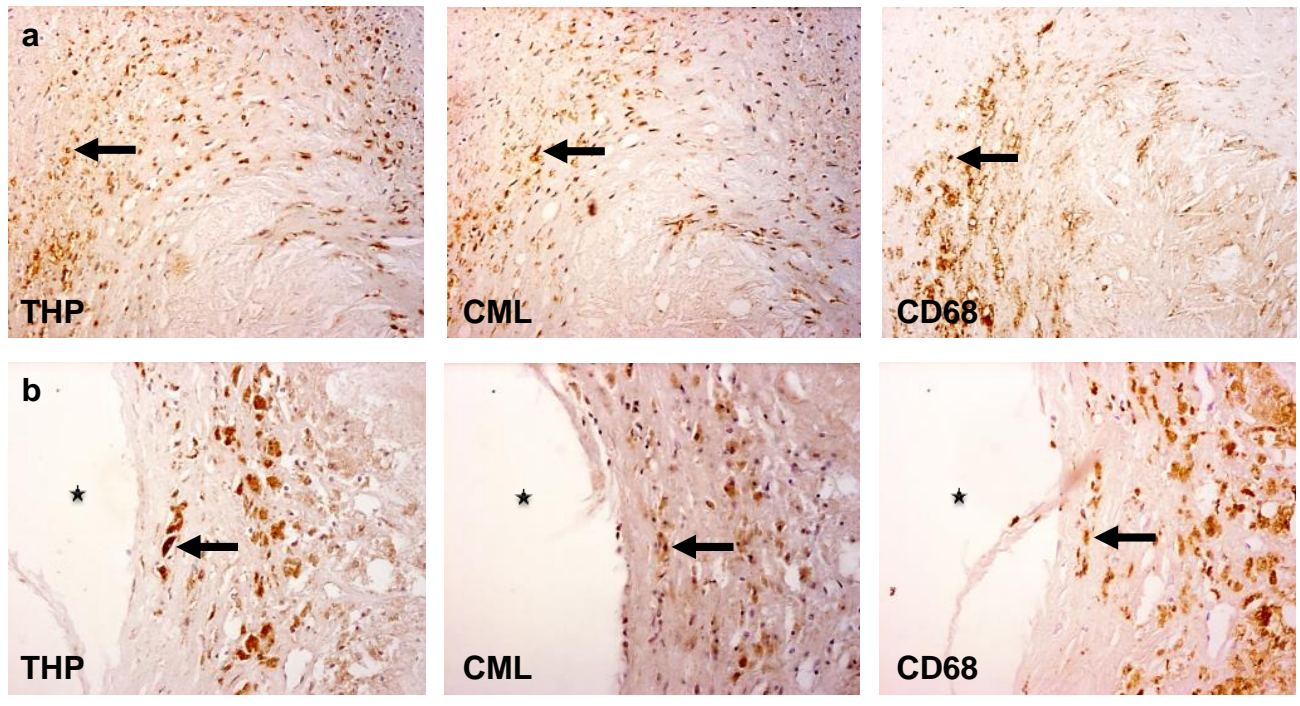

Figure 2.2 shows two representative immunohistochemical stainings of the coronary arteries studied, in serial sections. a and b represent the co-localization of tetrahydropyrimidine (THP) and NE-(Carboxymethyl)lysine (CML) with macrophages (CD68). An anti-CD68 antibody was used as a marker for macrophages. The black arrows indicate examples of the co-localization in macrophages; the asterisk indicates the lumen. Magnification: 200x. 


\section{DISCUSSION}

Rapid AGE formation from glucose-derived dicarbonyl precursors has attracted attention over the relatively slower non-enzymatic reactions between proteins and glucose ${ }^{1}$. MGO is believed to be the most potent glycating agent 3,4 . The main findings of this study were 4-fold. First, we developed a competitive ELISA for MGO-derived AGE THP and demonstrated increased plasma concentrations of THP in type 1 diabetes. Second, we found a strong association of plasma THP with SVCAM-1 in two, and SPLA2 in one type 1 diabetes cohort study. Third, we could not find any association of plasma THP with micro- nor macrovascular outcomes. Fourth, however, we demonstrated accumulation of THP in human atherosclerotic lesions.

We obtained a new murine monoclonal antibody that clearly distinguished MGO-modified proteins from non-modified proteins and from well-known AGEs such as CML and pentosidine, which can be used to further elucidate the role of MGO derived AGEs in the development of diabetic complications. It appeared that this monoclonal antibody has a strong preference for THP above MG-H1 and argpyrimidine (Figure 2.1). The formation of MGO-derived AGEs in MGO-modified albumin, as detected with antibodies, demonstrated that the formation of MG-H1 and THP was relatively rapid, mostly occurring within 24 hours, and that the formation of argpyrimidine occurred at a later stage. This time frame is consistent with data obtained with mass spectrometry $12,13,19$. Both the time frame as well as the competition experiments support the specificity of the antibody for THP. Comparable competition experiments with two well-known specific monoclonal antibodies against argpyrimidine ${ }^{7}$ and $\mathrm{MG}-\mathrm{H} 1{ }^{9}$ demonstrated that the epitope recognition of these monoclonal antibodies are indeed argpyrimidine and MG-H1 and confirmed the specificity of our test system. Interestingly, a preliminary report about a novel monoclonal antibody against MGOderived AGEs also found THP as the dominant epitope ${ }^{26}$. Why THP is found be the dominant epitope in this and in our study is unknown, but indicates that this MGO-derived AGE induces a highly antigenic epitope.

Although MGO-arginine modifications are also measurable with analytical techniques, such as UPLC-MS/MS, they are difficult to detect quantitatively. Because THP is not acid-stable, enzymatic digestion of proteins is essential for the detection of this MGO-derived AGE in proteins. However, proteins modified by AGEs may be incompletely digested ${ }^{27}$ and might therefore affect outcomes of such analyses. By using immunological analysis, as we did in our study, the above mentioned limitations for the detection of THP are overcome.

Plasma concentrations of MGO ${ }^{8}$ as well as MG-H1 ${ }^{9}$ and argpyrimidine ${ }^{10}$ have shown to be elevated in individuals with diabetes. We have shown for the first time that THP is also elevated in individuals with type 1 diabetes.

We showed a strong, positive association of MGO-derived AGE THP with SVCAM-1 in individuals with and without type 1 diabetes. This is consistent with experiments that demonstrated that AGEs are able to induce the expression of sVCAM-1 ${ }^{28,}{ }^{29}$. Both AGEs and SVCAM-1 have been shown to be elevated in type 1 diabetes ${ }^{30-35}$. sVCAM-1 is known as a marker of endothelial dysfunction and is associated with atherosclerosis ${ }^{36-38}$ and micro- and macrovascular complications in type 1 diabetes ${ }^{39}$, 40 . In additional analyses, we investigated the association of the AGEs CEL, CML and 
pentosidine with SVCAM-1. We found that CEL, CML and pentosidine were not associated with sVCAM-1, after adjustment for possible confounders, whereas THP was. Therefore, it appears that THP is not a reflection of other AGEs like CEL, CML and pentosidine. THP possibly reflects another pathophysiological pathway than these other, well-known, AGEs.

The strong association of plasma THP with SVCAM-1 in two separate cohort studies may suggest that THP is involved in the development of micro- and macrovascular complications. We additionally show the presence of THP in macrophages in atherosclerotic coronary arteries. This further supports the hypothesis that THP is associated with vascular complications. In a previous study we demonstrated that MGO-albumin did not bind or activate endothelial cells as measured by the expression of adhesion molecules, while, under the same conditions, TNF-a did ${ }^{41}$. In the same study we found binding of MGO-albumin to monocytes. Other studies have shown that MGOderived AGEs are able to activate monocytes, thereby stimulating the production of certain cytokines 42,43 . Therefore, endothelial cells may be indirectly activated by cytokines which are induced and released by MGO-AGE activated macrophages. In accordance with this mechanism, SPLA2, an enzyme expressed in activated macrophages and smooth muscle cells ${ }^{44}$ which can be proatherogenic both in the circulation and in the arterial wall 44,45 , was significantly associated with THP. Therefore, activation of macrophages by THP and the release of cytokines might be the mechanism by which THP is potentially associated with production of SVCAM-1. Since SVCAM-1 is associated with atherosclerosis, THP might be implicated in the pathogenesis of vascular complications in type 1 diabetes.

We did not find any association of THP with HbA1c in both studies. These findings are consistent with many others studies that reported no association of plasma AGEs with HbA1c 31, 46-49. An explanation for this lack of association could be that AGEs can also be formed through other pathways, for example lipid peroxidation, besides glucose metabolism. Moreover, HbA1c and AGEs presumably reflect different pathways following hyperglycaemia and different timeframes of hyperglycaemia.

\section{Limitations of our study}

Both our studies had a cross-sectional design; therefore we cannot draw any conclusion about causality in the association of THP with sVCAM-1. We developed an antibody against MGO-derived AGEs and demonstrated an at least 1000 -fold preference for THP as compared with argpyrimidine or MG-H1. Despite this preference for THP, we cannot exclude the possibility that other MGOderived AGEs than THP are detected in our analyses. Furthermore, we cannot rule out the possibility that plasma THP does not reflect intracellular glycation. This may imply that we underestimated the association of THP and vascular complications.

Since we do not have information about diet in both cohorts, we were not able to adjust our analyses for the possible influence of dietary AGEs on plasma AGE measurements. Since it is unknown if and how dietary AGEs are able to influence the levels of plasma AGEs measured in fasting plasma samples, this is a limitation of our study.

Since THP was detected in atherosclerotic arteries (Figure 2.2), we expected to find an association of plasma THP with cardiovascular complications. We found that plasma levels of THP were 
associated with sVCAM-1, i.e. a marker of atherosclerosis, but we could not find any association of THP with vascular complications. Although we do not have a clear explanation so far for this finding, this might be due to the limited number of cases of prior cardiovascular disease, i.e. the power to detect an association was low. In addition, retinopathy and neuropathy were evaluated via self-report in study $A$, which may have limited the power of the analyses.

\section{Conclusions}

In conclusion, our results suggest that MGO-derived THP may reflect endothelial dysfunction and is present in atherosclerotic lesions in individuals with and without type 1 diabetes. This could mean that MGO-derived AGE THP plays a role in the pathophysiology of atherosclerosis in individuals with or without type 1 diabetes. Future studies are needed to elucidate the potential causal role of THP in the development of cardiovascular complications of diabetes. 


\section{REFERENCES}

1. Brownlee M. Biochemistry and molecular cell biology of diabetic complications. Nature. 2001;414:813-820

2. Nin JW, Jorsal A, Ferreira I, Schalkwijk CG, Prins MH, Parving HH, Tarnow L, Rossing P, Stehouwer CD. Higher plasma levels of advanced glycation end products are associated with incident cardiovascular disease and all-cause mortality in type 1 diabetes: A 12-year follow-up study. Diabetes Care. 2011;34:442-447

3. Shinohara M, Thornalley PJ, Giardino I, Beisswenger P, Thorpe SR, Onorato J, Brownlee M. Overexpression of glyoxalase-i in bovine endothelial cells inhibits intracellular advanced glycation endproduct formation and prevents hyperglycemia-induced increases in macromolecular endocytosis. J Clin Invest. 1998;101:1142-1147

4. Brouwers O, Niessen PM, Ferreira I, Miyata T, Scheffer PG, Teerlink T, Schrauwen P, Brownlee M, Stehouwer CD, Schalkwijk CG. Overexpression of glyoxalase-i reduces hyperglycemia-induced levels of advanced glycation end products and oxidative stress in diabetic rats. J Biol Chem. 2011;286:1374-1380

5. Thornalley PJ. The glyoxalase system in health and disease. Mol Aspects Med. 1993;14:287-371

6. Rabbani N, Thornalley PJ. Glyoxalase in diabetes, obesity and related disorders. Semin Cell Dev Biol. 2011;22:309-317

7. Oya T, Hattori N, Mizuno Y, Miyata S, Maeda S, Osawa T, Uchida K. Methylglyoxal modification of protein. Chemical and immunochemical characterization of methylglyoxal-arginine adducts. J Biol Chem. 1999;274:18492-18502

8. McLellan AC, Thornalley PJ, Benn J, Sonksen PH. Glyoxalase system in clinical diabetes mellitus and correlation with diabetic complications. Clin Sci (Lond). 1994;87:21-29

9. Kilhovd BK, Giardino I, Torjesen PA, Birkeland KI, Berg TJ, Thornalley PJ, Brownlee M, Hanssen KF. Increased serum levels of the specific age-compound methylglyoxal-derived hydroimidazolone in patients with type 2 diabetes. Metabolism. 2003;52:163-167

10. Wilker SC, Chellan P, Arnold BM, Nagaraj RH. Chromatographic quantification of argpyrimidine, a methylglyoxal-derived product in tissue proteins: Comparison with pentosidine. Anal Biochem. 2001;290:353-358

11. Ahmed N, Thornalley PJ, Dawczynski J, Franke S, Strobel J, Stein G, Haik GM. Methylglyoxal-derived hydroimidazolone advanced glycation end-products of human lens proteins. Invest Ophthalmol Vis Sci. 2003;44:5287-5292

12. Brock JW, Cotham WE, Thorpe SR, Baynes JW, Ames JM. Detection and identification of arginine modifications on methylglyoxal-modified ribonuclease by mass spectrometric analysis. J Mass Spectrom. 2007;42:89-100

13. Klopfer A, Spanneberg R, Glomb MA. Formation of arginine modifications in a model system of nalpha-tertbutoxycarbonyl (boc)-arginine with methylglyoxal. J Agric Food Chem. 2011;59:394-401

14. Brouwers O, Niessen PM, Haenen G, Miyata T, Brownlee M, Stehouwer CD, De Mey JG, Schalkwijk CG. Hyperglycaemiainduced impairment of endothelium-dependent vasorelaxation in rat mesenteric arteries is mediated by intracellular methylglyoxal levels in a pathway dependent on oxidative stress. Diabetologia. 2010;53:989-1000

15. Wang H, Liu J, Wu L. Methylglyoxal-induced mitochondrial dysfunction in vascular smooth muscle cells. Biochem Pharmacol. 2009;77:1709-1716

16. Rosca MG, Mustata TG, Kinter MT, Ozdemir AM, Kern TS, Szweda LI, Brownlee M, Monnier VM, Weiss MF. Glycation of mitochondrial proteins from diabetic rat kidney is associated with excess superoxide formation. Am J Physiol Renal Physiol. 2005;289:F420-430

17. Rabbani N, Thornalley PJ. Dicarbonyls linked to damage in the powerhouse: Glycation of mitochondrial proteins and oxidative stress. Biochem Soc Trans. 2008;36:1045-1050

18. Yao D, Taguchi T, Matsumura T, Pestell R, Edelstein D, Giardino I, Suske G, Rabbani N, Thornalley PJ, Sarthy VP, Hammes HP, Brownlee M. High glucose increases angiopoietin-2 transcription in microvascular endothelial cells through methylglyoxal modification of msin3a. J Biol Chem. 2007;282:31038-31045

19. Ahmed N, Argirov OK, Minhas HS, Cordeiro CA, Thornalley PJ. Assay of advanced glycation endproducts (ages): Surveying ages by chromatographic assay with derivatization by 6 -aminoquinolyl-n-hydroxysuccinimidyl-carbamate and application to nepsilon-carboxymethyl-lysine- and nepsilon-(1-carboxyethyl)lysine-modified albumin. Biochem J. 2002;364:1-14

20. Colhoun HM, Rubens MB, Underwood SR, Fuller JH. The effect of type 1 diabetes mellitus on the gender difference in coronary artery calcification. J Am Coll Cardiol. 2000;36:2160-2167

21. Levey AS, Bosch JP, Lewis JB, Greene T, Rogers N, Roth D. A more accurate method to estimate glomerular filtration rate from serum creatinine: A new prediction equation. Modification of diet in renal disease study group. Ann Intern Med. 1999;130:461-470

22. Schalkwijk CG, Poland DC, van Dijk W, Kok A, Emeis JJ, Drager AM, Doni A, van Hinsbergh VW, Stehouwer CD. Plasma concentration of c-reactive protein is increased in type i diabetic patients without clinical macroangiopathy and correlates with markers of endothelial dysfunction: Evidence for chronic inflammation. Diabetologia. 1999;42:351-357

23. Tarnow L, Cambien F, Rossing P, Nielsen FS, Hansen BV, Lecerf L, Poirier O, Danilov S, Boelskifte S, Borch-Johnsen K. Insertion/deletion polymorphism in the angiotensin-i-converting enzyme gene is associated with coronary heart disease in iddm patients with diabetic nephropathy. Diabetologia. 1995;38:798-803

24. De Jager J, Kooy A, Lehert P, Bets D, Wulffele MG, Teerlink T, Scheffer PG, Schalkwijk CG, Donker AJ, Stehouwer CD. Effects of short-term treatment with metformin on markers of endothelial function and inflammatory activity in type 2 diabetes mellitus: A randomized, placebo-controlled trial. J Intern Med. 2005;257:100-109

25. Schalkwijk CG, Baidoshvili A, Stehouwer CD, van Hinsbergh VW, Niessen HW. Increased accumulation of the glycoxidation product nepsilon-(carboxymethyl)lysine in hearts of diabetic patients: Generation and characterisation of a monoclonal anti-cml antibody. Biochim Biophys Acta. 2004;1636:82-89

26. Oya-Ito T, Kawakishi S, Shibata N, Kobayashi M, Osawa T, Uchida K. A novel monoclonal antibody against methylglyoxal-arginine adduct. International Congress Series. 2002;1245:397-399 
27. Hegele J, Buetler T, Delatour T. Comparative Ic-ms/ms profiling of free and protein-bound early and advanced glycationinduced lysine modifications in dairy products. Anal Chim Acta. 2008;617:85-96

28. Schmidt AM, Hori O, Chen JX, Li JF, Crandall J, Zhang J, Cao R, Yan SD, Brett J, Stern D. Advanced glycation endproducts interacting with their endothelial receptor induce expression of vascular cell adhesion molecule-1 (vcam-1) in cultured human endothelial cells and in mice. A potential mechanism for the accelerated vasculopathy of diabetes. J Clin Invest. 1995; $96: 1395-1403$

29. Vlassara H, Fuh H, Donnelly T, Cybulsky M. Advanced glycation endproducts promote adhesion molecule (vcam-1, icam-1) expression and atheroma formation in normal rabbits. Mol Med. 1995;1:447-456

30. Salman AG, Mansour DE, Swelem AH, Al-Zawahary WM, Radwan AA. Pentosidine - a new biochemical marker in diabetic retinopathy. Ophthalmic Res. 2009;42:96-98

31. Han Y, Randell E, Vasdev S, Gill V, Curran M, Newhook LA, Grant M, Hagerty D, Schneider C. Plasma advanced glycation endproduct, methylglyoxal-derived hydroimidazolone is elevated in young, complication-free patients with type 1 diabetes. Clin Biochem. 2009;42:562-569

32. Ahmed N, Babaei-Jadidi R, Howell SK, Beisswenger PJ, Thornalley PJ. Degradation products of proteins damaged by glycation, oxidation and nitration in clinical type 1 diabetes. Diabetologia. 2005;48:1590-1603

33. Smulders RA, Stehouwer CD, Schalkwijk CG, Donker AJ, van Hinsbergh VW, TeKoppele JM. Distinct associations of hba1c and the urinary excretion of pentosidine, an advanced glycosylation end-product, with markers of endothelial function in insulin-dependent diabetes mellitus. Thromb Haemost. 1998;80:52-57

34. Hope SA, Meredith IT. Cellular adhesion molecules and cardiovascular disease. Part ii. Their association with conventional and emerging risk factors, acute coronary events and cardiovascular risk prediction. Intern Med $\mathrm{J}$. 2003;33:450-462

35. Glowinska B, Urban M, Peczynska J, Florys B. Soluble adhesion molecules (sicam-1, svcam-1) and selectins (se selectin, sp selectin, sl selectin) levels in children and adolescents with obesity, hypertension, and diabetes. Metabolism. 2005;54:1020-1026

36. Richardson M, Hadcock SJ, DeReske M, Cybulsky MI. Increased expression in vivo of vcam-1 and e-selectin by the aortic endothelium of normolipemic and hyperlipemic diabetic rabbits. Arterioscler Thromb. 1994;14:760-769

37. O'Brien KD, Allen MD, McDonald TO, Chait A, Harlan JM, Fishbein D, McCarty J, Ferguson M, Hudkins K, Benjamin CD, et al. Vascular cell adhesion molecule-1 is expressed in human coronary atherosclerotic plaques. Implications for the mode of progression of advanced coronary atherosclerosis. J Clin Invest. 1993;92:945-951

38. Peter K, Weirich U, Nordt TK, Ruef J, Bode C. Soluble vascular cell adhesion molecule-1 (vcam-1) as potential marker of atherosclerosis. Thromb Haemost. 1999;82 Suppl 1:38-43

39. Soedamah-Muthu SS, Chaturvedi N, Schalkwijk CG, Stehouwer CD, Ebeling P, Fuller JH. Soluble vascular cell adhesion molecule-1 and soluble e-selectin are associated with micro- and macrovascular complications in type 1 diabetic patients. J Diabetes Complications. 2006;20:188-195

40. Clausen P, Jacobsen P, Rossing K, Jensen JS, Parving HH, Feldt-Rasmussen B. Plasma concentrations of vcam-1 and icam-1 are elevated in patients with type 1 diabetes mellitus with microalbuminuria and overt nephropathy. Diabet Med. 2000;17:644-649

41. Lieuw-a-Fa ML, Schalkwijk CG, Engelse M, van Hinsbergh VW. Interaction of nepsilon(carboxymethyl)lysine- and methylglyoxal-modified albumin with endothelial cells and macrophages. Splice variants of rage may limit the responsiveness of human endothelial cells to ages. Thromb Haemost. 2006;95:320-328

42. Abordo EA, Thornalley PJ. Synthesis and secretion of tumour necrosis factor-alpha by human monocytic thp-1 cells and chemotaxis induced by human serum albumin derivatives modified with methylglyoxal and glucose-derived advanced glycation endproducts. Immunol Lett. 1997;58:139-147

43. Westwood ME, Thornalley PJ. Induction of synthesis and secretion of interleukin 1 beta in the human monocytic thp-1 cells by human serum albumins modified with methylglyoxal and advanced glycation endproducts. Immunol Lett. 1996;50:17-21

44. Hurt-Camejo E, Camejo G, Peilot H, Oorni K, Kovanen P. Phospholipase a(2) in vascular disease. Circ Res. 2001;89:298304

45. Piek JJ, de Winter RJ. Type ii secretory phospholipase a2: The emerging role of biochemical markers of plaque inflammation. European heart journal. 2003;24:1804-1806

46. Hirata K, Kubo K. Relationship between blood levels of n-carboxymethyl-lysine and pentosidine and the severity of microangiopathy in type 2 diabetes. Endocr J. 2004;51:537-544

47. Fosmark DS, Torjesen PA, Kilhovd BK, Berg TJ, Sandvik L, Hanssen KF, Agardh CD, Agardh E. Increased serum levels of the specific advanced glycation end product methylglyoxal-derived hydroimidazolone are associated with retinopathy in patients with type 2 diabetes mellitus. Metabolism. 2006;55:232-236

48. Shimoike $T$, Inoguchi $T$, Umeda $F$, Nawata $H$, Kawano $K$, Ochi $H$. The meaning of serum levels of advanced glycosylation end products in diabetic nephropathy. Metabolism. 2000;49:1030-1035

49. Kilhovd BK, Juutilainen A, Lehto S, Ronnemaa T, Torjesen PA, Hanssen KF, Laakso M. Increased serum levels of advanced glycation endproducts predict total, cardiovascular and coronary mortality in women with type 2 diabetes: A population-based 18 year follow-up study. Diabetologia. 2007;50:1409-1417 


\section{CHAPTER 3}

Plasma levels of advanced glycation endproducts are associated with type 1 diabetes and coronary artery calcification The Coronary Artery Calcification Study

Marcelle G.A. van Eupen, Miranda T. Schram, Helen M. Colhoun, Jean L.J.M. Scheijen, C.D.A. Stehouwer, C.G. Schalkwijk Cardiovascular Diabetology. 2013 Oct 17;12(1):149 


\section{ABSTRACT}

\section{Background}

Advanced glycation endproducts (AGEs) may play a role in the development of coronary artery calcification (CAC) in type 1 diabetes (T1DM). We studied plasma AGEs in association with T1DM and $\mathrm{CAC}$, and whether or not the latter association could be explained by low-grade inflammation (LGI) or endothelial dysfunction (ED).

\section{Methods}

We studied 165 individuals with and 169 without T1DM. CAC was quantified in a CAC score based on CT-scanning. Plasma levels of protein-bound pentosidine, $\mathrm{N} \varepsilon$-(carboxymethyl)lysine (CML) and $N \varepsilon$-(carboxyethyl)lysine (CEL) were measured with HPLC/UPLC with fluorescence detection or tandem-mass spectrometry. Tetrahydropyrimidine (THP) was measured with ELISA, as were HsCRP, and SVCAM-1 and VWF, as markers for LGI and ED, respectively. Associations were analysed with ANCOVA and adjusted for age, sex, BMI, waist-to-hip ratio, smoking, blood pressure, lipid profile, eGFR and T1DM.

\section{Results}

Individuals with T1DM had higher plasma levels of pentosidine, CML and THP compared with controls; means $(95 \% \mathrm{CI})$ were $0.69(0.65-0.73)$ vs. $0.51(0.48-0.54) \mathrm{nmol} / \mathrm{mmol} \mathrm{LYS}, \mathrm{p}<0.001$; 105 (102-107) vs. 93 (90-95) nmol/mmol LYS, p<0.001; and 126 (118-134) vs. 113 (106-120) $\mathrm{U} / \mathrm{mL}, \mathrm{p}=0.03$, respectively. Levels of pentosidine were higher in individuals with T1DM with a moderate to high compared with a low CAC score, means (95\%CI) were $0.81(0.70-0.93)$ vs. 0.67 $(0.63-0.71) \mathrm{nmol} / \mathrm{mmol} \mathrm{LYS}, \mathrm{p}=0.03$, respectively. This difference was not attenuated by adjustment for LGI or ED.

\section{Conclusions}

We found a positive association between pentosidine and CAC in T1DM. These results may indicate that AGEs are possibly involved in the development of CAC in individuals with T1DM. 


\section{INTRODUCTION}

Individuals with type 1 diabetes mellitus (T1DM) have an increased risk of cardiovascular disease $(C V D)^{1}$. Advanced glycation endproducts (AGEs), which are formed by a nonenzymatic reaction between reducing sugars and proteins, are thought to play an important role in the development of CVD in T1DM ${ }^{2}{ }^{3}$. AGEs are able to affect cell function via intracellular glycation of proteins, altering their function ${ }^{2}$, via cross-linking of extracellular matrix proteins in large arteries, resulting in arterial stiffness ${ }^{4}$, and by binding to the receptor for AGEs (RAGE), inducing receptor-mediated cell activation 5, 6. Well-studied AGEs are the cross-link $A G E$, pentosidine, and $N \varepsilon$ (carboxymethyl)lysine (CML), i.e. a ligand for RAGE. More recently, methylglyoxal (MGO) has gained increased attention as being the most important precursor of rapid intracellular production of $\mathrm{AGEs}^{2}, 7$. MGO primarily reacts with arginine to form 5-hydro-5-methylimidazolone (MG-H1), tetrahydropyrimidine (THP) and argpyrimidine, and with lysine to form $\mathrm{N}^{\varepsilon}$ (carboxyethyl)lysine (CEL) and methylglyoxal lysine dimer (MOLD) $)^{8,9}$.

Surprisingly, large studies comparing plasma AGE levels between individuals with and without T1DM are scarce. So far, most of them are based on relatively small patient and control groups 10,11 , have used non-specific immunological techniques for the detection of AGEs ${ }^{12,13}$ or concentrate on individuals with T1DM only. In individuals with T1DM, we recently demonstrated that plasma AGEs are positively associated with incident fatal and nonfatal CVD, independent of cardiovascular risk factors ${ }^{3}$.

Coronary artery calcification (CAC) is a well-accepted early marker and precursor of CVD ${ }^{14,15}$ and correlated with total atheroma burden. Individuals with T1DM have been shown to have more coronary $C^{A} C^{16,17}$. In individuals with kidney disease, the AGE pentosidine and the AGE-RAGE axis have been associated with arterial calcification ${ }^{14,18}$. In addition, experimental studies recently demonstrated that AGEs are able to induce vascular calcification ${ }^{19-23}$. However, no study has previously investigated the association of plasma AGEs with CAC in individuals with T1DM. We hypothesised that AGEs could lead to CVD either by increasing CAC directly or more indirectly by increasing the atherosclerotic process in individuals with T1DM. Potential mechanisms through which AGEs could lead to the development of CAC are via low-grade inflammation (LGI) and endothelial dysfunction (ED), which are both associated with higher AGE levels ${ }^{3}$.

In view of the above, the aims of this study were to examine, first, whether plasma levels of the AGEs pentosidine, CML, CEL and THP are higher in a large sample of individuals with T1DM, compared to controls; second, if these AGEs are associated with CAC in individuals with T1DM; and third, to which extent the association of AGEs with CAC could be explained (i.e. mediated) by markers of LGI and ED. 


\section{METHODS}

\section{Study population and design}

In 1998, a random sample of 199 men and women with T1DM aged 30 to 55 years was taken from the diabetes registers of five London hospitals. T1DM was defined by age of onset $\leq 25$ years and insulin treatment within one year of diagnosis. A random sample of 201 individuals from the general population, stratified to have a similar age and gender distribution to the group with diabetes, was drawn from the lists of two London general practices. It was confirmed that these individuals had no clinical history of diabetes and were not on any treatment for diabetes. Participants were included regardless of any history of heart disease. One participant (a woman with diabetes) had a history of angina; none had had a myocardial infarction. Pregnant women and patients on renal replacement therapy were excluded. Ethics Committee approval was obtained. All participants gave informed written consent prior to participation, having received full details of the study procedures. Further details of this study have been described elsewhere ${ }^{16}$. Individuals with missing data on plasma AGEs $(n=48)$ or on any of the potential confounders $(n=18)$, i.e. on triglycerides $(n=13), \operatorname{HDL}(n=1), \operatorname{LDL}(n=18)$ or eGFR $(n=1)$, were excluded from our analyses. Individuals with incomplete data did not materially differ in baseline characteristics from individuals with complete data, except for the percentage of individuals with a CAC score $>10$. We excluded 22 individuals with a CAC score $>10$ because of missing data on AGEs $(n=20)$, or potential confounders $(n=2)$. The complete case analysis included 165 individuals with and 169 without T1DM $(n=334)$.

\section{Analysis of protein bound AGEs and lysine in plasma}

Plasma AGEs were measured in EDTA samples obtained from fasting venous blood, which were stored at $-80^{\circ} \mathrm{C}$ until analysis. Protein-bound pentosidine was quantified using HPLC with fluorescence detection, as described in detail elsewhere ${ }^{24}$. Intra- and interassay coefficients of variation (CVs), as analysed in this study, for pentosidine were 3.8 and $6.9 \%$, respectively. Proteinbound CML, CEL and lysine were quantified using UPLC MS/MS ${ }^{25}$. Intra- and interassay CVs were 4.5 and $3.4 \%$ for CML, 5.4 and $18.1 \%$ for CEL and 5.0 and $5.0 \%$ for lysine, respectively. THP was measured using competitive ELISA ${ }^{26}$. Intra- and interassay variations were $5 \%$ and $8 \%$, respectively. Concentrations of protein-bound pentosidine, CML and CEL were adjusted for levels of lysine and expressed as $\mathrm{nmol} / \mathrm{mmol}$ lysine.

\section{EBCT scan}

An Ultrafast CT scanner (IMATRON C-150XL) was used to quantify coronary calcification. Two sets of 20 transverse tomograms of 3-mm thickness were obtained from the lower margin of the bifurcation of the right branch of the pulmonary artery to the apex of the heart with breath holding of the individual. A radiologist placed a region of interest around each potentially calcific lesion (peak density <130 Hounsfield $U$ ) within the right coronary, circumflex, left anterior descending and left main coronary arteries. The area and peak density of each lesion was measured. A density score of 1 to 4 was defined based on the peak density of the lesion; the calcification score was then calculated as the product of the area of the lesion and its density score as described by Agatston et al. ${ }^{27}$. To be included in the calcification score a lesion had to have an area of at least $0.51 \mathrm{~mm} 2$, i.e., two contiguous pixels and a peak density of at least 130 Hounsfield U. A total score for each artery and for the entire heart was calculated by summing the lesion scores. The 
radiation exposure was $<1 \mathrm{mSv}$. All scans were scored by the same radiologist, who was blinded to the gender and the diabetes status of the individual. Based on a small repeatability study $(n=20)$ the within-observer agreement for the presence of any calcification was high (kappa=0.84).

\section{Coronary artery calcification score}

The cut-off value of 10 for the CAC score was based on a recent review and meta-analysis on the validation of electron beam computed tomography for coronary artery disease in both symptomatic and asymptomatic individuals ${ }^{28}$. In this review, the CAC score was divided in three groups: low (0-10), moderate (10-400) and high ( $>400)$. Since only 3 individuals had a CAC score above 400 , the CAC score was analysed dichotomously comparing individuals with a CAC score of 0-10 (low) to individuals with a CAC score of $>10$ (moderate to high).

\section{Covariates}

Glomerular filtration rate (eGFR) was estimated according to the short Modification of Diet in Renal Disease equation $($ MDRD $)=186 *$ [serum creatinine $(\mathrm{mg} / \mathrm{dL})]^{-1.154} *[\text { age }(\mathrm{y})]^{-0.203} *[0.742$ if patient is female] ${ }^{29}$. Measurement of creatinine was based on the enzymatic method. HbA1c, systolic and diastolic blood pressure, total cholesterol, HDL and LDL cholesterol and triglycerides were measured as described elsewhere ${ }^{16}$. High-sensitivity C-reactive protein (hsCRP), a marker of LGI, was measured with a highly sensitive in-house ELISA, as described previously ${ }^{30}$. A commercially available ELISA kit was used to measure plasma soluble vascular cell adhesion molecule 1 (sVCAM-1) (R\&D Systems). Von Willebrand factor (VWF) activity was measured in heparin plasma by Shield vWF activity ELISA kit (Shield Diagnostics Ltd, Dundee, Scotland) using IgG monoclonal antibodies, and expressed as percentage of vWF in pooled plasma of healthy volunteers. sVCAM-1 and VWF were considered markers of ED.

\section{Statistical methods}

Analyses were carried out using SPSS version 20 for Windows. Comparisons of baseline characteristics between groups were made by use of a Student's $t$ or $X^{2}$ tests. In table 3.1, in case of CAC score levels, comparisons were made by use of a Mann-Whitney $U$ test. We performed complete case analyses. ANCOVA was used to identify the differences in levels of plasma AGES between individuals with and without T1DM and with and without a CAC score $>10$. Variables with a skewed distribution (e.g. plasma pentosidine and THP) were $\log _{10}$-transformed, and transformed back to provide geometric means. We investigated whether the associations of AGEs with CAC differed between men and women by adding interaction terms to the models. Finally, linear regression analysis was used to evaluate to what extent LGI and ED mediated the association of AGEs with CAC in individuals with T1DM. The percentage change in the magnitude of the linear regression coefficient between the model with or without LGI and/or ED reflects to what extent the association could be explained by mediation. P-values $<0.05$ were considered statistically significant, except for interaction terms, where a $\mathrm{p}$-value $<0.10$ was considered statistically significant. 


\section{RESULTS}

Table 3.1 shows the general characteristics of the study population. HbA1c levels were higher in individuals with T1DM, as were HDL cholesterol, systolic blood pressure (SBP), eGFR, hsCRP, SVCAM-1 and VWF. The percentage of individuals with a CAC score $>10$, compared to $0-10$, was higher in T1DM than in controls; only two individuals without T1DM had a CAC score $>10$, whereas 32 individuals with T1DM had a CAC score $>10$ (Table 3.1).

\section{Plasma AGEs in individuals with and without T1DM}

Plasma levels of the AGEs pentosidine, CML and THP were significantly higher in individuals with T1DM compared to controls (Table 3.1). Plasma levels of pentosidine, CML and THP remained significantly higher in individuals with T1DM after adjustment for age and sex and additional adjustment for systolic and diastolic blood pressure, body mass index (BMI), waist to hip ratio (WHR), smoking, LDL and HDL cholesterol, triglycerides and eGFR (Table 3.2). In individuals with T1DM, none of the plasma AGEs were significantly associated with HbA1c or diabetes duration (data not shown).

\section{Plasma AGEs in individuals with T1DM and a low or moderate to high coronary artery calcification score}

The associations of AGEs with CAC were analysed in T1DM only, due to the low number of individuals with a CAC score $>10$ in the control group. We performed a complete case analysis in the 165 individuals with T1DM, of whom 135 had a CAC score of $0-10$ and 30 had a score $>10$. The associations of AGEs with the CAC score did not significantly differ between men and women; therefore we presented the results for men and women combined. Plasma levels of the AGE pentosidine were significantly higher in individuals with a CAC score $>10$ compared to those with a score of 0-10 after adjustment for age and sex, while levels of CML, CEL and THP were similar (Table 3.3). After additional adjustment for systolic and diastolic blood pressure, BMI, WHR, smoking, LDL and HDL cholesterol, triglycerides and eGFR, plasma pentosidine levels remained significantly higher in individuals with a CAC score $>10$ (Table 3.3). Additional adjustment for $\mathrm{HbA1c}$ level and diabetes duration did not materially change these results. The association of plasma pentosidine with the CAC score was not explained (i.e. mediated) by LGI or ED (Table 3.4). 
Table 3.1. General characteristics of the coronary artery calcification study (CACS)

\begin{tabular}{|c|c|c|c|}
\hline & Controls $(n=169)$ & T1DM (n=165) & $\begin{array}{c}\mathrm{p}- \\
\text { value }\end{array}$ \\
\hline \multicolumn{4}{|l|}{ General } \\
\hline Age (years) & $38.0 \pm 3.8$ & $37.8 \pm 4.3$ & 0.75 \\
\hline Sex (number of males/females) & $72 / 97$ & $83 / 82$ & 0.16 \\
\hline Diabetes duration $(\mathrm{y})$ & - & $23.5 \pm 7.6$ & - \\
\hline $\mathrm{HbA1c}(\%)$ & $5.31 \pm 0.42$ & $8.83 \pm 1.53$ & $<0.001$ \\
\hline Smoking, former or current ( $\mathrm{n}(\%))$ & $84(50)$ & $75(46)$ & 0.44 \\
\hline Pack-years of smoking* $(y)$ & $8.6[3.5-17.0]$ & $10.0[4.5-18.0]$ & 0.87 \\
\hline BMI $\left(\mathrm{kg} / \mathrm{m}^{2}\right)$ & $25.2 \pm 4.5$ & $25.4 \pm 3.6$ & 0.53 \\
\hline Waist-to-hip ratio & $0.85 \pm 0.08$ & $0.87 \pm 0.08$ & 0.14 \\
\hline Total cholesterol $(\mathrm{mmol} / \mathrm{L})$ & $5.35 \pm 1.02$ & $5.32 \pm 1.06$ & 0.75 \\
\hline HDL cholesterol (mmol/L) & $1.73 \pm 0.40$ & $1.84 \pm 0.47$ & 0.02 \\
\hline LDL cholesterol (mmol/L) & $3.07 \pm 0.93$ & $2.95 \pm 0.93$ & 0.24 \\
\hline Triglycerides (mmol/L) & $1.06[0.76-1.44]$ & $0.97[0.77-1.35]$ & 0.37 \\
\hline Systolic BP (mmHg) & $117 \pm 14$ & $124 \pm 14$ & $<0.001$ \\
\hline Diastolic BP (mmHg) & $72 \pm 10$ & $73 \pm 9$ & 0.22 \\
\hline eGFRMDRD $\left(\mathrm{ml} / \mathrm{min} / 1.73 \mathrm{~m}^{2}\right)$ & $89 \pm 16$ & $97 \pm 15$ & $<0.001$ \\
\hline CAC score (units) & $0.0[0.0-1.0]$ & $1.0[0.0-5.0]$ & $<0.001$ \\
\hline CAC score > $10(\mathrm{n}(\%))$ & $2(1)$ & $30(18)$ & $<0.001$ \\
\hline hsCRP (mg/L) & $0.84[0.43-1.76]$ & $1.04[0.46-2.87]$ & 0.02 \\
\hline sVCAM-1 (ng/mL) & 985 [820-1175] & 1161 [964-1374] & $<0.001$ \\
\hline vWF (\%) & $87[65-108]$ & $97[72-126]$ & $<0.01$ \\
\hline \multicolumn{4}{|l|}{ Advanced glycation endproducts } \\
\hline Pentosidine (nmol/mmol LYS) & $0.48[0.41-0.58]$ & $0.65[0.55-0.81]$ & $<0.001$ \\
\hline CML (nmol/mmol LYS) & $92.5 \pm 15.7$ & $104.6 \pm 19.4$ & $<0.001$ \\
\hline CEL (nmol/mmol LYS) & $14.5 \pm 3.2$ & $15.1 \pm 3.7$ & 0.12 \\
\hline THP $(\mathrm{U} / \mathrm{mL})$ & $110.0[94.0-123.2]$ & $117.8[102.9-135.4]$ & 0.02 \\
\hline
\end{tabular}

Data are presented as mean \pm standard deviation (SD), in case of a normal distribution of data, or as median [inter quartile range (IQR)], in case of a skewed distribution of data, unless otherwise indicated HbA1c, glycated hemoglobin; BMI, body mass index; HDL, high-density lipoprotein; LDL, low-density lipoprotein; BP, blood pressure; eGFRMDRD, estimated Glomerular Filtration Rate by abbreviated Modification of Diet in Renal Disease equation; CAC, coronary artery calcification; hSCRP, high sensitivity C-reactive protein; sVCAM-1, soluble vascular cell adhesion molecule 1; VWF, von Willebrand Factor; CML, N(epsilon)-(carboxymethyl)lysine; CEL, N(epsilon)-(carboxyethyl)lysine; THP, tetrahydropyrimidine.

* for former or current smokers 
Table 3.2 - Plasma AGE-levels in individuals with and without T1DM

\begin{tabular}{|c|c|c|c|c|c|c|c|}
\hline & \multicolumn{3}{|c|}{ Model 1} & \multicolumn{3}{|c|}{ Model 2} \\
\hline & & mean & $95 \%-C I$ & p-value & mean & $95 \%-C I$ & p-value \\
\hline Pentosidine* & control & 0.51 & $0.48-0.53$ & & 0.51 & $0.48-0.54$ & \\
\hline (nmol/mmol LYS) & $T 1 D M$ & 0.69 & $0.65-0.73$ & $<0.001$ & 0.69 & $0.65-0.73$ & $<0.001$ \\
\hline CML & control & 92.3 & $89.6-94.9$ & & 92.6 & $90.1-95.1$ & \\
\hline (nmol/mmol LYS) & T1DM & 104.8 & $102.1-107.5$ & $<0.001$ & 104.5 & $102.0-107.0$ & $<0.001$ \\
\hline CEL & control & 14.5 & $14.0-15.0$ & & 14.6 & $14.1-15.2$ & \\
\hline (nmol/mmol LYS) & $T 1 D M$ & 15.0 & $14.5-15.5$ & 0.212 & 14.9 & $14.4-15.4$ & 0.489 \\
\hline THP* & control & 112.7 & $106.2-119.7$ & & 112.7 & $105.7-119.9$ & \\
\hline$(\mathrm{U} / \mathrm{mL})$ & T1DM & 125.6 & $118.0-133.4$ & 0.015 & 125.6 & $117.8-134.0$ & 0.025 \\
\hline
\end{tabular}

Data are presented as adjusted means or geometric means* of AGEs in individuals with and without T1DM, by use of a complete case analysis.

$\mathrm{n}=169$ for individuals without and $\mathrm{n}=165$ for individuals with T1DM.

Model 1 was adjusted for age and sex. Model 2 was adjusted for age, sex, SBP, DBP, BMI, WHR, pack-years of smoking, $\mathrm{LDL}, \mathrm{HDL}$, triglycerides and eGFR.

CML, N(epsilon)-(carboxymethyl)lysine; CEL, N(epsilon)-(carboxyethyl)lysine; THP, tetrahydropyrimidine.

Table 3.3. Plasma AGE-levels in individuals with T1DM and a moderate to high compared with a low CAC score

\begin{tabular}{|c|c|c|c|c|c|c|c|}
\hline & & & Model 1 & & & Model 2 & \\
\hline & & mean & 95\%-CI & p-value & mean & $95 \%-C I$ & p-value \\
\hline Pentosidine* & $C A C=0-10$ & 0.67 & $0.63-0.72$ & & 0.67 & $0.63-0.71$ & \\
\hline (nmol/mmol LYS) & $\mathrm{CAC}>10$ & 0.80 & $0.69-0.92$ & 0.034 & 0.81 & $0.70-0.93$ & 0.028 \\
\hline CML & $C A C=0-10$ & 105.0 & $101.7-108.2$ & & 104.5 & $101.5-107.5$ & \\
\hline (nmol/mmol LYS) & CAC $>10$ & 102.9 & $95.8-110.0$ & 0.608 & 105.0 & $98.3-111.8$ & 0.883 \\
\hline CEL & $C A C=0-10$ & 14.9 & $14.2-15.5$ & & 14.9 & $14.3-15.5$ & \\
\hline (nmol/mmol LYS) & $\mathrm{CAC}>10$ & 15.9 & $14.6-17.3$ & 0.166 & 15.9 & $14.6-17.3$ & 0.163 \\
\hline THP* & $C A C=0-10$ & 122.2 & $113.5-131.8$ & & 121.6 & $112.7-131.2$ & \\
\hline$(\mathrm{U} / \mathrm{mL})$ & $C A C>10$ & 140.6 & $119.4-165.6$ & 0.131 & 143.9 & $121.3-170.6$ & 0.086 \\
\hline
\end{tabular}

Data are presented as adjusted means or geometric means* of AGEs in individuals with a CAC score of 0-10 compared to $>10$ in individuals with T1DM, by use of a complete case analysis.

$\mathrm{n}=135$ for individuals with a calcification score of $0-10 ; n=30$ for individuals with a calcification score of $>10$. Model 1 was adjusted for age and sex. Model 2 was adjusted for age, sex, SBP, DBP, BMI, WHR, pack-years of smoking, LDL, $\mathrm{HDL}$, triglycerides and eGFR.

CML, N(epsilon)-(carboxymethyl)lysine; CEL, N(epsilon)-(carboxyethyl)lysine; THP, tetrahydropyrimidine. 
Table 3.4. Mediation analyses of the association of plasma pentosidine levels with the CAC score by low grade inflammation and endothelial dysfunction in T1DM

\begin{tabular}{|c|c|c|c|c|c|c|c|c|}
\hline \multicolumn{3}{|c|}{ Model 2} & \multicolumn{3}{|c|}{ Model 2 + LGI } & \multicolumn{3}{|c|}{ Model 2 + ED } \\
\hline $\mathbf{s} \boldsymbol{\beta}$ & 95\%-CI & $\begin{array}{c}\text { p- } \\
\text { value }\end{array}$ & $\mathbf{s} \boldsymbol{\beta}$ & 95\%-CI & $\begin{array}{c}\text { p- } \\
\text { value }\end{array}$ & $\mathbf{s} \boldsymbol{\beta}$ & 95\%-CI & $\begin{array}{c}\mathrm{p}- \\
\text { value }\end{array}$ \\
\hline 0.47 & $0.03-0.91$ & 0.036 & 0.47 & $0.03-0.91$ & 0.038 & 0.43 & $-0.02-0.87$ & 0.060 \\
\hline
\end{tabular}

Data are presented as standardized $\beta(s \beta)$. A s $\beta$ of 0.47 SD indicates that individuals with T1DM with a CAC score of $>10$ have on average 0.47 SD higher pentosidine levels compared to individuals with a score of 0-10.

$\mathrm{n}=122$ for individuals with a calcification score of $0-10 ; n=27$ for those with a calcification score of $>10$. Model 2 was adjusted for age, sex, SBP, DBP, BMI, WHR, pack-years of smoking, LDL, HDL, triglycerides and eGFR. This model was additionally adjusted for high sensitivity C-reactive protein (hsCRP), a marker for lowgrade inflammation (LGI), or for soluble vascular cell adhesion molecule 1 (sVCAM-1) and von Willebrand Factor (VWF), which are markers of endothelial dysfunction (ED). 


\section{DISCUSSION}

Our study had three main findings. First, we found higher plasma levels of the AGEs pentosidine, CML and THP in individuals with T1DM. Second, the AGE pentosidine was positively associated with CAC, an early marker of CVD. Third, the association of pentosidine with CAC was not explained by markers of LGI or ED.

\section{Plasma AGEs in type 1 diabetes}

This is the first larger study that has quantified multiple plasma AGEs with state-of-the-art ultraperformance liquid chromatography (UPLC) in combination with tandem mass spectrometry or, in case of pentosidine, with high-performance liquid chromatography (HPLC) and fluorescence detection. These techniques are considered to be the most accurate techniques for the measurement of AGEs at this moment. Unfortunately, because of acid instability of THP, it was not possible to measure THP with these techniques and therefore THP was measured with an ELISA. We investigated four out of many different AGEs and found that plasma levels of the AGEs pentosidine, CML and THP were significantly higher in individuals with T1DM as compared to controls, independent of age, sex, systolic and diastolic blood pressure, BMI, WHR, smoking, LDL and HDL cholesterol, triglycerides and eGFR. Levels of CEL were not statistically different. These results are in agreement with previous studies which were confined to small study populations ${ }^{10}$, 11 and/or have used non-specific immunological techniques for the detection of AGEs 12, 13 .

We did not find any association of plasma AGEs with $\mathrm{HbA1C}$ in the individuals with T1DM. These findings are consistent with many other studies that reported no association of plasma AGEs with $\mathrm{HbA1c}$ 31-35. An explanation for this lack of association could be that AGEs can also be formed through other pathways, for example lipid peroxidation, besides glucose metabolism. Moreover, $\mathrm{HbA1C}$ and AGEs presumably reflect different pathways following hyperglycaemia and different timeframes of hyperglycaemia.

\section{Associations between plasma AGEs and CAC in type 1 diabetes}

We and others have previously shown that the prevalence of CAC is increased in T1DM ${ }^{16,17}$. In individuals with kidney disease, the AGE pentosidine and the AGE-RAGE axis have been associated with arterial calcification ${ }^{14}, 18$. This is the first study that has examined the association of plasma AGEs with CAC in T1DM. We found higher levels of the plasma AGE pentosidine, but not CML, CEL and THP, in individuals with T1DM with a moderate to high compared to a low CAC score. These results are in line with a previous study that reported an independent positive association of pentosidine with CAC in individuals undergoing hemodialysis ${ }^{14}$, while no association was found between CML and CAC. Moreover, Conway et al. and Orchard et al. showed that skin autofluorescence, as a possible reflectance of tissue AGE accumulation, was associated with CAC severity in T1DM 36,37 .

\section{Potential mechanisms underlying the associations between AGEs and CAC}

In contrast to the positive association of pentosidine with CAC, CML, CEL and THP were not associated with CAC. This could indicate that plasma pentosidine is a better reflection of total AGE formation than these other AGEs or that it is more precisely quantified with current methods. Alternatively, pentosidine differs from the other AGEs measured because it is known as a cross- 
linking AGE 4, 38, and it might be that cross-linking AGEs in particular are linked to CAC. THP was borderline significantly associated with CAC $(p=0.09)$. THP is one of the AGEs, next to CEL, which is formed from the reaction of the reactive dicarbonyl MGO with arginine or lysine, respectively, predominantly formed from intracellular glycation 2. Little is known about THP, but it could represent a better reflection of intracellular MGO-AGEs than CEL. Moreover, auto-antibodies against MGO-modified apolipoprotein B100 have been found to be inversely associated with CAC in patients with type 2 diabetes ${ }^{39}$, also indicating a role of MGO in CAC. Therefore, if our results indeed reflect a causal link between AGEs and CAC, this might mean that cross-linking or intracellular glycation via MGO may stimulate the process of arterial calcification. The fact that we did find an association of pentosidine and THP with CAC in individuals with T1DM who were relatively young and had an early stage of CAC may indicate that increased levels of these AGES are associated with early development of CAC. However, overall, our numbers of individuals with substantial calcification in the study are low, probably partially due to the relatively young age of the participants, which is why these analyses should be replicated in larger cohorts.

AGEs are able to induce LGI and ED 3, 5, 40, and markers of these processes are associated with coronary or carotid artery disease in T1DM 41,42 . We demonstrated that the association of pentosidine with CAC was not explained (i.e. mediated) by LGI or ED. Other studies that investigated the mediating effect of LGI and ED in the association of AGEs with CVD in T1DM 3, 43 also found no mediating effect of either of these potential mechanisms. Therefore, other mechanisms besides LGI and ED might be involved in the association of AGEs with CAC. Recent publications show that AGEs-induced vascular calcification in rat vascular smooth muscle cells (VSMCs) is mediated by oxidative stress in vitro 44,45 , and oxidative stress may thus provide an additional mechanism explaining the association of AGEs with CAC.

The association between pentosidine and CAC might be causal since experimental studies have demonstrated a direct link of AGEs with calcification ${ }^{21}$. In response to AGEs, aortic VSMCs differentiate into cells that exhibit an osteoblast-like phenotype characterized by the deposition of calcium into the extracellular matrix ${ }^{19,20}$. These findings support a direct role of AGEs in the stimulation of CAC. Furthermore, the AGE-RAGE axis has been associated with arterial calcification in animal studies 22,23 . However, in our study, we did not find an association between $C M L$, a known ligand for RAGE, and CAC. Another pathway by which AGEs are thought to contribute to atherosclerosis is by the stimulation of apoptosis of endothelial progenitor cells (EPCs) and by the impairment of EPC functions 46,47 . Indeed, skin autofluorescence, an estimate of tissue AGE accumulation, has been negatively associated with circulating EPCs ${ }^{48}$. Furthermore, low levels of EPCs have been shown to be an independent determinant of carotid intima media thickness (cIMT) in young individuals with T1DM ${ }^{49}$. Interestingly, in individuals with compared to those without coronary atherosclerosis, it was found that a higher percentage of EPCs express the osteoblastic marker osteocalcin (OCN) ${ }^{50}$, which has been shown to correlate with markers of bone formation 51. Therefore, a particular subset of EPCs has been suggested to mediate abnormal vascular repair and vascular calcification ${ }^{52}$.

\section{Limitations of our study}

Our study had a cross-sectional design; therefore we cannot draw any conclusions about causality in the association of AGEs with T1DM and CAC. Because not all atherosclerotic plaques contain 
calcium, the CAC score does not take non-atherosclerotic plaques into account. Despite this caveat, it has been shown that CAC is highly associated with total coronary atherosclerotic plaque burden ${ }^{53}$. Additionally, individuals with diabetes are known to have a higher prevalence of medial calcification of the peripheral vessels. However, medial calcification of the coronary tree, not caused by atherosclerosis, is not very common in diabetes ${ }^{54}$. It therefore seems likely that the CAC score measured in our study indeed reflects intima calcification associated with atherosclerosis.

We cannot discard the possibility that the use of a single or a selection of markers representing LGI and ED, respectively, may have led to an underestimation of their mediating effects in the association of AGEs with CAC. However, hSCRP is one of the most studied and best validated markers and is thought to represent overall LGI. Furthermore, hsCRP is known to be associated with coronary heart disease ${ }^{55}$. sVCAM-1 and vWF are well known markers of ED ${ }^{56}$.

\section{Conclusions}

In conclusion, we found higher plasma levels of the AGEs pentosidine, CML and THP in individuals with compared to without T1DM, independent of age, sex, body mass index, waist-to-hip ratio, smoking, blood pressure, lipid profile and glomerular filtration rate. Pentosidine levels were higher in individuals with T1DM with a moderate to high compared to a low CAC score, independent of age, sex, body mass index, waist-to-hip ratio, smoking, blood pressure, lipid profile and glomerular filtration rate. The association of pentosidine with CAC was not explained (i.e. mediated) by LGI or ED. These results may indicate that AGEs are involved in the development of CAC in T1DM, but future studies are needed to fully elucidate the direction and potential causality of this relationship. If AGEs indeed play a role in the early development of coronary artery calcification in T1DM, they could be an early target for the prevention of CVD. 


\section{REFERENCES}

1. Soedamah-Muthu SS, Fuller JH, Mulnier HE, Raleigh VS, Lawrenson RA, Colhoun HM. High risk of cardiovascular disease in patients with type 1 diabetes in the u.K.: A cohort study using the general practice research database. Diabetes Care. 2006;29:798-804

2. Brownlee M. Biochemistry and molecular cell biology of diabetic complications. Nature. 2001;414:813-820

3. Nin JW, Jorsal A, Ferreira I, Schalkwijk CG, Prins MH, Parving HH, Tarnow L, Rossing P, Stehouwer CD. Higher plasma levels of advanced glycation end products are associated with incident cardiovascular disease and all-cause mortality in type 1 diabetes: A 12-year follow-up study. Diabetes Care. 2011;34:442-447

4. Aronson D. Cross-linking of glycated collagen in the pathogenesis of arterial and myocardial stiffening of aging and diabetes. J Hypertens. 2003;21:3-12

5. Basta G, Lazzerini G, Massaro M, Simoncini T, Tanganelli P, Fu C, Kislinger T, Stern DM, Schmidt AM, De Caterina R. Advanced glycation end products activate endothelium through signal-transduction receptor rage: A mechanism for amplification of inflammatory responses. Circulation. 2002;105:816-822

6. Bierhaus A, Humpert PM, Stern DM, Arnold B, Nawroth PP. Advanced glycation end product receptor-mediated cellular dysfunction. Ann N Y Acad Sci. 2005; 1043:676-680

7. Brouwers $O$, Niessen PM, Ferreira I, Miyata T, Scheffer PG, Teerlink T, Schrauwen P, Brownlee M, Stehouwer CD, Schalkwijk CG. Overexpression of glyoxalase-i reduces hyperglycemia-induced levels of advanced glycation end products and oxidative stress in diabetic rats. J Biol Chem. 2011;286:1374-1380

8. Oya T, Hattori N, Mizuno Y, Miyata S, Maeda S, Osawa T, Uchida K. Methylglyoxal modification of protein. Chemical and immunochemical characterization of methylglyoxal-arginine adducts. J Biol Chem. 1999;274:18492-18502

9. Thornalley PJ. Protein and nucleotide damage by glyoxal and methylglyoxal in physiological systems--role in ageing and disease. Drug metabolism and drug interactions. 2008;23:125-150

10. Ahmed N, Babaei-Jadidi R, Howell SK, Beisswenger PJ, Thornalley PJ. Degradation products of proteins damaged by glycation, oxidation and nitration in clinical type 1 diabetes. Diabetologia. 2005;48:1590-1603

11. Hwang JS, Shin $\mathrm{CH}$, Yang SW. Clinical implications of $\mathrm{n}$ epsilon-(carboxymethyl)lysine, advanced glycation end product, in children and adolescents with type 1 diabetes. Diabetes Obes Metab. 2005;7:263-267

12. Galler A, Muller G, Schinzel R, Kratzsch J, Kiess W, Munch G. Impact of metabolic control and serum lipids on the concentration of advanced glycation end products in the serum of children and adolescents with type 1 diabetes, as determined by fluorescence spectroscopy and nepsilon-(carboxymethyl)lysine elisa. Diabetes Care. 2003;26:2609-2615

13. Berg TJ, Dahl-Jorgensen K, Torjesen PA, Hanssen KF. Increased serum levels of advanced glycation end products (ages) in children and adolescents with iddm. Diabetes Care. 1997;20:1006-1008

14. Taki K, Takayama F, Tsuruta Y, Niwa T. Oxidative stress, advanced glycation end product, and coronary artery calcification in hemodialysis patients. Kidney international. 2006;70:218-224

15. Peters SA, Bakker M, den Ruijter HM, Bots ML. Added value of cac in risk stratification for cardiovascular events: A systematic review. Eur J Clin Invest. 2012;42:110-116

16. Colhoun HM, Rubens MB, Underwood SR, Fuller JH. The effect of type 1 diabetes mellitus on the gender difference in coronary artery calcification. J Am Coll Cardiol. 2000;36:2160-2167

17. Dabelea D, Kinney G, Snell-Bergeon JK, Hokanson JE, Eckel RH, Ehrlich J, Garg S, Hamman RF, Rewers M. Effect of type 1 diabetes on the gender difference in coronary artery calcification: A role for insulin resistance? The coronary artery calcification in type 1 diabetes (cacti) study. Diabetes. 2003;52:2833-2839

18. Nasrallah MM, El-Shehaby AR, Osman NA, Salem MM, Nassef A, El Din UA. Endogenous soluble receptor of advanced glycation end-products (esrage) is negatively associated with vascular calcification in non-diabetic hemodialysis patients. Int Urol Nephrol. 2012;44:1193-1199

19. Tanikawa T, Okada Y, Tanikawa R, Tanaka Y. Advanced glycation end products induce calcification of vascular smooth muscle cells through rage/p38 mapk. J Vasc Res. 2009;46:572-580

20. Ren X, Shao H, Wei Q, Sun Z, Liu N. Advanced glycation end-products enhance calcification in vascular smooth muscle cells. J Int Med Res. 2009;37:847-854

21. Wang Z, Jiang Y, Liu N, Ren L, Zhu Y, An Y, Chen D. Advanced glycation end-product nepsilon-carboxymethyl-lysine accelerates progression of atherosclerotic calcification in diabetes. Atherosclerosis. 2012;221:387-396

22. Gawdzik J, Mathew L, Kim G, Puri TS, Hofmann Bowman MA. Vascular remodeling and arterial calcification are directly mediated by s100a12 (en-rage) in chronic kidney disease. Am J Nephrol. 2011;33:250-259

23. Cecil DL, Terkeltaub RA. Arterial calcification is driven by rage in enpp1-/- mice. J Vasc Res. 2011;48:227-235

24. Scheijen JL, van de Waarenburg MP, Stehouwer CD, Schalkwijk CG. Measurement of pentosidine in human plasma protein by a single-column high-performance liquid chromatography method with fluorescence detection. J Chromatogr B Analyt Technol Biomed Life Sci. 2009;877:610-614

25. Hanssen NM, Engelen L, Ferreira I, Scheijen JL, Huijberts MS, van Greevenbroek MM, van der Kallen CJ, Dekker JM, Nijpels G, Stehouwer CD, Schalkwijk CG. Plasma levels of advanced glycation endproducts $\mathrm{n}$ \{epsilon\}(carboxymethyl)lysine, n\{epsilon\}-(carboxyethyl)lysine, and pentosidine are not independently associated with cardiovascular disease in individuals with or without type 2 diabetes: The hoorn and codam studies. J Clin Endocrinol Metab. 2013;98:E1369-1373

26. van Eupen MG, Schram MT, Colhoun HM, Hanssen NM, Niessen HW, Tarnow L, Parving HH, Rossing P, Stehouwer CD, Schalkwijk CG. The methylglyoxal-derived age tetrahydropyrimidine is increased in plasma of individuals with type 1 diabetes mellitus and in atherosclerotic lesions and is associated with svcam-1. Diabetologia. 2013;56:1845-1855

27. Agatston AS, Janowitz WR, Hildner FJ, Zusmer NR, Viamonte M, Jr., Detrano R. Quantification of coronary artery calcium using ultrafast computed tomography. J Am Coll Cardiol. 1990;15:827-832 
28. Dendukuri N, Chiu K, Brophy JM. Validity of electron beam computed tomography for coronary artery disease: Asystematic review and meta-analysis. BMC Med. 2007;5:35

29. Levey AS, Bosch JP, Lewis JB, Greene T, Rogers N, Roth D. A more accurate method to estimate glomerular filtration rate from serum creatinine: A new prediction equation. Modification of diet in renal disease study group. Ann Intern Med. 1999; 130:461-470

30. Schalkwijk CG, Poland DC, van Dijk W, Kok A, Emeis JJ, Drager AM, Doni A, van Hinsbergh VW, Stehouwer CD. Plasma concentration of c-reactive protein is increased in type $\mathrm{i}$ diabetic patients without clinical macroangiopathy and correlates with markers of endothelial dysfunction: Evidence for chronic inflammation. Diabetologia. 1999;42:351-357

31. Han Y, Randell E, Vasdev S, Gill V, Curran M, Newhook LA, Grant M, Hagerty D, Schneider C. Plasma advanced glycation endproduct, methylglyoxal-derived hydroimidazolone is elevated in young, complication-free patients with type 1 diabetes. Clin Biochem. 2009;42:562-569

32. Hirata K, Kubo K. Relationship between blood levels of n-carboxymethyl-lysine and pentosidine and the severity of microangiopathy in type 2 diabetes. Endocr J. 2004;51:537-544

33. Fosmark DS, Torjesen PA, Kilhovd BK, Berg TJ, Sandvik L, Hanssen KF, Agardh CD, Agardh E. Increased serum levels of the specific advanced glycation end product methylglyoxal-derived hydroimidazolone are associated with retinopathy in patients with type 2 diabetes mellitus. Metabolism. 2006;55:232-236

34. Shimoike $\mathrm{T}$, Inoguchi $\mathrm{T}$, Umeda $\mathrm{F}$, Nawata $\mathrm{H}$, Kawano $\mathrm{K}$, Ochi $\mathrm{H}$. The meaning of serum levels of advanced glycosylation end products in diabetic nephropathy. Metabolism. 2000;49:1030-1035

35. Kilhovd BK, Juutilainen A, Lehto S, Ronnemaa T, Torjesen PA, Hanssen KF, Laakso M. Increased serum levels of advanced glycation endproducts predict total, cardiovascular and coronary mortality in women with type 2 diabetes: A population-based 18 year follow-up study. Diabetologia. 2007;50:1409-1417

36. Conway B, Edmundowicz D, Matter N, Maynard J, Orchard T. Skin fluorescence correlates strongly with coronary artery calcification severity in type 1 diabetes. Diabetes Technol Ther. 2010;12:339-345

37. Orchard TJ, Lyons TJ, Cleary PA, Braffett BH, Maynard J, Cowie C, Gubitosi-Klug RA, Way J, Anderson K, Barnie A, Villavicencio S. The association of skin intrinsic fluorescence with type 1 diabetes complications in the dcct/edic study. Diabetes Care. 2013;36:3146-3153

38. Sell DR, Monnier VM. Structure elucidation of a senescence cross-link from human extracellular matrix. Implication of pentoses in the aging process. J Biol Chem. 1989;264:21597-21602

39. Engelbertsen D, Anand DV, Fredrikson GN, Hopkins D, Corder R, Shah PK, Lahiri A, Nilsson J, Bengtsson E. High levels of igm against methylglyoxal-modified apolipoprotein b100 are associated with less coronary artery calcification in patients with type 2 diabetes. J Intern Med. 2012;271:82-89

40. Harja E, Bu DX, Hudson BI, Chang JS, Shen X, Hallam K, Kalea AZ, Lu Y, Rosario RH, Oruganti S, Nikolla Z, Belov D, Lalla E, Ramasamy R, Yan SF, Schmidt AM. Vascular and inflammatory stresses mediate atherosclerosis via rage and its ligands in apoe-/- mice. J Clin Invest. 2008;118:183-194

41. Costacou T, Lopes-Virella MF, Zgibor JC, Virella G, Otvos J, Walsh M, Orchard TJ. Markers of endothelial dysfunction in the prediction of coronary artery disease in type 1 diabetes. The pittsburgh epidemiology of diabetes complications study. J Diabetes Complications. 2005;19:183-193

42. Hayaishi-Okano R, Yamasaki Y, Katakami N, Ohtoshi K, Gorogawa S, Kuroda A, Matsuhisa M, Kosugi K, Nishikawa N, Kajimoto Y, Hori M. Elevated c-reactive protein associates with early-stage carotid atherosclerosis in young subjects with type 1 diabetes. Diabetes Care. 2002;25:1432-1438

43. Schram MT, Chaturvedi N, Schalkwijk CG, Fuller JH, Stehouwer CD. Markers of inflammation are cross-sectionally associated with microvascular complications and cardiovascular disease in type 1 diabetes--the eurodiab prospective complications study. Diabetologia. 2005;48:370-378

44. Wei Q, Ren X, Jiang Y, Jin H, Liu N, Li J. Advanced glycation end products accelerate rat vascular calcification through rage/oxidative stress. BMC Cardiovasc Disord. 2013;13:13

45. Tada Y, Yano S, Yamaguchi T, Okazaki K, Ogawa N, Morita M, Sugimoto T. Advanced glycation end products-induced vascular calcification is mediated by oxidative stress: Functional roles of nad(p)h-oxidase. Horm Metab Res. 2013;45:267-272

46. Chen J, Song M, Yu S, Gao P, Yu Y, Wang H, Huang L. Advanced glycation endproducts alter functions and promote apoptosis in endothelial progenitor cells through receptor for advanced glycation endproducts mediate overpression of cell oxidant stress. Mol Cell Biochem. 2010;335:137-146

47. Li H, Zhang X, Guan X, Cui X, Wang Y, Chu H, Cheng M. Advanced glycation end products impair the migration, adhesion and secretion potentials of late endothelial progenitor cells. Cardiovasc Diabetol. 2012;11:46

48. Ueno H, Koyama H, Fukumoto S, Tanaka S, Shoji T, Emoto M, Tahara H, Inaba M, Kakiya R, Tabata T, Miyata T, Nishizawa Y. Advanced glycation end products, carotid atherosclerosis, and circulating endothelial progenitor cells in patients with end-stage renal disease. Metabolism. 2011;60:453-459

49. Palombo C, Kozakova M, Morizzo C, Gnesi L, Barsotti MC, Spontoni P, Massart F, Salvi P, Balbarini A, Saggese G, Di Stefano R, Federico G. Circulating endothelial progenitor cells and large artery structure and function in young subjects with uncomplicated type 1 diabetes. Cardiovasc Diabetol. 2011;10:88

50. Gossl M, Modder UI, Atkinson EJ, Lerman A, Khosla S. Osteocalcin expression by circulating endothelial progenitor cells in patients with coronary atherosclerosis. J Am Coll Cardiol. 2008;52:1314-1325

51. Eghbali-Fatourechi GZ, Lamsam J, Fraser D, Nagel D, Riggs BL, Khosla S. Circulating osteoblast-lineage cells in humans. N Engl J Med. 2005;352:1959-1966

52. Flammer AJ, Gossl M, Widmer RJ, Reriani M, Lennon R, Loeffler D, Shonyo S, Simari RD, Lerman LO, Khosla S, Lerman A. Osteocalcin positive cd133+/cd34-/kdr+ progenitor cells as an independent marker for unstable atherosclerosis. European heart journal. 2012;33:2963-2969 
53. Sangiorgi G, Rumberger JA, Severson A, Edwards WD, Gregoire J, Fitzpatrick LA, Schwartz RS. Arterial calcification and not lumen stenosis is highly correlated with atherosclerotic plaque burden in humans: A histologic study of 723 coronary artery segments using nondecalcifying methodology. J Am Coll Cardiol. 1998;31:126-133

54. Edmonds ME. Medial arterial calcification and diabetes mellitus. Z Kardiol. 2000;89 Suppl 2:101-104

55. Liuzzo G, Biasucci LM, Gallimore JR, Grillo RL, Rebuzzi AG, Pepys MB, Maseri A. The prognostic value of c-reactive protein and serum amyloid a protein in severe unstable angina. N Engl J Med. 1994;331:417-424

56. Muris DM, Houben AJ, Schram MT, Stehouwer CD. Microvascular dysfunction is associated with a higher incidence of type 2 diabetes mellitus: A systematic review and meta-analysis. Arterioscler Thromb Vasc Biol. 2012;32:3082-3094 



\section{CHAPTER 4}

Skin autofluorescence and pentosidine are associated with aortic stiffening The Maastricht Study

Marcelle G.A. van Eupen, Miranda T. Schram, Thomas T van Sloten, Jean Scheijen, Simone JS Sep, Carla J van der Kallen, Pieter C Dagnelie, Annemarie Koster, Nicolaas Schaper, Ronald MA Henry, Abraham A Kroon, Andries J Smit, Coen DA Stehouwer, Casper G Schalkwijk Hypertension. 68(4):956-63 (2016) 


\section{ABSTRACT}

\section{Background}

Arterial stiffening, as characterised by an increase in carotid-femoral pulse wave velocity or pulse pressure, increases the risk of cardiovascular disease, especially among individuals with type 2 diabetes mellitus. Advanced glycation endproducts are hypothesized to play a role in the development of arterial stiffness.

\section{Methods}

Therefore, we investigated the association between skin autofluorescence, an estimate of tissue advanced glycation endproducts, and plasma advanced glycation endproducts on the one hand and arterial stiffening on the other in 862 participants of The Maastricht Study (mean age of 60 years, $45 \%$ females) with normal glucose metabolism $(n=469)$, impaired glucose metabolism $(n=140)$, or type 2 diabetes $(n=253)$. Associations were analysed with linear regression analysis and adjusted for potential confounders.

\section{Results}

We found that higher skin autofluorescence as measured by the AGE Reader and plasma pentosidine were independently associated with higher carotid-femoral pulse wave velocity (s $\beta$ $0.10 ; 95 \% \mathrm{CI} 0.03-0.17$ and $0.10 ; 0.04-0.16$, respectively) and central pulse pressure (s $\beta 0.08$; $95 \%$ CI $0.01-0.15$ and $0.07 ; 0.01-0.13$, respectively). The associations between skin autofluorescence and pentosidine, and carotid-femoral pulse wave velocity were more pronounced in individuals with type 2 diabetes ( $p$-interaction<0.10).

\section{Conclusions}

These results support the hypothesis that accumulation of advanced glycation endproducts is involved in arterial stiffening, and may explain part of the increased risk of cardiovascular disease in individuals with type 2 diabetes. 


\section{INTRODUCTION}

Arterial stiffening, a measure of subclinical arterial injury, is associated with cardiovascular disease (CVD) and mortality ${ }^{1-4}$ in a variety of populations, including in type 2 diabetes mellitus (T2DM) 5 . Moreover, the age-related increase in arterial stiffness is steeper in individuals with T2DM compared to individuals without 6,7 . The exact mechanisms behind the development of arterial stiffness and subsequent CVD are not completely understood. The increased accumulation of advanced glycation endproducts (AGEs) on long lived proteins, such as collagen in the arterial wall, may lead to the formation of cross-links, and in the arterial wall, may subsequently lead to increased stiffening ${ }^{8}$. Additionally, AGEs have been linked to arterial stiffness via other mechanisms like intracellular protein glycation or RAGE activation ${ }^{9}$. AGEs are thus thought to play a crucial role in the development of arterial stiffness, especially in T2DM.

Indeed, several studies found an association between measures of AGE accumulation and arterial stiffening ${ }^{10-20}$. Only one case-control study investigated this association in individuals with T2DM. This study found no association between serum pentosidine and heart-brachial PWV or brachialankle PWV after adjustment for renal function ${ }^{15}$. However, it did not take other potential confounders into account. Moreover, the measurement of skin autofluorescence (SAF) has recently emerged as an estimate of AGE accumulation in skin tissue ${ }^{21}$, and may thereby be a better estimate of tissue AGE accumulation than plasma AGEs.

So far, no study has investigated the association between SAF and plasma AGEs, and cfPWV or pulse pressure (PP), both measures of aortic stiffening, in a population-based setting, including individuals with NGM, IGM and T2DM.

In view of these considerations, the aims of our study were, first, to evaluate the independent association between SAF and plasma AGEs on the one hand and measures of arterial stiffening, i.e. cfPWV, central PP and 24-hour ambulatory PP, on the other. Second, to examine whether these associations differed between individuals with NGM, IGM or T2DM. 


\section{METHODS}

\section{Study population and design}

In this study, we used data from The Maastricht Study, an observational prospective populationbased cohort study. The rationale and methodology have been described previously ${ }^{22}$. In brief, the study focuses on the etiology, pathophysiology, complications and comorbidities of type 2 diabetes mellitus (T2DM) and is characterized by an extensive phenotyping approach. Eligible for participation were all individuals aged between 40 and 75 years and living in the southern part of the Netherlands. Participants were recruited through mass media campaigns and from the municipal registries and the regional Diabetes Patient Registry via mailings. Recruitment was stratified according to known T2DM status for reasons of efficiency. The present report includes cross-sectional data from the first 866 participants, who completed the baseline survey between November 2010 and March 2012. The examinations of each participant were performed within a time window of three months. The study has been approved by the institutional medical ethical committee (NL31329.068.10) and the Netherlands Health Council under the Dutch "Law for Population Studies" (Permit 131088-105234-PG). All participants gave written informed consent. From the initial 866 individuals in included in this study, we excluded individuals with type 1 diabetes (T1DM) $(n=4)$.

\section{Skin autofluorescence (SAF)}

All participants were asked to refrain from smoking and caffeine at least 3 hours before the measurements. A light meal (breakfast and (or) lunch), low in fat content, was allowed. SAF was measured with the AGE Reader ${ }^{\mathrm{TM}}$ (DiagnOptics Technologies BV, Groningen, the Netherlands). The AGE reader is a desktop device that uses the characteristic fluorescent properties of certain AGEs to estimate the level of AGE accumulation in the skin. Technical details of this non-invasive method have been described more extensively elsewhere ${ }^{21}$. In short, the AGE Reader illuminates a skin surface of $4 \mathrm{~cm}^{2}$ guarded against surrounding light, with an excitation wavelength range of $300-420 \mathrm{~nm}$, with a peak excitation of $370 \mathrm{~nm}$. SAF was calculated as the ratio between the emission light from the skin in the wavelength range of 420-600 nm (fluorescence) and excitation light that is reflected by the skin (300-420nm), multiplied by 100 and expressed in arbitrary units (AU). Participants were asked not to use any sunscreen or selfbrowning creams on their lower arms within 2 days before the measurement. SAF was measured at room temperature in a semi-dark environment while participants were at rest in a seated position. The inner side of the forearm approximately $4 \mathrm{~cm}$ below the elbow fold of a participant was positioned on top of the device, as described by the manufacturer. The mean of three consecutive measurements was used in the analyses. Reproducibility was assessed in 14 individuals without diabetes (6 males; $32.2 \pm 7.1$ years). The intraclass correlation coefficient (ICC) of three intra-individual consecutive SAF measurements was 0.83 (95\% CI 0.65-0.94). SAF was calculated off-line by automated analysis using AGE Reader software, version 2.3, and was observer-independent. There were no significant differences between fasting and non-fasting measurements (mean difference $=0.01 \mathrm{AU}, \mathrm{p}=0.73$ ). Reproducibility in individuals with T2DM has been evaluated previously ${ }^{21}$ with an overall Altman error percentage of $5.03 \%$ for measurements taken over a single day. Skin pigmentation is known to influence the measurement of SAF ${ }^{23}$. Therefore, in participants with dark-colored skin with a reflectance of 6$10 \%$, a validated reflectance dependent correction was made by the software ${ }^{23}$. Measurements 
in participants with dark-colored skin and a mean reflectance below $6 \%$ are considered unreliable and are therefore not used to calculate SAF by the software. Therefore, these participants were automatically excluded $(n=1)$. Additionally, a single SAF value above 10 AU was considered as unreliable; these individual measurements $(n=3)$ were manually excluded and the mean of the remaining two measurements was used in analyses.

\section{Analysis of protein- bound AGEs and lysine in plasma}

Plasma AGEs were measured in EDTA samples obtained from fasting venous blood, which were stored at $-80^{\circ} \mathrm{C}$ until analysis. Protein-bound pentosidine was quantified using HPLC with fluorescence detection, as described in detail elsewhere ${ }^{24}$. Intra- and interassay coefficients of variation (CVs), as analysed in this study, were 6.5 and $7.8 \%$ for pentosidine, respectively. Protein-bound $\mathrm{N} \varepsilon$-(carboxymethyl)lysine (CML) and $\mathrm{N} \varepsilon$-(carboxyethyl)lysine (CEL) and lysine were quantified using UPLC MS/MS ${ }^{25}$. Intra- and interassay CVs were 4.5 and $6.7 \%$ for CML, 6.2 and $10.3 \%$ for CEL and 5.0 and $5.3 \%$ for lysine. Concentrations of protein-bound pentosidine, CML and CEL were adjusted for levels of lysine and expressed as nmol/mmol lysine.

\section{Carotid to femoral pulse wave velocity and central pulse pressure}

As described previously ${ }^{26}$, carotid-to-femoral pulse wave velocity (cfPWV) and central pulse pressure (cPP) were assessed non-invasively by means of applanation tonometry. All measurements (approximately $45 \mathrm{~min}$ ) were done by trained vascular technicians unaware of the participants' clinical or diabetes status. Measurements took place in a quiet temperature-controlled room $\left(21-23^{\circ} \mathrm{C}\right)$ and were performed in supine position, after 10 minutes of rest. Participants were asked to refrain from smoking and drinking coffee or tea or alcohol beverages three hours prior to the study. Participants were allowed to have a light meal (breakfast and/or lunch). Talking or sleeping was not allowed during the examination. A three-lead electrocardiogram was recorded continuously during the measurements to facilitate automatic signal processing. In addition, brachial systolic, diastolic, and mean arterial pressure (MAP) were determined repeatedly with a 5-min interval, using an oscillometric device (Accutorr Plus, Datascope Inc., Montvale, NJ, USA), and the average of these measurements was calculated. cfPWV was determined according to recent guidelines ${ }^{27}$ with the use of applanation tonometry (SphygmoCor, Atcor Medical, Sydney, Australia). Pressure waveforms were determined at the right common carotid and right common femoral arteries. The difference in the time of pulse arrival from the R-wave of the electrocardiogram between the two sites (transit time) was determined with the intersecting tangents algorithm. The pulse wave travel distance was calculated as $80 \%$ of the direct straight distance (measured with an infantometer) between the two arterial sites. cfPWV was defined as travelled distance / transit time. CPP was determined by radial applanation tonometry (Sphygmocor, Atcor Medical, Australia) ${ }^{28}$. The median of three consecutive cfPWV and cPP recordings were used in the analyses.

\section{Glucose metabolism status}

As described previously ${ }^{22}$, to determine glucose metabolism, all participants (except those who used insulin) underwent a standardized 7-point oral glucose tolerance test (OGTT) after an overnight fast. Blood samples were taken at baseline, and at 15, 30, 45, 60, 90 and 120 minutes after ingestion of a $75 \mathrm{~g}$ glucose drink. For safety reasons, participants with a fasting glucose level above $11.0 \mathrm{mmol} / \mathrm{l}$, as determined by a finger prick, did not undergo the OGTT. For these 
individuals $(n=13)$, fasting glucose level and information about diabetes medication use were used to determine glucose metabolism status. Glucose metabolism was defined according to the WHO 2006 criteria into normal glucose tolerance (NGT), impaired fasting glucose (IFG), impaired glucose tolerance (IGT), and T2DM ${ }^{29}$. For this study, we defined having either IFG or IGT as impaired glucose metabolism (IGM).

\section{4-hour ambulatory blood pressure}

Ambulatory blood pressure was measured with ambulatory 24-hour BP monitoring (WatchBP O3, Microlife AG, Switzerland). Cuffs were applied to the participants' nondominant arm. Measurements were programmed for every 15 minutes during daytime (08.00-23.00 hours) and every 30 minutes during the night (23.00-08.00 hours), for a total of 24 hours. As quality criteria, mean 24-hour blood pressure measurements were only calculated if more than 14 valid measurements at daytime and more than 7 valid measurements at night were available, based on recommendations of the British Hypertension Society ${ }^{30}$. Mean 24-hour ambulatory pulse pressure (aPP, defined as aSBP-aDBP), 24-hour ambulatory heart rate, and 24-hour ambulatory mean arterial pressure (MAP, defined as aDBP $+(0.412 \times$ aPP $))^{31}$ were calculated based on hourly averages ${ }^{32}$. Data on aPP was available for 774 individuals. Missing data were predominantly caused by device non-availability or technical problems.

\section{Measures of peripheral neuropathy and diabetic nephropathy}

Vibration perception threshold (VPT) was measured as a marker of peripheral neuropathy. VPT was assessed using a hand-held neurothesiometer (Horwell Scientific Laboratory Supplies, Nottingham, UK). After a test procedure on the participant's elbow, VPT was tested three times at the distal phalanx of the hallux of the right and left foot. The minimum VPT at which the subject was aware of vibration sensation was recorded to the nearest $0.5 \mathrm{~V}$, starting from $0.0 \mathrm{~V}$ with stimulation up to $50.0 \mathrm{~V}$. The mean of the three measurements for the least sensitive foot was used in further analyses ${ }^{33,34}$. Peripheral sensory neuropathy (PSN) was defined as VPT $\geq 25 \mathrm{~V}$ (2). To assess urinary albumin excretion, participants were requested to collect two 24-hour urine collections. Urinary albumin concentration was measured with a standard immunoturbidimetric assay by an automatic analyser (Beckman Synchron LX20, Beckman Coulter Inc., Brea, USA) and multiplied by collection volume to obtain the 24-hour urinary albumin excretion. Urinary albumin concentration below the detection limit of the assay $(2 \mathrm{mg} / \mathrm{l})$, the urinary albumin concentration was set at $1.5 \mathrm{mg} / \mathrm{l}$ before multiplying by collection volume. Only urine collections with a collection time between 20 and 28 hours were considered valid. If needed, urinary albumin excretion was extrapolated to a 24-hours' excretion. Microalbuminuria was defined as a urinary albumin excretion of 30-300 mg per 24 hours whereas macroalbuminuria was defined as a urinary albumin excretion of $\geq 300 \mathrm{mg}$ per 24 hours ${ }^{35}$. These definitions were preferably based on the average of two (90\%) 24-hour urine collections.

\section{Covariates}

As described previously ${ }^{22}$, fasting venous blood samples were used to assess total cholesterol, LDL and HDL cholesterol, triglycerides, creatinine and HbA1c. Serum total cholesterol, HDL cholesterol, triglycerides, albumin and serum and urine creatinine and uric acid levels were measured with standard (enzymatic and/or colorimetric) methods by an automatic analyzer (Beckman Synchron LX20, Beckman Coulter Inc., Brea, USA). LDL cholesterol was calculated according to the Friedewald formula ${ }^{36}$. Serum creatinine was measured with a Jaffé method 
traceable to isotope dilution mass spectrometry (Beckman Synchron LX20, Beckman Coulter Inc., Brea, USA). Glomerular filtration rate (eGFR) was estimated using the CKD-EPI (Chronic Kidney Disease Epidemiology Collaboration) equation based on serum creatinine ${ }^{37}$. HbA1c was measured with ion-exchange high performance liquid chromatography (HPLC) (Variant tm II, Bio-Rad, Hercules, California, USA). Urinary albumin was measured with a immunoturbidimetric assay (Cobas c systems, Roche diagnostics, Mannheim, Germany). Waist circumference was measured in duplicate midway between the lower rib margin and the iliac crest at the end of expiration, to the nearest $0.5 \mathrm{~cm}$, with a flexible plastic tape measure (Seca, Hamburg, Germany). Participants were requested to bring all the medication they used at the time of measurement or a list from their pharmacists to the research center. During a medication interview generic name, dose and frequency, and additional over-the-counter (OTC) medication use were registered by trained staff. All participants received extensive web-based questionnaires. Duration of diabetes was assessed by using the year of diagnosis reported in the questionnaire. Smoking status (never, former, current) was based on smoking cigarettes, cigars and/or pipe tobacco. History of cardiovascular disease was assessed with a modified version of the Rose Questionnaire for the diagnosis of ischemic heart pain and intermittent claudication 38 and defined as self-reported myocardial infarction, and/or cerebrovascular infarction or hemorrhage, and/or percutaneous artery angioplasty of, or vascular surgery on, the coronary arteries, abdominal arteries, peripheral arteries or carotid arteries. Office blood pressure was determined three times on the right arm after a 10-minute rest period, using a non-invasive blood pressure monitor (Omron 705IT, Japan). Hypertension was defined as office systolic blood pressure $\geq 140 \mathrm{mmHg}$, diastolic blood pressure $\geq 90$ and/or the use of antihypertensive medication.

\section{Statistical methods}

Analyses were conducted using SPSS version 21 for Windows. Comparisons of baseline characteristics between groups were made by use of ANOVA or $\mathrm{X}^{2}$ tests. Variables with a skewed distribution were $\log _{10}$-transformed before analysis. We used standardized multiple linear regression analysis to evaluate the association between SAF and plasma AGEs on the one hand and cfPWV, CPP and aPP on the other, which enabled us to adjust for possible confounding factors. As presented in each table, we included all available data in the analyses to avoid selection bias. We investigated whether or not these associations differed between individuals with different glucose metabolism status by adding interaction terms in our models (e.g. the product of: 1) SAF or plasma AGE levels, and 2) glucose metabolism status). P-values $<0.05$ were considered statistically significant, except for interaction terms, where a $p$-value $<0.10$ was considered statistically significant.

\section{RESULTS}

\section{General characteristics}

Table 4.1 shows the general characteristics, stratified according to tertiles of cfPWV. Data on SAF were available in 831 individuals, plasma AGEs in 843, cfPWV data in 820 and cPP data in 828 individuals. Missing data were predominantly caused by device non-availability or technical problems. Plasma AGEs were measured in blood samples, which, for the missing cases, were mostly not available due to difficulties in blood withdrawal. As a sensitivity analysis, we 
additionally performed all analyses in a dataset were missing values were imputed by multiple imputation using SPSS. These additional analyses were not materially different from our original analyses. The percentage of individuals with IGM or T2DM, peripheral sensory neuropathy, albuminuria, hypertension, anti-hypertensive or lipid-modifying or diabetes medication and a history of CVD was higher in the higher cfPWV tertiles. Also, with higher cfPWV tertile, the percentage of males and former smokers was higher, as were age, diabetes duration, HbA1c, waist circumference, total-to-HDL cholesterol ratio and triglycerides; eGFR was lower with higher cfPWV. SAF and plasma pentosidine level were higher with higher CfPWV, as were mean arterial pressure and heart rate (Table 4.1). For the general characteristics stratified by glucose metabolism status, please see http://hyper.ahajournals.org, supplementary Table 4.1.

\section{Associations between AGE accumulation and aortic stiffening}

Both SAF ( $s \beta 0.09,95 \%$-CI 0.03-0.16) and plasma pentosidine ( $s \beta 0.09,95 \%$-CI 0.03-0.16) were significantly associated with higher cfPWV, after adjustment for age, sex, glucose metabolism status, average mean arterial pressure and heart rate obtained during cfPWV measurement, waist circumference, smoking, antihypertensive, lipid-modifying and diabetes medication use, eGFR, total-to-HDL-cholesterol ratio, triglycerides and a history of cardiovascular disease (Table 4.2). These associations were more pronounced in individuals with T2DM (SAF: $s \beta 0.13,95 \%$-CI $-0.01-0.28$; pentosidine: $s \beta 0.12,95 \%$-CI $-0.02-0.26$, p-values for interaction $<0.10$ ) (Figure 4.1). The association between SAF and cfPWV was also more pronounced in individuals with IGM compared to those with NGM ( $s \beta 0.13,95 \%-C I-0.05-0.31)$, but without significant interaction ( $p=0.322$ ) (Figure 4.1). SAF ( $\mathrm{\beta} \beta 0.08,95 \%$-CI $0.01-0.15)$ and plasma pentosidine ( $s \beta 0.07,95 \%$-CI 0.01-0.13) showed positive and similar significant associations with cPP after adjustment for age, sex, glucose metabolism status, average 24-hour mean arterial pressure, average 24-hour heart rate, waist circumference, smoking, antihypertensive, lipid-modifying and diabetes medication use, eGFR, total-to-HDL-cholesterol ratio, triglycerides and a history of cardiovascular disease (Table 4.2). The associations between SAF and AGEs on the one hand and CPP on the other were not different for different glucose metabolism status ( $p$ for interaction $>0.10$, see Figure 4.1). SAF ( $s \beta 0.06,95 \%-C I-0.01-0.12)$, plasma pentosidine ( $s \beta$ $0.05,95 \%$-CI $-0.01-0.11)$ and plasma CML ( $\mathrm{s} \beta 0.06,95 \%-\mathrm{CI}-0.01-0.12)$ showed positive, nonsignificant associations with aPP (please see http://hyper.ahajournals.org, supplementary Table 4.2).

\section{The influence of prior CVD, peripheral neuropathy and diabetic nephropathy on the associations between AGE accumulation and aortic stiffening}

The inclusion of individuals with prior CVD in our analysis may have influenced the observed associations between measures of AGE accumulation and arterial stiffness. However, exclusion of individuals with prior CVD did not materially change the associations between SAF and plasma AGEs on the one hand, and cfPWV and cPP on the other (please see http://hyper.ahajournals.org, supplementary Table 4.3). Furthermore, additional adjustment for PSN and albuminuria, as markers of microvascular disease, did not materially change the associations between SAF and plasma AGEs on the one hand, and cfPWV and cPP on the other (please see http://hyper.ahajournals.org, supplementary Table 4.4). 
Table 4.1. General characteristics of The Maastricht Study participants

\begin{tabular}{|c|c|c|c|c|}
\hline & \multicolumn{4}{|c|}{ Tertiles of carotid to femoral pulse wave velocity $(n=820)$} \\
\hline & $\begin{array}{c}1^{\text {st }} \text { tertile }(n=273) \\
(4.8-7.8 \mathrm{~m} / \mathrm{s})\end{array}$ & $\begin{array}{c}2^{\mathrm{nd}} \text { tertile }(\mathrm{n}=274) \\
(7.8-9.4 \mathrm{~m} / \mathrm{s})\end{array}$ & $\begin{array}{c}3^{\text {rd }} \text { tertile }(n=273) \\
(9.4-20.2 \mathrm{~m} / \mathrm{s})\end{array}$ & p-value \\
\hline NGM/IGM/T2DM (\%) & $72 / 11 / 17$ & $57 / 18 / 25$ & $35 / 20 / 45$ & $<0.001$ \\
\hline Age (years) & $55 \pm 8$ & $60 \pm 8$ & $65 \pm 6$ & $<0.001$ \\
\hline Sex (number of males/females) & $122 / 151$ & $159 / 115$ & $165 / 108$ & $<0.001$ \\
\hline Diabetes duration $(y)$ & $4[2-7]$ & $7[2-11]$ & $8[5-13]$ & $<0.001$ \\
\hline HbA1c (\%) & $5.8 \pm 0.7$ & $5.9 \pm 0.6$ & $6.3 \pm 1.0$ & $<0.001$ \\
\hline $\mathrm{HbA1c}(\mathrm{mmol} / \mathrm{mol})$ & $40 \pm 8$ & $41 \pm 7$ & $45 \pm 11$ & $<0.001$ \\
\hline Smoking, never/former/current (\%) & $37 / 45 / 18$ & $28 / 56 / 16$ & $29 / 57 / 14$ & 0.052 \\
\hline Waist circumference (cm) & $93 \pm 13$ & $97 \pm 13$ & $100 \pm 13$ & $<0.001$ \\
\hline Total-to-HDL cholesterol ratio & $4.0 \pm 1.2$ & $4.4 \pm 1.2$ & $4.2 \pm 1.3$ & 0.006 \\
\hline Triglycerides (mmol/L) & $1.1[0.8-1.6]$ & $1.2[0.9-1.8]$ & $1.4[1.0-2.0]$ & $<0.001$ \\
\hline eGFRCKD-EPI $\left(\mathrm{ml} / \mathrm{min} / 1.73 \mathrm{~m}^{2}\right)$ & $90 \pm 13$ & $84 \pm 14$ & $80 \pm 15$ & $<0.001$ \\
\hline Albuminuria (normo/micro/macro) (\%) & $95 / 4 / 1$ & $94 / 5 / 1$ & $88 / 11 / 1$ & 0.008 \\
\hline Peripheral sensory neuropathy ( $\mathrm{n}(\%))$ & $9(4)$ & $16(8)$ & $40(22)$ & $<0.001$ \\
\hline Hypertension (n (\%)) & $97(36)$ & $157(57)$ & $217(80)$ & $<0.001$ \\
\hline Anti-hypertensive medication ( $\mathrm{n}(\%)$ ) & $74(27)$ & $108(39)$ & $141(52)$ & $<0.001$ \\
\hline Lipid-modifying medication (n (\%)) & $68(25)$ & $92(34)$ & $136(50)$ & $<0.001$ \\
\hline Diabetes medication ( $\mathrm{n}(\%))$ & $41(15)$ & $57(21)$ & $88(32)$ & $<0.001$ \\
\hline History of CVD (n (\%)) & $33(13)$ & $46(17)$ & $60(24)$ & 0.003 \\
\hline SAF $(A U)$ & $2.55 \pm 0.51$ & $2.70 \pm 0.50$ & $2.88 \pm 0.55$ & $<0.001$ \\
\hline Pentosidine (nmol/mmol LYS) & $0.44[0.37-0.53]$ & $0.47[0.38-0.56]$ & $0.49[0.40-0.61]$ & $<0.001$ \\
\hline CML (nmol/mmol LYS) & $74.8 \pm 14.4$ & $74.7 \pm 14.7$ & $73.6 \pm 15.1$ & 0.586 \\
\hline CEL (nmol/mmol LYS) & $34.3 \pm 10.8$ & $33.2 \pm 9.3$ & $34.8 \pm 10.6$ & 0.183 \\
\hline cfPWV (m/s) & $6.98 \pm 0.59$ & $8.60 \pm 0.47$ & $11.4 \pm 1.8$ & - \\
\hline MAP $(\mathrm{mmHg})$ & $92 \pm 8$ & $98 \pm 9$ & $103 \pm 10$ & $<0.001$ \\
\hline Heart rate (bpm) & $62 \pm 8$ & $63 \pm 8$ & $65 \pm 9$ & $<0.001$ \\
\hline Central pulse pressure $(\mathrm{mmHg})$ & 38 [33-47] & $45[38-55]$ & $55[44-68]$ & $<0.001$ \\
\hline Ambulatory $24 \mathrm{~h}$ PP $(\mathrm{mmHg})$ & $41 \pm 7$ & $44 \pm 8$ & $51 \pm 9$ & $<0.001$ \\
\hline Ambulatory 24h MAP (mmHg) & $90 \pm 7$ & $93 \pm 8$ & $96 \pm 9$ & $<0.001$ \\
\hline Ambulatory $24 \mathrm{~h}$ heart rate (bpm) & $70 \pm 8$ & $69 \pm 9$ & $71 \pm 9$ & 0.014 \\
\hline
\end{tabular}

Data are presented as mean \pm standard deviation (SD) or as median [inter quartile range (IQR)], unless otherwise indicated. NGM, normal glucose metabolism; IGM, impaired glucose metabolism; T2DM, type 2 diabetes; HbA1c, glycated hemoglobin; HDL, high-density lipoprotein; eGFRCKD-EPI, estimated Glomerular Filtration Rate; SBP, systolic blood pressure; DBP, diastolic blood pressure; cfPWV, carotid to femoral pulse wave velocity; MAP, mean arterial pressure; CVD, cardiovascular disease; SAF, skin autofluorescence; CML, N(epsilon)-(carboxymethyl)lysine; CEL, N(epsilon)-(carboxyethyl)lysine. 
Supplementary Table 4.1. General characteristics of the Maastricht Study participants by glucose metabolism status.

\begin{tabular}{|c|c|c|c|c|}
\hline & \multicolumn{4}{|c|}{ Glucose metabolism status $(\mathrm{n}=\mathbf{8 6 2})$} \\
\hline & NGM $(n=469)$ & $\operatorname{IGM}(n=140)$ & T2DM $(n=253)$ & p-value \\
\hline Age (years) & $57 \pm 9$ & $62 \pm 8$ & $64 \pm 7$ & $<0.001$ \\
\hline Sex (number of males/females) & $213 / 256$ & $83 / 57$ & $176 / 77$ & $<0.001$ \\
\hline Diabetes duration $(\mathrm{y})$ & - & - & $7[3-11]$ & - \\
\hline HbA1c (\%) & $5.6 \pm 0.3$ & $5.9 \pm 0.4$ & $6.9 \pm 0.9$ & $<0.001$ \\
\hline $\mathrm{HbA1c}(\mathrm{mmol} / \mathrm{mol})$ & $38 \pm 4$ & $41 \pm 4$ & $52 \pm 10$ & $<0.001$ \\
\hline Smoking, never/former/current (\%) & $36 / 46 / 18$ & $28 / 57 / 15$ & $22 / 64 / 14$ & $<0.001$ \\
\hline Waist circumference $(\mathrm{cm})$ & $92 \pm 11$ & $99 \pm 12$ & $106 \pm 13$ & $<0.001$ \\
\hline Total-to-HDL cholesterol ratio & $4.1 \pm 1.3$ & $4.4 \pm 1.3$ & $4.2 \pm 1.2$ & 0.003 \\
\hline Triglycerides (mmol/L) & $1.0[0.8-1.5]$ & $1.4[1.0-2.1]$ & $1.7[1.2-2.3]$ & $<0.001$ \\
\hline eGFRCKD-EPI $\left(\mathrm{ml} / \mathrm{min} / 1.73 \mathrm{~m}^{2}\right)$ & $87 \pm 14$ & $82 \pm 13$ & $82 \pm 16$ & 0.002 \\
\hline Albuminuria (normo/micro/macro) (\%) & $96 / 3 / 1$ & $93 / 6 / 1$ & $83 / 16 / 1$ & $<0.001$ \\
\hline Peripheral sensory neuropathy ( $\mathrm{n}(\%)$ ) & $31(6)$ & $10(10)$ & $39(22)$ & $<0.001$ \\
\hline Hypertension (n (\%)) & $189(40)$ & $92(66)$ & $219(87)$ & $<0.001$ \\
\hline Anti-hypertensive medication ( $\mathrm{n}(\%)$ ) & $102(22)$ & $62(44)$ & $182(72)$ & $<0.001$ \\
\hline Lipid lowering medication (n (\%)) & $76(16)$ & $51(36)$ & $191(76)$ & $<0.001$ \\
\hline Diabetes medication (n (\%)) & 0 & 0 & $198(78)$ & $<0.001$ \\
\hline History of CVD ( $(\%))$ & $53(12)$ & $25(18)$ & $73(31)$ & $<0.001$ \\
\hline $\operatorname{SAF}(A U)$ & $2.58 \pm 0.49$ & $2.70 \pm 0.45$ & $2.95 \pm 0.57$ & $<0.001$ \\
\hline Pentosidine (nmol/mmol LYS) & $0.48[0.39-0.58]$ & $0.44[0.38-0.54]$ & $0.45[0.35-0.57]$ & 0.057 \\
\hline CML (nmol/mmol LYS) & $77.2 \pm 14.2$ & $72.3 \pm 14.1$ & $70.0 \pm 14.7$ & $<0.001$ \\
\hline CEL (nmol/mmol LYS) & $32.8 \pm 9.3$ & $34.4 \pm 10.5$ & $36.3 \pm 11.3$ & 0.002 \\
\hline $\operatorname{cfPWV}(\mathrm{m} / \mathrm{s})$ & $8.37 \pm 1.77$ & $9.32 \pm 1.96$ & $9.96 \pm 2.47$ & $<0.001$ \\
\hline $\mathrm{MAP}(\mathrm{mmHg})$ & $96 \pm 11$ & $100 \pm 10$ & $99 \pm 9$ & 0.001 \\
\hline Heart rate (bpm) & $62 \pm 8$ & $63 \pm 9$ & $66 \pm 10$ & $<0.001$ \\
\hline Central pulse pressure $(\mathrm{mmHg})$ & $43[35-53]$ & $47[38-58]$ & 50 [40-64] & $<0.001$ \\
\hline Ambulatory 24h PP (mmHg) & $43 \pm 7$ & $47 \pm 9$ & $50 \pm 10$ & $<0.001$ \\
\hline Ambulatory 24h MAP (mmHg) & $91 \pm 8$ & $95 \pm 10$ & $94 \pm 8$ & $<0.001$ \\
\hline Ambulatory $24 \mathrm{~h}$ heart rate (bpm) & $69 \pm 8$ & $70 \pm 9$ & $71 \pm 10$ & 0.017 \\
\hline
\end{tabular}

Data are presented as mean \pm standard deviation (SD) or as median [inter quartile range (IQR)], unless otherwise indicated. NGM, normal glucose metabolism; IGM, impaired glucose metabolism; T2DM, type 2 diabetes; HbA1c, glycated hemoglobin; HDL, high-

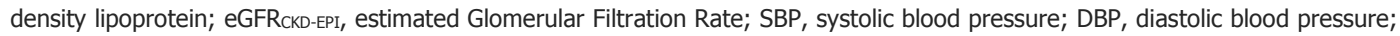
cfPWV, carotid to femoral pulse wave velocity; MAP, mean arterial pressure; CVD, cardiovascular disease; SAF, skin autofluorescence; CML, N(epsilon)-(carboxymethyl)lysine; CEL, N(epsilon)-(carboxyethyl)lysine. 
Figure 4.1. Associations between measures of AGE accumulation and cfPWV or cPP in individuals with NGM, IGM and T2DM
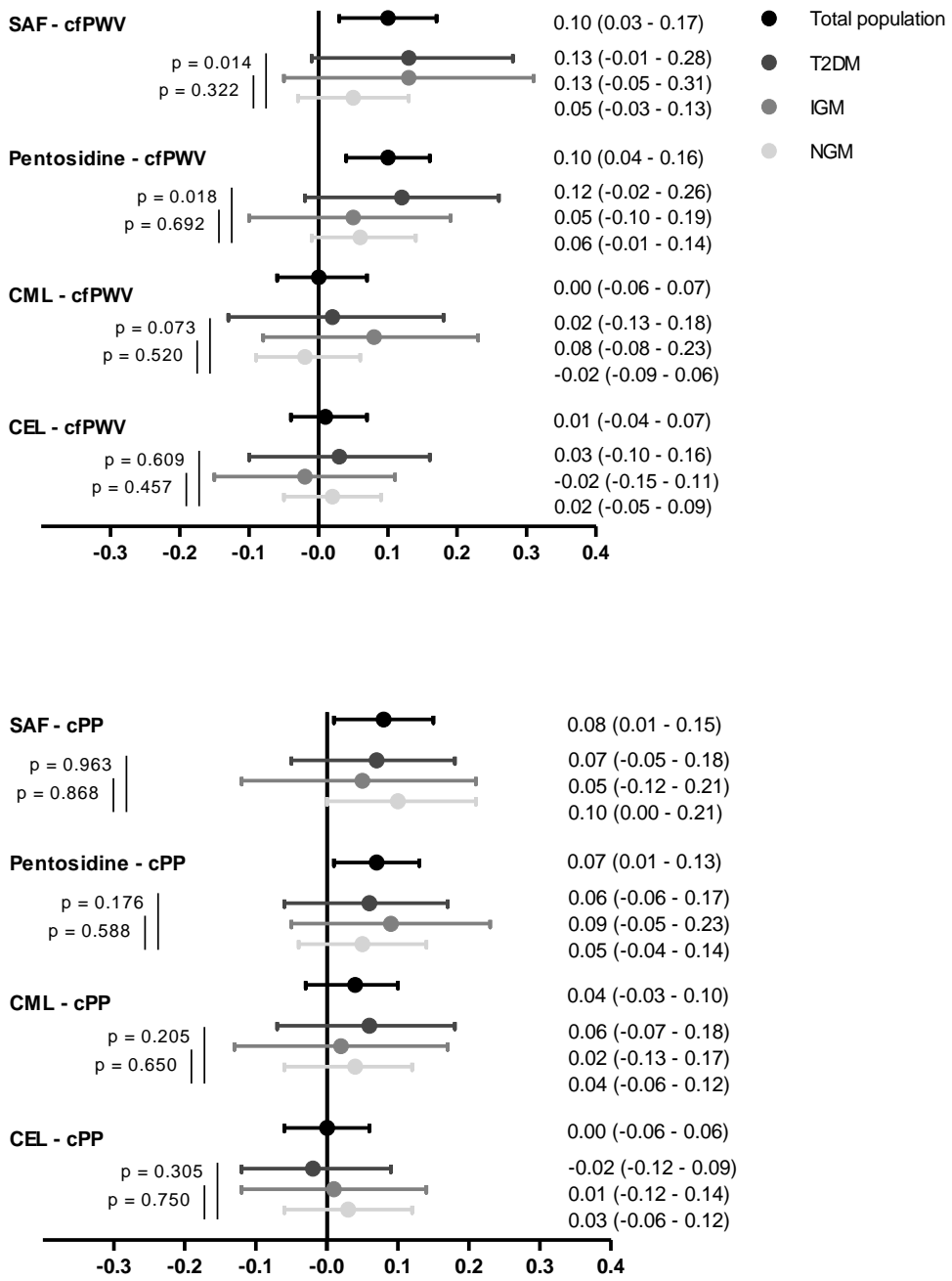

Data are presented as standardized $\beta(s \beta)$ and $95 \%$-confidence interval. $s \beta$ is the standardized regression coefficient obtained with linear regression analyses, which indicates the change in carotid to femoral pulse wave velocity (cfPWV) or central pulse pressure (CPP) in SD per 1 SD higher skin autofluorescence (SAF), level of plasma pentosidine, plasma CML or plasma CEL in the total population, individuals with normal glucose metabolism (NGM), impaired glucose metabolism (IGM) or type 2 diabetes (T2DM). The presented $s \beta^{\prime} s$ are adjusted for age and sex, average mean arterial pressure and heart rate, waist circumference, smoking, antihypertensive and lipid-modifying and diabetes medication use, eGFR, total-to-HDLcholesterol ratio, triglycerides and a history of cardiovascular disease. The displayed p-values indicate the significance of interaction of glucose metabolism status in these associations. 
Table 4.2. Associations between measures of AGE accumulation and cfPWV or cPP

\begin{tabular}{|c|c|c|c|c|c|c|c|}
\hline & \multirow[b]{2}{*}{ Model } & \multicolumn{3}{|c|}{$\begin{array}{l}\text { Carotid to femoral } \\
\text { pulse wave velocity }\end{array}$} & \multicolumn{3}{|c|}{ Central pulse pressure } \\
\hline & & $\boldsymbol{s \beta}$ & $95 \% C I$ & p-value & $s \beta$ & $95 \% C I$ & $p$-value \\
\hline \multirow[t]{3}{*}{ SAF } & 1 & 0.10 & $0.03-0.17$ & 0.006 & 0.06 & $-0.02-0.14$ & 0.114 \\
\hline & 2 & 0.11 & $0.05-0.17$ & 0.001 & 0.07 & $0.00-0.14$ & 0.050 \\
\hline & 3 & 0.10 & $0.03-0.17$ & 0.004 & 0.08 & $0.01-0.15$ & 0.018 \\
\hline \multirow[t]{3}{*}{ Plasma pentosidine } & 1 & 0.08 & $0.02-0.15$ & 0.011 & 0.09 & $0.03-0.16$ & 0.007 \\
\hline & 2 & 0.08 & $0.02-0.14$ & 0.005 & 0.09 & $0.03-0.15$ & 0.003 \\
\hline & 3 & 0.10 & $0.04-0.16$ & 0.002 & 0.07 & $0.01-0.13$ & 0.025 \\
\hline \multirow[t]{3}{*}{ Plasma CML } & 1 & -0.01 & $-0.07-0.06$ & 0.870 & 0.05 & $-0.02-0.12$ & 0.135 \\
\hline & 2 & 0.00 & $-0.06-0.06$ & 0.928 & 0.06 & $0.00-0.12$ & 0.062 \\
\hline & 3 & 0.00 & $-0.06-0.07$ & 0.895 & 0.04 & $-0.03-0.10$ & 0.281 \\
\hline \multirow[t]{3}{*}{ Plasma CEL } & 1 & 0.03 & $-0.04-0.09$ & 0.393 & -0.02 & $-0.09-0.05$ & 0.561 \\
\hline & 2 & 0.03 & $-0.03-0.08$ & 0.348 & -0.02 & $-0.08-0.04$ & 0.556 \\
\hline & 3 & 0.01 & $-0.04-0.07$ & 0.643 & 0.00 & $-0.06-0.06$ & 0.932 \\
\hline
\end{tabular}

Standardized $\beta$, the standardized regression coefficient obtained with linear regression analyses, indicates the change in carotid to femoral pulse wave velocity (cfPWV) or central pulse pressure (cPP) (in SD) per 1 SD higher skin autofluorescence (SAF) or level of plasma advanced glycation endproducts, i.e. plasma pentosidine, CML (N(epsilon)-(carboxymethyl)lysine) and CEL (N(epsilon)-(carboxyethyl)lysine).

Model 1 is adjusted for age, sex and glucose metabolism status. Model 2 is additionally adjusted for average mean arterial pressure. Model 3 is additionally adjusted for average heart rate, waist circumference, smoking, antihypertensive and lipidmodifying and diabetes medication use, eGFR, total-to-HDL-cholesterol ratio, triglycerides and a history of cardiovascular disease.

There were 740 individuals (414 with NGM, 122 with IGM and 203 with T2DM) included in the analyses between SAF and cfPWV, 752 individuals (417 with NGM, 122 with IGM and 208 with T2DM) in the analyses between plasma AGEs and cfPWV, 726 individuals (401 with NGM, 127 with IGM and 208 with T2DM) included in the analyses between SAF and cPP and 739 (405 with NGM, 127 with IGM and 207 with T2DM) individuals in the analyses between plasma AGEs and cPP. 


\section{Supplementary Table 4.2. Associations between measures of AGE accumulation and aPP}

\begin{tabular}{|c|c|c|c|c|}
\hline & \multirow[b]{2}{*}{ Model } & \multicolumn{3}{|c|}{$\begin{array}{c}\text { Ambulatory } \\
\text { 24-hour pulse pressure }\end{array}$} \\
\hline & & $s \boldsymbol{\beta}$ & $95 \% C I$ & $p$-value \\
\hline \multirow[t]{3}{*}{ SAF } & 1 & 0.05 & $-0.02-0.13$ & 0.160 \\
\hline & 2 & 0.06 & $-0.01-0.12$ & 0.079 \\
\hline & 3 & 0.06 & $-0.01-0.12$ & 0.085 \\
\hline \multirow[t]{3}{*}{ Plasma pentosidine } & 1 & 0.07 & $0.00-0.13$ & 0.043 \\
\hline & 2 & 0.06 & $0.01-0.12$ & 0.033 \\
\hline & 3 & 0.05 & $-0.01-0.11$ & 0.089 \\
\hline \multirow[t]{3}{*}{ Plasma CML } & 1 & 0.05 & $-0.01-0.12$ & 0.102 \\
\hline & 2 & 0.07 & $0.01-0.13$ & 0.016 \\
\hline & 3 & 0.06 & $-0.01-0.12$ & 0.078 \\
\hline \multirow[t]{3}{*}{ Plasma CEL } & 1 & 0.01 & $-0.05-0.08$ & 0.661 \\
\hline & 2 & 0.01 & $-0.05-0.07$ & 0.771 \\
\hline & 3 & 0.03 & $-0.03-0.09$ & 0.304 \\
\hline
\end{tabular}

Standardized $\beta$, the standardized regression coefficient obtained with linear regression analyses, indicates the change in 24hour ambulatory pulse pressure (aPP) (in SD) per 1 SD higher skin autofluorescence (SAF) or level of plasma advanced glycation endproducts, i.e. plasma pentosidine, CML (N(epsilon)-(carboxymethyl)lysine) and CEL (N(epsilon)(carboxyethyl)lysine).

Model 1 is adjusted for age, sex and glucose metabolism status. Model 2 is additionally adjusted for average mean arterial pressure*. Model 3 is additionally adjusted for average heart rate*, waist circumference, smoking, antihypertensive, lipidmodifying and diabetes medication use, eGFR, total-to-HDL-cholesterol ratio, triglycerides and a history of cardiovascular disease.

There were 696 individuals ( 389 with NGM, 114 with IGM and 193 with T2DM) included in the analyses between SAF and aPP, and 712 individuals (394 with NGM, 119 with IGM and 199 with T2DM) in the analyses between plasma AGEs and aPP. * In analyses with aPP, average mean arterial pressure and heart rate obtained from 24-hour ambulatory blood pressure measurement were used in Model 2 and 3. 
Supplementary Figure 4.1. Associations between measures of AGE accumulation and measures of arterial stiffness in the total population and in the population without prior cardiovascular disease

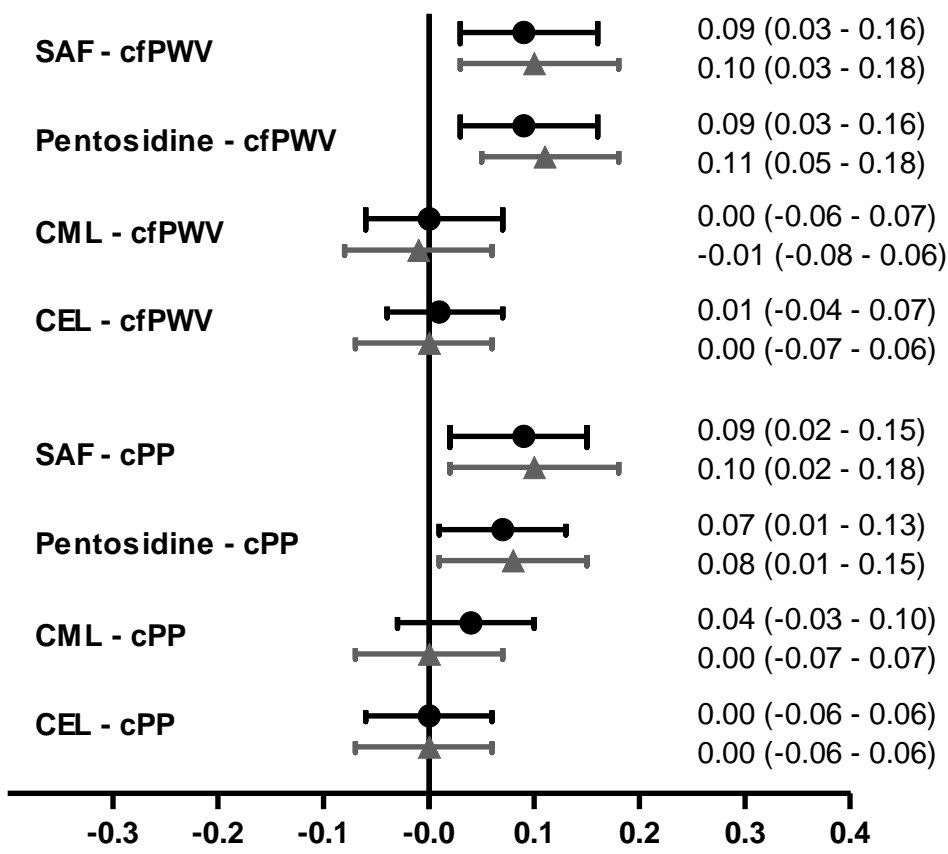

- Total population

$\Delta \quad$ Population w ithout CVD

Data are presented as standardized $\beta(\mathrm{s} \beta)$ and $95 \%$-confidence interval. $s \beta$ is the standardized regression coefficient obtained with linear regression analyses, which indicates the change in carotid to femoral pulse wave velocity (cfPWV) or central pulse pressure (CPP) (in SD) per 1 SD higher skin autofluorescence (SAF) or level of plasma pentosidine. The presented $s \beta^{\prime} s$ are adjusted for age, sex, glucose metabolism status, average mean arterial pressure and heart rate, waist circumference, smoking, antihypertensive and lipid-modifying medication use, eGFR, total-to-HDL-cholesterol ratio and triglycerides.

For the analyses in the total population, there were 740 individuals included in the analyses between SAF and cfPWV, 752 individuals in the analyses between plasma AGEs and cfPWV, 726 individuals in the analyses between SAF and CPP and 739 in the analyses between plasma AGEs and CPP. For the analyses in the population without prior CVD, there were 611 individuals included in the analyses between SAF and cfPWV, 622 individuals in the analyses between plasma AGEs and cfPWV, 599 individuals in the analyses between SAF and CPP, and 611 individuals in the analyses between plasma AGEs and cPP. 
Supplementary Table 4.3. Associations between measures of AGE accumulation and measures of arterial stiffness with and without additional adjustment for peripheral sensory neuropathy and albuminuria

\begin{tabular}{|c|c|c|c|c|c|c|c|}
\hline & \multirow[b]{2}{*}{ Model } & \multicolumn{3}{|c|}{$\begin{array}{l}\text { Carotid to femoral } \\
\text { pulse wave velocity }\end{array}$} & \multicolumn{3}{|c|}{ Central pulse pressure } \\
\hline & & $s \beta$ & $95 \% C I$ & p-value & $s \beta$ & $95 \% C I$ & p-value \\
\hline \multirow[t]{2}{*}{ SAF } & 1 & 0.09 & $0.02-0.17$ & 0.017 & 0.10 & $0.02-0.18$ & 0.015 \\
\hline & 2 & 0.09 & $0.02-0.17$ & 0.017 & 0.10 & $0.02-0.19$ & 0.013 \\
\hline \multirow[t]{2}{*}{ Plasma pentosidine } & 1 & 0.05 & $-0.02-0.13$ & 0.139 & 0.09 & $0.02-0.17$ & 0.015 \\
\hline & 2 & 0.06 & $-0.02-0.13$ & 0.127 & 0.09 & $0.02-0.17$ & 0.013 \\
\hline \multirow[t]{2}{*}{ Plasma CML } & 1 & 0.01 & $-0.07-0.08$ & 0.827 & 0.05 & $-0.03-0.12$ & 0.244 \\
\hline & 2 & 0.01 & $-0.06-0.08$ & 0.827 & 0.05 & $-0.03-0.12$ & 0.237 \\
\hline \multirow[t]{2}{*}{ Plasma CEL } & 1 & 0.02 & $-0.04-0.09$ & 0.512 & 0.02 & $-0.05-0.09$ & 0.526 \\
\hline & 2 & 0.02 & $-0.04-0.09$ & 0.498 & 0.02 & $-0.05-0.09$ & 0.521 \\
\hline
\end{tabular}

Standardized $\beta$, the standardized regression coefficient obtained with linear regression analyses, indicates the change in carotid to femoral pulse wave velocity (cfPWV) or central pulse pressure (CPP) (in SD) per 1 SD higher skin autofluorescence (SAF) or level of plasma advanced glycation endproducts, i.e. plasma pentosidine, CML (N(epsilon)-(carboxymethyl)lysine) and CEL (N(epsilon)-(carboxyethyl)lysine).

Model 1 is adjusted for age, sex and glucose metabolism status, average mean arterial pressure, average heart rate, waist circumference, smoking, antihypertensive and lipid-lowering medication use, eGFR, total-to-HDL-cholesterol ratio, triglycerides and a history of cardiovascular disease. Model 2 is additionally adjusted for peripheral sensory neuropathy (PSN) and albuminuria.

There were 547 individuals included in the analyses between SAF and CPPW, 555 individuals in the analyses between plasma AGEs and cfPWV, 536 individuals in the analyses between SAF and cPP, and 545 individuals in the analyses between plasma AGEs and cPP. 


\section{DISCUSSION}

This study had three main findings. First, we found that higher SAF and plasma pentosidine were independently associated with higher cfPWV and cPP. Second, in analyses stratified for glucose metabolism status, we found that the associations between SAF and plasma pentosidine on the one hand, and cfPWV on the other were more pronounced in individuals with T2DM.

This is the first population-based study that describes an association between SAF and measures of aortic stiffening in individuals with NGM, IGM and T2DM. Our results are in agreement with previous studies which demonstrated that skin AGEs are associated with arterial stiffening in T1DM 16 , heart disease ${ }^{10}$, end-stage renal disease ${ }^{11}$ and in the elderly ${ }^{12}, 19$. We found relatively small standardized regression coefficients in these associations. In comparison, $\mathrm{s} \beta \mathrm{s}$ and $95 \%$-CIs of the associations between MAP and age on the one hand and CFPWV on the other were $0.37(0.31$ 0.43 ) and 0.31 (0.24-0.38), respectively, in our study. However, the fact that these coefficients were statistically significant suggests that the association between the different measures of AGEs and measures of arterial stiffness, albeit small, indeed reflect a true association between AGE accumulation and aortic stiffening. In fact, the effect size on an association does not necessarily reflect the biological importance of the pathophysiological process. Therefore, these results provide us with more insight into the pathophysiology of arterial stiffening, and the possible role of AGEs herein.

AGEs are thought to affect vascular tissue via distinct pathways. First, certain AGEs, e.g. pentosidine, are able to form cross-links between extracellular matrix proteins such as collagen in the arterial wall, which may directly result in a decrease in vascular elasticity and an increase in arterial stiffening $8,13,39$. Second, other AGEs, e.g. CEL, are able to affect cell function via intracellular glycation of proteins, altering the function of these proteins ${ }^{9}$, e.g. leading to the quenching of nitric oxide resulting in increased smooth muscle cell tone, which contributes to arterial stiffening ${ }^{40}$. Third, some AGEs, e.g. CML, are known to bind to the receptor for AGEs (RAGE), inducing receptor-mediated cell activation and low-grade inflammation ${ }^{41}$, 42 , which in its turn may promote arterial stiffening via e.g. MMPs, endothelial dysfunction that elevates smooth muscle tone, and a reduction of endothelial flow-mediated dilation ${ }^{40}$. In addition to an association between SAF and measures of aortic stiffening, we found a positive association between plasma pentosidine and aortic stiffening. One previous study found no association between serum pentosidine and heart-brachial PWV or brachial-ankle PWV after adjustment for renal function ${ }^{15}$. However, this was based on a small case-control study. Next, we found no association between plasma CML and CEL and cfPWV or CPP. This is in contrast with other studies that demonstrated an association between the plasma AGEs, CML and CEL, and arterial stiffening in other populations $13,14,17-19$. In the case of CML, it has very recently been described that the trapping of CML by the receptor for AGEs (RAGE) in adipose tissue causes a decrease in AGE plasma levels in individuals with T2DM ${ }^{43}$. Therefore, plasma CML may not be a good reflection of CML accumulation in tissues in individuals with T2DM. This may explain why we did not find an association between plasma CML and aortic stiffening in our population. We do not have a clear explanation why we found no association between CEL and aortic stiffening, while others, in different populations, did. Since we only found an association between plasma pentosidine and cfPWV and CPP, this could indicate that cross-linking of AGEs, and not, or to a lesser extent intracellular glycation or RAGE activation, 
is the predominant pathway through which AGEs lead to aortic stiffening in T2DM. However, we cannot exclude the possibility that plasma pentosidine is simply a better reflection of the detrimental effects of AGEs on the vessel wall in general. Taken together, the results of our study combined with previous research support the hypothesis that AGE accumulation, and in particular AGE cross-linking, may play a role in the development of arterial stiffening in individuals with NGM, IGM and T2DM.

We found non-significant positive associations between SAF, plasma pentosidine and CML on the one hand and aPP on the other. These results may be explained by the fact that CPPW, as the 'gold standard' measurement of aortic stiffening ${ }^{28}$, and CPP are more precise markers of arterial stiffening compared with aPP.

The associations between both SAF and pentosidine on the one hand and CfPWV on the other were more pronounced in individuals with T2DM. Additionally, the association between SAF and cfPWV was also more pronounced in individuals with IGM. This could be caused by the fact that in individuals with higher AGE levels, there is not only more crosslinking, but also more RAGE activation with subsequent low-grade inflammation, and more intracellular glycation. As discussed above, these mechanisms could both lead to a further increase in arterial stiffening. Additionally, we cannot exclude the possibility that for individuals with NGM, having less variation in AGE accumulation and arterial stiffening compared with individuals with T2DM, it is more difficult to find an association between the two. We excluded the possibility that the inclusion of individuals with prior CVD or microvascular disease influenced our findings, by repeating analyses in individuals without CVD only, and by adjusting for markers of microvascular disease, after which we found similar results.

When we additionally adjust the association between SAF and plasma AGEs on the one hand, and cfPWV on the other for fasting glucose level, we find smaller $s \beta$ ( $s \beta 0.06,95 \%-C I-0.01-0.14$ for $\mathrm{SAF}$, and $\mathrm{s} \beta 0.05,95 \%-\mathrm{CI}-0.02-0.11$ for pentosidine) and associations were no longer significant. This could mean that part of the association between AGE measurements and arterial stiffening is explained by a difference in glucose levels between GMS groups. Another explanation for these findings is that glucose is a marker in the same pathway as SAF and AGEs, which causes the regression coefficient to diminish.

For this study, we used both SAF, an estimate of skin AGEs, and protein-bound AGEs in plasma to serve as a reflection of tissue AGEs. SAF is thought to reflect AGE accumulation and AGE crosslinking in the extracellular matrix of the vessel mall more accurately than plasma proteins, as plasma AGE levels are determined to a large extent by the half-life of plasma proteins, which is significantly shorter than the half-life of long-lived proteins in the skin and in vascular tissue ${ }^{44}$. The fact that we found an association between SAF and aortic stiffening, and not between plasma CML or CEL and aortic stiffening further supports this hypothesis, at least for plasma CML and CEL.

As AGE accumulation may be involved in the development of arterial stiffening and CVD in individuals with T2DM, AGE-lowering therapies may decrease the risk of CVD in individuals with T2DM. One of the well-studied potential anti-AGE therapies is the cross-link breaker alagebrium 
(ALT-711). Indeed, it has been shown that alagebrium is able to reduce large artery stiffening in animal models ${ }^{45}$. One double-blind RCT correspondingly showed a decrease in pulse pressure and cfPWV in individuals who received alagebrium ${ }^{46}$. However, another double-blind RCT showed no treatment effects on cardiac function and exercise tolerance ${ }^{47 .}$

Strengths of this study include the large and well-characterised samples, the assessment of aortic stiffening and the use of state-of-the art techniques to measure multiple markers of glycation endproducts. Limitations of the study include, first, this cross-sectional design of the study; therefore, we cannot draw any conclusions about causality in the association between AGE accumulation and aortic stiffening. Second, by stratifying for glucose metabolism status, we performed analyses in a smaller number of individuals, especially in the IGM group, which diminishes the power to detect an association. Third, as stated previously, we do not know if and to what extent the different plasma AGEs reflect specific pathophysiological pathways, i.e. crosslinking, intracellular protein glycation or RAGE activation, or are merely a reflection of AGE formation and vascular damage in general.

\section{Perspectives}

Arterial stiffening increases the risk of cardiovascular disease, especially among individuals with type 2 diabetes mellitus. We demonstrate that higher levels of SAF, plasma pentosidine and plasma CML were associated with more aortic stiffening and that associations for CPPWV were more pronounced in individuals with T2DM. These results support the hypothesis that AGE accumulation is involved in arterial stiffening in general, and, moreover, the accelerated arterial stiffening in individuals with T2DM. Prospective studies are needed. Assuming causality between AGEs and arterial stiffness, interference in the pathways of AGE accumulation might influence the development and progression of arterial stiffening, in particular in individuals with T2DM. Therefore, more large, specific and well-designed studies are needed to elucidate their potential effect in humans, in particular individuals with T2DM. 


\section{REFERENCES}

1. Vlachopoulos C, Aznaouridis K, Stefanadis C. Prediction of cardiovascular events and all-cause mortality with arterial stiffness: A systematic review and meta-analysis. J Am Coll Cardiol. 2010;55:1318-1327

2. Laurent S, Boutouyrie P, Asmar R, Gautier I, Laloux B, Guize L, Ducimetiere P, Benetos A. Aortic stiffness is an independent predictor of all-cause and cardiovascular mortality in hypertensive patients. Hypertension. 2001;37:12361241

3. Sutton-Tyrrell K, Najjar SS, Boudreau RM, Venkitachalam L, Kupelian V, Simonsick EM, Havlik R, Lakatta EG, Spurgeon H, Kritchevsky S, Pahor M, Bauer D, Newman A. Elevated aortic pulse wave velocity, a marker of arterial stiffness, predicts cardiovascular events in well-functioning older adults. Circulation. 2005;111:3384-3390

4. Willum-Hansen T, Staessen JA, Torp-Pedersen C, Rasmussen S, Thijs L, Ibsen H, Jeppesen J. Prognostic value of aortic pulse wave velocity as index of arterial stiffness in the general population. Circulation. 2006;113:664-670

5. Cruickshank K, Riste L, Anderson SG, Wright JS, Dunn G, Gosling RG. Aortic pulse-wave velocity and its relationship to mortality in diabetes and glucose intolerance: An integrated index of vascular function? Circulation. 2002;106:20852090

6. Cameron JD, Bulpitt CJ, Pinto ES, Rajkumar C. The aging of elastic and muscular arteries: A comparison of diabetic and nondiabetic subjects. Diabetes Care. 2003;26:2133-2138

7. Schram MT, Kostense PJ, Van Dijk RA, Dekker JM, Nijpels G, Bouter LM, Heine RJ, Stehouwer CD. Diabetes, pulse pressure and cardiovascular mortality: The hoorn study. J Hypertens. 2002;20:1743-1751

8. Sell DR, Monnier VM. Molecular basis of arterial stiffening: Role of glycation - a mini-review. Gerontology. 2012;58:227237

9. Brownlee M. Biochemistry and molecular cell biology of diabetic complications. Nature. 2001;414:813-820

10. Hofmann B, Adam AC, Jacobs K, Riemer M, Erbs C, Bushnaq H, Simm A, Silber RE, Santos AN. Advanced glycation end product associated skin autofluorescence: A mirror of vascular function? Exp Gerontol. 2013;48:38-44

11. Ueno H, Koyama H, Tanaka S, Fukumoto S, Shinohara K, Shoji T, Emoto M, Tahara H, Kakiya R, Tabata T, Miyata T, Nishizawa Y. Skin autofluorescence, a marker for advanced glycation end product accumulation, is associated with arterial stiffness in patients with end-stage renal disease. Metabolism. 2008;57:1452-1457

12. Watfa G, Soulis G, Tartagni E, Kearney-Schwartz A, Borghi C, Salvi P, Benetos A. Relationship between tissue glycation measured by autofluorescence and pulse wave velocity in young and elderly non-diabetic populations. Diabetes Metab. 2012;38:413-419

13. McNulty M, Mahmud A, Feely J. Advanced glycation end-products and arterial stiffness in hypertension. American journal of hypertension. 2007;20:242-247

14. Semba RD, Najjar SS, Sun K, Lakatta EG, Ferrucci L. Serum carboxymethyl-lysine, an advanced glycation end product, is associated with increased aortic pulse wave velocity in adults. American journal of hypertension. 2009;22:74-79

15. Yoshida N, Okumura K, Aso Y. High serum pentosidine concentrations are associated with increased arterial stiffness and thickness in patients with type 2 diabetes. Metabolism. 2005;54:345-350

16. Monnier VM, Vishwanath V, Frank KE, Elmets CA, Dauchot P, Kohn RR. Relation between complications of type i diabetes mellitus and collagen-linked fluorescence. N Engl J Med. 1986;314:403-408

17. Schram MT, Schalkwijk CG, Bootsma AH, Fuller JH, Chaturvedi N, Stehouwer CD. Advanced glycation end products are associated with pulse pressure in type 1 diabetes: The eurodiab prospective complications study. Hypertension. 2005; 46:232-237

18. Sourris KC, Lyons JG, Dougherty SL, Chand V, Straznicky NE, Schlaich MP, Grima MT, Cooper ME, Kingwell BA, de Courten MP, Forbes JM, de Courten B. Plasma advanced glycation end products (ages) and nf-kappab activity are independent determinants of diastolic and pulse pressure. Clin Chem Lab Med. 2013:1-10

19. Semba RD, Sun K, Schwartz AV, Varadhan R, Harris TB, Satterfield S, Garcia M, Ferrucci L, Newman AB. Serum carboxymethyl-lysine, an advanced glycation end product, is associated with arterial stiffness in older adults. J Hypertens. 2015;33:797-803; discussion 803

20. Llaurado G, Ceperuelo-Mallafre V, Vilardell C, Simo R, Gil P, Cano A, Vendrell J, Gonzalez-Clemente JM. Advanced glycation end products are associated with arterial stiffness in type 1 diabetes. J Endocrinol. 2014;221:405-413

21. Meerwaldt R, Graaff R, Oomen PH, Links TP, Jager JJ, Alderson NL, Thorpe SR, Baynes JW, Gans RO, Smit AJ. Simple non-invasive assessment of advanced glycation endproduct accumulation. Diabetologia. 2004;47:1324-1330

22. Schram MT, Sep SJ, van der Kallen CJ, Dagnelie PC, Koster A, Schaper N, Henry RM, Stehouwer CD. The maastricht study: An extensive phenotyping study on determinants of type 2 diabetes, its complications and its comorbidities. Eur J Epidemiol. 2014;29:439-451

23. Koetsier M, Nur E, Chunmao H, Lutgers HL, Links TP, Smit AJ, Rakhorst G, Graaff R. Skin color independent assessment of aging using skin autofluorescence. Opt Express. 2010;18:14416-14429 
24. Scheijen JL, van de Waarenburg MP, Stehouwer CD, Schalkwijk CG. Measurement of pentosidine in human plasma protein by a single-column high-performance liquid chromatography method with fluorescence detection. J Chromatogr B Analyt Technol Biomed Life Sci. 2009;877:610-614

25. Hanssen NM, Engelen L, Ferreira I, Scheijen JL, Huijberts MS, van Greevenbroek MM, van der Kallen CJ, Dekker JM, Nijpels G, Stehouwer CD, Schalkwijk CG. Plasma levels of advanced glycation endproducts n\{epsilon\}(carboxymethyl)lysine, n\{epsilon\}-(carboxyethyl)lysine, and pentosidine are not independently associated with cardiovascular disease in individuals with or without type 2 diabetes: The hoorn and codam studies. J Clin Endocrinol Metab. 2013;98:E1369-1373

26. van Sloten TT, Czernichow S, Houben AJ, Protogerou AD, Henry RM, Muris DM, Schram MT, Sep SJ, Dagnelie PC, van der Kallen CJ, Schaper NC, Blacher J, Hercberg S, Levy BI, Stehouwer CD. Association between arterial stiffness and skin microvascular function: The suvimax2 study and the maastricht study. American journal of hypertension. 2015;28:868-876

27. Van Bortel LM, Laurent S, Boutouyrie P, Chowienczyk P, Cruickshank JK, De Backer T, Filipovsky J, Huybrechts S, Mattace-Raso FU, Protogerou AD, Schillaci G, Segers P, Vermeersch S, Weber T. Expert consensus document on the measurement of aortic stiffness in daily practice using carotid-femoral pulse wave velocity. J Hypertens. 2012;30:445448

28. Laurent S, Cockcroft J, Van Bortel L, Boutouyrie P, Giannattasio C, Hayoz D, Pannier B, Vlachopoulos C, Wilkinson I, Struijker-Boudier H. Expert consensus document on arterial stiffness: Methodological issues and clinical applications. European heart journal. 2006;27:2588-2605

29. (WHO) WHO. Definition and diagnosis of diabetes mellitus and intermediate hyperglycemia: Report of a who/idf consultation. Geneva, Switzerland: World Health Organization (WHO); 2006.

30. O'Brien E, Coats A, Owens P, Petrie J, Padfield PL, Littler WA, de Swiet M, Mee F. Use and interpretation of ambulatory blood pressure monitoring: Recommendations of the british hypertension society. Bmj. 2000;320:1128-1134

31. Meaney E, Alva F, Moguel R, Meaney A, Alva J, Webel R. Formula and nomogram for the sphygmomanometric calculation of the mean arterial pressure. Heart. 2000;84:64

32. Mancia G, Fagard R, Narkiewicz K, Redon J, Zanchetti A, Bohm M, Christiaens T, Cifkova R, De Backer G, Dominiczak A, Galderisi M, Grobbee DE, Jaarsma T, Kirchhof P, Kjeldsen SE, Laurent S, Manolis AJ, Nilsson PM, Ruilope LM, Schmieder RE, Sirnes PA, Sleight P, Viigimaa M, Waeber B, Zannad F, Burnier M, Ambrosioni E, Caufield M, Coca A, Olsen $\mathrm{MH}$, Tsioufis $\mathrm{C}$, van de Borne $\mathrm{P}$, Zamorano JL, Achenbach S, Baumgartner H, Bax JJ, Bueno H, Dean V, Deaton C, Erol C, Ferrari R, Hasdai D, Hoes AW, Knuuti J, Kolh P, Lancellotti P, Linhart A, Nihoyannopoulos P, Piepoli MF, Ponikowski P, Tamargo JL, Tendera M, Torbicki A, Wijns W, Windecker S, Clement DL, Gillebert TC, Rosei EA, Anker SD, Bauersachs J, Hitij JB, Caulfield M, De Buyzere M, De Geest S, Derumeaux GA, Erdine S, Farsang C, Funck-Brentano C, Gerc V, Germano G, Gielen S, Haller H, Jordan J, Kahan T, Komajda M, Lovic D, Mahrholdt H, Ostergren J, Parati G, Perk J, Polonia J, Popescu BA, Reiner Z, Ryden L, Sirenko Y, Stanton A, Struijker-Boudier H, Vlachopoulos C, Volpe M, Wood DA. 2013 esh/esc guidelines for the management of arterial hypertension: The task force for the management of arterial hypertension of the european society of hypertension (esh) and of the european society of cardiology (esc). European heart journal. 2013;34:2159-2219

33. Boulton AJ, Malik RA, Arezzo JC, Sosenko JM. Diabetic somatic neuropathies. Diabetes Care. 2004;27:1458-1486

34. Karvestedt L, Martensson E, Grill V, Elofsson S, von Wendt G, Hamsten A, Brismar K. Peripheral sensory neuropathy associates with micro- or macroangiopathy: Results from a population-based study of type 2 diabetic patients in sweden. Diabetes Care. 2009;32:317-322

35. K/doqi clinical practice guidelines for chronic kidney disease: Evaluation, classification, and stratification. Am J Kidney Dis. 2002;39:S1-266

36. Friedewald WT, Levy RI, Fredrickson DS. Estimation of the concentration of low-density lipoprotein cholesterol in plasma, without use of the preparative ultracentrifuge. Clin Chem. 1972;18:499-502

37. Levey AS, Stevens LA, Schmid CH, Zhang YL, Castro AF, 3rd, Feldman HI, Kusek JW, Eggers P, Van Lente F, Greene T, Coresh J. A new equation to estimate glomerular filtration rate. Ann Intern Med. 2009;150:604-612

38. Leng GC, Fowkes FG. The edinburgh claudication questionnaire: An improved version of the who/rose questionnaire for use in epidemiological surveys. J Clin Epidemiol. 1992;45:1101-1109

39. Aronson D. Cross-linking of glycated collagen in the pathogenesis of arterial and myocardial stiffening of aging and diabetes. J Hypertens. 2003;21:3-12

40. Zieman SJ, Melenovsky V, Kass DA. Mechanisms, pathophysiology, and therapy of arterial stiffness. Arterioscler Thromb Vasc Biol. 2005;25:932-943

41. Basta G, Lazzerini G, Massaro M, Simoncini T, Tanganelli P, Fu C, Kislinger T, Stern DM, Schmidt AM, De Caterina R. Advanced glycation end products activate endothelium through signal-transduction receptor rage: A mechanism for amplification of inflammatory responses. Circulation. 2002;105:816-822

42. Bierhaus A, Humpert PM, Stern DM, Arnold B, Nawroth PP. Advanced glycation end product receptor-mediated cellular dysfunction. Ann N Y Acad Sci. 2005;1043:676-680 
43. Gaens KH, Stehouwer CD, Schalkwijk CG. Advanced glycation endproducts and its receptor for advanced glycation endproducts in obesity. Curr Opin Lipidol. 2013;24:4-11

44. Smit AJ, Hartog JW, Voors AA, van Veldhuisen DJ. Advanced glycation endproducts in chronic heart failure. Ann N Y Acad Sci. 2008;1126:225-230

45. Engelen L, Stehouwer CD, Schalkwijk CG. Current therapeutic interventions in the glycation pathway: Evidence from clinical studies. Diabetes Obes Metab. 2012

46. Kass DA, Shapiro EP, Kawaguchi M, Capriotti AR, Scuteri A, deGroof RC, Lakatta EG. Improved arterial compliance by a novel advanced glycation end-product crosslink breaker. Circulation. 2001;104:1464-1470

47. Hartog JW, Willemsen S, van Veldhuisen DJ, Posma JL, van Wijk LM, Hummel YM, Hillege HL, Voors AA. Effects of alagebrium, an advanced glycation endproduct breaker, on exercise tolerance and cardiac function in patients with chronic heart failure. Eur J Heart Fail. 2011;13:899-908 



\section{CHAPTER 5}

Skin autofluorescence, but not plasma AGEs, is positively associated with markers of endothelial dysfunction The Maastricht Study

Marcelle G.A. van Eupen, Miranda T. Schram, Jean Scheijen, Simone JS Sep, Carla J van der Kallen, Pieter C Dagnelie, Annemarie Koster, Nicolaas Schaper, Ronald MA Henry, Andries J Smit, Coen DA Stehouwer, Casper G Schalkwijk 


\section{ABSTRACT}

\section{Background}

Advanced glycation endproducts (AGEs) are thought to play a role in the development of cardiovascular complications of type 2 diabetes mellitus (T2DM), possibly through the induction of endothelial dysfunction (ED) and low-grade inflammation (LGI). Therefore, we investigated the association between skin autofluorescence (SAF) and plasma AGEs, and markers of ED and LGI in individuals with normal glucose metabolism (NGM), impaired glucose metabolism (IGM) and T2DM.

\section{Methods}

We studied a cohort of 862 individuals from The Maastricht Study (469 NGM, 140 IGM and 253 T2DM) with mean age of $60 y$ and $45 \%$ females. SAF was measured by use of the AGE Reader. Plasma levels of protein-bound pentosidine were measured with HPLC and fluorescence detection. Plasma protein-bound $\mathrm{N} \varepsilon$-(carboxymethyl)lysine (CML) and $\mathrm{N} \varepsilon$-(carboxyethyl)lysine (CEL) were measured with UPLC and tandem mass spectrometry. Plasma biomarkers of ED (sVCAM-1, SICAM1, sE-selectin, soluble thrombomodulin and vWF) and LGI (CRP, SAA, SICAM-1, IL-6, IL-8 and TNF-a) were measured with immunoassays and combined into a mean z-score for ED and LGI, respectively. Associations were analysed with linear regression analysis and adjusted for age, sex, glucose metabolism status, waist circumference, smoking, systolic and diastolic blood pressure, total/HDL cholesterol, triglycerides, oral antidiabetic, antihypertensive or lipid-modifying medication use, insulin use, eGFR and prior cardiovascular disease.

\section{Results}

Higher SAF was independently associated with the ED z-score ( $s \beta 0.09,95 \%$-CI $0.02 ; 0.17$ ), but only borderline significantly with the LGI z-score ( $s \beta 0.06,95 \%-C I-0.01 ; 0.13)$. In contrast, higher plasma CML was associated with a lower ED z-score (s $\beta-0.10,95 \%-C I-0.17 ;-0.03)$, and higher plasma pentosidine ( $\mathrm{s} \beta-0.09,95 \%-\mathrm{CI}-0.15 ;-0.03)$ and $\mathrm{CML}$ levels $(\mathrm{s} \beta-0.17,95 \%-\mathrm{CI}-0.23 ;-0.10)$ were associated with a lower LGI z-score. Additionally, higher plasma CEL was associated with a lower LGI z-score, but only in individuals with NGM ( $s \beta-0.09,95 \%-C I-0.18 ;-0.01)$ and IGM ( $s \beta$ 0.19 , 95\%-CI -0.33;-0.05).

\section{Conclusions}

These results support the hypothesis that AGE accumulation in vascular tissue is involved in the pathophysiological pathways leading to ED in individuals with and without T2DM. 


\section{INTRODUCTION}

Cardiovascular diseases (CVD) are the number one cause of death globally ${ }^{1}$ : an estimated 17.5 million people died from CVD in 2012, representing $31 \%$ of all global deaths ${ }^{1}$. Thereby, CVD provides a major health burden in modern-time society ${ }^{2}$. Type 2 diabetes mellitus (T2DM) is one of the major risk factors for the development of CVD. This is illustrated by a doubling of the risk of CVD and CVD related mortality in T2DM compared with the general population ${ }^{3,4}$. Although the mechanism(s) by which T2DM leads to an increased CVD risk are incompletely understood, damaging effects of advanced glycation endproducts (AGEs) on vascular tissues are thought to play a major role ${ }^{5}$. AGEs accumulate with natural ageing, and the accumulation of AGEs is known to be accelerated under hyperglycaemic conditions, like T2DM 6,7. We recently demonstrated that plasma AGEs were associated with incident cardiovascular events in individuals with type 2 diabetes in a follow-up study of 10 years ${ }^{8}$.

AGEs are thought to affect vascular tissue through the formation of cross-links between extracellular matrix proteins, through intracellular glycation of proteins and through the binding to the receptor for AGEs (RAGE). AGEs are suggested to lead to an increase in endothelial dysfunction (ED) and low-grade inflammation (LGI) through the expression of adhesion molecules, the generation of pro-inflammatory cytokines and the stimulation of oxidative stress ${ }^{9-17}$. It has become increasingly evident that ED and LGI are closely associated with CVD ${ }^{18-22}$. Therefore, the induction of ED and LGI by AGEs may constitute one of the mechanisms behind the increased risk of CVD in T2DM.

Skin autofluorescence (SAF) has recently emerged as a non-invasive measurement of skin AGEs and is proposed to be a better reflection of tissue AGEs than AGEs measured in plasma ${ }^{23}$. Data on the association between SAF and ED in T2DM are lacking, while SAF has been associated with C-reactive protein (CRP), a marker of LGI, in obesity ${ }^{24}$ and individuals with kidney failure ${ }^{25}$, but not in individuals with T2DM ${ }^{26}$. So far, no study has investigated the association between SAF and multiple plasma AGEs, measured with state-of-the art techniques on the one hand, and multiple markers of ED and LGI on the other in individuals with and without T2DM or impaired glucose metabolism (IGM).

In view of the above, our aim was to evaluate the association between the accumulation of tissue AGEs, estimated by SAF, and plasma AGE measurements on the one hand and markers of ED and LGI on the other, in a population with individuals with normal glucose metabolism, impaired glucose metabolism (IGM) and T2DM. Furthermore, we investigated the association between SAF and plasma AGEs. 


\section{MATERIALS AND METHODS}

\section{Study population and design}

In this study, we used data from The Maastricht Study, an observational prospective populationbased cohort study. The rationale and methodology have been described previously ${ }^{27}$. In brief, the study focuses on the etiology, pathophysiology, complications and comorbidities of type 2 diabetes mellitus (T2DM) and is characterized by an extensive phenotyping approach. Eligible for participation were all individuals aged between 40 and 75 years and living in the southern part of the Netherlands. Participants were recruited through mass media campaigns and from the municipal registries and the regional Diabetes Patient Registry via mailings. Recruitment was stratified according to known T2DM status for reasons of efficiency. The present report includes cross-sectional data from the first 866 participants, who completed the baseline survey between November 2010 and March 2012. The examinations of each participant were performed within a time window of three months. The study has been approved by the institutional medical ethical committee (NL31329.068.10) and the Netherlands Health Council under the Dutch "Law for Population Studies" (Permit 131088-105234-PG). All participants gave written informed consent. From the initial 866 individuals included in this study, we excluded individuals with type 1 diabetes (T1DM) $(n=4)$. Data on SAF were available in 831 individuals, plasma AGEs in 843, markers of ED in 831 and markers of LGI in 843 individuals. Missing data were predominantly caused by technical problems (for $\mathrm{SAF}, \mathrm{n}=31$ ) or problems with blood withdrawal (for EDTA samples, $\mathrm{n}=19$; for citrate samples, $\mathrm{n}=31)$.

\section{Skin autofluorescence (SAF)}

All participants were asked to refrain from smoking and caffeine at least 3 hours before the measurements. A light meal (breakfast and (or) lunch), low in fat content, was allowed. SAF was measured with the AGE Reader ${ }^{\mathrm{TM}}$ (DiagnOptics Technologies BV, Groningen, the Netherlands). The AGE reader is a desktop device that uses the characteristic fluorescent properties of certain AGEs to estimate the level of AGE accumulation in the skin. Technical details of this non-invasive method have been described more extensively elsewhere ${ }^{28}$. In short, the AGE Reader illuminates a skin surface of $4 \mathrm{~cm}^{2}$ guarded against surrounding light, with an excitation wavelength range of $300-420 \mathrm{~nm}$, with a peak excitation of $370 \mathrm{~nm}$. SAF was calculated as the ratio between the emission light from the skin in the wavelength range of 420-600 nm (fluorescence) and excitation light that is reflected by the skin $(300-420 \mathrm{~nm})$, multiplied by 100 and expressed in arbitrary units (AU). Participants were asked not to use any sunscreen or self-browning creams on their lower arms within 2 days before the measurement. SAF was measured at room temperature in a semidark environment while participants were at rest in a seated position. The inner side of the forearm approximately $4 \mathrm{~cm}$ below the elbow fold of a participant was positioned on top of the device, as described by the manufacturer. The mean of three consecutive measurements was used in the analyses. Reproducibility was assessed in 14 individuals without diabetes (6 males; $32.2 \pm 7.1$ years). The intraclass correlation coefficient (ICC) of three intra-individual consecutive SAF measurements was 0.83 (95\% CI 0.65-0.94). SAF was calculated off-line by automated analysis using AGE Reader software, version 2.3, and was observer-independent. There were no significant differences between fasting and non-fasting measurements (mean difference $=0.01 \mathrm{AU}, \mathrm{p}=0.73$ ). Reproducibility in individuals with T2DM has been evaluated previously ${ }^{28}$ with an overall Altman error percentage of $5.03 \%$ for measurements taken over a single day. Skin pigmentation is known 
to influence the measurement of SAF ${ }^{29}$. Therefore, in participants with dark-colored skin with a reflectance of $6-10 \%$, a validated reflectance dependent correction was made by the software ${ }^{29}$. Measurements in participants with dark-colored skin and a mean reflectance below $6 \%$ are considered unreliable and are therefore not used to calculate SAF by the software. Therefore, these participants were automatically excluded $(n=1)$. Additionally, a single SAF value above 10 AU was considered as unreliable; these individual measurements $(n=3)$ were manually excluded and the mean of the remaining two measurements was used in analyses.

\section{Analysis of protein- bound AGEs and lysine in plasma}

Plasma AGEs were measured in EDTA samples obtained from fasting venous blood, which were stored at $-80^{\circ} \mathrm{C}$ until analysis. Protein-bound pentosidine was quantified using HPLC with fluorescence detection, as described in detail elsewhere ${ }^{30}$. Intra- and interassay coefficients of variation (CVs), as analysed in this study, were 6.5 and $7.8 \%$ for pentosidine, respectively. Proteinbound CML, CEL and lysine were quantified using UPLC MS/MS ${ }^{31}$. Intra- and interassay CVs were 4.5 and $6.7 \%$ for CML, 6.2 and $10.3 \%$ for CEL and 5.0 and $5.3 \%$ for lysine. Concentrations of protein-bound pentosidine, CML and CEL were adjusted for levels of lysine and expressed as $\mathrm{nmol} / \mathrm{mmol}$ lysine.

\section{Makers of endothelial dysfunction (ED) and low-grade inflammation (LGI)}

Of the plasma biomarkers of ED (sVCAM-1, sICAM-1, sE-selectin, soluble thrombomodulin and vWF), sVCAM-1, sICAM-1, sE-selectin and soluble thrombomodulin were measured in EDTA plasma samples with commercially available 4-plex sandwich immunoassay kits (Meso Scale Discovery (MSD), Rockville, MD, US). vWf was determined in citrated plasma with sandwich ELISA (Dako, Glostrup, Denmark) ${ }^{32}$. Concentrations of vWf were expressed as a percentage of vWf detected in pooled citrated plasma of healthy volunteers. For this study, the intra- and inter-assay coefficients of variation were $3.5 \%$ and $5.9 \%$ for sVCAM- $1,2.5 \%$ and $5.3 \%$ for sICAM- $1,6.4 \%$ and $6.0 \%$ for sE-selectin, $1.9 \%$ and $4.4 \%$ for soluble thrombomodulin, and $3.2 \%$ and $5.4 \%$ for vWF. Plasma biomarkers of LGI (CRP, SAA, SICAM-1, IL-6, IL-8 and TNF-a) were measured in EDTA plasma samples with commercially available 4-plex sandwich immunoassay kits (Meso Scale Discovery (MSD), Rockville, MD, US). For this study, the intra- and inter-assay coefficients of variation were $3.0 \%$ and $4.7 \%$ for CRP, $2.6 \%$ and $7.5 \%$ for SAA, $2.5 \%$ and $5.3 \%$ for SICAM- 1 , $7.2 \%$ and $12.7 \%$ for IL-6, $3.1 \%$ and $5.6 \%$ for IL-8, and $4.3 \%$ and $7.5 \%$ for TNF-a, respectively.

\section{Glucose metabolism status}

As described previously ${ }^{27}$, to determine glucose metabolism, all participants (except those who used insulin) underwent a standardized 7-point oral glucose tolerance test (OGTT) after an overnight fast. Blood samples were taken at baseline, and at 15, 30, 45, 60, 90 and 120 minutes after ingestion of a $75 \mathrm{~g}$ glucose drink. For safety reasons, participants with a fasting glucose level above $11.0 \mathrm{mmol} / \mathrm{l}$, as determined by a finger prick, did not undergo the OGTT. For these individuals $(n=13)$, fasting glucose level and information about diabetes medication use were used to determine glucose metabolism status. Glucose metabolism was defined according to the WHO 2006 criteria into normal glucose tolerance (NGT), impaired fasting glucose (IFG), impaired glucose tolerance (IGT), and T2DM ${ }^{33}$. For this study, we defined having either IFG or IGT as impaired glucose metabolism (IGM). 


\section{Covariates}

As described previously ${ }^{27}$, fasting venous blood samples were used to assess total cholesterol, LDL and HDL cholesterol, triglycerides, creatinine and HbA1c. Serum total cholesterol, HDL cholesterol, triglycerides, albumin and serum and urine creatinine and uric acid levels were measured with standard (enzymatic and/or colorimetric) methods by an automatic analyzer (Beckman Synchron LX20, Beckman Coulter Inc., Brea, USA). LDL cholesterol was calculated according to the Friedewald formula ${ }^{34}$. Serum creatinine was measured with a Jaffé method traceable to isotope dilution mass spectrometry (Beckman Synchron LX20, Beckman Coulter Inc., Brea, USA). Glomerular filtration rate (eGFR) was estimated using the CKD-EPI (Chronic Kidney Disease Epidemiology Collaboration) equation based on serum creatinine ${ }^{35}$. HbA1c was measured with ion-exchange high performance liquid chromatography (HPLC) (Variant tm II, Bio-Rad, Hercules, California, USA). Urinary albumin was measured with a immunoturbidimetric assay (Cobas c systems, Roche diagnostics, Mannheim, Germany). Waist circumference was measured in duplicate midway between the lower rib margin and the iliac crest at the end of expiration, to the nearest $0.5 \mathrm{~cm}$, with a flexible plastic tape measure (Seca, Hamburg, Germany). Participants were requested to bring all the medication they used at the time of measurement or a list from their pharmacists to the research center. During a medication interview generic name, dose and frequency, and additional over-the-counter (OTC) medication use were registered by trained staff. All participants received extensive web-based questionnaires. Duration of diabetes was assessed by using the year of diagnosis reported in the questionnaire. Smoking status (never, former, current) was based on smoking cigarettes, cigars and/or pipe tobacco. History of cardiovascular disease was assessed with a modified version of the Rose Questionnaire for the diagnosis of ischemic heart pain and intermittent claudication ${ }^{36}$ and defined as self-reported myocardial infarction, and/or cerebrovascular infarction or hemorrhage, and/or percutaneous artery angioplasty of, or vascular surgery on, the coronary arteries, abdominal arteries, peripheral arteries or carotid arteries. Office blood pressure was determined three times on the right arm after a 10-minute rest period, using a non-invasive blood pressure monitor (Omron 705IT, Japan). Hypertension was defined as office systolic blood pressure $\geq 140 \mathrm{mmHg}$, diastolic blood pressure $\geq 90 \mathrm{mmHg}$ and/or the use of antihypertensive medication.

\section{Statistical methods}

Analyses were conducted using SPSS version 21 for Windows. Comparisons of baseline characteristics between groups were made by use of ANOVA or $X^{2}$ tests. Variables with a skewed distribution were $\log _{10}$-transformed before analysis. For reasons of statistical efficiency and to reduce the influence of the biological variability of each measure, an overall z-score was determined for both ED and LGI, according to predefined clusters of conceptually related biomarkers ${ }^{19,37}$. The overall z-scores were calculated as follows: for each individual biomarker, a $z$-score was calculated according to the formula: (individual value/population mean)/population standard deviation. The resulting individual biomarker z-scores were then averaged into an overall z-score for both ED and LGI using the same formula. The ED overall z-score consisted of the biomarkers SVCAM-1, sICAM-1, sE-selectin, soluble thrombomodulin and VWF; and the LGI overall z-score consisted of the biomarkers CRP, SAA, sICAM-1, IL-6, IL-8 and TNF-a. SICAM-1 was included in both overall z-scores, as it is expressed by both monocytes and the endothelium 38 . We used standardized multiple linear regression analysis to evaluate the association between SAF and plasma AGEs on the one hand and ED and LGI on the other. We investigated whether or not these associations differed between individuals with different glucose metabolism status by adding 
interaction terms in our models (e.g. the product of: 1) SAF or plasma AGE levels, and 2) glucose metabolism status). Pearson correlation was used to evaluate the correlations between SAF and the different plasma AGEs. P-values $<0.05$ were considered statistically significant, except for interaction terms, where a $\mathrm{p}$-value $<0.10$ was considered statistically significant.

\section{RESULTS}

\section{General characteristics}

Table 5.1 shows the general characteristics of the 862 individuals included in our study stratified according to tertiles of the ED and LGI z-scores. With higher ED and LGI tertiles, the percentage of individuals with IGM or T2DM, hypertension, lipid-modifying and oral antidiabetic medication, albuminuria, peripheral sensory neuropathy and a history of CVD was higher. Also, with higher ED and LGI tertile, the percentage of males (only for ED) and current smokers (only for LGI) was higher, as were age, HbA1c, insulin use, waist circumference, total-to-HDL cholesterol ratio and triglycerides; eGFR was lower with higher tertile of ED and LGI. SAF levels were higher with higher ED and LGI, whereas plasma CML levels were lower (Table 5.1). Plasma pentosidine and CEL did not significantly differ between tertiles. Mean \pm standard deviation HbA1c was $5.6 \pm 0.3$ in individuals with NGM, $5.9 \pm 0.4$ in individuals with IGM and $6.9 \pm 0.9$ in individuals with T2DM.

\section{Associations between AGE accumulation and the ED z-score}

Higher SAF was significantly associated with a higher ED z-score in both the model adjusted for age, sex and glucose metabolism status (s $\beta \quad 0.14,95 \%$-CI 0.06;0.21) and after additional adjustment for waist circumference, smoking, systolic and diastolic blood pressure, total/HDL cholesterol, triglycerides, oral antidiabetic, antihypertensive or lipid-modifying medication use, insulin use, eGFR and prior CVD (s $0.08,95 \%$-CI $0.01 ; 0.16)$ (Figure 5.1). Higher plasma CML was associated with a lower ED z-score ( $s \beta-0.10,95 \%-C I-0.16 ;-0.03$, fully adjusted model, Figure 5.1). We found no association between plasma pentosidine and CEL on the one hand and the ED z-score on the other (Figure 5.1). Additional adjustment for peripheral sensory neuropathy and albuminuria, as potential confounders, did not materially change any of the above mentioned associations (data not shown). The associations between SAF, plasma pentosidine and CML on the one hand and the ED z-score on the other did not differ between different groups of glucose metabolism status (for all, $\mathrm{p}$-interaction $>0.22$ ). The association between CEL and the ED z-score was significantly different between individuals with NGM ( $s \beta-0.05,95 \%-C I-0.13 ; 0.04)$, IGM ( $s \beta$ $-0.06,95 \%-C I-0.23 ; 0.11$ ) and T2DM (s $0.09,95 \%-C I-0.04 ; 0.22$ ) ( $p$ for interaction NGM vs. IGM $=0.79 ; \mathrm{NGM}$ vs. T2DM $=0.06$ ).

Eliminating STM from or applying the inverse of sTM in the ED z-score did not materially change our results (data not shown), except for the association between plasma pentosidine and the ED $z$-score, which diminished ( $s \beta-0.05$ and -0.04 , respectively, vs. -0.07 ) and became statistically significant ( $p=0.02$ in both analyses). Eliminating sICAM from the ED $z$-score diminished the association between SAF and the ED z-score ( $s \beta 0.03$ vs. 0.08 ) and made it non-significant $(p=0.29)$. However, when we separately evaluated the individual associations between SAF and markers of ED we additionally found a positive association between SAF and VWF (s 0.09 (95\%CI 0.01-0.18; $p=0.03$ ). 


\section{Associations between AGE accumulation and the LGI z-score}

Higher SAF was significantly associated with a higher LGI z-score after adjustment for age, sex and glucose metabolism status ( $\mathrm{s} \beta 0.10,95 \%$-CI $0.02 ; 0.17$ ). However, this association attenuated and became non-significant after additional adjustment for waist circumference, smoking, systolic and diastolic blood pressure, total/HDL cholesterol, triglycerides, oral antidiabetic, antihypertensive or lipid-modifying medication use, insulin use, eGFR and prior CVD (s $\beta 0.06$, $95 \%$-CI $-0.01 ; 0.14$ ) (Figure 5.2 ), of which smoking was the strongest confounder. Higher plasma pentosidine ( $s \beta-0.10,95 \%-C I-0.16 ;-0.03)$ and CML $(s \beta-0.17,95 \%-C I-0.23 ;-0.10)$ were associated with a lower LGI z-score in the fully adjusted model (Figure 5.2). We found no associations between plasma CEL and the LGI z-score (Figure 5.1). Additional adjustment for peripheral sensory neuropathy and albuminuria, as potential confounders, did not materially change any of the above mentioned associations (data not shown). The associations between SAF, plasma pentosidine and plasma CML on the one hand and the LGI z-score on the other did not differ between different groups of glucose metabolism status (for all, $p$-interaction $>0.18$ ). The association between CEL and the LGI z-score was significantly different between individuals with NGM ( $s \beta-0.09,95 \%-C I-0.18 ;-0.01)$, IGM ( $s \beta-0.19,95 \%-C I-0.33 ;-0.05)$ and T2DM (s $\beta 0.04$, $95 \%-C I-0.07 ; 0.15$ ) ( $p$ for interaction NGM vs. IGM $=0.21$; NGM vs. T2DM $=0.06$ ).

\section{Associations between SAF and plasma AGEs}

Since the associations with ED and LGI differed considerably for SAF compared with plasma AGEs, we evaluated the association between these different measures of AGE accumulation. Higher SAF was significantly correlated with higher plasma pentosidine $(r=0.17, p<0.001)$, but not with plasma CML $(r=-0.02, p=0.516)$ or CEL $(r=0.00, p=0.974)$. 
Table 5.1. General characteristics of The Maastricht Study participants

\begin{tabular}{|c|c|c|c|c|}
\hline & \multicolumn{4}{|c|}{ Tertiles of the endothelial dysfunction $z$-score $(n=831)$} \\
\hline & $\begin{array}{l}\text { Lowest tertile } \\
(n=277)\end{array}$ & $\begin{array}{l}\text { Middle tertile } \\
\qquad(\mathrm{n}=\mathbf{2 7 7})\end{array}$ & $\begin{array}{l}\text { Highest tertile } \\
(n=277)\end{array}$ & $p$-value \\
\hline NGM/IGM/T2DM (\%) & $70 / 13 / 17$ & $57 / 15 / 28$ & $36 / 21 / 43$ & $<0.001$ \\
\hline Age (years) & $57 \pm 8$ & $59 \pm 9$ & $63 \pm 8$ & $<0.001$ \\
\hline Sex (number of males/females) & $125 / 152$ & $145 / 132$ & $187 / 90$ & $<0.001$ \\
\hline Diabetes duration $(y)$ & $7[3-11]$ & $7[3-10]$ & $8[3-11]$ & 0.723 \\
\hline Oral antidiabetic medication use (n (\%)) & $30(11)$ & $57(21)$ & $91(33)$ & $<0.001$ \\
\hline Insulin use $(\mathrm{n}(\%))$ & $5(2)$ & $14(5)$ & $31(11)$ & $<0.001$ \\
\hline HbA1c (\%) & $5.8 \pm 0.6$ & $6.0 \pm 0.7$ & $6.3 \pm 1.0$ & $<0.001$ \\
\hline $\mathrm{HbA1c}(\mathrm{mmol} / \mathrm{mol})$ & $40 \pm 6$ & $42 \pm 8$ & $45 \pm 10$ & $<0.001$ \\
\hline Smoking, never/former/current (\%) & $37 / 45 / 18$ & $27 / 60 / 13$ & $28 / 54 / 18$ & 0.004 \\
\hline Waist circumference $(\mathrm{cm})$ & $92 \pm 12$ & $96 \pm 13$ & $103 \pm 13$ & $<0.001$ \\
\hline Total-to-HDL cholesterol ratio & $4.0 \pm 1.3$ & $4.2 \pm 1.3$ & $4.4 \pm 1.2$ & 0.002 \\
\hline Triglycerides (mmol/L) & $1.1[0.8-1.6]$ & $1.2[0.9-1.7]$ & $1.5[1.0-2.0]$ & $<0.001$ \\
\hline Lipid-modifying medication ( $\mathrm{n}(\%)$ ) & $78(28)$ & $99(36)$ & $133(48)$ & $<0.001$ \\
\hline eGFR & $89 \pm 13$ & $85 \pm 14$ & $80 \pm 16$ & $<0.001$ \\
\hline Peripheral sensory neuropathy ( $\mathrm{n}(\%)$ ) & $12(6)$ & $17(8)$ & $40(19)$ & $<0.001$ \\
\hline Albuminuria (normo/micro/macro) (\%) & $96 / 3 / 1$ & $92 / 7 / 1$ & $86 / 12 / 2$ & $<0.001$ \\
\hline $\mathrm{SBP}(\mathrm{mmHg})$ & $135 \pm 19$ & $135 \pm 18$ & $142 \pm 19$ & $<0.001$ \\
\hline $\mathrm{DBP}(\mathrm{mmHg})$ & $76 \pm 10$ & $76 \pm 10$ & $79 \pm 11$ & 0.001 \\
\hline Hypertension (n (\%)) & 135 (49) & $143(52)$ & $204(74)$ & $<0.001$ \\
\hline Anti-hypertensive medication ( $\mathrm{n}(\%)$ ) & $83(30)$ & $95(34)$ & $160(58)$ & $<0.001$ \\
\hline History of CVD (n (\%)) & $28(10)$ & $48(18)$ & $67(26)$ & $<0.001$ \\
\hline $\operatorname{SAF}(A U)$ & $2.59 \pm 0.44$ & $2.64 \pm 0.50$ & $2.90 \pm 0.59$ & $<0.001$ \\
\hline Pentosidine (nmol/mmol LYS) & $0.47[0.39-0.57]$ & $0.46[0.38-0.56]$ & $0.45[0.37-0.59]$ & 0.334 \\
\hline CML (nmol/mmol LYS) & $76.6 \pm 13.6$ & $75.3 \pm 14.9$ & $71.3 \pm 15.3$ & $<0.001$ \\
\hline CEL (nmol/mmol LYS) & $33.4 \pm 9.8$ & $34.4 \pm 10.4$ & $34.5 \pm 10.5$ & 0.381 \\
\hline
\end{tabular}

Data are presented as mean \pm standard deviation (SD) or as median [inter quartile range (IQR)], unless otherwise indicated. NGM, normal glucose metabolism; IGM, impaired glucose metabolism; T2DM, type 2 diabetes; HbA1c, glycated hemoglobin; $\mathrm{HDL}$, high-density lipoprotein; eGFR blood pressure; CVD, cardiovascular disease; SAF, skin autofluorescence; CML, N(epsilon)-(carboxymethyl)lysine; CEL, $\mathrm{N}$ (epsilon)-(carboxyethyl)lysine. 
Table 5.1. (continued)

\begin{tabular}{|c|c|c|c|c|}
\hline & \multicolumn{4}{|c|}{ Tertiles of the low-grade inflammation $z$-score $(n=843)$} \\
\hline & $\begin{array}{l}\text { Lowest tertile } \\
\qquad(n=281)\end{array}$ & $\begin{array}{l}\text { Middle tertile } \\
(\mathrm{n}=\mathbf{2 8 1})\end{array}$ & $\begin{array}{l}\text { Highest tertile } \\
\qquad(n=281)\end{array}$ & p-value \\
\hline NGM/IGM/T2DM (\%) & $74 / 13 / 13$ & $54 / 18 / 28$ & $35 / 18 / 47$ & $<0.001$ \\
\hline Age (years) & $56 \pm 9$ & $60 \pm 8$ & $63 \pm 8$ & $<0.001$ \\
\hline Sex (number of males/females) & $158 / 123$ & $147 / 134$ & $159 / 122$ & 0.529 \\
\hline Diabetes duration $(y)$ & $7[3-12]$ & $6[3-9]$ & $8[3-11]$ & 0.605 \\
\hline Oral antidiabetic medication use ( $\mathrm{n}(\%))$ & $28(10)$ & $57(20)$ & $95(34)$ & $<0.001$ \\
\hline Insulin use $(\mathrm{n}(\%))$ & $5(2)$ & $13(5)$ & $31(11)$ & $<0.001$ \\
\hline $\mathrm{HbA1c}(\%)$ & $5.7 \pm 0.5$ & $6.0 \pm 0.8$ & $6.3 \pm 0.9$ & $<0.001$ \\
\hline $\mathrm{HbA1c}(\mathrm{mmol} / \mathrm{mol})$ & $39 \pm 6$ & $42 \pm 8$ & $46 \pm 10$ & $<0.001$ \\
\hline Smoking, never/former/current (\%) & $35 / 52 / 13$ & $33 / 51 / 16$ & $24 / 56 / 20$ & 0.030 \\
\hline Waist circumference $(\mathrm{cm})$ & $91 \pm 11$ & $98 \pm 13$ & $102 \pm 14$ & $<0.001$ \\
\hline Total-to-HDL cholesterol ratio & $4.0 \pm 1.2$ & $4.4 \pm 1.3$ & $4.3 \pm 1.2$ & $<0.001$ \\
\hline Triglycerides (mmol/L) & $1.0[0.7-1.4]$ & $1 . .3[0.9-1.9]$ & $1.5[1.0-2.2]$ & $<0.001$ \\
\hline Lipid-modifying medication ( $\mathrm{n}(\%)$ ) & $70(25)$ & $106(38)$ & $136(48)$ & $<0.001$ \\
\hline eGFR CKD-EPI $_{\left(\mathrm{ml} / \mathrm{min} / 1.73 \mathrm{~m}^{2}\right)}$ & $89 \pm 13$ & $85 \pm 14$ & $80 \pm 16$ & $<0.001$ \\
\hline Peripheral sensory neuropathy ( $\mathrm{n}(\%)$ ) & $16(7)$ & $17(9)$ & $36(18)$ & 0.001 \\
\hline Albuminuria (normo/micro/macro) (\%) & $95 / 5 / 0$ & $93 / 6 / 1$ & $88 / 11 / 2$ & 0.018 \\
\hline $\mathrm{SBP}(\mathrm{mmHg})$ & $133 \pm 19$ & $137 \pm 19$ & $141 \pm 19$ & $<0.001$ \\
\hline $\mathrm{DBP}(\mathrm{mmHg})$ & $76 \pm 10$ & $77 \pm 10$ & $78 \pm 10$ & 0.072 \\
\hline Hypertension (n (\%)) & $121(43)$ & $166(59)$ & $200(71)$ & $<0.001$ \\
\hline Anti-hypertensive medication ( $\mathrm{n}(\%)$ ) & $62(22)$ & $116(41)$ & $161(57)$ & $<0.001$ \\
\hline History of CVD (n (\%)) & $28(10)$ & $51(19)$ & $67(25)$ & $<0.001$ \\
\hline $\operatorname{SAF}(A U)$ & $2.57 \pm 0.44$ & $2.67 \pm 0.49$ & $2.89 \pm 0.58$ & $<0.001$ \\
\hline Pentosidine (nmol/mmol LYS) & $0.49[0.41-0.58]$ & $0.46[0.37-0.55]$ & $0.44[0.36-0.57]$ & 0.350 \\
\hline CML (nmol/mmol LYS) & $78.8 \pm 13.5$ & $74.5 \pm 14.3$ & $69.7 \pm 15.0$ & $<0.001$ \\
\hline CEL (nmol/mmol LYS) & $33.6 \pm 9.7$ & $33.7 \pm 10.4$ & $34.9 \pm 10.6$ & 0.248 \\
\hline
\end{tabular}

Data are presented as mean \pm standard deviation (SD) or as median [inter quartile range (IQR)], unless otherwise indicated. NGM, normal glucose metabolism; IGM, impaired glucose metabolism; T2DM, type 2 diabetes; HbA1c, glycated hemoglobin; $\mathrm{HDL}$, high-density lipoprotein; eGFRCKD-EPI, estimated Glomerular Filtration Rate; SBP, systolic blood pressure; DBP, diastolic blood pressure; CVD, cardiovascular disease; SAF, skin autofluorescence; CML, N(epsilon)-(carboxymethyl)lysine; CEL, N(epsilon)-(carboxyethyl)lysine. 
Figure 5.1. Associations between measures of AGE accumulation and the endothelial dysfunction z-score

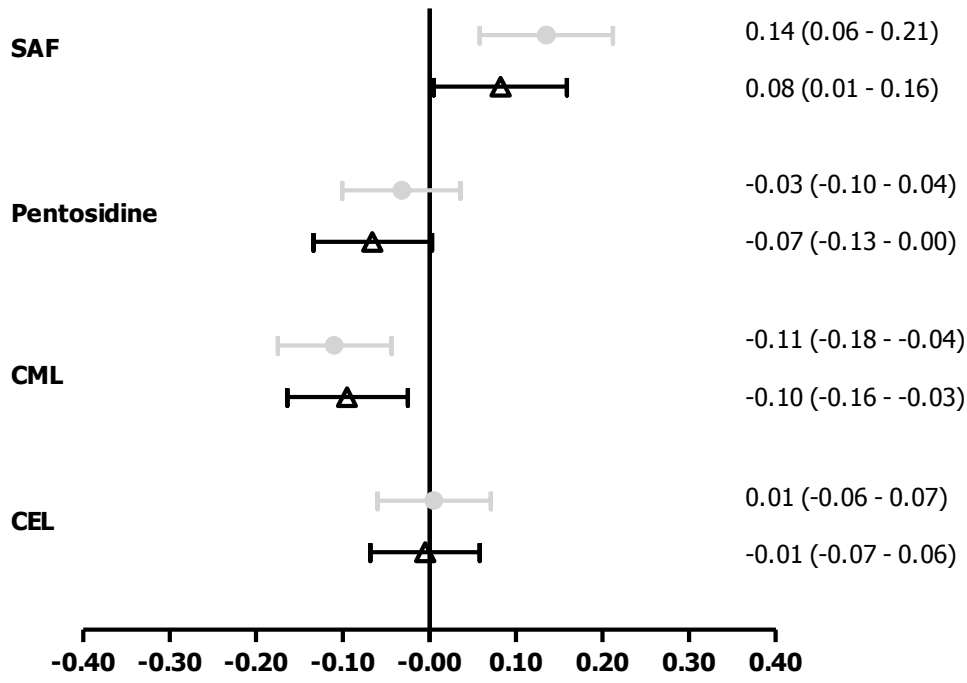

Data are presented as standardized $\beta(\mathrm{s} \beta)$ and $95 \%$-confidence interval. $s \beta$ is the standardized regression coefficient obtained with linear regression analyses, which indicates the change in z-score of endothelial dysfunction (in SD) per 1 SD higher skin autofluorescence (SAF) or level of plasma advanced glycation endproducts, i.e. plasma pentosidine, CML (N(epsilon)(carboxymethyl)lysine) and CEL (N(epsilon)-(carboxyethyl)lysine). GMS, glucose metabolism status. Light grey dots represent associations adjusted for age, sex and glucose metabolism status. Black triangles represent associations that are additionally adjusted for waist circumference, smoking, systolic and diastolic blood pressure, total/HDL cholesterol, triglycerides, oral antidiabetic, antihypertensive or lipid-modifying medication use, insulin use, eGFR and prior cardiovascular disease.

There were 751 individuals included in the analyses between SAF and the endothelial dysfunction z-score, and 780 individuals in the analyses between plasma AGEs and the endothelial dysfunction z-score. 
Figure 5.2. Associations between measures of AGE accumulation and the low-grade inflammation z-score

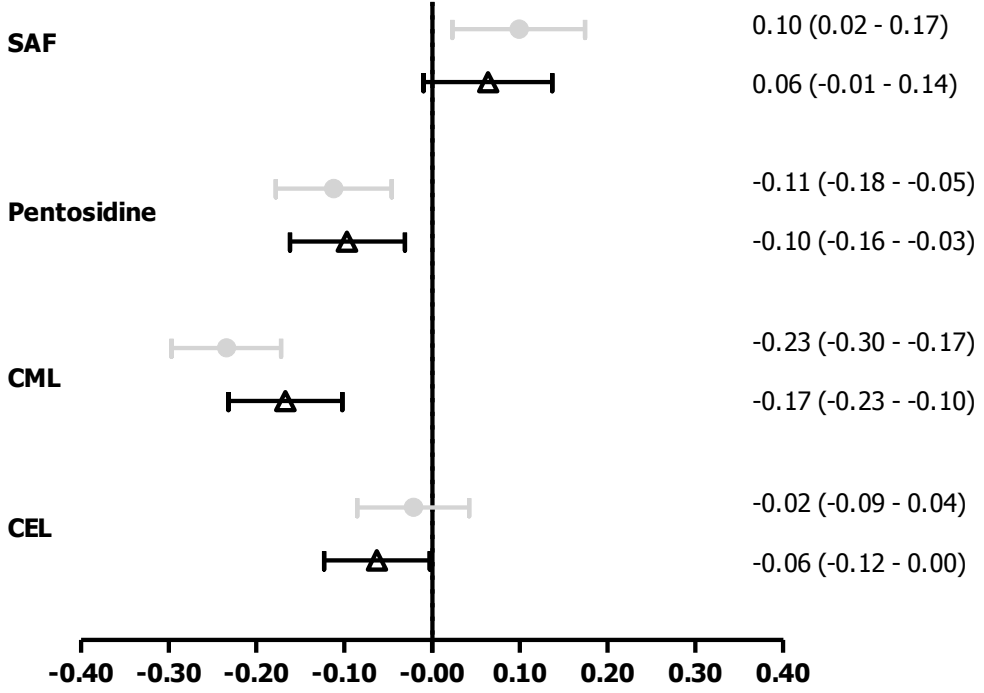

Data are presented as standardized $\beta(s \beta)$ and $95 \%$-confidence interval. $s \beta$ is the standardized regression coefficient obtained with linear regression analyses, which indicates the change in z-score of low-grade inflammation (in SD) per 1 SD higher skin autofluorescence (SAF) or level of plasma advanced glycation endproducts, i.e. plasma pentosidine, CML (N(epsilon)(carboxymethyl)lysine) and CEL (N(epsilon)-(carboxyethyl)lysine). GMS, glucose metabolism status.

Light grey dots represent associations adjusted for age, sex and glucose metabolism status. Black triangles represent associations that are additionally adjusted for waist circumference, smoking, systolic and diastolic blood pressure, total/HDL cholesterol, triglycerides, oral antidiabetic, antihypertensive or lipid-modifying medication use, insulin use, eGFR and prior cardiovascular disease.

There were 763 individuals included in the analyses between SAF and the low-grade inflammation z-score and 792 individuals in the analyses between plasma AGEs and the low-grade inflammation z-score. 


\section{DISCUSSION}

The present study is the first to evaluate, in a large population-based cohort, the association between SAF and different plasma AGEs on the one hand and markers of endothelial dysfunction and low-grade inflammation on the other in individuals with or without IGM or T2DM. We found that higher SAF was associated with markers of ED and borderline significantly with markers of LGI. Contrastingly, we found that higher plasma levels of CML were associated with lower levels of markers of ED and that higher levels of plasma pentosidine and CML were associated with lower levels of markers of LGI. SAF correlated with plasma pentosidine, but not with plasma CML or CEL.

To our knowledge, we are the first to describe an association between higher SAF and higher markers of ED in the general population and individuals with IGM or T2DM. Our results are in line with a recent study reporting higher SAF to be associated with serum concentrations of the ED markers VWF, ICAM-1, and VCAM-1 in a small group of individuals with T1DM or T2DM 39. Additionally, in our observational study, we found that plasma CML was inversely associated with markers of ED. The association between AGEs and markers of ED has predominantly been reported in animal models of T2DM and cell experiments $10,13,40-42$. In contrast with our results for CML, one study previously observed an association between higher serum AGEs and impaired endothelium dependent vasodilatation in individuals with and without T2DM ${ }^{43}$. However, it should be emphasized that this study used a non-specified anti-AGE ELISA to measure serum AGEs, while we used state-of-the-art techniques to specifically measure different plasma AGEs. Therefore, we cannot rule out the possibility that other serum AGEs than CML, CEL or pentosidine, as detected with this ELISA, but not with our technique, are indeed positively associated with endothelial dysfunction.

In addition, we found no association between SAF and markers of LGI. Others have found associations between SAF and CRP in individuals with and without obesity ${ }^{24}$, heart disease ${ }^{44}$ or kidney failure ${ }^{25}$, while a study by Mulder et al. found no association between SAF and CRP ${ }^{26}$. However, these last results were based on a small group of only 67 individuals with T2DM. Moreover, animal ${ }^{41}$ and cell experimental studies ${ }^{9}$ have shown that AGEs are able to promote low-grade inflammation. In parallel with the associations with ED, we found that plasma CML and pentosidine were inversely associated with markers of LGI in individuals with NGM, IGM or T2DM. Again, a positive association was previously found between serum AGEs, and hsCRP in T2DM 45, however, serum AGEs were measured with the same non-specified anti-AGE ELISA.

Although we do not have a valid explanation yet for the inverse association between plasma AGES and markers of ED and LGI, our findings are in accordance with several studies that have shown that plasma CML levels were lower in individuals with T2DM ${ }^{31}$ and with obesity ${ }^{46-49}$. As recently demonstrated by Gaens et al. ${ }^{49}$, the trapping of CML by the receptor for AGEs (RAGE) in adipose tissue may be responsible for the decrease in plasma AGE levels in obese individuals with T2DM. Indeed, also in our study, plasma CML levels were significantly lower with deteriorating glucose metabolism status (data not shown). In line with the model proposed by Gaens et al, the differences in plasma CML levels between individuals with NGM, IGM and T2DM diminished and became non-significant after adjustment for waist circumference (data not shown). This strongly suggests that plasma CML is not a good reflection of CML accumulation in tissues in individuals with T2DM, as T2DM is often accompanied by obesity. Still, we are left with no clear explanation 
for the fact that plasma pentosidine, and plasma CEL with borderline significance, were inversely associated with LGI. It might be that low plasma AGE levels are a reflection of less degradation of tissue AGEs and/or less release from tissues. In that case low plasma AGE levels would reflect higher tissue levels. However, this is entirely speculative. Additionally, plasma AGE levels are determined to a large extent by the half-life of plasma proteins, which is significantly shorter than the half-life time of long-lived proteins in the skin or the vascular wall ${ }^{23}$. Our observation of a positive association between SAF and markers of ED, but contrasting associations for plasma AGES, might reflect that SAF is a better marker of AGE accumulation in vascular tissue than plasma AGEs. However, further studies are needed to further investigate this hypothesis.

Additionally, we evaluated the associations between SAF and plasma AGEs and found only an association between SAF and plasma pentosidine. This may be caused, at least partly, by the fact that both techniques are measuring fluorescent AGEs. Although studies on this relationship are scarce, several have reported both a positive association between SAF and pentosidine ${ }^{50,51}$, CML or CEL ${ }^{52}$ and no association between SAF and plasma pentosidine, CML or CEL ${ }^{53}$. Taken together, it seems that SAF and plasma AGEs, and even plasma AGEs amongst each other, are not reflections of the same processes.

AGEs are able to interact with RAGE on, amongst others, endothelial cells, macrophages and smooth muscle cells in the vessel wall. This leads to the translocation of NF-KB to the nucleus, where it activates transcription of its target genes, among them adhesion molecules, proinflammatory cytokines, and RAGE itself $15,54,55$. Furthermore, it was shown that the formation of AGEs through its most important precursor methylglyoxal results in increased expression of adhesion molecules, e.g. vascular cell adhesion molecule 1 (VCAM-1) and intracellular adhesion molecule 1 (ICAM-1) and a sensitizing of cells to the effects of pro-inflammatory cytokines 56,57 , i.e. early events in the initiation of atherosclerosis. Our findings together with previous research support the hypothesis that AGE accumulation in tissues may lead to CVD through the stimulation of ED, and possibly LGI, in individuals with and without T2DM or IGM.

One of the strengths of our study is that we based our estimates of ED and LGI on five different markers of ED (sVCAM-1, sICAM-1, sE-selectin, soluble thrombomodulin and VWF) and six markers of LGI (CRP, SAA, SICAM-1, IL-6, IL-8 and TNF-a). These markers of ED are all known to be synthesized by endothelial cells $38,58,59$, whereas all the LGI markers are involved in inflammatory processes ${ }^{59}$. For these reasons, it is plausible to assume that higher circulating concentrations of these markers reflect more dysfunction of the endothelium or inflammatory activity, respectively. However, endothelial dysfunction is closely linked to low-grade inflammation and these concepts are difficult to separate. This is supported by the fact that we found a similar pattern in the direction of the associations comparing the associations between AGEs and LGI on the one hand and between AGEs and ED on the other (Figure 5.1 and 5.2). Therefore, it seems likely that AGE formation stimulates both the process of $L G I$ and $E D$, and that these processes together lead to the development of CVD.

A limitation of this study is that it was of cross-sectional design. Therefore, we cannot draw any conclusions about causality in the association between SAF on the one hand and LGI and ED on the other. However, to this day, there are no longitudinal studies evaluating this association. 


\section{Conclusions}

We found that higher levels of SAF were associated with higher markers of ED. We found no significant association for LGI. For plasma AGEs we found contrasting results, which might illustrate that plasma AGEs are not a good reflection of AGE accumulation in the vascular wall. These results support the hypothesis that AGE accumulation in tissues is involved in the stimulation of LGI and ED in individuals with and without T2DM, which could lead to an increased risk of CVD. 


\section{REFERENCES}

1. Mendis S. Global status report on noncommunicable diseases 2014. World Health Organization. 2014

2. Yusuf S, Reddy S, Ounpuu S, Anand S. Global burden of cardiovascular diseases: Part i: General considerations, the epidemiologic transition, risk factors, and impact of urbanization. Circulation. 2001;104:2746-2753

3. Sarwar N, Gao P, Seshasai SR, Gobin R, Kaptoge S, Di Angelantonio E, Ingelsson E, Lawlor DA, Selvin E, Stampfer M, Stehouwer CD, Lewington S, Pennells L, Thompson A, Sattar N, White IR, Ray KK, Danesh J. Diabetes mellitus, fasting blood glucose concentration, and risk of vascular disease: A collaborative meta-analysis of 102 prospective studies. Lancet. 2010;375:2215-2222

4. Seshasai SR, Kaptoge S, Thompson A, Di Angelantonio E, Gao P, Sarwar N, Whincup PH, Mukamal KJ, Gillum RF, Holme I, Njolstad I, Fletcher A, Nilsson P, Lewington S, Collins R, Gudnason V, Thompson SG, Sattar N, Selvin E, Hu FB, Danesh J. Diabetes mellitus, fasting glucose, and risk of cause-specific death. N Engl J Med. 2011;364:829-841

5. Brownlee M. Biochemistry and molecular cell biology of diabetic complications. Nature. 2001;414:813-820

6. Vlassara H, Bucala R, Striker L. Pathogenic effects of advanced glycosylation: Biochemical, biologic, and clinical implications for diabetes and aging. Lab Invest. 1994;70:138-151

7. McCance DR, Dyer DG, Dunn JA, Bailie KE, Thorpe SR, Baynes JW, Lyons TJ. Maillard reaction products and their relation to complications in insulin-dependent diabetes mellitus. J Clin Invest. 1993;91:2470-2478

8. Hanssen NM, Beulens JW, van Dieren S, Scheijen JL, van der AD, Spijkerman AM, van der Schouw YT, Stehouwer CD, Schalkwijk CG. Plasma advanced glycation end products are associated with incident cardiovascular events in individuals with type 2 diabetes: A case-cohort study with a median follow-up of 10 years (epic-nl). Diabetes. 2015;64:257-265

9. Rashid G, Benchetrit S, Fishman D, Bernheim J. Effect of advanced glycation end-products on gene expression and synthesis of tnf-alpha and endothelial nitric oxide synthase by endothelial cells. Kidney international. 2004;66:10991106

10. Schmidt AM, Hori O, Chen JX, Li JF, Crandall J, Zhang J, Cao R, Yan SD, Brett J, Stern D. Advanced glycation endproducts interacting with their endothelial receptor induce expression of vascular cell adhesion molecule-1 (vcam-1) in cultured human endothelial cells and in mice. A potential mechanism for the accelerated vasculopathy of diabetes. J Clin Invest. 1995; $96: 1395-1403$

11. Uchida Y, Ohba K, Yoshioka T, Irie K, Muraki T, Maru Y. Cellular carbonyl stress enhances the expression of plasminogen activator inhibitor-1 in rat white adipocytes via reactive oxygen species-dependent pathway. $J$ Biol Chem. 2004;279:4075-4083

12. Ramasamy R, Yan SF, Schmidt AM. The diverse ligand repertoire of the receptor for advanced glycation endproducts and pathways to the complications of diabetes. Vascul Pharmacol. 2012;57:160-167

13. Basta G, Lazzerini G, Massaro M, Simoncini T, Tanganelli P, Fu C, Kislinger T, Stern DM, Schmidt AM, De Caterina R. Advanced glycation end products activate endothelium through signal-transduction receptor rage: A mechanism for amplification of inflammatory responses. Circulation. 2002;105:816-822

14. Bierhaus A, Humpert PM, Stern DM, Arnold B, Nawroth PP. Advanced glycation end product receptor-mediated cellular dysfunction. Ann N Y Acad Sci. 2005; 1043:676-680

15. Goldin A, Beckman JA, Schmidt AM, Creager MA. Advanced glycation end products: Sparking the development of diabetic vascular injury. Circulation. 2006;114:597-605

16. Basta G, Schmidt AM, De Caterina R. Advanced glycation end products and vascular inflammation: Implications for accelerated atherosclerosis in diabetes. Cardiovasc Res. 2004;63:582-592

17. Bierhaus A, Nawroth PP. Multiple levels of regulation determine the role of the receptor for age (rage) as common soil in inflammation, immune responses and diabetes mellitus and its complications. Diabetologia. 2009;52:2251-2263

18. Blankenberg S, Rupprecht HJ, Bickel C, Peetz D, Hafner G, Tiret L, Meyer J. Circulating cell adhesion molecules and death in patients with coronary artery disease. Circulation. 2001;104:1336-1342

19. de Jager J, Dekker JM, Kooy A, Kostense PJ, Nijpels G, Heine RJ, Bouter LM, Stehouwer CD. Endothelial dysfunction and low-grade inflammation explain much of the excess cardiovascular mortality in individuals with type 2 diabetes: The hoorn study. Arterioscler Thromb Vasc Biol. 2006;26:1086-1093

20. Jager A, van Hinsbergh VW, Kostense PJ, Emeis JJ, Yudkin JS, Nijpels G, Dekker JM, Heine RJ, Bouter LM, Stehouwer CD. Von willebrand factor, c-reactive protein, and 5-year mortality in diabetic and nondiabetic subjects: The hoorn study. Arterioscler Thromb Vasc Biol. 1999;19:3071-3078

21. Morange PE, Simon C, Alessi MC, Luc G, Arveiler D, Ferrieres J, Amouyel P, Evans A, Ducimetiere P, Juhan-Vague I. Endothelial cell markers and the risk of coronary heart disease: The prospective epidemiological study of myocardial infarction (prime) study. Circulation. 2004;109:1343-1348

22. Ridker PM, Hennekens $\mathrm{CH}$, Buring JE, Rifai N. C-reactive protein and other markers of inflammation in the prediction of cardiovascular disease in women. N Engl J Med. 2000;342:836-843

23. Smit AJ, Hartog JW, Voors AA, van Veldhuisen DJ. Advanced glycation endproducts in chronic heart failure. Ann $N Y$ Acad Sci. 2008;1126:225-230

24. den Engelsen C, van den Donk M, Gorter KJ, Salome PL, Rutten GE. Advanced glycation end products measured by skin autofluorescence in a population with central obesity. Dermatoendocrinol. 2012;4:33-38

25. Nagano M, Fukami K, Yamagishi S, Sakai K, Kaida Y, Matsumoto T, Hazama T, Tanaka M, Ueda S, Okuda S. Tissue level of advanced glycation end products is an independent determinant of high-sensitivity c-reactive protein levels in haemodialysis patients. Nephrology (Car/ton). 2011;16:299-303

26. Mulder DJ, de Boer JF, Graaff R, de Vries R, Annema W, Lefrandt JD, Smit AJ, Tietge UJ, Dullaart RP. Skin autofluorescence is inversely related to hdl anti-oxidative capacity in type 2 diabetes mellitus. Atherosclerosis. 2011;218:102-106 
27. Schram MT, Sep SJ, van der Kallen CJ, Dagnelie PC, Koster A, Schaper N, Henry RM, Stehouwer CD. The maastricht study: An extensive phenotyping study on determinants of type 2 diabetes, its complications and its comorbidities. Eur J Epidemiol. 2014;29:439-451

28. Meerwaldt R, Graaff R, Oomen PH, Links TP, Jager JJ, Alderson NL, Thorpe SR, Baynes JW, Gans RO, Smit AJ. Simple non-invasive assessment of advanced glycation endproduct accumulation. Diabetologia. 2004;47:1324-1330

29. Koetsier M, Nur E, Chunmao H, Lutgers HL, Links TP, Smit AJ, Rakhorst G, Graaff R. Skin color independent assessment of aging using skin autofluorescence. Opt Express. 2010;18:14416-14429

30. Scheijen JL, van de Waarenburg MP, Stehouwer CD, Schalkwijk CG. Measurement of pentosidine in human plasma protein by a single-column high-performance liquid chromatography method with fluorescence detection. $J$ Chromatogr B Analyt Technol Biomed Life Sci. 2009;877:610-614

31. Hanssen NM, Engelen L, Ferreira I, Scheijen JL, Huijberts MS, van Greevenbroek MM, van der Kallen CJ, Dekker JM, Nijpels G, Stehouwer CD, Schalkwijk CG. Plasma levels of advanced glycation endproducts n\{epsilon\}(carboxymethyl)lysine, n\{epsilon\}-(carboxyethyl)lysine, and pentosidine are not independently associated with cardiovascular disease in individuals with or without type 2 diabetes: The hoorn and codam studies. $J$ Clin Endocrinol Metab. 2013;98:E1369-1373

32. de Valk-de Roo GW, Stehouwer CD, Lambert J, Schalkwijk CG, van der Mooren MJ, Kluft C, Netelenbos C. Plasma homocysteine is weakly correlated with plasma endothelin and von willebrand factor but not with endotheliumdependent vasodilatation in healthy postmenopausal women. Clin Chem. 1999;45:1200-1205

33. (WHO) WHO. Definition and diagnosis of diabetes mellitus and intermediate hyperglycemia: Report of a who/idf consultation. Geneva, Switzerland: World Health Organization (WHO); 2006.

34. Friedewald WT, Levy RI, Fredrickson DS. Estimation of the concentration of low-density lipoprotein cholesterol in plasma, without use of the preparative ultracentrifuge. Clin Chem. 1972;18:499-502

35. Levey AS, Stevens LA, Schmid CH, Zhang YL, Castro AF, 3rd, Feldman HI, Kusek JW, Eggers P, Van Lente F, Greene T, Coresh J. A new equation to estimate glomerular filtration rate. Ann Intern Med. 2009;150:604-612

36. Leng GC, Fowkes FG. The edinburgh claudication questionnaire: An improved version of the who/rose questionnaire for use in epidemiological surveys. J Clin Epidemiol. 1992;45:1101-1109

37. Yudkin JS, Stehouwer CD, Emeis JJ, Coppack SW. C-reactive protein in healthy subjects: Associations with obesity, insulin resistance, and endothelial dysfunction: A potential role for cytokines originating from adipose tissue? Arterioscler Thromb Vasc Biol. 1999;19:972-978

38. Schram MT, Stehouwer CD. Endothelial dysfunction, cellular adhesion molecules and the metabolic syndrome. Horm Metab Res. 2005;37 Suppl 1:49-55

39. Skrha J, Jr., Soupal J, Loni Ekali G, Prazny M, Kalousova M, Kvasnicka J, Landova L, Zima T, Skrha J. Skin autofluorescence relates to soluble receptor for advanced glycation end-products and albuminuria in diabetes mellitus. J Diabetes Res. 2013;2013:650694

40. Vlassara H, Fuh H, Donnelly T, Cybulsky M. Advanced glycation endproducts promote adhesion molecule (vcam-1, icam-1) expression and atheroma formation in normal rabbits. Mol Med. 1995;1:447-456

41. Gao X, Zhang H, Schmidt AM, Zhang C. Age/rage produces endothelial dysfunction in coronary arterioles in type 2 diabetic mice. Am J Physiol Heart Circ Physiol. 2008;295:H491-498

42. Sena CM, Matafome P, Crisostomo J, Rodrigues L, Fernandes R, Pereira P, Seica RM. Methylglyoxal promotes oxidative stress and endothelial dysfunction. Pharmacol Res. 2012;65:497-506

43. Tan KC, Chow WS, Ai VH, Metz C, Bucala R, Lam KS. Advanced glycation end products and endothelial dysfunction in type 2 diabetes. Diabetes Care. 2002;25:1055-1059

44. Mulder DJ, van Haelst PL, Graaff R, Gans RO, Zijlstra F, Smit AJ. Skin autofluorescence is elevated in acute myocardial infarction and is associated with the one-year incidence of major adverse cardiac events. Neth Heart J. 2009;17:162168

45. Tan KC, Chow WS, Tam S, Bucala R, Betteridge J. Association between acute-phase reactants and advanced glycation end products in type 2 diabetes. Diabetes Care. 2004;27:223-228

46. Semba RD, Arab L, Sun K, Nicklett EJ, Ferrucci L. Fat mass is inversely associated with serum carboxymethyl-lysine, an advanced glycation end product, in adults. J Nutr. 2011;141:1726-1730

47. Grote VA, Nieters A, Kaaks R, Tjonneland A, Roswall N, Overvad K, Nielsen MR, Clavel-Chapelon F, Boutron-Ruault MC, Racine A, Teucher B, Lukanova A, Boeing H, Drogan D, Trichopoulou A, Trichopoulos D, Lagiou P, Palli D, Sieri S, Tumino R, Vineis P, Mattiello A, Arguelles Suarez MV, Duell EJ, Sanchez MJ, Dorronsoro M, Huerta Castano JM, Barricarte A, Jeurnink SM, Peeters PH, Sund M, Ye W, Regner S, Lindkvist B, Khaw KT, Wareham N, Allen NE, Crowe FL, Fedirko V, Jenab M, Romaguera D, Siddiq A, Bueno-de-Mesquita HB, Rohrmann S. The associations of advanced glycation end products and its soluble receptor with pancreatic cancer risk: A case-control study within the prospective epic cohort. Cancer Epidemiol Biomarkers Prev. 2012;21:619-628

48. Sebekova K, Somoza V, Jarcuskova M, Heidland A, Podracka L. Plasma advanced glycation end products are decreased in obese children compared with lean controls. Int J Pediatr Obes. 2009;4:112-118

49. Gaens KH, Stehouwer CD, Schalkwijk CG. Advanced glycation endproducts and its receptor for advanced glycation endproducts in obesity. Curr Opin Lipidol. 2013;24:4-11

50. Ueno H, Koyama H, Fukumoto S, Tanaka S, Shoji T, Emoto M, Tahara H, Inaba M, Kakiya R, Tabata T, Miyata T, Nishizawa Y. Advanced glycation end products, carotid atherosclerosis, and circulating endothelial progenitor cells in patients with end-stage renal disease. Metabolism. 2011;60:453-459

51. Tanaka K, Katoh T, Asai J, Nemoto F, Suzuki H, Asahi K, Sato K, Sakaue M, Miyata T, Watanabe T. Relationship of skin autofluorescence to cardiovascular disease in japanese hemodialysis patients. Ther Apher Dial. 2010;14:334-340 
52. Nienhuis HL, de Leeuw K, Bijzet J, Smit A, Schalkwijk CG, Graaff R, Kallenberg CG, Bijl M. Skin autofluorescence is increased in systemic lupus erythematosus but is not reflected by elevated plasma levels of advanced glycation endproducts. Rheumatology (Oxford). 2008;47:1554-1558

53. Hartog JW, Hummel YM, Voors AA, Schalkwijk CG, Miyata T, Huisman RM, Smit AJ, Van Veldhuisen DJ. Skinautofluorescence, a measure of tissue advanced glycation end-products (ages), is related to diastolic function in dialysis patients. J Card Fail. 2008;14:596-602

54. Li J, Schmidt AM. Characterization and functional analysis of the promoter of rage, the receptor for advanced glycation end products. J Biol Chem. 1997;272:16498-16506

55. Bierhaus A, Humpert PM, Morcos M, Wendt T, Chavakis T, Arnold B, Stern DM, Nawroth PP. Understanding rage, the receptor for advanced glycation end products. J Mol Med (Berl). 2005;83:876-886

56. Yao D, Taguchi T, Matsumura T, Pestell R, Edelstein D, Giardino I, Suske G, Rabbani N, Thornalley PJ, Sarthy VP, Hammes HP, Brownlee M. High glucose increases angiopoietin-2 transcription in microvascular endothelial cells through methylglyoxal modification of msin3a. J Biol Chem. 2007;282:31038-31045

57. Maessen DE, Stehouwer CD, Schalkwijk CG. The role of methylglyoxal and the glyoxalase system in diabetes and other age-related diseases. Clinical science. 2015;128:839-861

58. Vischer UM. Von willebrand factor, endothelial dysfunction, and cardiovascular disease. J Thromb Haemost. 2006;4:1186-1193

59. Ross R. Atherosclerosis--an inflammatory disease. N Eng/ J Med. 1999;340:115-126 


\section{CHAPTER 6}

Higher skin autofluorescence, but not plasma AGEs, is associated with lower ankle-brachial index in individuals without and with type 2 diabetes

The Maastricht Study

Marcelle G.A. van Eupen, Miranda T. Schram, Jean Scheijen, Simone JS Sep, Carla J van der Kallen, Pieter C Dagnelie, Annemarie Koster, Nicolaas Schaper, Ronald MA Henry, Andries J Smit, Coen DA Stehouwer, Casper G Schalkwijk 


\section{ABSTRACT}

\section{Background}

Individuals with type 2 diabetes mellitus (T2DM) have an increased risk of developing cardiovascular disease (CVD) compared with the general population. Advanced glycation endproducts (AGEs) are thought to play a role by stimulating atherosclerosis. Therefore, we investigated the associations between skin autofluorescence (SAF) and plasma AGEs on the one hand and the ankle-brachial index (ABI) and carotid intima-media thickness (cIMT), as early markers of atherosclerosis on the other in individuals with normal glucose metabolism (NGM), impaired glucose metabolism (IGM) and type 2 diabetes (T2DM).

\section{Methods}

We studied a cohort of 862 individuals from The Maastricht Study (469 NGM, 140 IGM and 253 T2DM) with mean age of $60 y$ and $45 \%$ females. SAF was measured by use of the AGE Reader. Plasma levels of protein-bound pentosidine were measured with HPLC and fluorescence detection. Plasma protein-bound $\mathrm{N} \varepsilon$-(carboxymethyl)lysine (CML) and $\mathrm{N} \varepsilon$-(carboxyethyl)lysine (CEL) were measured with UPLC and tandem mass spectrometry. Associations were analysed with linear regression analysis and adjusted for age, sex, glucose metabolism status, waist circumference, smoking, systolic and diastolic blood pressure, antihypertensive, lipid-modifying and oral antidiabetic medication use, insulin use, eGFR, total-to-HDL-cholesterol ratio, triglycerides and prior CVD.

\section{Results}

Higher SAF was associated with a lower ABI ( $s \beta-0.13,95 \%-C I-0.21 ;-0.05)$ but not with cIMT ( $s \beta$ $-0.0295 \%-C I-0.10 ; 0.06)$. In contrast, higher plasma CML was associated with a higher ABI (s $\beta$ $0.13,95 \%$-CI $0.06 ; 0.21)$ and higher plasma CEL was associated with lower CIMT (s $\beta-0.07,95 \%$ CI $-0.14 ; 0.00)$.

\section{Conclusions}

Our observation that SAF was associated with a lower ABI supports the hypothesis that AGE accumulation is involved in the development of peripheral atherosclerosis in individuals with and without T2DM. 


\section{INTRODUCTION}

Having type 2 diabetes mellitus (T2DM) increases the risk of cardiovascular disease (CVD) by 2fold, as compared with the general population ${ }^{1,2}$. Moreover, even in individuals with impaired glucose tolerance (IGT) or impaired fasting glucose (IFG) there is an increased risk of CVD compared with the general population 3, 4 . Indeed, hyperglycaemia has been linked to the development of atherosclerosis 5,6 , next to and independent of other risk factors as increasing age, an adverse lipid profile, high blood pressure and smoking. However, the exact mechanisms behind the link between hyperglycaemia and atherosclerosis are still to be unravelled. One of the major pathways in the development of vascular disease in diabetes involves the damaging effects of advanced glycation endproducts (AGEs) on vascular tissues ${ }^{7}$. AGEs accumulate in long lived tissues during lifetime, which is regarded as a process of normal ageing. Hyperglycaemia and oxidative stress are known to increase AGE accumulation ${ }^{7}$.

Previous studies strongly suggest that AGEs play a role in the development of atherosclerosis. We recently demonstrated that plasma AGEs were associated with incident cardiovascular events in individuals with type 2 diabetes ${ }^{8}$. In addition, AGEs have been localized in human atherosclerotic lesions by immunohistochemistry ${ }^{9,10}$. Moreover, higher concentrations of CML and MG-H1 have recently been observed in rupture-prone as opposed to stable atherosclerotic plaques, suggesting that AGEs may also influence the progression of stable to rupture-prone plaques ${ }^{11}$. Indeed, therapeutically lowering AGEs or blocking the receptor for AGEs in murine models has been shown to attenuate plaque formation ${ }^{12,13}$. AGEs are proposed to stimulate atherosclerosis through the induction of low-grade inflammation and endothelial dysfunction ${ }^{14-21}$.

Skin autofluorescence (SAF), a non-invasive estimate of AGEs in the skin 22 , is higher in individuals with PAD ${ }^{23,} 24$ and has been associated with carotid intima-media thickness (CIMT) in T1DM 25, the general population ${ }^{26,27}$ and in end stage renal disease (ESRD) ${ }^{28,29}$. To our knowledge, there are no studies available that investigated the association between SAF and surrogate markers of early atherosclerosis, such as the ankle-brachial index (ABI) and carotid intima-media thickness (cIMT) in individuals with impaired glucose metabolism (IGM) and T2DM.

Therefore, the aim of our study was first, to evaluate the associations between SAF on the one hand and the ABI and cIMT on the other in individuals with normal glucose metabolism (NGM), IGM and T2DM; and second, to evaluate the associations between well-studied plasma AGEs and the ABI and CIMT in the same population. Additionally, since measures of atherosclerosis are associated with measures of arterial stiffness $30-32$, we investigated whether or not adjustment for cfPWV, considered the 'gold standard' for the measurement of arterial stiffness 33 , attenuated these associations. Furthermore, we investigated to which extent any of these associations could be explained by markers of low-grade inflammation or endothelial dysfunction. 


\section{MATERIALS AND METHODS}

\section{Study population and design}

In this study, we used data from The Maastricht Study, an observational prospective populationbased cohort study. The rationale and methodology have been described previously ${ }^{34}$. In brief, the study focuses on the etiology, pathophysiology, complications and comorbidities of type 2 diabetes mellitus (T2DM) and is characterized by an extensive phenotyping approach. Eligible for participation were all individuals aged between 40 and 75 years and living in the southern part of the Netherlands. Participants were recruited through mass media campaigns and from the municipal registries and the regional Diabetes Patient Registry via mailings. Recruitment was stratified according to known T2DM status for reasons of efficiency. The present report includes cross-sectional data from the first 866 participants, who completed the baseline survey between November 2010 and March 2012. The examinations of each participant were performed within a time window of three months. The study has been approved by the institutional medical ethical committee (NL31329.068.10) and the Netherlands Health Council under the Dutch "Law for Population Studies" (Permit 131088-105234-PG). All participants gave written informed consent. From the initial 866 individuals included in this study, individuals with type 1 diabetes were excluded from analyses (T1DM; $n=4)$. Data on SAF were available in 831 individuals, plasma AGEs in 843, ABI in 842 and CIMT in 817 individuals. Missing SAF, ABI and CIMT data were predominantly due to technical problems. Missing plasma AGE data were mostly due to difficulties in blood withdrawal.

\section{Skin autofluorescence (SAF)}

All participants were asked to refrain from smoking and caffeine at least 3 hours before the measurements. A light meal (breakfast and (or) lunch), low in fat content, was allowed. SAF was measured with the AGE Reader ${ }^{\mathrm{TM}}$ (DiagnOptics Technologies BV, Groningen, the Netherlands). The AGE reader is a desktop device that uses the characteristic fluorescent properties of certain AGEs to estimate the level of AGE accumulation in the skin. Technical details of this non-invasive method have been described more extensively elsewhere ${ }^{22}$. In short, the AGE Reader illuminates a skin surface of $4 \mathrm{~cm}^{2}$ guarded against surrounding light, with an excitation wavelength range of $300-420 \mathrm{~nm}$, with a peak excitation of $370 \mathrm{~nm}$. SAF was calculated as the ratio between the emission light from the skin in the wavelength range of 420-600 nm (fluorescence) and excitation light that is reflected by the skin (300-420nm), multiplied by 100 and expressed in arbitrary units (AU). Participants were asked not to use any sunscreen or self-browning creams on their lower arms within 2 days before the measurement. SAF was measured at room temperature in a semidark environment while participants were at rest in a seated position. The inner side of the forearm approximately $4 \mathrm{~cm}$ below the elbow fold of a participant was positioned on top of the device, as described by the manufacturer. The mean of three consecutive measurements was used in the analyses. Reproducibility was assessed in 14 individuals without diabetes (6 males; $32.2 \pm 7.1$ years). The intraclass correlation coefficient (ICC) of three intra-individual consecutive SAF measurements was 0.83 (95\% CI 0.65-0.94). SAF was calculated off-line by automated analysis using AGE Reader software, version 2.3, and was observer-independent. There were no significant differences between fasting and non-fasting measurements (mean difference $=0.01 \mathrm{AU}, \mathrm{p}=0.73$ ). Reproducibility in individuals with T2DM has been evaluated previously 22 with an overall Altman error percentage of $5.03 \%$ for measurements taken over a single day. Skin pigmentation is known 
to influence the measurement of SAF ${ }^{35}$. Therefore, in participants with dark-colored skin with a reflectance of $6-10 \%$, a validated reflectance dependent correction was made by the software ${ }^{35}$. Measurements in participants with dark-colored skin and a mean reflectance below $6 \%$ are considered unreliable and are therefore not used to calculate SAF by the software. Therefore, these participants were automatically excluded $(n=1)$. Additionally, a single SAF value above 10 AU was considered as unreliable; these individual measurements $(n=3)$ were manually excluded and the mean of the remaining two measurements was used in analyses.

\section{Analysis of protein- bound AGEs and lysine in plasma}

Plasma AGEs were measured in EDTA samples obtained from fasting venous blood, which were stored at $-80^{\circ} \mathrm{C}$ until analysis. Protein-bound pentosidine was quantified using HPLC with fluorescence detection, as described in detail elsewhere ${ }^{36}$. Intra- and interassay coefficients of variation (CVs), as analysed in this study, were 6.5 and $7.8 \%$ for pentosidine, respectively. Proteinbound CML, CEL and lysine were quantified using UPLC MS/MS ${ }^{37}$. Intra- and interassay CVs were 4.5 and $6.7 \%$ for CML, 6.2 and $10.3 \%$ for CEL and 5.0 and $5.3 \%$ for lysine. Concentrations of protein-bound pentosidine, CML and CEL were adjusted for levels of lysine and expressed as $\mathrm{nmol} / \mathrm{mmol}$ lysine.

\section{Measurement of ankle-brachial index and carotid intima-media thickness}

The Omron VP2000 (Omron, Kyoto, Japan) was used to automatically determine the ankle-brachial index based on blood pressure measurements at the brachial artery of the left and right arm, and above the left and right ankle joint. The lowest $A B I$ of either leg was used in the analyses. Individuals with an $A B I>1.4(n=2)$, which is indicative of arterial calcification, were exclude from the analyses. For the measurement of CIMT, the left common carotid artery was visualised with an ultrasound scanner (Esaote Mylab 70, Esaote, Maastricht, the Netherlands) equipped with a 7.5 $\mathrm{MHz}$ linear array probe and connected to a personal computer. This computer was equipped with an acquisition system and a vessel wall movement detector software system based on radio frequency signal processing (Wall Track System Artlab, ESAOTE, Maastricht, the Netherlands). The cIMT was computed, by calculating the mean of three readings, as the distance between the leading edge interface between the lumen and the intima layer to the leading edge interface between the media and the adventitia layers at level of the posterior carotid artery wall.

\section{Makers of endothelial dysfunction (ED) and low-grade inflammation (LGI)}

Of the plasma biomarkers of ED (sVCAM-1, sICAM-1, sE-selectin, soluble thrombomodulin and vWF), sVCAM-1, sICAM-1, sE-selectin and soluble thrombomodulin were measured in EDTA plasma samples with commercially available 4-plex sandwich immunoassay kits (Meso Scale Discovery (MSD), Rockville, MD, US). vWf was determined in citrated plasma with sandwich ELISA (Dako, Glostrup, Denmark) ${ }^{38}$. Concentrations of vWf were expressed as a percentage of vWf detected in pooled citrated plasma of healthy volunteers. For this study, the intra- and inter-assay coefficients of variation were $3.5 \%$ and $5.9 \%$ for sVCAM- $1,2.5 \%$ and $5.3 \%$ for sICAM- $1,6.4 \%$ and $6.0 \%$ for sE-selectin, $1.9 \%$ and $4.4 \%$ for soluble thrombomodulin, and $3.2 \%$ and $5.4 \%$ for vWF. Plasma biomarkers of LGI (CRP, SAA, sICAM-1, IL-6, IL-8 and TNF-a) were measured in EDTA plasma samples with commercially available 4-plex sandwich immunoassay kits (Meso Scale Discovery (MSD), Rockville, MD, US). For this study, the intra- and inter-assay coefficients of 
variation were $3.0 \%$ and $4.7 \%$ for CRP, $2.6 \%$ and $7.5 \%$ for SAA, $2.5 \%$ and $5.3 \%$ for sICAM-1, $7.2 \%$ and $12.7 \%$ for IL-6, $3.1 \%$ and $5.6 \%$ for IL-8, and $4.3 \%$ and $7.5 \%$ for TNF-a, respectively.

\section{Glucose metabolism status}

As described previously ${ }^{34}$, to determine glucose metabolism, all participants (except those who used insulin) underwent a standardized 7-point oral glucose tolerance test (OGTT) after an overnight fast. Blood samples were taken at baseline, and at 15, 30, 45, 60, 90 and 120 minutes after ingestion of a $75 \mathrm{~g}$ glucose drink. For safety reasons, participants with a fasting glucose level above $11.0 \mathrm{mmol} / \mathrm{l}$, as determined by a finger prick, did not undergo the OGTT. For these individuals $(n=13)$, fasting glucose level and information about diabetes medication use were used to determine glucose metabolism status. Glucose metabolism was defined according to the WHO 2006 criteria into normal glucose tolerance (NGT), impaired fasting glucose (IFG), impaired glucose tolerance (IGT), and T2DM ${ }^{39}$. For this study, we defined having either IFG or IGT as impaired glucose metabolism (IGM).

\section{Measures of peripheral neuropathy and diabetic nephropathy}

Vibration perception threshold (VPT) was measured as a marker of peripheral neuropathy. VPT was assessed using a hand-held neurothesiometer (Horwell Scientific Laboratory Supplies, Nottingham, UK). After a test procedure on the participant's elbow, VPT was tested three times at the distal phalanx of the hallux of the right and left foot. The minimum VPT at which the subject was aware of vibration sensation was recorded to the nearest $0.5 \mathrm{~V}$, starting from $0.0 \mathrm{~V}$ with stimulation up to $50.0 \mathrm{~V}$. The mean of the three measurements for the least sensitive foot was used in further analyses 40,41 . Peripheral sensory neuropathy was defined as VPT $\geq 25 \mathrm{~V}$ (2). To assess urinary albumin excretion, participants were requested to collect two 24-hour urine collections. Urinary albumin concentration was measured with a standard immunoturbidimetric assay by an automatic analyser (Beckman Synchron LX20, Beckman Coulter Inc., Brea, USA) and multiplied by collection volume to obtain the 24-hour urinary albumin excretion. Urinary albumin concentration below the detection limit of the assay $(2 \mathrm{mg} / \mathrm{l})$, the urinary albumin concentration was set at $1.5 \mathrm{mg} / \mathrm{l}$ before multiplying by collection volume. Only urine collections with a collection time between 20 and 28 hours were considered valid. If needed, urinary albumin excretion was extrapolated to a 24-hours' excretion. Microalbuminuria was defined as a urinary albumin excretion of 30-300 mg per 24 hours whereas macroalbuminuria was defined as a urinary albumin excretion of $\geq 300 \mathrm{mg}$ per 24 hours ${ }^{42}$. These definitions were preferably based on the average of two (90\%) 24-hour urine collections.

\section{Covariates}

As described previously ${ }^{34}$, fasting venous blood samples were used to assess total cholesterol, LDL and HDL cholesterol, triglycerides, creatinine and HbA1c. Serum total cholesterol, HDL cholesterol, triglycerides, albumin and serum and urine creatinine and uric acid levels were measured with standard (enzymatic and/or colorimetric) methods by an automatic analyzer (Beckman Synchron LX20, Beckman Coulter Inc., Brea, USA). LDL cholesterol was calculated according to the Friedewald formula ${ }^{43}$. Serum creatinine was measured with a Jaffé method traceable to isotope dilution mass spectrometry (Beckman Synchron LX20, Beckman Coulter Inc., Brea, USA). Glomerular filtration rate (eGFR) was estimated using the CKD-EPI (Chronic Kidney Disease Epidemiology Collaboration) equation based on serum creatinine ${ }^{44}$. HbA1c was measured with ion-exchange high performance liquid chromatography (HPLC) (Variant tm II, Bio-Rad, Hercules, California, USA). Urinary albumin was measured with a immunoturbidimetric assay 
(Cobas c systems, Roche diagnostics, Mannheim, Germany). Waist circumference was measured in duplicate midway between the lower rib margin and the iliac crest at the end of expiration, to the nearest $0.5 \mathrm{~cm}$, with a flexible plastic tape measure (Seca, Hamburg, Germany). Participants were requested to bring all the medication they used at the time of measurement or a list from their pharmacists to the research center. During a medication interview generic name, dose and frequency, and additional over-the-counter (OTC) medication use were registered by trained staff. All participants received extensive web-based questionnaires. Duration of diabetes was assessed by using the year of diagnosis reported in the questionnaire. Smoking status (never, former, current) was based on smoking cigarettes, cigars and/or pipe tobacco. History of cardiovascular disease was assessed with a modified version of the Rose Questionnaire for the diagnosis of ischemic heart pain and intermittent claudication ${ }^{45}$ and defined as self-reported myocardial infarction, and/or cerebrovascular infarction or hemorrhage, and/or percutaneous artery angioplasty of, or vascular surgery on, the coronary arteries, abdominal arteries, peripheral arteries or carotid arteries. Office blood pressure was determined three times on the right arm after a 10-minute rest period, using a non-invasive blood pressure monitor (Omron 705IT, Japan). Hypertension was defined as office systolic blood pressure $\geq 140 \mathrm{mmHg}$, diastolic blood pressure $\geq 90$ and/or the use of antihypertensive medication. Carotid to femoral pulse wave velocity (cfPWV) was determined according to recent guidelines ${ }^{46}$ with the use of applanation tonometry (SphygmoCor, Atcor Medical, Sydney, Australia). Pressure waveforms were determined at the right common carotid and right common femoral arteries. The pulse wave travel distance was calculated as $80 \%$ of the direct straight distance (measured with an infantometer) between the two arterial sites. The median of three consecutive cfPWV (defined as traveled distance/transit time) recordings was used in the analyses.

\section{Statistical analyses}

Analyses were conducted using SPSS version 21 for Windows. Comparisons of baseline characteristics between groups were made by use of the independent sample t-test or $x^{2}$ tests, whatever appropriate. Variables with a skewed distribution were $\log _{10}$-transformed before analysis. We used standardized multiple linear regression analysis to evaluate the association between SAF and plasma AGEs on the one hand and ABI and CIMT on the other. We investigated whether or not these associations differed between individuals with different glucose metabolism status by adding interaction terms in our models (e.g. the product of: 1) SAF or plasma AGE levels, and 2) glucose metabolism status). We evaluated mediation by adding the possible mediator to the model and then compared the standardized regression coefficients of the model before and after the introduction of the possible mediator. P-values $<0.05$ were considered statistically significant, except for interaction terms, where a p-value $<0.10$ was considered statistically significant. 


\section{RESULTS}

\section{General characteristics}

Table 6.1 shows the general characteristics of the 862 individuals included in our study, stratified for $A B I{ }^{47,} 48$ or CIMT ${ }^{49}$. Individuals with a low ABI or high CIMT were more likely to be older, smoke, have T2DM, hypertension, albuminuria, peripheral sensory neuropathy, a history of CVD, or be on antihypertensive or lipid-modifying medication. Also, they had higher HbA1c, waist circumference, systolic blood pressure, cfPWV, LGI and ED z-score and lower eGFR. Individuals with a low ABI or high CIMT had a higher SAF. Plasma CML was lower in individuals with a low ABI, whereas plasma pentosidine was higher in individuals with higher CIMT. Plasma CEL levels did not differ between groups. Mean \pm standard deviation HbA1c was $5.6 \pm 0.3$ in individuals with NGM, $5.9 \pm 0.4$ in individuals with IGM and $6.9 \pm 0.9$ in individuals with T2DM.

\section{Association between SAF and the ankle-brachial index}

Higher SAF was significantly associated with a lower ABI ( $s \beta-0.13,95 \%-C I-0.21 ;-0.05)$ after adjustment for age, sex, glucose metabolism status, waist circumference, smoking, systolic and diastolic blood pressure, antihypertensive, lipid-modifying and oral antidiabetic medication use, insulin use, eGFR, total-to-HDL-cholesterol ratio, triglycerides and CVD (Table 6.2, model 2). Additional adjustment for peripheral sensory neuropathy and albuminuria, as markers of microvascular disease, did not materially change the associations between SAF and the ABI (s $\beta$ 0.13 vs $s \beta-0.13)$. Exclusion of individuals with an $A B I>1.3(n=18 ; 11$ with NGM, 3 with IGM and 4 with T2DM), which potentially indicates arterial calcification in individuals with diabetes, did not materially change this association ( $s \beta-0.15$ vs $s \beta-0.13$ ). The association between SAF and the ABI could not be explained by differences in cfPWV ( $s \beta-0.13$ vs $s \beta-0.13$ ) or the difference in glucose metabolism status between individuals ( $p$-values for interaction $>0.10$ ). Additionally, we evaluated whether the association between SAF and the ABI was mediated (i.e. explained) by ED or LGI. We found no mediation by ED ( $s \beta-0.12$ vs. $s \beta-0.12$ ) or LGI ( $s \beta-0.11$ vs. $s \beta-0.12$ ).

\section{Associations between plasma AGEs and the ankle-brachial index}

Higher plasma CML was associated with a higher ABI ( $s \beta 0.13,95 \%-C I \quad 0.06 ; 0.21)$ after full adjustment (Table 6.2, model 2), while pentosidine and CEL were not. Additional adjustment for peripheral sensory neuropathy and albuminuria, did not materially change the association between plasma CML and the $A B I$ ( $s \beta 0.12$ vs. $s \beta 0.12$ ), nor did exclusion of individuals with an $A B I>1.3$ ( $s \beta 0.12$ vs. $s \beta 0.13$ ) or additional adjustment for cfPWV ( $s \beta 0.14$ vs $s \beta 0.14$ ). Furthermore, we evaluated whether the association between plasma $C M L$ and the $A B I$ was mediated (i.e. explained) by ED or LGI. We found no such mediation of ED ( $s \beta 0.13$ vs. $s \beta 0.14$ ) or LGI (s $\beta 0.12$ vs. s $\beta$ 0.13 ). The association between plasma CML and the $A B I$ was not significantly different between individuals with different glucose metabolism status ( $p$-values for interaction $>0.10$ ).

\section{Associations between SAF and intima-media thickness}

We found no association between SAF and CIMT ( $\mathrm{S} \beta-0.02$ 95\%-CI -0.10;0.06) after full adjustment (Table 6.3, model 2). However, the association between SAF and cIMT was significantly different in individuals with IGM (s $30.35,95 \%$-CI $0.08 ; 0.63)$, as compared to those with NGM ( $s \beta-0.04,95 \%$-CI $-0.15 ; 0.06)$ or T2DM ( $s \beta-0.14,95 \%-C I-0.28 ; 0.01)$ ( $p$ for interaction IGM vs. NGM=0.01; IGM vs. T2DM $=0.01)$. 


\section{Associations between plasma AGEs and intima-media thickness}

Higher plasma CEL was associated with lower cIMT after full adjustment ( $s \beta-0.07,95 \%-C I$ $0.14 ; 0.00$, Table 6.3, model 2), while plasma pentosidine and CML were not. Additional adjustment for peripheral sensory neuropathy and albuminuria, did not materially change the association between plasma CEL and CIMT ( $s \beta-0.04$ vs s $\beta-0.04$ ). The association between plasma CEL and cIMT was more pronounced in individuals with IGM (s $\beta-0.20,95 \%-C I-0.40 ; 0.01)$ compared to those with NGM (s $\beta-0.04,95 \%-C I-0.12 ; 0.05$ ) or T2DM (s $\beta-0.04,95 \%-C I-0.16 ; 0.09$ ) ( $p$ for interaction IGM vs. NGM $=0.01$; IGM vs. $\mathrm{T} 2 \mathrm{DM}=0.09$ ). 
Table 6.1. General characteristics of The Maastricht Study participants

\begin{tabular}{|c|c|c|c|}
\hline & \multicolumn{3}{|c|}{ Ankle-brachial index $(n=842)$} \\
\hline & $\begin{array}{c}\text { ABI 1.0-1.4* } \\
(n=776)\end{array}$ & $\begin{array}{c}A B I \leq 1.0 * \\
(n=64)\end{array}$ & $\begin{array}{c}p- \\
\text { value }\end{array}$ \\
\hline NGM/IGM/T2DM (\%) & $56 / 17 / 27$ & $30 / 12 / 58$ & $<0.001$ \\
\hline Age (years) & $60 \pm 8$ & $64 \pm 8$ & $<0.001$ \\
\hline Sex (number of males/females) & $423 / 353$ & $37 / 27$ & 0.610 \\
\hline Diabetes duration $(y)$ & $7[3-11]$ & $7[2-12]$ & 0.989 \\
\hline HbA1c (\%) & $6.0 \pm 0.8$ & $6.5 \pm 1.1$ & 0.001 \\
\hline $\mathrm{HbA1c}(\mathrm{mmol} / \mathrm{mol})$ & $42 \pm 8$ & $47 \pm 12$ & 0.001 \\
\hline Oral antidiabetic medication ( $\mathrm{n}(\%)$ ) & $153(20)$ & $27(42)$ & $<0.001$ \\
\hline Insulin use (n (\%)) & $41(5)$ & $11(17)$ & $<0.001$ \\
\hline Smoking, never/former/current (\%) & $32 / 53 / 15$ & $11 / 53 / 36$ & $<0.001$ \\
\hline Waist circumference $(\mathrm{cm})$ & $96 \pm 13$ & $105 \pm 17$ & $<0.001$ \\
\hline Total-to-HDL cholesterol ratio & $4.2 \pm 1.3$ & $4.0 \pm 1.0$ & 0.056 \\
\hline Triglycerides (mmol/L) & $1.2[0.9-1.8]$ & $1.5[1.0-1.8]$ & 0.098 \\
\hline Lipid-modifying medication ( $\mathrm{n}(\%)$ ) & $275(35)$ & $37(58)$ & $<0.001$ \\
\hline eGFRCKD-EPI ( $\left(\mathrm{ml} / \mathrm{min} / 1.73 \mathrm{~m}^{2}\right)$ & $85 \pm 15$ & $81 \pm 15$ & 0.038 \\
\hline Albuminuria (normo/micro/macro) (\%) & $93 / 6 / 1$ & $79 / 18 / 3$ & 0.001 \\
\hline Peripheral sensory neuropathy (n (\%)) & $60(11)$ & $8(16)$ & 0.239 \\
\hline Systolic blood pressure (mmHg) & $137 \pm 19$ & $142 \pm 22$ & 0.066 \\
\hline Diastolic blood pressure $(\mathrm{mmHg})$ & $77 \pm 10$ & $75 \pm 10$ & 0.154 \\
\hline Hypertension (n (\%)) & $438(57)$ & $48(75)$ & 0.004 \\
\hline Anti-hypertensive medication ( $\mathrm{n}(\%)$ ) & $292(38)$ & $42(66)$ & $<0.001$ \\
\hline cfPWV (m/s) & $8.9 \pm 2.1$ & $9.7 \pm 2.7$ & 0.052 \\
\hline History of CVD (n (\%)) & $121(16)$ & $27(44)$ & $<0.001$ \\
\hline LGI z-score & $-0.05 \pm 0.99$ & $0.61 \pm 0.92$ & $<0.001$ \\
\hline ED z-score & $-0.04 \pm 0.99$ & $0.41 \pm 0.99$ & 0.001 \\
\hline $\operatorname{SAF}(A U)$ & $2.68 \pm 0.51$ & $3.13 \pm 0.62$ & $<0.001$ \\
\hline Pentosidine (nmol/mmol LYS) & $0.47[0.39-0.57]$ & $0.44[0.35-0.55]$ & 0.380 \\
\hline CML (nmol/mmol LYS) & $74.9 \pm 14.7$ & $67.7 \pm 12.7$ & $<0.001$ \\
\hline CEL (nmol/mmol LYS) & $34.1 \pm 10.3$ & $34.3 \pm 10.3$ & 0.871 \\
\hline Ankle-brachial index & $1.15 \pm 0.07$ & $0.89 \pm 0.12$ & - \\
\hline Carotid intima-media thickness $(\mu \mathrm{m})$ & $849 \pm 147$ & $897 \pm 194$ & 0.066 \\
\hline
\end{tabular}

Data are presented as mean \pm standard deviation (SD) or as median [inter quartile range (IQR)], unless otherwise indicated.

NGM, normal glucose metabolism; IGM, impaired glucose metabolism; T2DM, type 2 diabetes; HbA1c, glycated hemoglobin; $\mathrm{HDL}$, high-density lipoprotein; eGFRCKD-EPI, estimated Glomerular Filtration Rate; CVD, cardiovascular disease; SAF, skin autofluorescence; CML, N(epsilon)-(carboxymethyl)lysine; CEL, N(epsilon)-(carboxyethyl)lysine.

*cut-off value base on Aboyans et al. (AHA) (46) and Clairotte et al. (47)

${ }^{\wedge}$ cut-off value based on Mancia et al. (ESH/ESC) (48) 
Table 6.1. General characteristics of The Maastricht Study participants (continued)

\begin{tabular}{|c|c|c|c|}
\hline & \multicolumn{3}{|c|}{ Carotid intima-media thickness $(n=817)$} \\
\hline & $\begin{array}{c}\text { cIMT } \leq 900 \mu \mathrm{m}^{\wedge} \\
(n=549)\end{array}$ & $\begin{array}{c}\text { CIMT }>900 \mu \mathrm{m}^{\wedge} \\
(n=268)\end{array}$ & p-value \\
\hline NGM/IGM/T2DM (\%) & $61 / 15 / 24$ & $43 / 17 / 40$ & $<0.001$ \\
\hline Age (years) & $58 \pm 9$ & $63 \pm 7$ & $<0.001$ \\
\hline Sex (number of males/females) & $273 / 276$ & $172 / 96$ & $<0.001$ \\
\hline Diabetes duration $(y)$ & $7[3-11]$ & $7[4-12]$ & 0.174 \\
\hline HbA1c (\%) & $5.9 \pm 0.7$ & $6.2 \pm 0.9$ & $<0.001$ \\
\hline $\mathrm{HbA1c}(\mathrm{mmol} / \mathrm{mol})$ & $41 \pm 8$ & $44 \pm 10$ & $<0.001$ \\
\hline Oral antidiabetic medication ( $\mathrm{n}(\%)$ ) & $99(18)$ & $75(28)$ & 0.001 \\
\hline Insulin use (n (\%)) & $30(6)$ & $21(8)$ & 0.188 \\
\hline Smoking, never/former/current (\%) & $34 / 50 / 16$ & $24 / 58 / 18$ & 0.019 \\
\hline Waist circumference $(\mathrm{cm})$ & $96 \pm 14$ & $99 \pm 13$ & 0.008 \\
\hline Total-to-HDL cholesterol ratio & $4.2 \pm 1.3$ & $4.3 \pm 1.2$ & 0.062 \\
\hline Triglycerides (mmol/L) & $1.18[0.85-1.74]$ & $1.35[0.90-1.81]$ & 0.028 \\
\hline Lipid-modifying medication ( $\mathrm{n}(\%)$ ) & $175(32)$ & $122(46)$ & $<0.001$ \\
\hline eGFR CKD-EPI $_{\left(\mathrm{ml} / \mathrm{min} / 1.73 \mathrm{~m}^{2}\right)}$ & $86 \pm 15$ & $82 \pm 14$ & 0.002 \\
\hline Albuminuria (normo/micro/macro) (\%) & $93 / 6 / 1$ & $89 / 9 / 2$ & 0.056 \\
\hline Peripheral sensory neuropathy ( $\mathrm{n}(\%)$ ) & $33(8)$ & $34(18)$ & $<0.001$ \\
\hline Systolic blood pressure (mmHg) & $134 \pm 18$ & $143 \pm 20$ & $<0.001$ \\
\hline Diastolic blood pressure $(\mathrm{mmHg})$ & $76 \pm 10$ & $77 \pm 10$ & 0.630 \\
\hline Hypertension (n (\%)) & $281(51)$ & $189(71)$ & $<0.001$ \\
\hline Anti-hypertensive medication ( $\mathrm{n}(\%)$ ) & $197(36)$ & $129(48)$ & 0.001 \\
\hline $\operatorname{cfPWV}(\mathrm{m} / \mathrm{s})$ & $8.7 \pm 2.0$ & $9.6 \pm 2.3$ & $<0.001$ \\
\hline History of CVD (n (\%)) & $78(15)$ & $65(25)$ & $<0.001$ \\
\hline LGI z-score & $-0.09 \pm 1.00$ & $0.17 \pm 0.94$ & 0.001 \\
\hline ED z-score & $-0.06 \pm 1.00$ & $0.11 \pm 0.96$ & 0.028 \\
\hline $\operatorname{SAF}(A U)$ & $2.66 \pm 0.52$ & $2.82 \pm 0.55$ & $<0.001$ \\
\hline Pentosidine (nmol/mmol LYS) & $0.46[0.38-0.55]$ & $0.47[0.39-0.59]$ & 0.013 \\
\hline CML (nmol/mmol LYS) & $74.2 \pm 14.8$ & $74.9 \pm 14.8$ & 0.538 \\
\hline CEL (nmol/mmol LYS) & $34.4 \pm 10.2$ & $33.8 \pm 10.4$ & 0.439 \\
\hline Ankle-brachial index & $1.13 \pm 0.10$ & $1.13 \pm 0.11$ & 0.302 \\
\hline Carotid intima-media thickness $(\mu \mathrm{m})$ & $768 \pm 82$ & $1023 \pm 114$ & - \\
\hline
\end{tabular}

Data are presented as mean \pm standard deviation (SD) or as median [inter quartile range (IQR)], unless otherwise indicated.

NGM, normal glucose metabolism; IGM, impaired glucose metabolism; T2DM, type 2 diabetes; HbA1c, glycated hemoglobin;

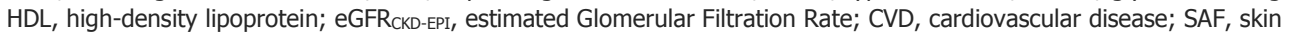
autofluorescence; CML, N(epsilon)-(carboxymethyl)lysine; CEL, N(epsilon)-(carboxyethyl)lysine.

*cut-off value base on Aboyans et al. (AHA) (46) and Clairotte et al. (47)

$\wedge^{\wedge}$ Cut-off value based on Mancia et al. (ESH/ESC) (48) 
Table 6.2. Associations between SAF, pentosidine, CML and CEL on the one hand and ABI on the other

\begin{tabular}{lcccc}
\hline & & \multicolumn{3}{c}{ ABI } \\
& & \multicolumn{3}{c}{$\left(\mathbf{n = 7 5 8 * / 7 7 3 ^ { \# } )}\right.$} \\
\cline { 2 - 5 } & Model & $\boldsymbol{s} \boldsymbol{\beta}$ & $\mathbf{9 5 \%} \boldsymbol{C I}$ & $\boldsymbol{p}$-value \\
\hline SAF & 1 & -0.17 & $-0.25--0.09$ & $<0.001$ \\
Plasma pentosidine & 2 & -0.13 & $-0.21--0.05$ & 0.002 \\
& 1 & 0.07 & $0.00-0.14$ & 0.047 \\
Plasma CML & 2 & 0.06 & $-0.01-0.14$ & 0.088 \\
& 1 & 0.14 & $0.08-0.21$ & $<0.001$ \\
Plasma CEL & 2 & 0.13 & $0.06-0.21$ & 0.001 \\
& 1 & 0.04 & $-0.03-0.11$ & 0.279 \\
& 2 & 0.06 & $-0.01-0.13$ & 0.091 \\
\hline
\end{tabular}

Standardized $\beta$, the standardized regression coefficient obtained with linear regression analyses, indicates the change ABI (in SD) per 1 SD higher skin autofluorescence (SAF) or level of plasma advanced glycation endproducts, i.e. plasma pentosidine, CML (N(epsilon)-(carboxymethyl)lysine) and CEL (N(epsilon)-(carboxyethyl)lysine).

*for SAF; \# for plasma AGEs. There were 758 individuals (420 with NGM, 123 with IGM and 215 with T2DM) included in the analyses between SAF and the ABI, and 773 individuals (425 with NGM, 128 with IGM and 220 with T2DM) in the analyses between plasma AGEs and the ABI.

Model 1 is adjusted for age, sex and glucose metabolism status. Model 2 is additionally adjusted for waist circumference, smoking, systolic and diastolic blood pressure, antihypertensive, lipid-modifying and oral antidiabetic medication use, insulin use, eGFR, total-to-HDL-cholesterol ratio, triglycerides and CVD.

Table 6.3. Associations between SAF, pentosidine, CML and CEL on the one hand and carotid IMT on the other

\begin{tabular}{lcccc}
\hline & & \multicolumn{3}{c}{$\begin{array}{c}\text { CIMT } \\
\left(\mathbf{n}=\mathbf{7 3 7} / \mathbf{7 5 2} \mathbf{2}^{*}\right)\end{array}$} \\
\cline { 2 - 5 } & Model & $\boldsymbol{s} \boldsymbol{\beta}$ & $\mathbf{9 5 \%} \boldsymbol{C I}$ & $\boldsymbol{p}$-value \\
\hline SAF & 1 & 0.00 & $-0.08-0.08$ & 0.948 \\
& 2 & -0.02 & $-0.10-0.06$ & 0.591 \\
Plasma pentosidine & 1 & 0.03 & $-0.04-0.10$ & 0.459 \\
Plasma CML & 2 & 0.01 & $-0.06-0.09$ & 0.715 \\
& 1 & 0.03 & $-0.04-0.10$ & 0.379 \\
Plasma CEL & 2 & 0.03 & $-0.05-0.10$ & 0.497 \\
& 1 & -0.06 & $-0.13-0.00$ & 0.061 \\
& 2 & -0.07 & $-0.14-0.00$ & 0.038 \\
\hline
\end{tabular}

Standardized $\beta$, the standardized regression coefficient obtained with linear regression analyses, indicates the change cIMT (in SD) per 1 SD higher skin autofluorescence (SAF) or level of plasma advanced glycation endproducts, i.e. plasma pentosidine, CML (N(epsilon)-(carboxymethyl)lysine) and CEL (N(epsilon)-(carboxyethyl)lysine).

Model 1 is adjusted for age, sex and glucose metabolism status. Model 2 is additionally adjusted for waist circumference, smoking, systolic and diastolic blood pressure, antihypertensive, lipid-modifying and oral antidiabetic medication use, insulin use, eGFR, total-to-HDL-cholesterol ratio, triglycerides and CVD.*for SAF; "for plasma AGEs. There were 737 individuals (414 with NGM, 116 with IGM and 207 with T2DM) included in the analyses between SAF and CIMT, and 752 individuals (419 with NGM, 121 with IGM and 212 with T2DM) in the analyses between plasma AGEs and cIMT. 


\section{DISCUSSION}

This study had three main findings. First, higher SAF was independently associated with a lower $A B I$, whereas we found no association between SAF and CIMT. Second, higher plasma CML was independently associated with a higher ABI, and higher plasma CEL was independently associated with lower cIMT. Some of these associations were different between individuals with NGM, IGM and T2DM. Third, the association between higher SAF and a lower ABI was not mediated by LGI, ED or cfPWV.

This is the first study to describe an association between higher SAF and a lower ABI in a population-based sample of individuals with NGM, IGM and T2DM. Our findings are in agreement with other studies that show an association between higher SAF and a lower ABI in selected populations. Monami et al. observed an association between SAF and arteriopathy of the lower limbs in individuals with T2DM ${ }^{50}$. Others found SAF to be higher in individuals with PAD compared with those without ${ }^{23,24}$ and to predict amputation in patients with PAD ${ }^{51}$. The study by de Vos et al. ${ }^{24}$ describes a negative trend in the association between SAF and the ABI; however, this was not statistically significant. The ankle-brachial index (ABI) was originally proposed as a noninvasive measure in the diagnosis of peripheral arterial disease (PAD). Later, it became apparent that the ABI is able to predict cardiovascular events, even in absence of symptoms of PAD $47,52-$ 54. Our findings suggest that tissue AGE accumulation might be involved in the development of peripheral atherosclerosis and, possibly, subsequent CVD.

We found no association between SAF and CIMT in our population. However, analyses stratified for glucose metabolism status revealed a positive association in individuals with IGM only. To our knowledge, we are the first to describe such an association in individuals with IGM. Lutgers et al. did find a positive association between SAF and cIMT in non-diabetic subjects without clinically manifest cardiovascular disease ${ }^{27}$, as did den Dekker et al. in individuals referred for cardiovascular primary or secondary prevention ${ }^{55}$. We do not have a clear explanation for the finding of a positive association between SAF and CIMT in individuals with IGM, while we did not find an association in T2DM. Therefore, we cannot exclude that this finding is caused by the play of chance. We expected SAF to be associated with both the ABI and CIMT, as both are thought to be indicators of atherosclerosis, but found only an association with the ABI. Accordingly, a previous study found that femoral IMT was independently associated with T2DM, whereas CIMT was not 56. Both this study and our results could indicate that hyperglycaemia is a greater risk factor for peripheral than carotid atherosclerosis. This is supported by the fact that in T2DM, atherosclerosis is generally located more peripherally compared with individuals without diabetes ${ }^{57-59}$.

We found inconsistent associations between plasma AGEs and the ABI or CIMT. Only plasma CML was associated with a higher ABI, while only CEL was negatively associated with CIMT. This is in contrast with previous studies, which have shown that non-specified serum AGEs and serum pentosidine were associated with a lower ABI 60,61 . However, these studies had a small sample size and, predominantly, used ELISA-techniques to measure AGEs. To our knowledge, we are the first to describe a negative association between CEL and CIMT. For CML and pentosidine, one study found no association between plasma CML and CIMT in the general population ${ }^{62}$, while another does describe a positive association between serum pentosidine and CIMT in individuals 
with T2DM 63. Our study together with previous studies reveal inconsistent findings when investigating the relationship between plasma AGEs and the ABI or CIMT. It has previously been hypothesized that SAF may be a better reflection of tissue AGE accumulation than plasma AGEs 64. This may partially be explained by the trapping of AGEs by the receptor for AGEs (RAGE) in adipose tissue, causing a decrease in plasma AGE levels in obese individuals ${ }^{65,66}$. As there is a higher prevalence of obesity among individuals with IGM and T2DM, this may explain our results regarding the positive association between plasma CML and ABI. However, adjustment for waist circumference, as a marker of obesity, did not materially change this association, making this proposed explanation less likely. Taken together, this may suggest that plasma AGEs are not adequately reflecting tissue AGE accumulation, especially in IGM and T2DM.

We found that the association between higher SAF and a lower ABI could not be explained by LGI or ED. This finding is in accordance with earlier studies in T1DM ${ }^{67-69}$. AGEs are thought to lead to atherosclerosis through their binding to RAGE, inducing the generation of pro-inflammatory cytokines, expression of adhesion molecules and the stimulation of oxidative stress ${ }^{14-21}$, all linked to the development of atherosclerosis ${ }^{70,71}$. Based on our findings, we conclude that other mechanisms besides LGI and ED must be involved in the association between AGEs and atherosclerosis. Oxidative stress may provide such a mechanism, which we were not able to investigate in this study. Arterial calcification 69,72 may be another, however, we found that our associations did not change after exclusion of individuals with an $A B I>1.3$. It has been proposed that in individuals with diabetes, an ABI $>1.3$ is already indicative of arterial calcification ${ }^{73}$.

Measures of atherosclerosis are associated with measures of arterial stiffness ${ }^{30-32}$. In this same cohort study, we previously found a positive association between SAF and plasma pentosidine on the one hand and aortic stiffness on the other ${ }^{74}$. Therefore, we investigated whether or not adjustment for cfPWV, considered the 'gold standard' for the measurement of arterial stiffness 33 , attenuated the associations between SAF and plasma AGEs on the one hand and the ABI and CIMT on the other. We found that the associations between AGEs and atherosclerosis did not materially change after adjustment for cfPWV, indicating that the associations we observed are indeed reflecting the association between AGEs and measures of atherosclerosis.

\section{Strengths and limitations of the study}

One of the strengths of our study is that we analysed two well-established estimates of atherosclerosis: the ABI and CIMT. We analysed estimates of AGEs in the skin by SAF as well as the well-characterised protein-bound AGEs pentosidine, CML and CEL in plasma by state-of the art analytical techniques. Furthermore, we studied these associations in a large population based cohort study with additional samples of well-defined sub-cohorts of individuals with T2DM or IGM. Additionally, we measured six different markers representing LGI and five markers representing ED. We then combined them in an overall z-score of LGI and ED to be used in our analyses. This increases validity and limits the loss of power to detect an association. A limitation of our study is the cross-sectional design; therefore, we cannot draw any conclusions about causality in the association between AGE accumulation and the ABI or cIMT.

\section{Conclusions}

Higher levels of SAF were associated with a lower ABI in a large cohort study of individuals with NGM, IGM and T2DM. We found contrasting results evaluating these associations for plasma AGEs, 
indicating that SAF might a better reflection of tissue AGE accumulation than plasma AGEs. Our results regarding SAF support the hypothesis that AGE accumulation is involved in the development of lower-limb atherosclerosis and arterial disease. 


\section{REFERENCES}

1. Sarwar N, Gao P, Seshasai SR, Gobin R, Kaptoge S, Di Angelantonio E, Ingelsson E, Lawlor DA, Selvin E, Stampfer M, Stehouwer CD, Lewington S, Pennells L, Thompson A, Sattar N, White IR, Ray KK, Danesh J. Diabetes mellitus, fasting blood glucose concentration, and risk of vascular disease: A collaborative meta-analysis of 102 prospective studies. Lancet. 2010;375:2215-2222

2. Seshasai SR, Kaptoge S, Thompson A, Di Angelantonio E, Gao P, Sarwar N, Whincup PH, Mukamal KJ, Gillum RF, Holme I, Njolstad I, Fletcher A, Nilsson P, Lewington S, Collins R, Gudnason V, Thompson SG, Sattar N, Selvin E, Hu FB, Danesh J. Diabetes mellitus, fasting glucose, and risk of cause-specific death. N Engl J Med. 2011;364:829-841

3. Blake DR, Meigs JB, Muller DC, Najjar SS, Andres R, Nathan DM. Impaired glucose tolerance, but not impaired fasting glucose, is associated with increased levels of coronary heart disease risk factors: Results from the baltimore longitudinal study on aging. Diabetes. 2004;53:2095-2100

4. Levitan EB, Song Y, Ford ES, Liu S. Is nondiabetic hyperglycemia a risk factor for cardiovascular disease? A metaanalysis of prospective studies. Arch Intern Med. 2004;164:2147-2155

5. Aronson D, Rayfield EJ. How hyperglycemia promotes atherosclerosis: Molecular mechanisms. Cardiovasc Diabetol. 2002;1:1

6. Bornfeldt KE, Tabas I. Insulin resistance, hyperglycemia, and atherosclerosis. Cell Metab. 2011;14:575-585

7. Brownlee M. Biochemistry and molecular cell biology of diabetic complications. Nature. 2001;414:813-820

8. Hanssen NM, Beulens JW, van Dieren S, Scheijen JL, van der AD, Spijkerman AM, van der Schouw YT, Stehouwer CD, Schalkwijk CG. Plasma advanced glycation end products are associated with incident cardiovascular events in individuals with type 2 diabetes: A case-cohort study with a median follow-up of 10 years (epic-nl). Diabetes. 2015;64:257-265

9. van Eupen MG, Schram MT, Colhoun HM, Hanssen NM, Niessen HW, Tarnow L, Parving HH, Rossing P, Stehouwer CD, Schalkwijk CG. The methylglyoxal-derived age tetrahydropyrimidine is increased in plasma of individuals with type 1 diabetes mellitus and in atherosclerotic lesions and is associated with svcam-1. Diabetologia. 2013;56:1845-1855

10. Baidoshvili A, Niessen HW, Stooker W, Huybregts RA, Hack CE, Rauwerda JA, Meijer CJ, Eijsman L, van Hinsbergh VW, Schalkwijk CG. N(omega)-(carboxymethyl)lysine depositions in human aortic heart valves: Similarities with atherosclerotic blood vessels. Atherosclerosis. 2004;174:287-292

11. Hanssen NM, Wouters K, Huijberts MS, Gijbels MJ, Sluimer JC, Scheijen JL, Heeneman S, Biessen EA, Daemen MJ, Brownlee M, de Kleijn DP, Stehouwer CD, Pasterkamp G, Schalkwijk CG. Higher levels of advanced glycation endproducts in human carotid atherosclerotic plaques are associated with a rupture-prone phenotype. European heart journal. 2014;35:1137-1146

12. Park L, Raman KG, Lee KJ, Lu Y, Ferran LJ, Jr., Chow WS, Stern D, Schmidt AM. Suppression of accelerated diabetic atherosclerosis by the soluble receptor for advanced glycation endproducts. Nat Med. 1998;4:1025-1031

13. Forbes JM, Yee LT, Thallas V, Lassila M, Candido R, Jandeleit-Dahm KA, Thomas MC, Burns WC, Deemer EK, Thorpe $\mathrm{SR}$, Cooper ME, Allen TJ. Advanced glycation end product interventions reduce diabetes-accelerated atherosclerosis. Diabetes. 2004;53:1813-1823

14. Rashid G, Benchetrit S, Fishman D, Bernheim J. Effect of advanced glycation end-products on gene expression and synthesis of tnf-alpha and endothelial nitric oxide synthase by endothelial cells. Kidney international. 2004;66:10991106

15. Schmidt AM, Hori O, Chen JX, Li JF, Crandall J, Zhang J, Cao R, Yan SD, Brett J, Stern D. Advanced glycation endproducts interacting with their endothelial receptor induce expression of vascular cell adhesion molecule-1 (vcam1 ) in cultured human endothelial cells and in mice. A potential mechanism for the accelerated vasculopathy of diabetes. J Clin Invest. 1995;96:1395-1403

16. Uchida Y, Ohba K, Yoshioka T, Irie K, Muraki T, Maru Y. Cellular carbonyl stress enhances the expression of plasminogen activator inhibitor-1 in rat white adipocytes via reactive oxygen species-dependent pathway. J Biol Chem. 2004;279:4075-4083

17. Ramasamy R, Yan SF, Schmidt AM. The diverse ligand repertoire of the receptor for advanced glycation endproducts and pathways to the complications of diabetes. Vascul Pharmacol. 2012;57:160-167

18. Basta G, Lazzerini G, Massaro M, Simoncini T, Tanganelli P, Fu C, Kislinger T, Stern DM, Schmidt AM, De Caterina R. Advanced glycation end products activate endothelium through signal-transduction receptor rage: A mechanism for amplification of inflammatory responses. Circulation. 2002;105:816-822

19. Bierhaus A, Humpert PM, Stern DM, Arnold B, Nawroth PP. Advanced glycation end product receptor-mediated cellular dysfunction. Ann N Y Acad Sci. 2005; 1043:676-680

20. Goldin A, Beckman JA, Schmidt AM, Creager MA. Advanced glycation end products: Sparking the development of diabetic vascular injury. Circulation. 2006;114:597-605

21. Basta G, Schmidt AM, De Caterina R. Advanced glycation end products and vascular inflammation: Implications for accelerated atherosclerosis in diabetes. Cardiovasc Res. 2004;63:582-592

22. Meerwaldt R, Graaff R, Oomen PH, Links TP, Jager JJ, Alderson NL, Thorpe SR, Baynes JW, Gans RO, Smit AJ. Simple non-invasive assessment of advanced glycation endproduct accumulation. Diabetologia. 2004;47:1324-1330

23. Noordzij MJ, Lefrandt JD, Loeffen EA, Saleem BR, Meerwaldt R, Lutgers HL, Smit AJ, Zeebregts CJ. Skin autofluorescence is increased in patients with carotid artery stenosis and peripheral artery disease. Int J Cardiovasc Imaging. 2012;28:431-438

24. de Vos LC, Noordzij MJ, Mulder DJ, Smit AJ, Lutgers HL, Dullaart RP, Kamphuisen PW, Zeebregts CJ, Lefrandt JD. Skin autofluorescence as a measure of advanced glycation end products deposition is elevated in peripheral artery disease. Arterioscler Thromb Vasc Biol. 2013;33:131-138 
25. Araszkiewicz A, Naskret D, Zozulinska-Ziolkiewicz D, Pilacinski S, Uruska A, Grzelka A, Wegner M, Wierusz-Wysocka B. Skin autofluorescence is associated with carotid intima-media thickness, diabetic microangiopathy, and long-lasting metabolic control in type 1 diabetic patients. Results from poznan prospective study. Microvascular research. 2015;98:62-67

26. den Hollander NC, Mulder DJ, Graaff R, Thorpe SR, Baynes JW, Smit GP, Smit AJ. Advanced glycation end products and the absence of premature atherosclerosis in glycogen storage disease ia. J Inherit Metab Dis. 2007;30:916-923

27. Lutgers HL, Graaff R, de Vries R, Smit AJ, Dullaart RP. Carotid artery intima media thickness associates with skin autofluoresence in non-diabetic subjects without clinically manifest cardiovascular disease. Eur J Clin Invest. 2010;40:812-817

28. Ueno H, Koyama H, Fukumoto S, Tanaka S, Shoji T, Emoto M, Tahara H, Inaba M, Kakiya R, Tabata T, Miyata T, Nishizawa Y. Advanced glycation end products, carotid atherosclerosis, and circulating endothelial progenitor cells in patients with end-stage renal disease. Metabolism. 2011;60:453-459

29. Tanaka K, Katoh T, Asai J, Nemoto F, Suzuki H, Asahi K, Sato K, Sakaue M, Miyata T, Watanabe T. Relationship of skin autofluorescence to cardiovascular disease in japanese hemodialysis patients. Ther Apher Dial. 2010;14:334-340

30. Taniwaki H, Shoji T, Emoto M, Kawagishi T, Ishimura E, Inaba M, Okuno Y, Nishizawa Y. Femoral artery wall thickness and stiffness in evaluation of peripheral vascular disease in type 2 diabetes mellitus. Atherosclerosis. 2001;158:207214

31. van Popele NM, Grobbee DE, Bots ML, Asmar R, Topouchian J, Reneman RS, Hoeks AP, van der Kuip DA, Hofman A, Witteman JC. Association between arterial stiffness and atherosclerosis: The rotterdam study. Stroke. 2001;32:454460

32. Catalano M, Scandale G, Carzaniga G, Cinquini M, Minola M, Dimitrov G, Carotta M. Increased aortic stiffness and related factors in patients with peripheral arterial disease. J Clin Hypertens (Greenwich). 2013;15:712-716

33. Laurent S, Cockcroft J, Van Bortel L, Boutouyrie P, Giannattasio C, Hayoz D, Pannier B, Vlachopoulos C, Wilkinson I, Struijker-Boudier H. Expert consensus document on arterial stiffness: Methodological issues and clinical applications. European heart journal. 2006;27:2588-2605

34. Schram MT, Sep SJ, van der Kallen CJ, Dagnelie PC, Koster A, Schaper N, Henry RM, Stehouwer CD. The maastricht study: An extensive phenotyping study on determinants of type 2 diabetes, its complications and its comorbidities. Eur J Epidemiol. 2014;29:439-451

35. Koetsier M, Nur E, Chunmao H, Lutgers HL, Links TP, Smit AJ, Rakhorst G, Graaff R. Skin color independent assessment of aging using skin autofluorescence. Opt Express. 2010;18:14416-14429

36. Scheijen JL, van de Waarenburg MP, Stehouwer CD, Schalkwijk CG. Measurement of pentosidine in human plasma protein by a single-column high-performance liquid chromatography method with fluorescence detection. J Chromatogr B Analyt Technol Biomed Life Sci. 2009;877:610-614

37. Hanssen NM, Engelen L, Ferreira I, Scheijen JL, Huijberts MS, van Greevenbroek MM, van der Kallen CJ, Dekker JM, Nijpels G, Stehouwer CD, Schalkwijk CG. Plasma levels of advanced glycation endproducts $\mathrm{n}\{$ epsilon\}(carboxymethyl)lysine, $\mathrm{n}\{$ epsilon\}-(carboxyethyl)lysine, and pentosidine are not independently associated with cardiovascular disease in individuals with or without type 2 diabetes: The hoorn and codam studies. J Clin Endocrinol Metab. 2013;98:E1369-1373

38. de Valk-de Roo GW, Stehouwer CD, Lambert J, Schalkwijk CG, van der Mooren MJ, Kluft C, Netelenbos C. Plasma homocysteine is weakly correlated with plasma endothelin and von willebrand factor but not with endotheliumdependent vasodilatation in healthy postmenopausal women. Clin Chem. 1999;45:1200-1205

39. (WHO) WHO. Definition and diagnosis of diabetes mellitus and intermediate hyperglycemia: Report of a who/idf consultation. Geneva, Switzerland: World Health Organization (WHO); 2006.

40. Boulton AJ, Malik RA, Arezzo JC, Sosenko JM. Diabetic somatic neuropathies. Diabetes Care. 2004;27:1458-1486

41. Karvestedt L, Martensson E, Grill V, Elofsson S, von Wendt G, Hamsten A, Brismar K. Peripheral sensory neuropathy associates with micro- or macroangiopathy: Results from a population-based study of type 2 diabetic patients in sweden. Diabetes Care. 2009;32:317-322

42. K/doqi clinical practice guidelines for chronic kidney disease: Evaluation, classification, and stratification. Am J Kidney Dis. 2002;39:S1-266

43. Friedewald WT, Levy RI, Fredrickson DS. Estimation of the concentration of low-density lipoprotein cholesterol in plasma, without use of the preparative ultracentrifuge. Clin Chem. 1972;18:499-502

44. Levey AS, Stevens LA, Schmid CH, Zhang YL, Castro AF, 3rd, Feldman HI, Kusek JW, Eggers P, Van Lente F, Greene T, Coresh J. A new equation to estimate glomerular filtration rate. Ann Intern Med. 2009;150:604-612

45. Leng GC, Fowkes FG. The edinburgh claudication questionnaire: An improved version of the who/rose questionnaire for use in epidemiological surveys. J Clin Epidemiol. 1992;45:1101-1109

46. Van Bortel LM, Laurent $S$, Boutouyrie P, Chowienczyk P, Cruickshank JK, De Backer T, Filipovsky J, Huybrechts S, Mattace-Raso FU, Protogerou AD, Schillaci G, Segers P, Vermeersch S, Weber T, Artery S, European Society of Hypertension Working Group on Vascular S, Function, European Network for Noninvasive Investigation of Large A. Expert consensus document on the measurement of aortic stiffness in daily practice using carotid-femoral pulse wave velocity. Journal of hypertension. 2012;30:445-448

47. Aboyans V, Criqui MH, Abraham P, Allison MA, Creager MA, Diehm C, Fowkes FG, Hiatt WR, Jonsson B, Lacroix $P$, Marin B, McDermott MM, Norgren L, Pande RL, Preux PM, Stoffers HE, Treat-Jacobson D. Measurement and interpretation of the ankle-brachial index: A scientific statement from the american heart association. Circulation. 2012;126:2890-2909

48. Clairotte C, Retout S, Potier L, Roussel R, Escoubet B. Automated ankle-brachial pressure index measurement by clinical staff for peripheral arterial disease diagnosis in nondiabetic and diabetic patients. Diabetes Care. 2009;32:1231-1236

49. Mancia G, De Backer G, Dominiczak A, Cifkova R, Fagard R, Germano G, Grassi G, Heagerty AM, Kjeldsen SE, Laurent S, Narkiewicz K, Ruilope L, Rynkiewicz A, Schmieder RE, Struijker Boudier HA, Zanchetti A, Vahanian A, Camm J, De 
Caterina R, Dean V, Dickstein K, Filippatos G, Funck-Brentano C, Hellemans I, Kristensen SD, McGregor K, Sechtem U, Silber S, Tendera M, Widimsky P, Zamorano JL, Erdine S, Kiowski W, Agabiti-Rosei E, Ambrosioni E, Lindholm LH, Manolis A, Nilsson PM, Redon J, Struijker-Boudier HA, Viigimaa M, Adamopoulos S, Bertomeu V, Clement D, Farsang C, Gaita D, Lip G, Mallion JM, Manolis AJ, O'Brien E, Ponikowski P, Ruschitzka F, Tamargo J, van Zwieten P, Waeber B, Williams $B$, The task force for the management of arterial hypertension of the European Society of $H$, The task force for the management of arterial hypertension of the European Society of C. 2007 guidelines for the management of arterial hypertension: The task force for the management of arterial hypertension of the european society of hypertension (esh) and of the european society of cardiology (esc). European heart journal. 2007;28:1462-1536

50. Monami M, Lamanna C, Gori F, Bartalucci F, Marchionni N, Mannucci E. Skin autofluorescence in type 2 diabetes: Beyond blood glucose. Diabetes Res Clin Pract. 2008;79:56-60

51. de Vos LC, Boersema J, Mulder DJ, Smit AJ, Zeebregts CJ, Lefrandt JD. Skin autofluorescence as a measure of advanced glycation end products deposition predicts 5-year amputation in patients with peripheral artery disease. Arterioscler Thromb Vasc Biol. 2015;35:1532-1537

52. Criqui MH, Langer RD, Fronek A, Feigelson HS, Klauber MR, McCann TJ, Browner D. Mortality over a period of 10 years in patients with peripheral arterial disease. N Engl J Med. 1992;326:381-386

53. Fowkes FG, Murray GD, Butcher I, Heald CL, Lee RJ, Chambless LE, Folsom AR, Hirsch AT, Dramaix M, deBacker G, Wautrecht JC, Kornitzer M, Newman AB, Cushman M, Sutton-Tyrrell K, Lee AJ, Price JF, d'Agostino RB, Murabito JM, Norman PE, Jamrozik K, Curb JD, Masaki KH, Rodriguez BL, Dekker JM, Bouter LM, Heine RJ, Nijpels G, Stehouwer CD, Ferrucci L, McDermott MM, Stoffers HE, Hooi JD, Knottnerus JA, Ogren M, Hedblad B, Witteman JC, Breteler MM, Hunink MG, Hofman A, Criqui MH, Langer RD, Fronek A, Hiatt WR, Hamman R, Resnick HE, Guralnik J. Ankle brachial index combined with framingham risk score to predict cardiovascular events and mortality: A meta-analysis. Jama. 2008;300:197-208

54. McDermott MM, Guralnik JM, Tian L, Liu K, Ferrucci L, Liao Y, Sharma L, Criqui MH. Associations of borderline and low normal ankle-brachial index values with functional decline at 5-year follow-up: The walcs (walking and leg circulation study). J Am Coll Cardiol. 2009;53:1056-1062

55. den Dekker MA, Zwiers M, van den Heuvel ER, de Vos LC, Smit AJ, Zeebregts CJ, Oudkerk M, Vliegenthart R, Lefrandt JD, Mulder DJ. Skin autofluorescence, a non-invasive marker for age accumulation, is associated with the degree of atherosclerosis. PLoS One. 2013;8:e83084

56. Faeh D, William J, Yerly P, Paccaud F, Bovet P. Diabetes and pre-diabetes are associated with cardiovascular risk factors and carotid/femoral intima-media thickness independently of markers of insulin resistance and adiposity. Cardiovasc Diabetol. 2007;6:32

57. Diehm N, Shang A, Silvestro A, Do DD, Dick F, Schmidli J, Mahler F, Baumgartner I. Association of cardiovascular risk factors with pattern of lower limb atherosclerosis in 2659 patients undergoing angioplasty. Eur J Vasc Endovasc Surg. 2006;31:59-63

58. Jude EB, Oyibo SO, Chalmers N, Boulton AJ. Peripheral arterial disease in diabetic and nondiabetic patients: A comparison of severity and outcome. Diabetes Care. 2001;24:1433-1437

59. Rueda CA, Nehler MR, Perry DJ, McLafferty RB, Casserly IP, Hiatt WR, Peyton BD. Patterns of artery disease in 450 patients undergoing revascularization for critical limb ischemia: Implications for clinical trial design. J Vasc Surg. 2008;47:995-999; discussion 999-1000

60. Takahashi R, Imamura A, Yoshikane M, Suzuki M, Murakami R, Cheng XW, Numaguchi Y, Ikeda N, Murohara T, Okumura K. High serum concentrations of pentosidine, an advanced glycation end product, are associated with low normal value of ankle-brachial index in apparently healthy men. Metabolism. 2011;60:649-654

61. Lapolla A, Piarulli F, Sartore G, Ceriello A, Ragazzi E, Reitano R, Baccarin L, Laverda B, Fedele D. Advanced glycation end products and antioxidant status in type 2 diabetic patients with and without peripheral artery disease. Diabetes Care. 2007;30:670-676

62. Baumann M, Richart T, Sollinger D, Pelisek J, Roos M, Kouznetsova T, Eckstein HH, Heemann U, Staessen JA. Association between carotid diameter and the advanced glycation end product $\mathrm{n}$-epsilon-carboxymethyllysine $(\mathrm{cml})$. Cardiovasc Diabetol. 2009;8:45

63. Yoshida N, Okumura K, Aso Y. High serum pentosidine concentrations are associated with increased arterial stiffness and thickness in patients with type 2 diabetes. Metabolism. 2005;54:345-350

64. Smit AJ, Hartog JW, Voors AA, van Veldhuisen DJ. Advanced glycation endproducts in chronic heart failure. Ann N Y Acad Sci. 2008;1126:225-230

65. Gaens $\mathrm{KH}$, Stehouwer CD, Schalkwijk CG. Advanced glycation endproducts and its receptor for advanced glycation endproducts in obesity. Curr Opin Lipidol. 2013;24:4-11

66. Gaens KH, Goossens GH, Niessen PM, van Greevenbroek MM, van der Kallen C], Niessen HW, Rensen SS, Buurman WA, Greve JW, Blaak EE, van Zandvoort MA, Bierhaus A, Stehouwer CD, Schalkwijk CG. Nepsilon(carboxymethyl)lysine-receptor for advanced glycation end product axis is a key modulator of obesity-induced dysregulation of adipokine expression and insulin resistance. Arterioscler Thromb Vasc Biol. 2014;34:1199-1208

67. Schram MT, Chaturvedi N, Schalkwijk CG, Fuller JH, Stehouwer CD. Markers of inflammation are cross-sectionally associated with microvascular complications and cardiovascular disease in type 1 diabetes--the eurodiab prospective complications study. Diabetologia. 2005;48:370-378

68. Nin JW, Jorsal A, Ferreira I, Schalkwijk CG, Prins MH, Parving HH, Tarnow L, Rossing P, Stehouwer CD. Higher plasma levels of advanced glycation end products are associated with incident cardiovascular disease and all-cause mortality in type 1 diabetes: A 12-year follow-up study. Diabetes Care. 2011;34:442-447

69. van Eupen MG, Schram MT, Colhoun HM, Scheijen JL, Stehouwer CD, Schalkwijk CG. Plasma levels of advanced glycation endproducts are associated with type 1 diabetes and coronary artery calcification. Cardiovasc Diabetol. 2013;12:149 
70. Ross R. Atherosclerosis--an inflammatory disease. N Engl J Med. 1999;340:115-126

71. Son SM, Whalin MK, Harrison DG, Taylor WR, Griendling KK. Oxidative stress and diabetic vascular complications. Curr Diab Rep. 2004;4:247-252

72. Brodeur MR, Bouvet C, Bouchard S, Moreau S, Leblond J, Deblois D, Moreau P. Reduction of advanced-glycation end products levels and inhibition of rage signaling decreases rat vascular calcification induced by diabetes. PLoS One. 2014;9:e85922

73. Potier L, Abi Khalil C, Mohammedi K, Roussel R. Use and utility of ankle brachial index in patients with diabetes. Eur J Vasc Endovasc Surg. 2011;41:110-116

74. van Eupen MG, Schram MT, van Sloten TT, Scheijen J, Sep SJ, van der Kallen CJ, Dagnelie PC, Koster A, Schaper N, Henry RM, Kroon AA, Smit AJ, Stehouwer CD, Schalkwijk CG. Skin autofluorescence and pentosidine are associated with aortic stiffening: The maastricht study. Hypertension. 2016;68:956-96 



\section{CHAPTER 7}

Associations of advanced glycation endproducts with cognitive decline in individuals with and without type 2 diabetes The Maastricht Study

Peggy J.J. Spauwen, Marcelle G.A. van Eupen, Sebastian Köhler, Coen DA Stehouwer, Frans R.J. Verhey, Carla J van der Kallen, Simone JS Sep, Annemarie Koster, Nicolaas Schaper, Pieter C Dagnelie, Casper G Schalkwijk, Miranda T. Schram, Martin P.J. van Boxtel The Journal of Clinical Endocrinology and Metabolism 2015;100:951-60 


\section{ABSTRACT}

\section{Context}

Advanced glycation endproducts (AGEs) are thought to be involved in the pathogenesis of Alzheimer's disease. AGEs are products resulting from non-enzymatic chemical reactions between reduced sugars and proteins, which accumulate during natural aging and their accumulation is accelerated in hyperglycemic conditions such as type 2 diabetes mellitus.

\section{Objective}

Examine associations between AGEs and cognitive functions

\section{Design, setting, participants}

This study was performed as part of The Maastricht study, a population-based cohort study, in which, by design, 215 participants (28.1\%) had type 2 diabetes mellitus.

\section{Main outcome measures}

We examined associations of skin autofluorescence (SAF) $(n=764)$, an overall estimate of skin AGEs, and specific plasma protein-bound AGEs $(n=781)$ with performance on tests for global cognitive functioning, information processing speed, verbal memory (immediate and delayed word recall), and response inhibition.

\section{Results}

After adjustment for demographics, diabetes, smoking, alcohol, waist circumference, total cholesterol/HDL cholesterol ratio, triglycerides, and lipid-lowering medication use, higher SAF was significantly associated with worse delayed word recall (regression coefficient $b=-0.44, P=0.04$ ), and response inhibition $(b=0.03, P=0.04)$. After further adjustment for systolic blood pressure, cardiovascular disease, estimated glomerular filtration rate, and depression, associations were attenuated (delayed word recall: $b=-0.38, P=0.07$; response inhibition: $b=0.02, P=0.07$ ). Higher pentosidine levels were associated with worse global cognitive functioning $(b=-0.61, P=0.04)$ after full adjustment, but other plasma AGEs were not. Associations did not differ between individuals with and without diabetes.

\section{Conclusion}

We found inverse associations of SAF, a non-invasive marker for tissue AGES, with cognitive performance, which were attenuated after adjustment for vascular risk factors and depression. 


\section{INTRODUCTION}

Dementia is highly prevalent worldwide and the number of people with dementia is expected to increase rapidly. ${ }^{1}$ The most common cause of dementia is Alzheimer's disease (AD), which is characterized by progressive decline in cognitive function, more specifically memory loss. It is associated with the presence and the accumulation of neurofibrillary tangles and amyloid plaques in the brain. ${ }^{2}$ Although the etiology of dementia has not been elucidated, the relationship between, on the one hand, type 2 diabetes mellitus and other cardiovascular risk factors including hypertension, obesity and smoking, and the development of dementia and cognitive decline on the other has become more evident. ${ }^{3,4}$

Advanced glycation endproducts (AGEs), which are products resulting from non-enzymatic chemical reactions between reduced sugars and proteins, ${ }^{5}$ are thought to be involved in the pathogenesis of AD. ${ }^{6}$ AGEs accumulate during natural aging and their accumulation is accelerated in hyperglycemic conditions such as type 2 diabetes. ${ }^{5,7}$ Long-lived proteins, including $\beta$-amyloid $(A \beta)$, have been found to be modified by AGEs and a recent study has shown that the formation of $A G E$-modified $A \beta$ exacerbates the toxicity of $A \beta .{ }^{8} A G E s$ are present in both neurofibrillary tangles and senile plaques of patients with Alzheimer's disease (AD) ${ }^{9}$ and the receptor for AGE (RAGE) appears to be involved in the transport of amyloid peptides through the blood-brain barrier. ${ }^{10}$ In addition, $A D$ patients with type 2 diabetes seem to have more severe $A D$ pathology and higher AGE levels in the brain compared with those with $A D$ alone. ${ }^{9}$

AGEs can be measured in plasma (circulating AGEs) or estimated in tissue using a relative simple non-invasive measurement of skin autofluorescence (SAF), a method based on the fluorescent properties of some AGEs. ${ }^{11}$ SAF has been suggested to be a simple alternative to invasive measurement of AGE accumulation and has shown to be correlated with fluorescent (pentosidine) and even non-fluorescent plasma AGEs (N(epsilon)-(carboxymethyl)lysine (CML) and N(epsilon)(carboxyethyl)lysine (CEL)) in biopsy-derived skin tissue. ${ }^{11}$ In addition, SAF has recently been shown to be associated with lower grey matter volume ${ }^{12}$ and it may therefore be hypothesized that SAF indicates AGE accumulation in other tissue, like the brain, as well. Furthermore, SAF may reflect AGE accumulation more accurately than plasma proteins as intracellular glycation is thought to be the major local source of AGEs and not all AGEs may end up in the circulation. ${ }^{13,14}$

Although there is evidence that AGEs might be associated with dementia and cognitive decline, research on the relationship between AGEs and cognitive functions is scarce. Yaffe et al. ${ }^{15}$ have shown that the AGE pentosidine, measured in its free form in urine, was associated with a greater 9 -year cognitive decline in older people independent of diabetes status. Furthermore, Chen et al. ${ }^{16}$ showed that higher levels of serum AGEs were cross-sectionally associated with Mild Cognitive Impairment (MCI) in diabetic patients. No study to date has investigated the relationship between SAF and cognitive performance on multiple cognitive domains. One recent study has shown a cross-sectional association between higher SAF and a higher likelihood of cognitive impairment, but did not examine associations with separate cognitive functions. ${ }^{12}$

Examination of the association between AGEs and cognitive function might provide a marker for cognitive impairment and might increase our knowledge about the etiology of cognitive decline 
and dementia. Therefore, the aim of our study was to examine the associations of SAF and plasma AGEs with performance on a range of cognitive tests in participants from The Maastricht Study, a population-based cohort study. Next, we investigated whether or not these associations were different in participants with and without type 2 diabetes.

\section{MATERIALS AND METHODS}

\section{Study populations}

In this study, we used data from The Maastricht Study, an observational prospective populationbased cohort study. The rationale and methodology have been described previously. ${ }^{17}$ In brief, the study focuses on the etiology, pathophysiology, complications and comorbidities of type 2 diabetes mellitus and is characterized by an extensive phenotyping approach. Eligible for participation were all individuals aged between 40 and 75 years and living in the southern part of the Netherlands. Participants were recruited through mass media campaigns and from the municipal registries and the regional Diabetes Patient Registry via mailings. Recruitment was stratified according to known type 2 diabetes status for reasons of efficiency. The present report includes cross-sectional data from the first 866 participants, who completed the baseline survey between November 2010 and March 2012. The examinations of each participant were performed within a time window of three months. The study has been approved by the institutional medical ethical committee (NL31329.068.10) and the Netherlands Health Council under the Dutch "Law for Population Studies" (Permit 131088-105234-PG). All participants gave written informed consent.

\section{Skin autofluorescence}

All participants were asked to refrain from smoking and caffeine at least 3 hours before the measurements. A light meal (breakfast and (or) lunch), low in fat content, was allowed. SAF was measured with the AGE Reader ${ }^{\mathrm{TM}}$ (DiagnOptics Technologies BV, Groningen, the Netherlands). The AGE reader is a desktop device that uses the characteristic fluorescent properties of certain AGEs to estimate the level of AGE accumulation in the skin. Technical details of this non-invasive method have been described more extensively elsewhere. ${ }^{11}$ In short, the AGE Reader illuminates a skin surface of $4 \mathrm{~cm}^{2}$ guarded against surrounding light, with an excitation wavelength range of $300-420 \mathrm{~nm}$, with a peak excitation of $370 \mathrm{~nm}$. SAF was calculated as the ratio between the emission light from the skin in the wavelength range of 420-600 nm (fluorescence) and excitation light that is reflected by the skin (300-420nm), multiplied by 100 and expressed in arbitrary units (AU). Participants were asked not to use any sunscreen or self-browning creams on their lower arms within 2 days before the measurement. SAF was measured at room temperature in a semidark environment while participants were at rest in a seated position. The forearm of a participant was positioned on top of the device, as described by the manufacturer. The mean of three consecutive measurements was used in the analyses. Reproducibility was assessed in 14 individuals without diabetes (6 males; $32.2 \pm 7.1$ years). The intraclass correlation coefficient (ICC) of three intra-individual consecutive SAF measurements was 0.83 (95\% CI 0.65-0.94). SAF was calculated off-line by automated analysis using AGE Reader software, version 2.3, and was observer-independent. There were no significant differences between fasting and non-fasting measurements (mean difference $=0.01 \mathrm{AU}, P=0.73$ ). Reproducibility in individuals with type 2 
diabetes has been evaluated previously ${ }^{11}$ with an overall Altman error percentage of $5.03 \%$ for measurements taken over a single day. Skin pigmentation is known to influence the measurement of SAF. ${ }^{18}$ Therefore, in participants with dark-colored skin with a reflectance of $6-10 \%$, a validated reflectance dependent correction was made by the software. ${ }^{18}$ Measurements in participants with dark-colored skin and a mean reflectance below $6 \%$ are considered unreliable and are therefore not used to calculate SAF by the software. Therefore, these participants were automatically excluded. Additionally, a single SAF value above 10 AU was considered as unreliable; these individual measurements $(n=3)$ were manually excluded and the mean of the remaining two measurements was used in analyses.

\section{Analysis of protein- bound AGEs and lysine in plasma}

Plasma AGEs were measured in EDTA samples obtained from fasting venous blood, which were stored at $-80^{\circ} \mathrm{C}$ until analysis. Protein-bound pentosidine was quantified using HPLC with fluorescence detection, as described in detail elsewhere. ${ }^{19}$ Intra- and interassay coefficients of variation (CVs), as analyzed in this study, were 6.5 and $7.8 \%$ for pentosidine, respectively. Proteinbound CML, CEL and lysine were quantified using UPLC MS/MS. ${ }^{14}$. Intra- and interassay CVs were 4.5 and $6.7 \%$ for CML, 6.2 and $10.3 \%$ for CEL and 5.0 and $5.3 \%$ for lysine. Concentrations of protein-bound pentosidine, CML and CEL were adjusted for levels of lysine and expressed as $\mathrm{nmol} / \mathrm{mmol}$ lysine.

\section{Assessment of cognitive function}

A concise battery (30 min) of cognitive tests was used to assess cognitive functioning. ${ }^{17}$ An a priori selection of these cognitive tests was used in the current study. Since diabetes is strongly linked to AGE accumulation, we have chosen tests that each represent cognitive domains (i.e. information processing speed, verbal memory, and executive functions) which are often used and have been shown to be most sensitive to effects of diabetes. ${ }^{20} \mathrm{Global}$ cognitive functioning was measured by the Mini-Mental state examination (MMSE) (score range 0-30). ${ }^{21}$ Verbal memory was assessed with the Visual Verbal Word Learning Test. ${ }^{22}$ In this test, 15 words are presented in five subsequent trials, followed by a recall phase immediately after each trial (immediate recall) (score range 0-75), and a delayed recall phase 20 minutes thereafter (delayed recall) (score range 015). Response inhibition was measured with the Stroop Color Word Test. ${ }^{23}$ The variable of interest was the interference measure expressed in seconds. The Letter-Digit Substitution Test ${ }^{24}$ was used to measure information processing speed. Participants were instructed to match digits to letters as quickly as possible within 90 seconds.

\section{Covariates}

History of cardiovascular disease, diabetes duration, smoking status (never, former, current) and alcohol consumption were assessed by questionnaire. ${ }^{17}$ Participants were regarded as having a history of cardiovascular disease if they reported to have had a: myocardial infarction, and/or cerebrovascular infarction or hemorrhage, and/or percutaneous artery angioplasty of, or vascular surgery on, the coronary, abdominal, peripheral or carotid arteries. Alcohol consumption was classified into three categories: non-consumers, low-consumers ( $\leq 7$ glasses per week for females and $\leq 14$ glasses per week for males) and high-consumers ( $>7$ glasses per week for females and $>14$ glasses per week for males). Lipid-lowering, antihypertensive, and glucose-lowering medication use were assessed during a medication interview where generic name, dose and 
frequency were registered. ${ }^{17}$ Waist circumference, glycosylated hemoglobin A1c (HbA1c), glucose levels, total and high-density lipoprotein (HDL) cholesterol, creatinine, and triglycerides were determined as described elsewhere. ${ }^{17}$ Estimated glomerular filtration rate (eGFR) was estimated according to the CKD-EPI (Chronic Kidney Disease Epidemiology Collaboration) equation. ${ }^{25}$ Office blood pressure was determined three times on the right arm after a 10-minute rest period, using a non-invasive blood pressure monitor (Omron 705IT, Japan). ${ }^{17}$

To determine glucose metabolism, all participants (except those who use insulin) underwent a standardized 7-point OGTT after an overnight fast as previously described. ${ }^{17}$ Glucose metabolism was defined according to the WHO 2006 criteria into normal glucose tolerance (NGT), impaired fasting glucose (IFG), impaired glucose tolerance (IGT), and type 2 diabetes. ${ }^{26}$ Additionally, individuals without type 1 diabetes and on diabetes medication were considered as having type 2 diabetes. ${ }^{17}$ For this study we defined having either IFG or IGT as impaired glucose metabolism (IGM).

Level of education was assessed during the cognitive assessment and was classified into 8 categories commonly used in the Netherlands ${ }^{27}$ : (1) no education, (2) primary education, (3) lower vocational education, (4) intermediate general secondary education, (5) intermediate vocational education, (6) higher general secondary education, (7) higher vocational education, (8) university. For this study, three groups were created for educational level: low (level 1 to 3 ), intermediate (level 4 to 6), and high (level 7-8). Depression was assessed by the Mini International Neuropsychiatric Interview (MINI). ${ }^{17,28}$

\section{Statistical analyses}

Analyses were conducted using the SPSS software, version 20 for Mac OSX. Differences between tertiles of SAF were tested using analysis of variance for continuous variables and chi-square-tests for categorical variables. Multiple linear regression analysis was used to estimate the association of SAF and of plasma AGEs with cognitive performance, adjusted for different sets of covariates in separate models. In Model 1 , we adjusted for age, which is a known predictor of AGE accumulation and cognitive performance and therefore considered as an important potential confounder. In Model 2 we added other potential important confounders: sex, educational level, and diabetes (yes/no). In Model 3, we additionally adjusted for cardiovascular risk factors that have been previously associated with higher AGE accumulation and with cognitive performance, and therefore may be potential confounders (i.e. smoking, alcohol, waist circumference, total cholesterol/HDL cholesterol ratio, triglycerides, and lipid-lowering medication use). Finally, in Model 4, we adjusted for variables that could be potential mediators of the associations between AGEs and cognition, because they may be caused by higher AGE accumulation and may cause cognitive impairment (i.e. systolic blood pressure, cardiovascular disease, depression, and eGFR). Interaction effects were tested to examine whether the association of SAF and plasma AGEs with cognitive performance differed between participants with and without diabetes. Pentosidine levels and response inhibition scores were log-transformed before regression analysis, because they were positively skewed. A $P$-value of $<0.05$ was considered statistically significant in two-sided tests. 


\section{RESULTS}

\section{Sample}

Four individuals with type 1 diabetes and 4 participants who did not undergo cognitive assessment were excluded. Of the remaining 858 participants, we additionally excluded individuals with missing data on the independent variables SAF $(n=31)$ or plasma AGEs $(n=19)$, or on potential confounders $(n=63)$. This resulted in 764 individuals available for complete case analyses with SAF and 781 individuals for complete case analyses with plasma AGEs. Participants excluded due to missing values were more likely to have diabetes, to use insulin, had higher levels of $\mathrm{HbA1C}$ and SAF, and had lower scores for cognitive performance (global cognitive functioning, information processing speed, immediate word recall, and response inhibition $(P<0.05))$. There were no differences in other characteristics (data not shown).

Characteristics of the 764 participants included for analyses with SAF are shown in Table 7.1, stratified according to tertiles of SAF. Of these, 215 participants (28.1\%) had type 2 diabetes, of whom $35(16.3 \%)$ participants were newly diagnosed at study entry. Median diabetes duration was 7.0 years (interquartile range $=3.0-11.0)$, and mean $\mathrm{HbA1c}$ level was $6.9 \%(\mathrm{SD}=+/-0.8)$. Of the 549 participants without diabetes, 126 participants ( $16.5 \%$ of the total sample) had IGM.

Mean scores for cognitive tests in the total sample were $28.9(\mathrm{SD}=+/-1.2)$ for global cognitive functioning, 48.8 digits $(S D=+/-9.3)$ for information processing speed, 45.4 words $(S D=+/-9.7)$ for immediate word recall, and 9.5 words $(S D=+/-2.9)$ for delayed word recall. The median score for response inhibition was 41.7 seconds (IQR=31.9-55.9). Participants with type 2 diabetes had significantly lower scores on all cognitive measures compared with those with NGT $(P<0.001)$ after adjustment for age, while participants with IGM did not perform significantly worse on any cognitive test compared with those with NGT ( $P>0.10$ for all cognitive measures). We therefore combined participants with NGT with those with IGM for the interaction analyses.

Tertiles of SAF were significantly associated with age, educational level, glucose metabolism status, smoking status, alcohol consumption, waist circumference, systolic blood pressure, history of cardiovascular disease, $\mathrm{HbA} 1 \mathrm{c}$ level, antihypertensive medication use, lipid-lowering medication use, glucose-lowering medication use, eGFR, pentosidine level, and cognitive functions (Table 7.1). 
Table 7.1 Characteristics of the study group $(\mathrm{N}=764)$, stratified by tertiles of skin autofluorescence

\begin{tabular}{|c|c|c|c|c|}
\hline Characteristic & Low $(n=254)$ & Middle $(n=255)$ & High $(n=255)$ & $P$-value \\
\hline Skin autofluorescence $(A U)$, mean (SD) & $2.17(0.20)$ & $2.65(0.12)$ & $3.27(0.38)$ & - \\
\hline Age $(y)$, mean $(S D)$ & $54.9(8.7)$ & $60.2(7.3)$ & $63.8(6.9)$ & $<0.001$ \\
\hline Sex: Male, n (\%) & $129(50.8)$ & $138(54.1)$ & $154(60.4)$ & 0.09 \\
\hline Educational level, low/middle/high, n (\%) & $\begin{array}{c}26 / 98 / 130 \\
(10.2 / 38.6 / 51.2)\end{array}$ & $\begin{array}{c}31 / 106 / 118 \\
(12.2 / 41.6 / 46.3)\end{array}$ & $\begin{array}{c}66 / 108 / 81 \\
(25.9 / 42.4 / 31.8)\end{array}$ & $<0.001$ \\
\hline $\begin{array}{l}\text { Glucose metabolism status, NGT/IGM/T2DM, } \\
\text { n (\%) }\end{array}$ & $\begin{array}{c}175 / 41 / 38 \\
(68.9 / 16.1 / 15.0)\end{array}$ & $\begin{array}{c}153 / 38 / 64 \\
(60.0 / 14.9 / 25.1)\end{array}$ & $\begin{array}{c}95 / 47 / 113 \\
(37.3 / 18.4 / 44.3)\end{array}$ & $<0.001$ \\
\hline Smoking status, never/former/current, n (\%) & $\begin{array}{c}97 / 133 / 24 \\
(38.2 / 52.4 / 9.4)\end{array}$ & $\begin{array}{c}80 / 135 / 40 \\
(31.4 / 52.9 / 15.7)\end{array}$ & $\begin{array}{c}62 / 139 / 54 \\
(24.3 / 54.5 / 21.2)\end{array}$ & 0.001 \\
\hline Alcohol consumption, none/low/high, n (\%) & $\begin{array}{c}39 / 141 / 74 \\
(15.4 / 55.5 / 29.1)\end{array}$ & $\begin{array}{c}34 / 126 / 95 \\
(13.4 / 49.4 / 37.3)\end{array}$ & $\begin{array}{c}57 / 136 / 62 \\
(22.4 / 53.3 / 24.3)\end{array}$ & 0.01 \\
\hline Waist circumference $(\mathrm{cm})$, mean (SD) & $95.2(12.1)$ & $96.0(3.0)$ & $100.0(15.1)$ & $<0.001$ \\
\hline Systolic blood pressure $(\mathrm{mmHg})$, mean (SD) & $134.1(16.9)$ & $137.4(19.2)$ & $139.6(20.1)$ & 0.01 \\
\hline Antihypertensive medication, n (\%) & $68(26.8)$ & $95(37.4)$ & $140(55.1)$ & $<0.001$ \\
\hline Lipid-lowering medication, n (\%) & $56(22.0)$ & $88(34.5)$ & $130(51.0)$ & $<0.001$ \\
\hline $\begin{array}{l}\text { Glucose-lowering medication } \\
\text { None/orala/insulin, } \mathrm{n}(\%)\end{array}$ & $\begin{array}{c}229 / 22 / 3 \\
(90.2 / 8.7 / 1.2)\end{array}$ & $\begin{array}{c}207 / 42 / 6 \\
(81.2 / 16.5 / 2.4)\end{array}$ & $\begin{array}{c}160 / 66 / 29 \\
(62.7 / 25.9 / 11.4)\end{array}$ & $<0.001$ \\
\hline Cardiovascular disease, $\mathrm{n}(\%)$ & $31(12.2)$ & $36(14.1)$ & $70(27.5)$ & $<0.001$ \\
\hline HbA1c (\%), mean (SD) & $5.8(0.5)$ & $5.9(0.7)$ & $6.3(0.9)$ & $<0.001$ \\
\hline Triglycerides (mmol/l), median (IQR) & $1.20(0.82-1.73)$ & $1.24(0.85-1.76)$ & $1.23(0.88-1.88)$ & $0.59 *$ \\
\hline Total cholesterol/HDL cholesterol, mean (SD) & $4.24(1.26)$ & $4.24(1.24)$ & $4.18(1.27)$ & 0.84 \\
\hline eGFR ml/min $/ 1.73 \mathrm{~m}^{2}$, mean (SD) & $89.1(13.84)$ & $85.83(13.27)$ & $79.86(14.15)$ & $<0.001$ \\
\hline Depression, n (\%) & $8(3.1)$ & $9(3.5)$ & $14(5.5)$ & 0.36 \\
\hline Pentosidine nmol/mmol LYS, median (IQR) & $0.45(0.37-0.53)$ & $0.47(0.38-0.55)$ & $0.50(0.40-0.60)$ & $<0.001^{*}$ \\
\hline CML nmol/mmol LYS, mean (SD) & $74.8(14.2)$ & $74.6(14.3)$ & $73.8(15.9)$ & 0.67 \\
\hline CEL nmol/mmol LYS, mean (SD) & $34.0(10.4)$ & $33.9(10.4)$ & $34.1(10.0)$ & 0.95 \\
\hline Global cognitive functioning ${ }^{\mathrm{b}}$, mean (SD) & $29.1(1.2)$ & $29.0(1.2)$ & $28.7(1.3)$ & 0.001 \\
\hline Information processing speed ${ }^{\mathrm{b}}$, mean (SD) & $51.5(9.3)$ & $48.7(8.7)$ & $46.1(9.2)$ & $<0.001$ \\
\hline Immediate word recall ${ }^{b}$, mean (SD) & $48.0(9.3)$ & $46.4(9.1)$ & $41.8(9.7)$ & $<0.001$ \\
\hline Delayed word recall ${ }^{b}$, mean (SD) & $10.3(2.8)$ & $9.7(2.8)$ & $8.5(2.9)$ & $<0.001$ \\
\hline${\text { Response inhibition }{ }^{c} \text {, median (IQR) }}$ & $37.8(29.0-48.5)$ & $41.1(33.0-54.1)$ & $48.1(35.5-63.5)$ & $<0.001^{*}$ \\
\hline
\end{tabular}

${ }^{a}$ Two participants in this group used glucagon-like peptide-1 receptor agonists in addition to oral glucose-lowering medication. ${ }^{b}$ Higher scores indicate better performance. 'Lower scores indicate better performance. $* P$-values were derived from analysis of variance with log-transformed outcomes. SD, standard deviation; IQR, interquartile rang; IGM, impaired glucose metabolism; T2DM, type 2 diabetes mellitus; HbA1c, glycated hemoglobin; HDL, high-density lipoprotein; eGFR, estimated glomerular filtration rate; $\mathrm{CML}, \mathrm{N}$ (epsilon)-(carboxymethyl)lysine; CEL, N(epsilon)-(carboxyethyl)lysine.

\section{Skin autofluorescence and cognitive performance}

In unadjusted analyses a higher SAF level was significantly associated with worse performance on all cognitive measures (regression coefficient $b=-0.44, P<0.001$ for global cognitive functioning; $\mathrm{b}=-4.69, P<0.001$ for information processing speed; $\mathrm{b}=-5.28, P<0.001$ for immediate word recall; $\mathrm{b}=-1.51, P<0.001$ for delayed word recall; $\mathrm{b}=0.11, P<0.001$ for response inhibition). After adjustment for age (Table 7.2, Model 1 ), SAF was still significantly associated with all cognitive measures. 
Table 7.2 Adjusted association between skin autofluorescence and cognitive performance

\begin{tabular}{|c|c|c|c|}
\hline & $\mathrm{b}$ (regression coefficient) & $95 \% \mathrm{CI}$ & $P$-value \\
\hline \multicolumn{4}{|c|}{ Global cognitive functioning } \\
\hline Model 1 & $-0.25^{c}$ & -0.43 to -0.06 & 0.01 \\
\hline Model 2 & -0.10 & -0.28 to 0.08 & 0.29 \\
\hline Model 3 & -0.08 & -0.26 to 0.11 & 0.42 \\
\hline Model 4 & -0.08 & -0.27 to 0.11 & 0.41 \\
\hline \multicolumn{4}{|c|}{ Information processing speed ${ }^{A}$} \\
\hline Model 1 & -1.73 & -3.03 to -0.42 & 0.01 \\
\hline Model 2 & -0.42 & -1.68 to 0.84 & 0.52 \\
\hline Model 3 & -0.13 & -1.42 to 1.17 & 0.84 \\
\hline Model 4 & 0.07 & -1.24 to 1.38 & 0.91 \\
\hline \multicolumn{4}{|c|}{ Immediate Word recal ${ }^{\beta}$} \\
\hline Model 1 & -2.58 & -3.96 to -1.20 & $<0.001$ \\
\hline Model 2 & -1.39 & -2.68 to -0.10 & 0.03 \\
\hline Model 3 & -1.15 & -2.46 to 0.17 & 0.09 \\
\hline Model 4 & -0.97 & -2.30 to 0.36 & 0.15 \\
\hline \multicolumn{4}{|c|}{ Delayed Word recalP } \\
\hline Model 1 & -0.74 & -1.16 to -0.32 & 0.001 \\
\hline Model 2 & -0.48 & -0.88 to -0.08 & 0.02 \\
\hline Model 3 & -0.44 & -0.85 to -0.03 & 0.04 \\
\hline Model 4 & -0.38 & -0.79 to 0.04 & 0.07 \\
\hline \multicolumn{4}{|c|}{ Response inhibition ${ }^{b}$} \\
\hline Model 1 & 0.05 & 0.03 to 0.08 & $<0.001$ \\
\hline Model 2 & 0.03 & 0.00 to 0.05 & 0.03 \\
\hline Model 3 & 0.03 & 0.00 to 0.05 & 0.04 \\
\hline Model 4 & 0.02 & 0.00 to 0.05 & 0.07 \\
\hline
\end{tabular}

${ }^{a}$ Higher scores indicate better performance (MMSE score for global cognitive functioning, number of digits for information processing speed, number of words for total and delayed word recall). ${ }^{\mathrm{b}}$ Lower scores indicate better performance. Scores for response inhibition (seconds) are log-transformed. ${ }^{c}$ A regression coefficient of -0.25 indicates that one unit increase in skin autofluorescence level is associated with a decrease of 0.25 points on a test for global cognitive functioning. Model 1 : Adjustment for age; Model 2: Model $1+$ adjustments for sex, diabetes, and educational level; Model 3: Model $2+$ adjustments for smoking, alcohol consumption, waist circumference, total cholesterol/HDL cholesterol ratio, triglycerides, and lipid-lowering medication use; Model 4: Model 3 + adjustments for systolic blood pressure, cardiovascular disease, depression, and estimated glomerular filtration rate.

Associations of SAF with delayed word recall and response inhibition were attenuated and became non-significant after further adjustment for systolic blood pressure, cardiovascular disease, eGFR, and depression (Table 7.2, Model 4). In a post-hoc analysis, we additionally adjusted the associations for antihypertensive medication (yes/no) use and glucose-lowering medication use (yes/no). The association with delayed recall increased somewhat $(b=-0.41, P=0.05)$, while the association with response inhibition was somewhat attenuated $(b=0.02, P=0.10)$. Other associations remained virtually unchanged $(b=-0.10, P=0.32$ for global cognitive functioning; $b=$ $0.04, P=0.96$ for speed; $b=-1.08, P=0.12$ for immediate word recall).

Interactions between SAF and diabetes on cognitive measures were not significant (Model 4: regression coefficient $\mathrm{b}$ for interaction $=-0.31 ; P=0.09$ for global cognitive functioning; $\mathrm{b}=-0.09$, $P=0.95$ for speed; $b=0.41, P=0.75$ for immediate word recall; $b=0.12, P=0.77$ for delayed word recall; $b=0.02, P=0.35$ for response inhibition). 


\section{Plasma AGEs and cognitive performance}

In unadjusted analyses, higher pentosidine levels were significantly associated with worse immediate and delayed word recall, and response inhibition $(b=-4.67, P=0.04$ for immediate word recall; $b=-1.73, P=0.01$ for delayed word recall; $b=0.09, P=0.04$ for response inhibition). In adjusted models (Table 7.3) these associations became non-significant, while the association between pentosidine and global cognitive functioning became stronger and significant (Table 7.3, Model 4). After additional adjustment for antihypertensive and glucose-lowering medication use, these results were largely unchanged (for global cognitive functioning: $b=-0.63, P=0.03$; for speed: $-1.46, P=0.47$; for immediate word recall: $b=-3.61, P=0.08$; for delayed word recall: $b=-1.11, P=0.08$; for response inhibition: $b=0.01, P=0.72$ ). Interactions between pentosidine and diabetes on cognitive measures were not significant (Model 4: $b$ for interaction $=0.09, P=0.87$ for global cognitive functioning; $\mathrm{b}=-3.30, P=0.38$ for information processing speed; $\mathrm{b}=-2.77, P=0.47$ for immediate word recall; $b=-0.23, P=0.85$ for delayed word recall; $b=0.07, P=0.38$ for response inhibition).

Plasma CML and CEL were not significantly associated with any cognitive measures after adjustment for confounders (Supplementary Tables S7.1 and S7.2, respectively). We found no significant interactions between $\mathrm{CML}$ and diabetes on any of the cognitive measures (data not shown). There was a significant interaction between CEL and diabetes on global cognitive functioning ( $b$ for interaction $=0.03, P=0.003$ ), but not on the other cognitive measures. Stratified analyses showed that CEL was only associated with global cognitive functioning in participants without diabetes $(b=-0.01, P=0.003)$, but not in participants with diabetes $(b=0.01, P=0.13)$. 
Table 7.3 Adjusted association between plasma pentosidine and cognitive performance

\begin{tabular}{|c|c|c|c|}
\hline & b (regression coefficient) & $95 \% \mathrm{CI}$ & $P$-value \\
\hline \multicolumn{4}{|c|}{ Global cognitive functioninga } \\
\hline Model 1 & $-0.14^{c}$ & -0.70 to 0.42 & 0.62 \\
\hline Model 2 & -0.46 & -1.00 to 0.07 & 0.09 \\
\hline Model 3 & -0.51 & -1.05 to 0.04 & 0.07 \\
\hline Model 4 & -0.61 & -1.17 to -0.04 & 0.04 \\
\hline \multicolumn{4}{|c|}{ Information processing speed ${ }^{A}$} \\
\hline Model 1 & 1.37 & -2.56 to 5.30 & 0.50 \\
\hline Model 2 & -1.29 & -4.98 to 2.40 & 0.49 \\
\hline Model 3 & -1.38 & -5.15 to 2.40 & 0.47 \\
\hline Model 4 & -1.37 & -5.30 to 2.56 & 0.49 \\
\hline \multicolumn{4}{|c|}{ Immediate Word RecalP } \\
\hline Model 1 & -0.15 & -4.33 to 4.03 & 0.95 \\
\hline Model 2 & -2.63 & -6.40 to 1.15 & 0.17 \\
\hline Model 3 & -3.39 & -7.23 to 0.45 & 0.08 \\
\hline Model 4 & -3.45 & -7.45 to 0.55 & 0.09 \\
\hline \multicolumn{4}{|c|}{ Delayed Word RecalP } \\
\hline Model 1 & -0.44 & -1.71 to 0.82 & 0.49 \\
\hline Model 2 & -1.00 & -2.18 to 0.18 & 0.10 \\
\hline Model 3 & -1.05 & -2.25 to 0.14 & 0.09 \\
\hline Model 4 & -1.02 & -2.26 to 0.23 & 0.11 \\
\hline \multicolumn{4}{|c|}{ Response inhibition ${ }^{b}$} \\
\hline Model 1 & -0.01 & -0.09 to 0.06 & 0.74 \\
\hline Model 2 & 0.04 & -0.04 to 0.11 & 0.33 \\
\hline Model 3 & 0.03 & -0.04 to 0.10 & 0.44 \\
\hline Model 4 & 0.02 & -0.06 to 0.10 & 0.65 \\
\hline
\end{tabular}

${ }^{a}$ Higher scores indicate better performance (MMSE score for global cognitive functioning, number of digits for information processing speed, number of words for total and delayed word recall). 'bower scores indicate better performance. Scores for pentosidine and response inhibition (seconds) are log-transformed. ${ }^{\mathrm{C}} \mathrm{A}$ regression coefficient of -0.14 indicates that one unit increase in log-transformed pentosidine level is associated with a decrease of 0.14 points on a test for global cognitive functioning. Model 1: Adjustment for age; Model 2: Model 1 + adjustments for sex, diabetes, and educational level; Model 3: Model 2 + adjustments for smoking, alcohol consumption, waist circumference, total cholesterol/HDL cholesterol ratio, triglycerides, and lipid-lowering medication use; Model 4: Model 3 + adjustments for systolic blood pressure, cardiovascular disease, depression, and estimated glomerular filtration rate

\section{Sensitivity analysis}

Z-scores for SAF and pentosidine were calculated for each individual as their value for AGE level minus the mean and divided by the SD of the study sample. In a sensitivity analysis we excluded participants with AGEs Z-scores higher than 3 or lower than -3 to examine if our results would change. Six participants had a Z-score higher than 3. When these six participants were excluded from analyses, the associations of SAF with immediate word recall (Model 4: $b=-0.99, P=0.17$ ) and delayed word recall did not change (Model $4: b=-0.41, P=0.07$ ), while the association of SAF with response inhibition $(b=0.02, P=0.26)$ was attenuated. Other associations remained nonsignificant. For analyses with pentosidine, we excluded sixteen participants with Z-score larger than 3. The association of pentosidine with global cognitive functioning (Model $4: b=-0.52$, $P=0.15$ ) was attenuated and became non-significant. Other associations remained non-significant. 


\section{SUPPLEMENTAL DATA}

Table S7.1 Adjusted association between plasma CML and cognitive performance

\begin{tabular}{|c|c|c|c|}
\hline & $\mathrm{b}$ (regression coefficient) & $95 \% \mathrm{CI}$ & $P$-value \\
\hline \multicolumn{4}{|c|}{ Global cognitive functioning ${ }^{a}$} \\
\hline Model 1 & $0.008^{c}$ & 0.002 to 0.014 & 0.01 \\
\hline Model 2 & 0.002 & -0.004 to 0.008 & 0.48 \\
\hline Model 3 & 0.002 & -0.004 to 0.008 & 0.56 \\
\hline Model 4 & 0.001 & -0.005 to 0.008 & 0.65 \\
\hline \multicolumn{4}{|c|}{ Information processing speed ${ }^{A}$} \\
\hline Model 1 & 0.059 & 0.019 to 0.100 & 0.004 \\
\hline Model 2 & 0.011 & -0.028 to 0.049 & 0.59 \\
\hline Model 3 & 0.009 & -0.032 to 0.051 & 0.66 \\
\hline Model 4 & 0.011 & -0.032 to 0.054 & 0.62 \\
\hline \multicolumn{4}{|c|}{ Immediate Word recalP ${ }^{\circledR}$} \\
\hline Model 1 & 0.065 & 0.022 to 0.107 & 0.003 \\
\hline Model 2 & 0.012 & -0.028 to 0.052 & 0.55 \\
\hline Model 3 & -0.008 & -0.051 to 0.034 & 0.70 \\
\hline Model 4 & -0.009 & -0.053 to 0.035 & 0.69 \\
\hline \multicolumn{4}{|c|}{ Delayed Word recalP } \\
\hline Model 1 & 0.017 & 0.004 to 0.030 & 0.01 \\
\hline Model 2 & 0.004 & -0.008 to 0.017 & 0.51 \\
\hline Model 3 & 0.000 & -0.013 to 0.014 & 0.96 \\
\hline Model 4 & 0.001 & -0.013 to 0.014 & 0.93 \\
\hline \multicolumn{4}{|c|}{ Response inhibition ${ }^{b}$} \\
\hline Model 1 & 0.000 & -0.001 to 0.001 & 0.45 \\
\hline Model 2 & 0.001 & 0.000 to 0.001 & 0.09 \\
\hline Model 3 & 0.001 & 0.000 to 0.001 & 0.15 \\
\hline Model 4 & 0.001 & 0.000 to 0.001 & 0.23 \\
\hline
\end{tabular}

${ }^{a}$ Higher scores (MMSE score for global cognitive functioning, number of digits for information processing speed, number of words for total and delayed word recall) indicate better performance. bower scores indicate better performance. Scores for pentosidine and response inhibition (seconds) are log-transformed. ${ }^{\mathrm{C}} \mathrm{A}$ regression coefficient of 0.008 indicates that one unit increase in N(epsilon)-(carboxymethyl)lysine (CML) level is associated with an increase of 0.008 points on a test for global cognitive functioning. Model 1: Adjustment for age; Model 2: Model 1 + adjustments for sex, diabetes, and educational level; Model 3: Model 2 + adjustments for smoking, alcohol use, waist circumference, total cholesterol/HDL cholesterol ratio, triglycerides, and lipid-lowering medication use; Model 4: Model $3+$ adjustments for systolic blood pressure, cardiovascular disease, depression, and estimated glomerular filtration rate 
Table S7.2 Adjusted association between plasma CEL and cognitive performance

\begin{tabular}{|c|c|c|c|}
\hline & $\mathrm{b}$ (regression coefficient) & $95 \% \mathrm{CI}$ & $P$-value \\
\hline \multicolumn{4}{|c|}{ Global cognitive functioning } \\
\hline Model 1 & $-0.008^{c}$ & -0.016 to 0.001 & 0.07 \\
\hline Model 2 & -0.004 & -0.012 to 0.004 & 0.28 \\
\hline Model 3 & -0.004 & -0.012 to 0.004 & 0.35 \\
\hline Model 4 & -0.004 & -0.012 to 0.004 & 0.36 \\
\hline \multicolumn{4}{|c|}{ Information processing speed ${ }^{A}$} \\
\hline Model 1 & -0.002 & -0.060 to 0.056 & 0.94 \\
\hline Model 2 & 0.028 & -0.027 to 0.082 & 0.32 \\
\hline Model 3 & 0.026 & -0.030 to 0.082 & 0.36 \\
\hline Model 4 & 0.025 & -0.032 to 0.081 & 0.39 \\
\hline \multicolumn{4}{|c|}{ Immediate Word RecalP } \\
\hline Model 1 & 0.019 & -0.081 to 0.043 & 0.54 \\
\hline Model 2 & 0.005 & -0.051 to 0.061 & 0.87 \\
\hline Model 3 & 0.003 & -0.054 to 0.060 & 0.92 \\
\hline Model 4 & 0.002 & -0.055 to 0.060 & 0.94 \\
\hline \multicolumn{4}{|c|}{ Delayed Word RecalP } \\
\hline Model 1 & 0.001 & -0.017 to 0.020 & 0.88 \\
\hline Model 2 & 0.007 & -0.011 to 0.024 & 0.45 \\
\hline Model 3 & 0.005 & -0.013 to 0.023 & 0.60 \\
\hline Model 4 & 0.005 & -0.013 to 0.023 & 0.59 \\
\hline \multicolumn{4}{|c|}{ Response inhibition ${ }^{b}$} \\
\hline Model 1 & 0.001 & 0.000 to 0.002 & 0.04 \\
\hline Model 2 & 0.001 & -0.001 to 0.002 & 0.31 \\
\hline Model 3 & 0.001 & -0.001 to 0.002 & 0.29 \\
\hline Model 4 & 0.001 & 0.000 to 0.002 & 0.25 \\
\hline
\end{tabular}

${ }^{a}$ Higher scores (MMSE score for global cognitive functioning, number of digits for information processing speed, number of words for total and delayed word recall) indicate better performance. bLower scores indicate better performance. Scores for pentosidine and response inhibition (seconds) are log-transformed. ${ }^{\mathrm{C}} \mathrm{A}$ regression coefficient of -0.008 indicates that one unit increase in N(epsilon)-(carboxyethyl)lysine (CEL) level is associated with a decrease of 0.008 points on a test for global cognitive functioning. Model 1: Adjustment for age; Model 2: Model $1+$ adjustments for sex, diabetes, and educational level; Model 3: Model 2 + adjustments for smoking, alcohol use, waist circumference, total cholesterol/HDL cholesterol ratio, triglycerides, and lipid-lowering medication use; Model 4: Model 3 + adjustments for systolic blood pressure, cardiovascular disease, depression, and estimated glomerular filtration rate 


\section{DISCUSSION}

This is the first study to examine the association of SAF, as an estimate of tissue AGE accumulation, and plasma AGEs with multiple cognitive functions. Our results indicate that SAF is inversely associated with memory, although cardiovascular risk factors seem to be involved in the association. In addition we found associations between SAF and response inhibition and between pentosidine and global cognitive functioning which should be interpreted with caution, because these associations were attenuated after excluding some influential cases. Therefore, in our study the association between SAF and memory was most robust. As not all AGEs may end up in the circulation, ${ }^{13,14}$ our results indicate that SAF may be a better marker for AGE accumulation in brain tissue than plasma AGEs.

The associations between SAF or plasma pentosidine and cognitive performance were not significantly different between individuals with and without type 2 diabetes. While our study may not have enough power to detect significant differences, our results are in line with previous research demonstrating no interaction between diabetes and urinary pentosidine on cognitive decline. ${ }^{15}$

Accumulation of AGEs in the brain has been linked to AD by increasing inflammation, oxidative stress, and subsequent neuronal dysfunction. ${ }^{6}$ These mechanisms may be involved in the development of cognitive impairment. Interestingly, in our study the strongest association was found between SAF and delayed word recall, which is the best neuropsychological predictor of AD. ${ }^{29}$ However, associations of SAF with cognitive functions were attenuated after adjustment for potential confounders/mediators. Several (cardio)vascular risk factors may confound the relationship between AGEs and cognitive impairment.

Diabetes has been associated with higher accumulation of $\mathrm{AGEs}^{5}$ and cognitive decline. ${ }^{30}$ In addition, research has shown that obesity increases the risk of developing dementia and cognitive impairment, possibly in part through the accumulation of AGEs. ${ }^{31,32}$ In addition, higher levels of lipids, which are involved in the formation of AGEs, ${ }^{33}$ may also increase the risk of cognitive impairment. ${ }^{34}$ However, in our sample lipids were not associated with SAF.

In addition to in vivo production, AGEs have been found in cigarettes, ${ }^{35}$ and therefore smoking can increase AGE levels and may increase the risk of cognitive impairment. ${ }^{36}$ High alcohol consumption may increase oxidative stress, and thereby AGE levels, ${ }^{37}$ and can affect cognitive function. ${ }^{38}$ However, in our sample, high SAF level was not associated with high alcohol consumption.

Some other factors may mediate the association between AGEs and cognitive impairment, e.g. systolic blood pressure, depression, kidney functioning, and cardiovascular disease. AGE accumulation may contribute to vascular stiffening, by collagen crosslinking of the vascular wall and thereby leading to (systolic) hypertension, ${ }^{39}$ which has been associated with lower cognitive performance and lower total brain matter volume. ${ }^{40}$ Additionally, depression has been both associated with vascular stiffness ${ }^{41}$ and cognitive decline ${ }^{42}$ but in our sample depression was not associated with SAF. Furthermore, the kidney metabolizes and removes plasma AGEs and is a site for accumulation of AGEs. Research has shown that a decreased GFR is associated both with higher plasma AGE levels ${ }^{43}$ and more cognitive decline. ${ }^{44} \mathrm{~A}$ decreased GFR may therefore mediate the association between AGEs and cognitive impairment, but may also predict AGE accumulation. Finally, AGEs can lead to cardiovascular disease, through mechanisms discussed previously (e.g. vascular stiffness and hypertension), which can in turn lead to cognitive impairment. ${ }^{45}$ 
It is important to note that some of the variables we adjusted for, e.g. GFR, systolic blood pressure and cardiovascular disease, could be part of the causal pathway from AGEs to cognitive impairment. Therefore, we may have overadjusted our associations, resulting in a reduction in the potential total causal effect of AGEs on cognition by controlling for an intermediate variable. ${ }^{46}$ Moreover, since participants that were excluded from analyses (due to missing values) had higher SAF levels and lower cognitive scores, our results may be an underestimation of the true association of AGEs and cognitive functions.

Furthermore, the associations between AGE accumulation and cognition may be stronger in individuals with cognitive impairment. Studies that found associations with plasma AGEs mostly investigated this in individuals with cognitive impairment or dementia. ${ }^{16,47}$ In addition, in one recent study, SAF was associated with cognitive impairment (score <-1.5 standard deviations in any domain from age, sex, and education adjusted norms). ${ }^{12}$ Stronger associations could emerge in longitudinal data in which participants develop cognitive decline or impairment. ${ }^{15}$

\section{Strengths and limitations}

Our study has several strengths. A major strength is that it is the first study to associate SAF and several plasma AGEs with separate cognitive domains. In addition, we were able to adjust for multiple important potential confounders. Our study also has some limitations. First, due to the cross-sectional design we were not able to address causal relationships. However, longitudinal data are not available yet. Second, SAF may not only reflect skin AGEs, but also non-AGE skin fluorophores. ${ }^{11}$ Nevertheless, results of previous research support the use of SAF as a marker for skin tissue AGEs. ${ }^{11}$ Third, it remains unclear if SAF is an accurate reflectance of the level of AGE accumulation in the brain. However, research has shown that higher SAF is associated with lower brain volume. ${ }^{12}$

\section{Conclusion}

We found significant inverse associations between SAF, a potential marker of tissue AGEs, and memory. These were attenuated and became non-significant after adjustment for vascular risk factors and depression. In addition, we found associations of SAF with response inhibition and of pentosidine with global cognitive functioning, albeit not robust. Our results may suggest that AGEs are involved in the development of cognitive decline, particularly memory decline, and possibly in part through the action of vascular risk factors. More longitudinal research is needed to examine the effect of tissue and plasma AGEs on decline in separate cognitive domains. 


\section{REFERENCES}

1. Prince M, Bryce R, Albanese $E$, et al. The global prevalence of dementia: a systematic review and metaanalysis. Alzheimers Dement 2013;9:63-75 e2

2. LaFerla FM, Oddo S. Alzheimer's disease: Abeta, tau and synaptic dysfunction. Trends Mol Med 2005;11:170-6

3. Daviglus ML, Bell CC, Berrettini W, et al. NIH state-of-the-science conference statement: Preventing Alzheimer's disease and cognitive decline. NIH Consens State Sci Statements 2010;27:1-30

4. Barnes DE, Yaffe K. The projected effect of risk factor reduction on Alzheimer's disease prevalence. Lancet Neurol $2011 ; 10: 819-28$

5. Brownlee M. Advanced protein glycosylation in diabetes and aging. Annu Rev Med 1995;46:223-34

6. Li J, Liu D, Sun L, et al. Advanced glycation end products and neurodegenerative diseases: mechanisms and perspective. J Neurol Sci 2012;317:1-5

7. Schalkwijk CG, Brouwers O, Stehouwer CD. Modulation of insulin action by advanced glycation endproducts: a new player in the field. Horm Metab Res 2008;40:614-9

8. Li XH, Du LL, Cheng XS, et al. Glycation exacerbates the neuronal toxicity of beta-amyloid. Cell Death Dis 2013;4:e673

9. Valente $T$, Gella A, Fernandez-Busquets $X$, et al. Immunohistochemical analysis of human brain suggests pathological synergism of Alzheimer's disease and diabetes mellitus. Neurobiol Dis 2010;37:67-76

10. Candela P, Gosselet F, Saint-Pol J, et al. Apical-to-basolateral transport of amyloid-beta peptides through blood-brain barrier cells is mediated by the receptor for advanced glycation end-products and is restricted by P-glycoprotein. J Alzheimers Dis 2010;22:849-59

11. Meerwaldt $\mathrm{R}$, Graaff $\mathrm{R}$, Oomen $\mathrm{PH}$, et al. Simple non-invasive assessment of advanced glycation endproduct accumulation. Diabetologia 2004;47:1324-30

12. Moran C, Munch G, Forbes JM, et al. Type 2 diabetes mellitus, skin autofluorescence and brain atrophy. Diabetes 2015;64:279-83.

13. Shinohara M, Thornalley PJ, Giardino I, et al. Overexpression of glyoxalase-I in bovine endothelial cells inhibits intracellular advanced glycation endproduct formation and prevents hyperglycemia-induced increases in macromolecular endocytosis. J Clin Invest 1998;101:1142-7

14. Hanssen NM, Engelen L, Ferreira I, et al. Plasma levels of advanced glycation endproducts Nepsilon(carboxymethyl)lysine, Nepsilon-(carboxyethyl)lysine, and pentosidine are not independently associated with cardiovascular disease in individuals with or without type 2 diabetes: the Hoorn and CODAM studies. J Clin Endocrinol Metab 2013;98:E1369-73

15. Yaffe K, Lindquist K, Schwartz AV, et al. Advanced glycation end product level, diabetes, and accelerated cognitive aging. Neurology 2011;77:1351-6

16. Chen G, Cai L, Chen B, et al. Serum level of endogenous secretory receptor for advanced glycation end products and other factors in type 2 diabetic patients with mild cognitive impairment. Diabetes care 2011;34:2586-90

17. Schram MT, Sep SJ, van der Kallen CJ, et al. The Maastricht Study: an extensive phenotyping study on determinants of type 2 diabetes, its complications and its comorbidities. Eur J Epidemiol 2014;29: 439-51

18. Koetsier M, Nur E, Chunmao $\mathrm{H}$, et al. Skin color independent assessment of aging using skin autofluorescence. Opt Express 2010;18:14416-29

19. Scheijen $\mathrm{JL}$, van de Waarenburg MP, Stehouwer $C D$, et al. Measurement of pentosidine in human plasma protein by a single-column high-performance liquid chromatography method with fluorescence detection. J Chromatogr B Analyt Technol Biomed Life Sci 2009;877:610-4

20. Kodl CT, Seaquist ER. Cognitive dysfunction and diabetes mellitus. Endocr Rev 2008;29:494-511

21. Folstein MF, Folstein SE, McHugh PR. "Mini-mental state". A practical method for grading the cognitive state of patients for the clinician. J Psychiatr Res 1975;12:189-98

22. Van der Elst W, van Boxtel MP, van Breukelen GJ, et al. Rey's verbal learning test: normative data for 1855 healthy participants aged 24-81 years and the influence of age, sex, education, and mode of presentation. J Int Neuropsychol Soc 2005; $11: 290-302$

23. Van der Elst W, Van Boxtel MP, Van Breukelen GJ, et al. The Stroop color-word test: influence of age, sex, and education; and normative data for a large sample across the adult age range. Assessment 2006;13:62-79

24. van der Elst W, van Boxtel MP, van Breukelen GJ, et al. The Letter Digit Substitution Test: normative data for 1,858 healthy participants aged 24-81 from the Maastricht Aging Study (MAAS): influence of age, education, and sex. J Clin Exp Neuropsychol 2006;28:998-1009

25. Levey AS, Stevens LA, Schmid $\mathrm{CH}$, et al. A new equation to estimate glomerular filtration rate. Ann Intern Med 2009;150:604-12 
26. WHO. Definition and Diagnosis of diabetes mellitus and intermediate hyperglycemia. http://www.who.int/diabetes/publications/Definition and diagnosis of diabetes_new.pdf 2006.

27. De Bie SE. Standaardvragen 1987: Voorstellen voor uniformering van vraagstellingen naar achtergrondkenmerken en interviews [Standard questions 1987: Proposal for uniformization of questions regarding background variables and interviews]. Leiden, The Netherlands: Leiden University Press.; 1987.

28. Sheehan DV, Lecrubier Y, Sheehan KH, et al. The Mini-International Neuropsychiatric Interview (M.I.N.I.): the development and validation of a structured diagnostic psychiatric interview for DSM-IV and ICD-10. J Clin Psychiatry 1998;59 Suppl 20:22-33;quiz 4-57

29. Gainotti G, Quaranta D, Vita MG, et al. Neuropsychological predictors of conversion from mild cognitive impairment to Alzheimer's disease. J Alzheimers Dis 2014;38:481-95

30. Spauwen PJ, Kohler S, Verhey FR, et al. Effects of type 2 diabetes on 12-year cognitive change: results from the maastricht aging study. Diabetes Care 2013;36:1554-61

31. Luchsinger JA, Gustafson DR. Adiposity and Alzheimer's disease. Curr Opin Clin Nutr Metab Care 2009;12:15-21

32. Yoon $\mathrm{DH}, \mathrm{Choi} \mathrm{SH}, \mathrm{Yu} \mathrm{JH}$, et al. The relationship between visceral adiposity and cognitive performance in older adults. Age Ageing 2012;41:456-61

33. Fu MX, Requena JR, Jenkins AJ, et al. The advanced glycation end product, Nepsilon-(carboxymethyl)lysine, is a product of both lipid peroxidation and glycoxidation reactions. J Biol Chem 1996;271:9982-6

34. Reitz C, Tang MX, Luchsinger J, et al. Relation of plasma lipids to Alzheimer disease and vascular dementia. Arch Neurol 2004;61:705-14

35. Cerami C, Founds $\mathrm{H}$, Nicholl I, et al. Tobacco smoke is a source of toxic reactive glycation products. Proc Natl Acad Sci U S A 1997;94:13915-20

36. Sabia S, Marmot M, Dufouil C, et al. Smoking history and cognitive function in middle age from the Whitehall II study. Arch Intern Med 2008;168:1165-73

37. Kalousova M, Zima T, Popov P, et al. Advanced glycation end-products in patients with chronic alcohol misuse. Alcohol Alcohol 2004;39:316-20

38. Xu G, Liu X, Yin Q, et al. Alcohol consumption and transition of mild cognitive impairment to dementia. Psychiatry Clin Neurosci 2009;63:43-9

39. Zieman SJ, Kass DA. Advanced glycation endproduct crosslinking in the cardiovascular system: potential therapeutic target for cardiovascular disease. Drugs 2004;64:459-70

40. Nagai M, Hoshide S, Ishikawa J, et al. Ambulatory blood pressure as an independent determinant of brain atrophy and cognitive function in elderly hypertension. J Hypertens 2008;26:1636-41

41. Tiemeier $\mathrm{H}$, Breteler MM, van Popele NM, et al. Late-life depression is associated with arterial stiffness: a populationbased study. J Am Geriatr Soc 2003;51:1105-10

42. Kohler S, van Boxtel MP, van Os J, et al. Depressive symptoms and cognitive decline in community-dwelling older adults. J Am Geriatr Soc 2010;58:873-9

43. Semba RD, Ferrucci L, Fink JC, et al. Advanced glycation end products and their circulating receptors and level of kidney function in older community-dwelling women. Am J Kidney Dis 2009;53:51-8

44. Buchman AS, Tanne D, Boyle PA, et al. Kidney function is associated with the rate of cognitive decline in the elderly. Neurology 2009;73:920-7

45. Breteler MM, Claus J], Grobbee DE, et al. Cardiovascular disease and distribution of cognitive function in elderly people: the Rotterdam Study. BMJ 1994;308:1604-8

46. Schisterman EF, Cole SR, Platt RW. Overadjustment bias and unnecessary adjustment in epidemiologic studies. Epidemiology 2009;20:488-95

47. Meli M, Perier C, Ferron C, et al. Serum pentosidine as an indicator of Alzheimer's disease. J Alzheimers Dis 2002;4:936 



\section{CHAPTER 8}

GENERAL DISCUSSION 


\section{GENERAL DISCUSSION}

The general aim of this thesis was to provide more insight in the association between AGE accumulation on the one hand and vascular diseases on the other in individuals with and without T1DM and T2DM. To determine the amount of AGE accumulation, we used both state-of-the-art plasma AGE measurements and the relatively new measurement of skin autofluorescence (SAF). In this final chapter, methodological issues related to the epidemiological studies included in this thesis will be discussed. The clinical relevance of our findings and the implications for future research are discussed in the valorization addendum.

\subsection{In Summary}

Chapter 2 describes how we raised and characterized an antibody against the relatively unknown MGO-derived plasma AGE THP. Using this antibody, we found that THP is higher in individuals with T1DM, associated with SVCAM-1 levels and we detected THP in atherosclerotic plaques. In Chapter 3, we further investigated the association of THP with diabetes and vascular disease next to other well-known AGEs, i.e. plasma pentosidine, CML and CEL. In this Chapter, we show that plasma pentosidine and CML are also higher in T1DM. Of all these AGEs, only plasma pentosidine was associated with coronary artery calcification. In the following Chapters 4-7, we investigated both SAF and the plasma AGEs pentosidine, CML and CEL in relation to several markers of vascular disease and its precursors. We found that higher SAF was associated with higher carotid to femoral pulse wave velocity (cfPWV) and central pulse pressure (cPP) (Chapter 4), higher markers of endothelial dysfunction (Chapter 5), a lower ankle-brachial index (Chapter 6) and cognitive impairment (Chapter 7). Associations between higher SAF and higher pulse pressure and markers of low-grade inflammation had a similar direction and magnitude; however, these were not statistically significant (Chapters $4 \& 5$, respectively). We found no association between SAF and carotid intima-media thickness (Chapter 6). Additionally, in the same Chapters 4-7, we evaluated the possible associations between the plasma AGEs pentosidine, CML and CEL and the same surrogate markers of vascular disease. We found an association between higher plasma pentosidine on the one hand, and higher cfPWV, central pulse pressure (Chapter 4) and cognitive decline (Chapter 7) on the other. In contrast, higher plasma pentosidine was associated with lower markers of low-grade inflammation (Chapter 5). We found no association between plasma pentosidine and pulse pressure, endothelial dysfunction, the ankle-brachial index or and carotid intima-media thickness. For plasma $\mathrm{CML}$, higher levels were associated with lower markers of endothelial dysfunction and low-grade inflammation and a higher ankle-brachial index. We found no association between plasma CML and cfPWV, central or brachial pulse pressure, and carotid intima-media thickness. Lower plasma CEL was associated with higher carotid intima-media thickness (Chapter 6). We found no association between plasma CEL and cfPWV or pulse pressure (Chapter 4), markers of endothelial dysfunction or low-grade inflammation (Chapter 5).

\subsection{Study populations}

In Chapters 2 and 3, we evaluated the data of two different cohorts of individuals with and without T1DM. The first study, which included both individuals with and without T1DM, was designed as a case-control study. This study was set up in London in 1998 and based on a random sample of 199 men and women with T1DM aged 30 to 55 years, taken from the diabetes registers of five London hospitals. A random sample of 201 individuals from the general population, stratified to 
have a similar age and sex distribution to the individuals with diabetes, was drawn from the lists of two London general practices, to serve as a control group ${ }^{1}$. The second study, as described in Chapter 2, was a Danish prospective observational study of individuals with T1DM, of which we evaluated only the data collected as baseline. This study was set up in 1993 and included 199 individuals with T1DM and diabetic nephropathy and retinopathy and 192 individuals with T1DM and persistent normoalbuminuria. All participants were recruited from the outpatient clinic at Steno Diabetes Center².

The first study gave us the opportunity to investigate whether or not there were differences in plasma AGE concentrations between individuals with and without T1DM. A limitation of this study was its case-control design, where the controls were matched for age and sex, which attenuates generalizability to the general population. However, due to the low prevalence of T1DM, a casecontrol study the most efficient and achievable option. The second study provided us with a sufficient number of individuals with microvascular complications, which made it possible to compare THP levels between individuals with and without diabetic complications. Due to its crosssectional design we were unable investigate which marker precedes the other, a sign of possible causality in the association between AGEs and microvascular complications. This is a limitation of this study.

In Chapters 4-7, we evaluated data from The Maastricht Study, an on-going observational prospective population-based cohort study that focuses on the etiology and pathophysiology of T2DM, its classic complications (cardiovascular disease, nephropathy, neuropathy and retinopathy) and its emerging comorbidities (e.g., cognitive decline, depression, and gastrointestinal, respiratory and musculoskeletal diseases), as well as on the development of chronic diseases in the general population. In this study, individuals with T2DM were oversampled for reasons of statistical efficiency. For the analyses included in this thesis, we used data from the first baseline measurements. Recruitment for The Maastricht Study started in 2010. In our analyses, we included the first 866 participants, of whom 253 with T2DM. Participants from the general population were recruited from the municipal registries; participants with T2DM were recruited from the regional Diabetes Patient Registry, which is kept by the regional association of General Practitioners. The Maastricht Study gave us the opportunity to investigate the association between AGEs and vascular diseases in both the general population and individuals with T2DM. Furthermore, since different measures of AGEs were used, i.e. skin autofluorescence and plasma AGE measurements, we were able to compare the two. We were only able to evaluate the baseline data of this study. Therefore, we were not able to investigate the hypothesized causality in the associations we found, which is a limitation of this study. Moreover, we do not have the opportunity to investigate possible associations between AGEs and incident vascular disease. Another limitation of the Maastricht Study is that participants with T2DM were recruited from a different source population compared with participants from the general population. For this reason, we tested for each analysis whether or not the associations differed between these two groups, by performing interaction-analyses. In most analyses, we found no significant differences between these groups. If there were, we reported these differences, which enabled us to take them into account when interpreting the results. 


\subsection{Determinants of tissue AGEs}

As mentioned in the introduction of this thesis, AGEs are thought to exert their detrimental effects by the accumulation in tissues that are vulnerable to complications of diabetes, such as the eye, the kidney, the brain and blood vessels. Obviously, direct measurement in these tissues would be very invasive and complex. Therefore, we have used different estimates of tissue AGE accumulation throughout this thesis to investigate the association between AGEs and cardiovascular diseases.

\subsubsection{Circulating AGEs}

The most accurate and state-of-the-art measurement of circulating AGEs is by liquid chromatography (UPLC) in combination with tandem mass spectrometry (MSMS) or, in case of pentosidine, with high-performance liquid chromatography (HPLC) and fluorescence detection. Throughout this thesis, we used these methods to quantify the well-known and largely studied plasma AGEs pentosidine, $\mathrm{N} \varepsilon$-(carboxymethyl)lysine (CML) and $\mathrm{N} \varepsilon$-(carboxyethyl)lysine (CEL). To accurately measure AGEs with these methods, AGEs in peptides and proteins must be released to their free form prior to analysis. This is done by hydrolyzing the peptide bonds, thereby releasing free amino acids. Acid hydrolysis is the easiest, least expensive, and most reliable procedure and is the preferred method. The major disadvantage, however, is that it can only be used for AGEs that are acid stable. For the compounds that are not stable, such as THP, enzymatic hydrolysis could be an alternative. However, due to blockage of cleavage sites by modified arginine and lysine residues by glycation, enzymatic hydrolysis can lead to an underestimation of AGE content. To circumvent this problem, we developed an antibody against MGO-derived AGEs, specifically THP, which can be used in an ELISA to detect THP in plasma. Although generally these techniques are considered to be less specific, the above mentioned limitations for the detection of THP are overcome by using immunological analysis, as we describe in Chapter 2. Although we mostly used state-of-the-art measurements to determine the amount of plasma AGEs, it is currently unknown whether or not these plasma AGEs are indeed accurately reflecting AGE accumulation in tissues.

\subsubsection{Skin autofluorescence}

Measurement of skin autofluorescence (SAF) as an estimate of tissue AGE accumulation has gained increased attention in the last years. Previously, skin AGEs were estimated by the determination of collagen linked fluorescence in biopsy specimens ${ }^{3-5}$. However, the AGE-reader (DiagnOptics) was developed as a non-invasive alternative, which is much more patient friendly and suitable for large epidemiological studies. SAF is a promising new AGE measurement, and has shown to be associated with AGEs in skin biopsy specimens ${ }^{6}$, T1DM and T2DM ${ }^{122,}{ }^{123}$ and its complications $^{7-19}$. However, there are some limitations to take under consideration. First, the measurement of SAF as a reflection of skin AGEs is limited by the fact that not all AGEs are fluorescent and, therefore, not detected by the AGE-reader. However, SAF has been shown to associate with the non-fluorescent AGEs, CML and CEL in skin biopsy specimens. Another limitation is that several fluorophores in the skin, such as keratin, vitamin D, lipofuscin, ceroid, NADH and pyridoxine, have overlapping excitation and emission spectra, which can potentially contribute to the overall excitation of the $\operatorname{skin}^{20}$, thereby influencing the measurement of SAF. Despite this limitation, it has been shown, that the dermal content of pentosidine explains a major part (75\%) of the variance in SAF 21 . 
The fact that SAF is associated with skin AGEs and complications of diabetes further supports the assumption that SAF is indeed a reflection of tissue AGE accumulation. It is even hypothesized that SAF is a better reflection of tissue AGE accumulation than plasma AGEs ${ }^{22}$, because SAF measures AGEs in tissue (skin) instead of plasma. Another reason to favor SAF measurement above plasma AGE measurements is that plasma AGE levels are determined to a large extent by the half-life of plasma proteins, which is significantly shorter than the half-life of long-lived proteins in the skin and in vascular tissue ${ }^{22}$.

\subsubsection{Comparison between circulating AGEs and skin autofluorescence}

In Chapters 4-7, we were able to analyze both plasma AGEs and SAF. In Chapter 4, both higher plasma pentosidine and SAF were associated with more arterial stiffness, whereas we found no association for plasma CML and CEL. In Chapter 5, we found a similar positive association between $\mathrm{SAF}$ and markers of endothelial function and low-grade inflammation. However, the association between plasma CML and markers of endothelial function, and the association between plasma pentosidine and $C M L$, and markers of low-grade inflammation were negative. In Chapter 6 , we found that higher SAF was associated with lower $A B I$, whereas for plasma CML there was an inverse association; lower plasma CML was associated with a lower ABI. As discussed in these chapters, we know from previous literature that plasma CML levels are lower in individuals with obesity ${ }^{23-26}$ and T2DM ${ }^{27}$. This may be caused by the trapping of CML by the receptor for AGEs (RAGE), as recently demonstrated by Gaens et al. ${ }^{26}$. Therefore, plasma CML may not be a good reflection of CML accumulation in tissues in individuals with T2DM, as T2DM is often accompanied by obesity. Furthermore, protein-bound plasma CML had shown to be inversely associated with central obesity and inflammation and explains a part of the central obesity-related increase in inflammation ${ }^{28}$. Taken together, this might suggest that lower CML levels are indicative of a more detrimental outcome in selected populations. We do not have an explanation why we found an inverse association between plasma pentosidine and low-grade inflammation and between CEL and carotid intima-media thickness. As discussed in Chapter 6, low plasma AGE levels might be a reflection of less degradation of tissue AGEs or less release from tissues. In that case low plasma AGE levels would reflect higher tissue levels. However, this is only speculating. Another possible explanation is that plasma AGE levels reflect only a short period of glycation, as they are determined to a large extent by the half-life of plasma proteins, which is significantly shorter than the half-life time of long-lived proteins in the skin or the vascular wall22. Chapter 7 showed an association between both SAF and plasma pentosidine on the one hand and worse cognitive functioning on the other. Plasma CML and CEL levels were not associated with cognitive functioning ${ }^{29}$. Taken together, our results show that SAF is consistently associated with a diversity of vascular disease and diabetes complications. Associations for plasma AGEs are less consistent. This could be caused by the fact that SAF is a better reflection of AGE accumulation in vascular tissue than plasma AGEs. However, future studies are needed to further investigate this hypothesis.

\subsection{Outcome measures}

\subsubsection{Type 1 diabetes mellitus}

In Chapter 2, we used several outcome measurements in order to investigate the association between tetrahydropyrimidine (THP) and T1DM, endothelial dysfunction, low-grade inflammation, 
vascular complications and atherosclerosis. T1DM was defined by age of onset $<25$ years and insulin treatment within one year of diagnosis ${ }^{1}$. This definition is based on the fact that the onset of T1DM is generally during childhood ${ }^{30,31}$. However, as mentioned in the introduction of this thesis, the prevalence of T2DM in children is also increasing following the trend of increased obesity in children $32-34$. Therefore, this definition is not completely solid in the detection of individuals with T1DM only. It could be that individuals with early onset T2DM were included as having T1DM, which may have influenced our results.

\subsubsection{Impaired glucose metabolism and type 2 diabetes mellitus}

In Chapters 4-7, we evaluated SAF and plasma AGEs in individuals with normal glucose metabolism (NGM), impaired glucose metabolism (IGM) and T2DM. To determine glucose metabolism in the Maastricht study, all participants (except those who used insulin) underwent a standardized 7point oral glucose tolerance test (OGTT) after an overnight fast. Glucose metabolism was defined according to the WHO $2006^{35}$.

\subsubsection{Endothelial dysfunction and low-grade inflammation}

We used several plasma markers of endothelial dysfuction (ED) as outcome variables in both Chapter 2 and 5, i.e. soluble vascular cell adhesion molecule 1 (sVCAM-1), soluble intracellular cell adhesion molecule 1 (sICAM-1), Von Willebrand factor (vWf), E-selectin and soluble thrombomodulin. Additionally, we used several markers of low-grade inflammation (LGI) in both chapters to serve as outome variables, i.e. C-reactive protein (CRP), serum amyloid A (SAA), sICAM-1, Interleukin 6 (IL-6), Interleukin 8 (IL-8) and tumor necrosis factor alpha (TNF-a). A major strenght of our approach is that we analysed five different markers of ED and six markers of LGI. In Chapter 2, we separately evaluated the association between THP and different markers of ED and LGI. In Chapter 5, ED and LGI were our mean outcome variables. In Chapter 6, we combined these markers in overall z-score for ED and LGI, to obtain statistical efficiency and to reduce the influence of the biological variability of each measure ${ }^{36}$. A disadvantage of this approach is that we hereby let each individual biomarker contribute equally to this score, whereas we do not know if this is biologically justified. Our markers of ED are all known to be synthesized by endothelial cells ${ }^{37-39}$, whereas all our LGI markers are involved in inflammatory processes ${ }^{39}$. For this reason, it is plausible to assume that higher circulating concentrations of these markers reflect more dysfunction of the endothelium or inflammatory activity, respectively. However, as discussed in Chapter 5, endothelial dysfunction is closely linked to low-grade inflammation and these concepts are difficult to separate ${ }^{40,41}$. Therefore, we cannot rule out the possibility that they are both reflecting the same general process, which eventually leads to the development of CVD.

\subsubsection{Microvascular disease}

In Chapter 2, we evaluated the association between THP and several microvascular complications, i.e. micro- and macroalbuminuria, neuropathy and retinopathy. For the measurement of microand macroalbuminuria, urinary albumin was measured with an immunoturbidimetric method in study $A$ and by an enzyme immunoassay in study $B$. In study $A$, microalbuminuria was defined as a urinary albumin excretion rate (AER) of $20-200 \mu \mathrm{g} / \mathrm{min}$ and macroalbuminuria as an AER of $>200 \mu \mathrm{g} / \mathrm{min}$, based on two $24-\mathrm{h}$ urine collections. In study B, macroalbuminuria was defined as an AER of $>300 \mathrm{mg} / 24 \mathrm{~h}$ in at least two out of three previous consecutive 24-h urine collections. These definitions are commonly used in literature ${ }^{42-45}$, and an AER based on minimally two urine collections is considered the most reliable. Both micro and macroalbuminuria have been shown to 
associate with an increased risk of CVD individuals with diabetes ${ }^{46}$. However, sampling is done by the study participant, and incorrect and incomplete sampling may influence the reliability of this outcome measurement. In study A of Chapter 2, neuropathy and retinopathy were selfreported via a standardized questionnaire. Since these morbidities have not been confirmed by medical records or clinical investigation, this may have led to misclassification due to recall bias. In study B of Chapter 2, retinopathy was assessed by fundus photography after pupillary dilatation and graded as nil, simplex, or proliferative retinopathy, a valid method commonly used for the clinical diagnosis of diabetic retinopathy.

\subsubsection{Macrovascular disease}

In Chapter 2, we used prior CVD, defined as any history of acute myocardial infarction or stroke based on a standardized questionnaire, as an outcome variable. As mentioned above, this may have led to misclassification due to recall bias, which may have led to a underestimation of prior CVD. Additionally, we determined whether or not THP was present in atherosclerotic plaques. To do so, we used immunohistochemistry to stain AGEs in coronary arteries from biopsy specimens. Thereby, we were not only able to evaluate associations between plasma AGEs and vascular disease, but also showed that AGEs are indeed present in atherosclerotic plaques. As discussed before, the specificity of this technique can be low (Chapter 2). Although we found a 1000 -fold preference of our antibody for THP as compared with argpyrimidine and MG-H1, we cannot exclude the possibility that other MGO-derived AGEs than THP are detected in our analyses. In Chapter 3, we evaluated the association between several plasma AGEs and coronary artery calcification (CAC). CAC is a well-accepted early marker and precursor of CVD 47,48 . However, not all atherosclerotic plaques contain calcium. Therefore, it may be that our results are only applicable to calcified atherosclerotic plaques. In Chapter 4, we used carotid to femoral pulse wave velocity (cfPW), central pulse pressure (cPP) and 24-hour ambulatory pulse pressure (aPP) as outcome measures. All three of these measures are used in epidemiological studies as measures of arterial stiffness; cfPWV being considered the 'gold standard' ${ }^{49}$. In Chapter 6, we used the abkle-brachial index (ABI) and carotid intima-media thickness (cIMT) as measures of atherosclerosis. Both these measures are widely used in epidemiological research and are known to associate with increased cardiovascular events, morbidity and mortality ${ }^{50-55}$. A low ABI $(<0.9$ or $<1.0)$ is considered as a marker of atherosclerosis, whereas a high $\mathrm{ABI}(>1.4)$ is thought to be indicative of arterial calcification ${ }^{56,57}$. Fowkes et al. showed that the association between the ABI and the risk of mortality keeps decreasing with a higher $A B I$, even above an $A B I$ of 1.0 , but not above 1.4. Therefore, we analysed the $A B I$ as a continuous variable, excluding individuals with an $A B I>1.4$. Performing our analyses using predefined cut-off points of the $A B I$ gave similar results. In individuals with diabetes, an ABI >1.3 can already be indicative of arterial calcification, since they are known to have a higher prevalence of medial calcification than the general population ${ }^{58}$. Therefore, we additionally performed our analyses excluding individuals with an $A B I>1.3$, but found no differences in our results (Chapter 6).

\subsubsection{Cognitive impairment}

Chapter 7 discusses the association between measures of AGE accumulation and cognitive decline. A strenght of this study is that cognitive impairement was measured in separate cognitive domains, by a variation of validated test (i.e. information processing speed, 
verbal memory, and executive functions). Furthermore, these specific test have been shown to be most sensitive to effects of diabetes compared with other tests for the measurement of cognitive decline ${ }^{29}$.

\subsection{General considerations}

General considerations for observational epidemiological studies like ours, in which the association between a determinant and an outcome measure is evaluated, have to be made.

\subsubsection{Confounding}

An observational study, such as the studies in this thesis, differs from experimental studies and randomized clinical trials in several aspects. An advantage of observational studies is that they provide us with the opportunity to study natural relations between factors in predefined groups of individuals, all subtracted from the same population. A disadvantage of observational studies is that differences between individuals with or without the determinant or outcome measure are not controlled. If these differences are associated with both the determinant and the outcome measure they are called 'confounders'. These confounders can lead to a bias of the results. There are multiple possible confounders identified in the relation between AGE accumulation and vascular diseases, e.g. age and kidney function. Most observational studies lack the data, or simple do not have the statistical power to adjust for all these known confounders. As the individuals in the studies used in our analyses were extensively phenotyped, we were able to adjust for many of these possible confounders. This makes it more likely that the associations we found are indeed reflecting true associations between AGEs and vascular diseases. However, it has to be said that residual confounding by factors that are not currently known to be confounders may still have led to a certain amount of bias.

\subsubsection{Missing data}

We performed complete case analyses in all the studies included in this thesis. Thereby, selection bias may have occurred when the individuals that were excluded because of missing data differed from the individuals included that were included in our analyses. This could have been the case if missing data were not randomly distributed throughout the study population. We investigated this possible selection bias by evaluating differences in baseline characteristics between included and excluded individuals. Generally, we found no notable differences. In the cases were we did, we reported these differences and took them into account when interpreting the results of that study.

\subsection{Conclusion}

The studies included in this thesis were set up to investigate the potential role of advanced glycation endproducts in the development of vascular diseases in individuals with and without diabetes. The observational nature of our studies enabled us to investigate the associations between AGEs and vascular diseases in an uncontrolled sample of individuals. This design makes it likely that the associations found are indeed reflecting the true associations in the population represented by the studied sample, i.e. the general population, individuals with T1DM or T2DM, or impaired glucose metabolism (IGM). The random selection of individuals has its advantages, e.g. generalizability, but there is also a, partially circumventable, disadvantage. Besides a difference in the determinant or outcome measure, individuals may differ in many other factors, such as co-morbidities and CVD risk factors, thereby possibly distorting the investigated 
association. Where most association studies only adjust for a small number of potential confounder, we have taken all known potential confounding factors into account. This makes it less likely that our results were based on confounding by other variables, and more likely that they reflect a true association.

We measured AGEs in plasma and estimated their presence in skin tissue, while AGEs are thought to exert their detrimental effects in tissues vulnerable to complications of diabetes. It remains unknown whether SAF or plasma AGE concentrations are indeed a reflection of AGEs in e.g. vascular tissue, the eye and the kidney. Most of the outcome measures we used in our studies are markers of intermediate processes in the relation between vascular diseases and complications. Hereby, we aimed to gain more information about the possible pathophysiological processes that lead to vascular diseases. We haven't measured cardiovascular outcome, such as incident myocardial infarction, stroke and death, which would have enabled us to investigate the direct relation to incident cardiovascular diseases. However, the consistent results of our studies, especially for SAF, strongly support the hypothesis that AGEs are involved in vascular diseases, especially in individuals with diabetes.

Taken together, this thesis, combined with previous literature, provides more evidence to support the potential pathway in which aging and diabetes can be linked to vascular diseases, namely by the accumulation of advanced glycation endproducts. Future large prospective cohort studies are required to fully investigate the role of AGE accumulation in cardiovascular morbidity and mortality, to investigate the effect of AGE lowering therapies and to evaluate the possible effects of implementation of AGE measurements and interventions to lower AGE accumulation in daily practice. 


\section{REFERENCES}

1. Colhoun HM, Rubens MB, Underwood SR, Fuller JH. The effect of type 1 diabetes mellitus on the gender difference in coronary artery calcification. J Am Coll Cardiol. 2000;36:2160-2167

2. Tarnow L, Cambien F, Rossing P, Nielsen FS, Hansen BV, Lecerf L, Poirier O, Danilov S, Boelskifte S, Borch-Johnsen K. Insertion/deletion polymorphism in the angiotensin-i-converting enzyme gene is associated with coronary heart disease in iddm patients with diabetic nephropathy. Diabetologia. 1995;38:798-803

3. Monnier VM, Vishwanath V, Frank KE, Elmets CA, Dauchot P, Kohn RR. Relation between complications of type i diabetes mellitus and collagen-linked fluorescence. N Engl J Med. 1986;314:403-408

4. Monnier VM, Bautista O, Kenny D, Sell DR, Fogarty J, Dahms W, Cleary PA, Lachin J, Genuth S. Skin collagen glycation, glycoxidation, and crosslinking are lower in subjects with long-term intensive versus conventional therapy of type 1 diabetes: Relevance of glycated collagen products versus hba1c as markers of diabetic complications. Dcct skin collagen ancillary study group. Diabetes control and complications trial. Diabetes. 1999;48:870-880

5. Monnier VM, Sell DR, Genuth S. Glycation products as markers and predictors of the progression of diabetic complications. Ann N Y Acad Sci. 2005;1043:567-581

6. Meerwaldt R, Graaff R, Oomen PH, Links TP, Jager JJ, Alderson NL, Thorpe SR, Baynes JW, Gans RO, Smit AJ. Simple non-invasive assessment of advanced glycation endproduct accumulation. Diabetologia. 2004;47:1324-1330

7. Araszkiewicz A, Naskret D, Niedzwiecki P, Samborski P, Wierusz-Wysocka B, Zozulinska-Ziolkiewicz D. Increased accumulation of skin advanced glycation end products is associated with microvascular complications in type 1 diabetes. Diabetes Technol Ther. 2011;13:837-842

8. Bos DC, de Ranitz-Greven WL, de Valk HW. Advanced glycation end products, measured as skin autofluorescence and diabetes complications: A systematic review. Diabetes Technol Ther. 2011;13:773-779

9. Chabroux S, Canoui-Poitrine F, Reffet S, Mills-Joncour G, Morelon E, Colin C, Thivolet C. Advanced glycation end products assessed by skin autofluorescence in type 1 diabetics are associated with nephropathy, but not retinopathy. Diabetes Metab. 2010;36:152-157

10. Meerwaldt R, Links TP, Graaff R, Hoogenberg K, Lefrandt JD, Baynes JW, Gans RO, Smit AJ. Increased accumulation of skin advanced glycation end-products precedes and correlates with clinical manifestation of diabetic neuropathy. Diabetologia. 2005;48:1637-1644

11. Orchard TJ, Lyons TJ, Cleary PA, Braffett BH, Maynard J, Cowie C, Gubitosi-Klug RA, Way J, Anderson K, Barnie A, Villavicencio $\mathrm{S}$. The association of skin intrinsic fluorescence with type 1 diabetes complications in the dcct/edic study. Diabetes Care. 2013;36:3146-3153

12. Gerrits EG, Lutgers HL, Kleefstra N, Graaff R, Groenier KH, Smit AJ, Gans RO, Bilo HJ. Skin autofluorescence: A tool to identify type 2 diabetic patients at risk for developing microvascular complications. Diabetes Care. 2008;31:517-521

13. Lutgers HL, Graaff R, Links TP, Ubink-Veltmaat LJ, Bilo HJ, Gans RO, Smit AJ. Skin autofluorescence as a noninvasive marker of vascular damage in patients with type 2 diabetes. Diabetes Care. 2006;29:2654-2659

14. Monami M, Lamanna C, Gori F, Bartalucci F, Marchionni N, Mannucci E. Skin autofluorescence in type 2 diabetes: Beyond blood glucose. Diabetes Res Clin Pract. 2008;79:56-60

15. Tanaka K, Tani Y, Asai J, Nemoto F, Kusano Y, Suzuki H, Hayashi Y, Asahi K, Nakayama M, Miyata T, Watanabe T. Skin autofluorescence is associated with severity of vascular complications in japanese patients with type 2 diabetes. Diabet Med. 2012;29:492-500

16. Meerwaldt R, Lutgers HL, Links TP, Graaff R, Baynes JW, Gans RO, Smit AJ. Skin autofluorescence is a strong predictor of cardiac mortality in diabetes. Diabetes Care. 2007;30:107-112

17. Conway B, Edmundowicz D, Matter N, Maynard J, Orchard T. Skin fluorescence correlates strongly with coronary artery calcification severity in type 1 diabetes. Diabetes Technol Ther. 2010;12:339-345

18. Lutgers HL, Gerrits EG, Graaff R, Links TP, Sluiter WJ, Gans RO, Bilo HJ, Smit AJ. Skin autofluorescence provides additional information to the uk prospective diabetes study (ukpds) risk score for the estimation of cardiovascular prognosis in type 2 diabetes mellitus. Diabetologia. 2009;52:789-797

19. Noordzij MJ, Mulder DJ, Oomen PH, Brouwer T, Jager J, Castro Cabezas M, Lefrandt JD, Smit AJ. Skin autofluorescence and risk of micro- and macrovascular complications in patients with type 2 diabetes mellitus-a multi-centre study. Diabet Med. 2012;29:1556-1561

20. Koetsier M, Nur E, Chunmao H, Lutgers HL, Links TP, Smit AJ, Rakhorst G, Graaff R. Skin color independent assessment of aging using skin autofluorescence. Opt Express. 2010;18:14416-14429

21. Smit AJ, Gerrits EG. Skin autofluorescence as a measure of advanced glycation endproduct deposition: A novel risk marker in chronic kidney disease. Curr Opin Nephrol Hypertens. 2010;19:527-533

22. Smit AJ, Hartog JW, Voors AA, van Veldhuisen DJ. Advanced glycation endproducts in chronic heart failure. Ann N Y Acad Sci. 2008;1126:225-230

23. Semba RD, Arab L, Sun K, Nicklett EJ, Ferrucci L. Fat mass is inversely associated with serum carboxymethyl-lysine, an advanced glycation end product, in adults. J Nutr. 2011;141:1726-1730

24. Grote VA, Nieters A, Kaaks R, Tjonneland A, Roswall N, Overvad K, Nielsen MR, Clavel-Chapelon F, Boutron-Ruault MC, Racine A, Teucher B, Lukanova A, Boeing H, Drogan D, Trichopoulou A, Trichopoulos D, Lagiou P, Palli D, Sieri S, Tumino R, Vineis P, Mattiello A, Arguelles Suarez MV, Duell EJ, Sanchez MJ, Dorronsoro M, Huerta Castano JM, Barricarte A, Jeurnink SM, Peeters PH, Sund M, Ye W, Regner S, Lindkvist B, Khaw KT, Wareham N, Allen NE, Crowe FL, Fedirko V, Jenab M, Romaguera D, Siddiq A, Bueno-de-Mesquita HB, Rohrmann S. The associations of advanced 
glycation end products and its soluble receptor with pancreatic cancer risk: A case-control study within the prospective epic cohort. Cancer Epidemiol Biomarkers Prev. 2012;21:619-628

25. Sebekova K, Somoza V, Jarcuskova M, Heidland A, Podracka L. Plasma advanced glycation end products are decreased in obese children compared with lean controls. Int J Pediatr Obes. 2009;4:112-118

26. Gaens KH, Stehouwer CD, Schalkwijk CG. Advanced glycation endproducts and its receptor for advanced glycation endproducts in obesity. Curr Opin Lipidol. 2013;24:4-11

27. Hanssen NM, Engelen L, Ferreira I, Scheijen JL, Huijberts MS, van Greevenbroek MM, van der Kallen CJ, Dekker JM, Nijpels G, Stehouwer CD, Schalkwijk CG. Plasma levels of advanced glycation endproducts n\{epsilon\}(carboxymethyl)lysine, $\mathrm{n}\{$ epsilon\}-(carboxyethyl)lysine, and pentosidine are not independently associated with cardiovascular disease in individuals with or without type 2 diabetes: The hoorn and codam studies. J Clin Endocrinol Metab. 2013;98:E1369-1373

28. Gaens KH, Ferreira I, van de Waarenburg MP, van Greevenbroek MM, van der Kallen CJ, Dekker JM, Nijpels G, Rensen SS, Stehouwer CD, Schalkwijk CG. Protein-bound plasma nepsilon-(carboxymethyl)lysine is inversely associated with central obesity and inflammation and significantly explain a part of the central obesity-related increase in inflammation: The hoorn and codam studies. Arterioscler Thromb Vasc Biol. 2015;35:2707-2713

29. Spauwen PJ, van Eupen MG, Kohler S, Stehouwer CD, Verhey FR, van der Kallen CJ, Sep SJ, Koster A, Schaper NC, Dagnelie PC, Schalkwijk CG, Schram MT, van Boxtel MP. Associations of advanced glycation end-products with cognitive functions in individuals with and without type 2 diabetes: The maastricht study. J Clin Endocrinol Metab. 2015;100:951960

30. Durruty P, Ruiz F, Garcia de los Rios M. Age at diagnosis and seasonal variation in the onset of insulin-dependent diabetes in chile (southern hemisphere). Diabetologia. 1979;17:357-360

31. Felner EI, Klitz W, Ham M, Lazaro AM, Stastny P, Dupont B, White PC. Genetic interaction among three genomic regions creates distinct contributions to early- and late-onset type 1 diabetes mellitus. Pediatr Diabetes. 2005;6:213-220

32. Rosenbloom AL, Joe JR, Young RS, Winter WE. Emerging epidemic of type 2 diabetes in youth. Diabetes Care. $1999 ; 22: 345-354$

33. Ehtisham S, Barrett TG, Shaw NJ. Type 2 diabetes mellitus in uk children--an emerging problem. Diabet Med. 2000;17:867-871

34. Goran MI, Ball GD, Cruz ML. Obesity and risk of type 2 diabetes and cardiovascular disease in children and adolescents. J Clin Endocrinol Metab. 2003;88:1417-1427

35. WHO. Definition and diagnosis of diabetes mellitus and intermediate hyperglycemia. www.who.int/diabetes/publications/Definition\%20and\%20diagnosis\%20of\%20diabetes_new.pdf. 2006

36. van Bussel BC, Henry RM, Schalkwijk CG, Ferreira I, Feskens EJ, Streppel MT, Smulders YM, Twisk JW, Stehouwer CD. Fish consumption in healthy adults is associated with decreased circulating biomarkers of endothelial dysfunction and inflammation during a 6-year follow-up. J Nutr. 2011;141:1719-1725

37. Vischer UM. Von willebrand factor, endothelial dysfunction, and cardiovascular disease. J Thromb Haemost. 2006;4:1186-1193

38. Schram MT, Stehouwer CD. Endothelial dysfunction, cellular adhesion molecules and the metabolic syndrome. Horm Metab Res. 2005;37 Suppl 1:49-55

39. Ross R. Atherosclerosis--an inflammatory disease. N Engl J Med. 1999;340:115-126

40. Borissoff JI, Spronk HM, ten Cate H. The hemostatic system as a modulator of atherosclerosis. N Engl J Med. 2011;364:1746-1760

41. Stehouwer $C D$, Henry RM, Ferreira I. Arterial stiffness in diabetes and the metabolic syndrome: A pathway to cardiovascular disease. Diabetologia. 2008;51:527-539

42. Mattock MB, Keen H, Viberti GC, el-Gohari MR, Murrells TJ, Scott GS, Wing JR, Jackson PG. Coronary heart disease and urinary albumin excretion rate in type 2 (non-insulin-dependent) diabetic patients. Diabetologia. 1988;31:82-87

43. Gall MA, Rossing P, Skott P, Damsbo P, Vaag A, Bech K, Dejgaard A, Lauritzen M, Lauritzen E, Hougaard P, et al. Prevalence of micro- and macroalbuminuria, arterial hypertension, retinopathy and large vessel disease in european type 2 (non-insulin-dependent) diabetic patients. Diabetologia. 1991;34:655-661

44. Randomised placebo-controlled trial of lisinopril in normotensive patients with insulin-dependent diabetes and normoalbuminuria or microalbuminuria. The euclid study group. Lancet. 1997;349:1787-1792

45. Stehouwer CD, Nauta JJ, Zeldenrust GC, Hackeng WH, Donker AJ, den Ottolander GJ. Urinary albumin excretion, cardiovascular disease, and endothelial dysfunction in non-insulin-dependent diabetes mellitus. Lancet. 1992;340:319323

46. Rosenson RS, Fioretto P, Dodson PM. Does microvascular disease predict macrovascular events in type 2 diabetes? Atherosclerosis. 2011;218:13-18

47. Taki K, Takayama F, Tsuruta Y, Niwa T. Oxidative stress, advanced glycation end product, and coronary artery calcification in hemodialysis patients. Kidney international. 2006;70:218-224

48. Peters SA, Bakker M, den Ruijter HM, Bots ML. Added value of cac in risk stratification for cardiovascular events: A systematic review. Eur J Clin Invest. 2012;42:110-116

49. Laurent S, Cockcroft J, Van Bortel L, Boutouyrie P, Giannattasio C, Hayoz D, Pannier B, Vlachopoulos C, Wilkinson I, Struijker-Boudier H. Expert consensus document on arterial stiffness: Methodological issues and clinical applications. European heart journal. 2006;27:2588-2605

50. McKenna M, Wolfson S, Kuller L. The ratio of ankle and arm arterial pressure as an independent predictor of mortality. Atherosclerosis. 1991;87:119-128

51. Murabito JM, Evans JC, Larson MG, Nieto K, Levy D, Wilson PW. The ankle-brachial index in the elderly and risk of stroke, coronary disease, and death: The framingham study. Arch Intern Med. 2003;163:1939-1942 
52. Fowkes FG, Murray GD, Butcher I, Heald CL, Lee RJ, Chambless LE, Folsom AR, Hirsch AT, Dramaix M, deBacker G, Wautrecht JC, Kornitzer M, Newman AB, Cushman M, Sutton-Tyrrell K, Lee AJ, Price JF, d'Agostino RB, Murabito JM, Norman PE, Jamrozik K, Curb JD, Masaki KH, Rodriguez BL, Dekker JM, Bouter LM, Heine RJ, Nijpels G, Stehouwer CD, Ferrucci L, McDermott MM, Stoffers HE, Hooi JD, Knottnerus JA, Ogren M, Hedblad B, Witteman JC, Breteler MM, Hunink MG, Hofman A, Criqui MH, Langer RD, Fronek A, Hiatt WR, Hamman R, Resnick HE, Guralnik J. Ankle brachial index combined with framingham risk score to predict cardiovascular events and mortality: A meta-analysis. Jama. 2008;300:197-208

53. Den Ruijter HM, Peters SA, Anderson TJ, Britton AR, Dekker JM, Eijkemans MJ, Engstrom G, Evans GW, de Graaf J, Grobbee DE, Hedblad B, Hofman A, Holewijn S, Ikeda A, Kavousi M, Kitagawa K, Kitamura A, Koffijberg H, Lonn EM, Lorenz MW, Mathiesen EB, Nijpels G, Okazaki S, O'Leary DH, Polak JF, Price JF, Robertson C, Rembold CM, Rosvall M, Rundek T, Salonen JT, Sitzer M, Stehouwer CD, Witteman JC, Moons KG, Bots ML. Common carotid intima-media thickness measurements in cardiovascular risk prediction: A meta-analysis. Jama. 2012;308:796-803

54. O'Leary DH, Polak JF, Kronmal RA, Manolio TA, Burke GL, Wolfson SK, Jr. Carotid-artery intima and media thickness as a risk factor for myocardial infarction and stroke in older adults. Cardiovascular health study collaborative research group. N Engl J Med. 1999;340:14-22

55. Lorenz MW, Markus HS, Bots ML, Rosvall M, Sitzer M. Prediction of clinical cardiovascular events with carotid intimamedia thickness: A systematic review and meta-analysis. Circulation. 2007;115:459-467

56. Aboyans V, Criqui MH, Abraham P, Allison MA, Creager MA, Diehm C, Fowkes FG, Hiatt WR, Jonsson B, Lacroix P, Marin B, McDermott MM, Norgren L, Pande RL, Preux PM, Stoffers HE, Treat-Jacobson D. Measurement and interpretation of the ankle-brachial index: A scientific statement from the american heart association. Circulation. 2012;126:2890-2909

57. Clairotte C, Retout S, Potier L, Roussel R, Escoubet B. Automated ankle-brachial pressure index measurement by clinical staff for peripheral arterial disease diagnosis in nondiabetic and diabetic patients. Diabetes Care. 2009;32:1231-1236

58. Potier L, Abi Khalil C, Mohammedi K, Roussel R. Use and utility of ankle brachial index in patients with diabetes. Eur J Vasc Endovasc Surg. 2011;41:110-116 


\section{CHAPTER 9}

VALORISATION ADDENDUM 


\section{VALORISATION ADDENDUM}

In today's health care system, evidence-based medicine is considered to be of great importance. The interpretation of study results and their relevance and possible impact and contribution to the current health care system may be difficult to implement for the individual reader. For that purpose, the valorisation of our research results will be discussed in this addendum.

\section{Social and economical relevance}

The global prevalence of diabetes was estimated to be $8.8 \%$ in adults aged $20-79$ years in $2015^{1}$, and is believed to increase even further to $10.4 \%$, or one in every 10 adults, in $2040^{1}$. Due to this high prevalence, diabetes is the leading cause of renal failure in many populations ${ }^{2}$. Furthermore, more than half of all non-traumatic lower limb amputations are due to diabetes ${ }^{2,3}$ and diabetes is one of the leading causes of visual impairment and blindness in developed countries ${ }^{2,4}$. Besides the impact on their health and general life, the costs of health-care resources of an individual with diabetes are two to three times higher compared with individuals without diabetes ${ }^{2}, 5$. Taken together, this illustrates the great impact of diabetes on modern-time society and healthcare. Therefore, studies investigating the link between diabetes and its complications, such as ours, may help to reveal opportunities to prevent or delay the development and progression of these complications. Furthermore, relevant markers of disease progression or severity may more effectively identify individuals at risk of vascular complications of diabetes.

\section{Target group}

Our main target group is the academic community. As discussed before, our research reveals potential new pathways in the development of cardiovascular disease in the general population and cardiovascular complication in diabetes. As with all studies, more new studies are needed to further investigate and validate our results. Overall, our results confirm the hypothesis that advanced glycation endproducts (AGEs) are involved in the development of multiple (cardio)vascular diseases and diabetes complications.

\section{Implementation in daily practice}

In the current health care system, diabetes is monitored by fasting glucose measurements and $\mathrm{HbA1c}$, a precursor of AGEs. HbA1c provides an indication of the average glucose level over the past weeks, corresponding to the half-life of haemoglobin. This makes the HbA1c suitable to monitor the glucose burden and dietary and medicine compliance over a short term period. AGEs are accumulating on long-lived proteins in tissues, e.g. vascular tissue, the skin and vital organs. Therefore, AGE measurements are thought to represent the glucose burden over a longer period compared with $\mathrm{HbA1c}$, especially when measured in tissues. Naturally, tissue biopsy specimens for the determination of AGE-levels are not suitable for daily practice. The measurement of skin autofluorescence (SAF) provides an alternative for tissue biopsies. As discussed in the introduction of this thesis, SAF has been associated with neuropathy, nephropathy and retinopathy in individuals with T1DM ${ }^{6-10}$ and T2DM 7, 9, 11-14 and macrovascular complications in both T1DM 7, 15, 16 and T2DM7, 12, 14, 15, 17, 18. Additionally, SAF has shown to provide additional information to the UK Prospective Diabetes Study (UKPDS) risk score for the estimation of cardiovascular prognosis in T2DM ${ }^{17}$. In this thesis, we have shown that SAF in associated with arterial stiffness (Chapter 
4), endothelial dysfunction (Chapter 5), peripheral arterial disease (Chapter 6) and cognitive impairment (Chapter 7). Since SAF is a relatively new measurement, researchers are currently studying its potential for implementation in daily practice. For now, it seems a promising new tool in the prediction of the cardiovascular risk of individuals with diabetes.

\section{Contribution to the current field}

AGE accumulation and its relation to the development of complications of diabetes is an area which is studied by numerous researchers, as shown by the multiple references throughout the former chapters. Multiple experimental studies have been and are currently being performed to look into the possible causal nature of this relation. Others have used observational studies to investigate this association in humans, such as we did in this thesis. With research presented in this thesis we believe we made some unique contributions to the current field. First, we developed and studied a new antibody against MGO-derived AGEs, which showed to be specific for THP. Second, we used state-of-the-art ultra-performance liquid chromatography (UPLC) in combination with tandem mass spectrometry or, in case of pentosidine, with high-performance liquid chromatography (HPLC) and fluorescence detection to determine different AGEs-levels in plasma. These techniques are considered to be the most accurate techniques for the measurement of AGEs at this moment. Moreover, we were able to investigate skin autofluorescence (SAF), a relatively new and promising marker of AGE accumulation, in relation to plasma AGEs and markers of vascular disease. Third, we used large cohort studies with extensively phenotyped individuals with and without diabetes, making it possible to adjust for numerous possible confounding factors. Fourth, as outcome measures in our analyses, e.g. for vascular stiffness, microvascular complications and markers endothelial dysfunction or low-grade inflammation, we did not use only one maker, but several well-known validated markers of the same processes, which makes our results more likely to reflect true associations and which strengthens our conclusions.

\section{Future research}

As described in the former chapters, we found consistent results for the associations between higher SAF and markers of vascular disease. This may implicate that AGEs are indeed implemented in the development of vascular diseases and vascular complications of diabetes. We found less homogenous results for the association between plasma AGEs and vascular diseases. Associations for plasma pentosidine were similar to SAF, but plasma CML and CEL showed nonexistent or even inverse associations. Future studies are needed to evaluate these negative associations. For now, SAF seems to provide a more consistent measurement in relation to vascular disease and vascular complications of diabetes. Prospective studies are required to investigate whether or not SAF is indeed a more valid marker of AGE accumulation than plasma AGEs.

Lutgers et al. show that SAF provides additional information to the UK Prospective Diabetes Study (UKPDS) risk score for the estimation of cardiovascular prognosis in T2DM17. However, the possible influence of the implementation of SAF measurements in daily practice for patients with diabetes on cardiovascular morbidity and mortality remains uncertain. In our health care system, individuals with diabetes are already intensively monitored and treated with regard to glycemic control, microand macrovascular complications and other risk factors of cardiovascular disease. Therefore, without new treatment options, the potential impact of adding SAF-measurement to the current protocol for diabetes management requires further investigation. 
As AGE accumulation is proposed be involved in the development of vascular disease, AGElowering therapies may be able to diminish the increased risk of CVD in individuals with increased AGE accumulation, e.g. in diabetes. Several therapeutic interventions aiming to limit AGE-related vascular damage have been investigated. Aminoguanidine is one of the most extensively studied AGE inhibitors. Aminoguanidine was shown to increase elasticity of large arteries in diabetes animal models ${ }^{19}$. However, because of disappointing results from clinical studies in individuals with diabetic nephropathy ${ }^{20,21}$ and its detrimental side effects, such as deteriorated liver function and gastrointestinal toxicity ${ }^{21}$, it is unlikely that aminoguanidine will be implemented in anti-AGE therapy in humans. Another well-studied potential anti-AGE therapy is the cross-link breaker alagebrium (ALT-711). It has been shown that alagebrium is able to reduce large artery stiffness in different animal models, including diabetes animal models ${ }^{22}$. One double-blind RCT correspondingly showed a decrease in pulse pressure and CFPWV in individuals with hypertension who received alagebrium ${ }^{23}$. However, another double-blind RCT showed no treatment effects in individuals with chronic heart failure ${ }^{24}$. Therefore, more large, specific and well-designed studies are needed to elucidate their potential effect in humans. 


\section{REFERENCES}

1. International Diabetes Federation. Idf diabetes atlas, 7th edition. Brussels, Belgium: International Diabetes Federation. 2015

2. Alwan A. Global status report on noncommunicable diseases 2010. World Health Organization. 2011

3. Icks A, Haastert B, Trautner C, Giani G, Glaeske G, Hoffmann F. Incidence of lower-limb amputations in the diabetic compared to the non-diabetic population. Findings from nationwide insurance data, germany, 2005-2007. Exp Clin Endocrinol Diabetes. 2009;117:500-504

4. Resnikoff S, Pascolini D, Etya'ale D, Kocur I, Pararajasegaram R, Pokharel GP, Mariotti SP. Global data on visual impairment in the year 2002. Bull World Health Organ. 2004;82:844-851

5. Zhang P, Zhang X, Brown J, Vistisen D, Sicree R, Shaw J, Nichols G. Global healthcare expenditure on diabetes for 2010 and 2030. Diabetes Res Clin Pract. 2010;87:293-301

6. Araszkiewicz A, Naskret D, Niedzwiecki P, Samborski P, Wierusz-Wysocka B, Zozulinska-Ziolkiewicz D. Increased accumulation of skin advanced glycation end products is associated with microvascular complications in type 1 diabetes. Diabetes Technol Ther. 2011;13:837-842

7. Bos DC, de Ranitz-Greven WL, de Valk HW. Advanced glycation end products, measured as skin autofluorescence and diabetes complications: A systematic review. Diabetes Technol Ther. 2011;13:773-779

8. Chabroux S, Canoui-Poitrine F, Reffet S, Mills-Joncour G, Morelon E, Colin C, Thivolet C. Advanced glycation end products assessed by skin autofluorescence in type 1 diabetics are associated with nephropathy, but not retinopathy. Diabetes Metab. 2010;36:152-157

9. Meerwaldt R, Links TP, Graaff R, Hoogenberg K, Lefrandt JD, Baynes JW, Gans RO, Smit AJ. Increased accumulation of skin advanced glycation end-products precedes and correlates with clinical manifestation of diabetic neuropathy. Diabetologia. 2005; 48:1637-1644

10. Orchard TJ, Lyons TJ, Cleary PA, Braffett BH, Maynard J, Cowie C, Gubitosi-Klug RA, Way J, Anderson K, Barnie A, Villavicencio $\mathrm{S}$. The association of skin intrinsic fluorescence with type 1 diabetes complications in the dcct/edic study. Diabetes Care. 2013;36:3146-3153

11. Gerrits EG, Lutgers HL, Kleefstra N, Graaff R, Groenier KH, Smit AJ, Gans RO, Bilo HJ. Skin autofluorescence: A tool to identify type 2 diabetic patients at risk for developing microvascular complications. Diabetes Care. 2008;31:517-521

12. Lutgers HL, Graaff R, Links TP, Ubink-Veltmaat LJ, Bilo HJ, Gans RO, Smit AJ. Skin autofluorescence as a noninvasive marker of vascular damage in patients with type 2 diabetes. Diabetes Care. 2006;29:2654-2659

13. Monami M, Lamanna C, Gori F, Bartalucci F, Marchionni N, Mannucci E. Skin autofluorescence in type 2 diabetes: Beyond blood glucose. Diabetes Res Clin Pract. 2008;79:56-60

14. Tanaka K, Tani Y, Asai J, Nemoto F, Kusano Y, Suzuki H, Hayashi Y, Asahi K, Nakayama M, Miyata T, Watanabe T. Skin autofluorescence is associated with severity of vascular complications in japanese patients with type 2 diabetes. Diabet Med. 2012;29:492-500

15. Meerwaldt R, Lutgers HL, Links TP, Graaff R, Baynes JW, Gans RO, Smit AJ. Skin autofluorescence is a strong predictor of cardiac mortality in diabetes. Diabetes Care. 2007;30:107-112

16. Conway B, Edmundowicz D, Matter N, Maynard J, Orchard T. Skin fluorescence correlates strongly with coronary artery calcification severity in type 1 diabetes. Diabetes Technol Ther. 2010;12:339-345

17. Lutgers HL, Gerrits EG, Graaff R, Links TP, Sluiter WJ, Gans RO, Bilo HJ, Smit AJ. Skin autofluorescence provides additional information to the uk prospective diabetes study (ukpds) risk score for the estimation of cardiovascular prognosis in type 2 diabetes mellitus. Diabetologia. 2009;52:789-797

18. Noordzij MJ, Mulder DJ, Oomen PH, Brouwer T, Jager J, Castro Cabezas M, Lefrandt JD, Smit AJ. Skin autofluorescence and risk of micro- and macrovascular complications in patients with type 2 diabetes mellitus-a multi-centre study. Diabet Med. 2012;29:1556-1561

19. Huijberts MS, Wolffenbuttel BH, Boudier HA, Crijns FR, Kruseman AC, Poitevin P, Levy BI. Aminoguanidine treatment increases elasticity and decreases fluid filtration of large arteries from diabetic rats. J Clin Invest. 1993;92:1407-1411

20. Bolton WK, Cattran DC, Williams ME, Adler SG, Appel GB, Cartwright K, Foiles PG, Freedman BI, Raskin P, Ratner RE, Spinowitz BS, Whittier FC, Wuerth JP. Randomized trial of an inhibitor of formation of advanced glycation end products in diabetic nephropathy. Am J Nephrol. 2004;24:32-40

21. Freedman BI, Wuerth JP, Cartwright K, Bain RP, Dippe S, Hershon K, Mooradian AD, Spinowitz BS. Design and baseline characteristics for the aminoguanidine clinical trial in overt type 2 diabetic nephropathy (action ii). Control Clin Trials. 1999;20:493-510

22. Engelen L, Stehouwer CD, Schalkwijk CG. Current therapeutic interventions in the glycation pathway: Evidence from clinical studies. Diabetes Obes Metab. 2012

23. Kass DA, Shapiro EP, Kawaguchi M, Capriotti AR, Scuteri A, deGroof RC, Lakatta EG. Improved arterial compliance by a novel advanced glycation end-product crosslink breaker. Circulation. 2001;104:1464-1470 
160 | Chapter 9

24. Hartog JW, Willemsen S, van Veldhuisen DJ, Posma JL, van Wijk LM, Hummel YM, Hillege HL, Voors AA. Effects of alagebrium, an advanced glycation endproduct breaker, on exercise tolerance and cardiac function in patients with chronic heart failure. Eur J Heart Fail. 2011;13:899-908 


\section{NEDERLANDSTALIGE SAMENVATTING}




\section{NEDERLANDSTALIGE SAMENVATTING}

Diabetes mellitus, of suikerziekte, is een groep stofwisselingsziekten. De kenmerkende eigenschap van deze groep ziekten is een verhoging van de glucose (suiker) waarde in het bloed. In 2015 waren er maar liefst 415 miljoen mensen wereldwijd met diabetes. In Nederland waren er in datzelfde jaar 1,1 miljoen diabetespatiënten bekend bij hun huisarts. Het hebben van diabetes verhoogt het risico op het ontwikkelen van hart- en vaatziekten, nier-, oog- en zenuwschade en leidt zo tot een lagere levensverwachting. Door het grote aantal diabetespatiënten en het verhoogde risico op daarmee samenhangende ziekten schat de World Health Organisation (WHO) dat diabetes in 2030 op de $7^{e}$ plaats komt van doodsoorzaken wereldwijd.

Er zijn verschillende typen diabetes, maar de meest voorkomende en bekende zijn diabetes type 1 en diabetes type 2 . Hoewel ze beide gekenmerkt worden door een verhoogde glucosewaarde in het bloed, zijn het twee verschillende ziektes. Bij type 1 diabetes worden de cellen van de alvleesklier die insuline produceren aangevallen en kapot gemaakt. Insuline is het hormoon dat ervoor zorgt dat glucose kan worden opgenomen in cellen voor de verbranding. Doordat de cellen kapot gaan wordt er geen insuline meer door het eigen lichaam aangemaakt, en moeten mensen met diabetes type 1 zichzelf dagelijks insuline toedienen om in leven te blijven. Ongeveer 5 tot $10 \%$ van de mensen met diabetes heeft diabetes type 1 . De oorzaak voor het ontwikkelen van diabetes type 1 is grotendeels onbekend en het kan tot nu toe niet voorkomen of genezen worden. Diabetes type 2, ook wel ouderdomssuikerziekte genoemd, wordt veroorzaakt doordat het lichaam de insuline niet goed en efficiënt kan gebruiken doordat de cellen die glucose gebruiken voor de verbranding ongevoeliger worden voor insuline. Type 2 diabetes is voor een deel erfelijk bepaald en komt steeds meer voor. Mensen met overgewicht hebben een verhoogd risico op het ontwikkelen van diabetes type 2; het overgewicht zorgt voor ongevoeligheid voor insuline. De behandeling van diabetes type 2 bestaat uit een dieet, gewichtsreductie en het stimuleren van bewegen, wat alle de gevoeligheid voor insuline bevordert. Daarnaast maakt, als dit onvoldoende helpt, ook medicatie deel uit van de behandeling. Hierbij wordt gestart met tabletten, maar kan zo nodig ook worden overgegaan tot de toediening van insuline. Tot voor kort werd dit ouderdomssuikerziekte genoemd, maar met het toenemen van overgewicht onder de bevolking komt het tegenwoordig zelfs voor bij kinderen met obesitas (extreem overgewicht).

Diabetes leidt tot een verhoogd risico op hart- en vaatziekten, nier-, oog- en zenuwschade door een beschadiging van de vaatwand. Dat kan in de kleine vaatjes van de nieren, zenuwen en de ogen, maar ook in de grote vaten van het lichaam en het hart. In de laatste jaren is bekend geworden dat diabetes ook het risico op dementie verhoogt. Er zijn verschillende mogelijke verklaringen gevonden waarom mensen met diabetes een groter risico lopen op het ontwikkelen van hart- en vaatziekten, nier-, oog-, zenuwschade en dementie. Eén van deze verklaringen is de schade die versuikerde eiwitten, de zogenaamde advanced glycation endproducts (AGE's), aanbrengen in de vaatwand. Versuikering van eiwitten treedt bij iedereen op, maar het aantal versuikerde eiwitten in ons lichaam neemt toe naarmate we ouder worden en nog eens extra bij diabetes. Een van de meest bekende AGEs is het HbA1c, wat gebruikt wordt in de diagnostiek en controle van mensen met diabetes. HbA1c is een voorbeeld van een eiwit dat nog 'ontsuikerd' kan raken. Er zijn ook vormen van AGEs bekend waarbij het eiwit- en suikergedeelte voorgoed met elkaar verbonden is. Dit zijn de AGEs waarvan gedacht wordt dat ze schade toebrengen. 
Voorbeelden van deze laatste AGEs zijn pentosidine, CML (Ne-carboxymethyllysine), CEL (NEcarboxyethyllysine) en THP (tetrahydropyrimidine).

In dit proefschrift staan verschillende onderzoeken beschreven met als doel meer inzicht te krijgen in de relatie tussen AGEs en het ontstaan van vaat-, nier-, oog- en zenuwschade. Voor deze studies hebben we gebruik gemaakt van verschillende cohorten. Dit zijn groepen mensen die een afspiegeling zijn van een bepaalde grotere groep, bijvoorbeeld alle diabetespatiënten of de algehele populatie. Deze groep mensen wordt uitgebreid onderzocht, ondervraagd en ondergaat verschillende metingen die relevant zijn voor het onderzoek. Door verbanden te leggen tussen kenmerken van deze mensen, bijvoorbeeld hun leeftijd, de hoeveelheid AGEs die ze hebben, hoe gezond hun vaten zijn en of ze een hartinfarct ontwikkelen, hopen we iets te kunnen zeggen over deze verbanden in de grotere groep mensen die deze groep weerspiegelt.

\section{Samenvatting en interpretatie van de hoofdstukken}

In hoofdstuk 2 beschrijven we hoe we een nieuwe methode hebben ontwikkeld om één van de AGEs te meten in het bloed, namelijk THP. We hebben deze nieuwe meetmethode gebruikt om de THP waarde in het bloed te meten in een cohort mensen met en zonder diabetes type 1 . We vonden dat de THP-waarde in bloed hoger was bij mensen met diabetes type 1 vergeleken met de mensen zonder diabetes. Daarnaast vonden we dat mensen met een hoge THP-waarde in hun bloed ook hoge SVCAM-1 waarden hadden, een maat voor schade aan de binnenste bekleding van de vaatwand. Toen we onder de microscoop naar vaten gingen kijken waarin slagaderverkalking zit, kwamen we op de plekken van de verkalking ook daadwerkelijk THP tegen. In hoofdstuk 3 beschrijven we, naast THP, ook de relatie van de AGEs pentosidine, CML en CEL met diabetes en vasculaire schade. We vonden dat mensen met diabetes type 1 , naast THP, ook meer pentosidine en $\mathrm{CML}$ in hun bloed hadden dan mensen zonder diabetes. Daarnaast hadden mensen met een hoge pentosidine waarde ook een hogere kalkwaarde in de slagaders van hun hart, een maat voor slagaderverkalking van de hartslagaders. Vanaf hoofdstuk 4 nemen we een nieuwe maat voor AGEs mee in onze studies, namelijk een lichtmeting in de huid; afgekort SAF, wat staat voor skin autofluorescence. Een aantal AGEs staat erom bekend licht met een specifieke golflente uit te kunnen zenden. De SAF meting maakt daar gebruikt van en gebruikt de huid als orgaan dat mogelijk ook de stapeling in de rest van de organen, bijvoorbeeld het hart, de nieren en de ogen, weerspiegelt. Daarnaast is de huid makkelijker te bereiken dan de andere organen; dit maakt de meting makkelijk toepasbaar. Vanaf dit hoofdstuk maken we gebruik van een ander cohort voor ons onderzoek, de Maastricht Studie: een cohort met mensen met én zonder diabetes type 2, en mensen met een verhoogd risico op het ontwikkelen van diabetes type 2 . In hoofdstuk $4 \mathrm{t} / \mathrm{m} 7$ staat beschreven dat mensen met een hoge SAF ook stijvere grote slagaders hadden (hoofdstuk 4). Daarnaast hadden mensen met een hoge SAF, hogere bloedwaarden die duiden op schade van de binnenste bekleding van de vaatwand (hoofdstuk 5). Mensen met een hogere SAF hadden gemiddeld een lagere score op een maat voor de doorbloeding van de beenslagaders, wat een aanwijzing is voor slagaderverkalking in de benen (hoofdstuk 6). In datzelfde hoofdstuk vonden we geen relatie tussen SAF en de dikte van de vaatwand in de slagader in de hals, een maat voor slagaderverkalking in de halsslagader. Ten slotte beschrijven we in hoofdstuk 7 de relatie tussen

een hoge SAF waarde en cognitieve achteruitgang, een voorloper van ouderdomsvergeetachtigheid en dementie. We onderzochten in hoofdstuk $4 \mathrm{t} / \mathrm{m} 7$ ook de relatie tussen AGEs gemeten in het bloed met al deze (voorlopers van) ziekten. We vonden dat mensen 
met een hoge pentosidine waarde in het bloed stijvere grote slagaders hadden (hoofdstuk 4) en minder goede cognitie (hoofdstuk 7). In tegenstelling tot voorgaande bevindingen vonden we dat mensen met een hoge pentosidine waarden een lagere laaggradige ontstekingswaarde hadden; ook een maat voor vaatschade (hoofdstuk 5). Bij de AGEs CML en CEL vonden we géén of juist een omgekeerde relatie met maten van vaatschade (hoofdstuk $4 \mathrm{t} / \mathrm{m} 7$ ); dus waren er veel AGEs aanwezig in het bloed, dan was er juist minder vaatschade.

Uit eerdere studies weten we dat CML lager is in het bloed van mensen met obesitas en diabetes type 2 in vergelijking tot mensen zonder overgewicht en diabetes. Hierbij wordt gesuggereerd dat dit kan komen doordat CML wordt 'weggevangen' door een receptor in het vetweefsel. CML gemeten in het bloed is dus mogelijk geen goede weerspiegeling van de mate van CML in het weefsel bij mensen met overgewicht of diabetes type 2 . We hebben geen goede verklaring voor het feit dat we ook een omgekeerde relatie vonden tussen CEL en vaatschade. Het zou kunnen zijn dat een lage hoeveelheid AGEs in het bloed betekent dat er juist veel AGEs in de weefsels zijn achtergebleven, maar dat is slechts speculeren. AGEs in het bloed weerspiegelen mogelijk een kortere periode van versuikering dan AGEs gemeten in de huid, zoals bij SAF. Ook dat kan een oorzaak zijn voor de verschillen in gevonden relaties met vaatschade tussen beiden. Concluderend laten onze resultaten zien dat hogere SAF consequent gerelateerd is aan meer vaatschade. De relatie tussen AGEs gemeten in het bloed en vaatschade is niet consistent.

\section{Epidemiologisch onderzoek en confounding}

In het onderzoek beschreven in dit proefschrift kijken we naar de relatie tussen twee kenmerken van een persoon. Wat hierbij zeer belangrijk is, is het corrigeren voor mogelijke confounding. In de cohorten die wij hebben onderzocht zitten mensen die niet zijn geselecteerd omdat ze allemaal gezond zijn en op elkaar lijken, maar juist verschillende ziektes hebben, en hun eigen individuele kenmerken. Als je een relatie tussen diabetes en het hebben van vaatschade onderzoekt wil je niet dat andere kenmerken, bijvoorbeeld roken, ervoor zorgen dat de relatie die je vindt eigenlijk (deels) wordt veroorzaakt door de andere kenmerken van die personen. We weten bijvoorbeeld dat roken ook zorgt voor vaatschade. Als de mensen in het cohort met diabetes veel meer roken dan de mensen zonder diabetes, en je kijkt alleen naar het aantal mensen met diabetes die vaatschade hebben, dan zullen dat er meer zijn dan wanneer het aantal rokers in de groep met en zonder diabetes gelijk is. Het effect dat roken heeft op de relatie tussen diabetes en vaatschade heet confounding. Omdat wij willen weten wat het netto effect van diabetes en AGEs op vaatschade is, zonder deze verstorende confounding, hebben we bij alle relaties die we hebben onderzocht gecorrigeerd voor confounding, dus factoren die de onderzochte relatie kunnen verstoren. We hebben hierbij alle bekend confounders, zoals roken, geslacht, leeftijd, bloeddruk, etc. meegenomen. Hierdoor kunnen we concluderen dat de relaties die wij hebben gevonden ook zeer waarschijnlijk echte relaties zijn. Het hebben van veel AGEs hangt dus samen met meer vaatschade, onafhankelijk van het feit hoe oud iemand is, of iemand rookt, etc.

\section{Conclusie}

De studies beschreven in dit proefschrift zijn uitgevoerd om de mogelijke rol van AGEs in het ontwikkelen van hart- en vaatziekten, nier-, oog- en zenuwschade en dementie te onderzoeken bij mensen met en zonder diabetes. Door de opzet van ons onderzoek konden we deze relaties onderzoeken in een, zoveel mogelijk, waarheidsgetrouwe steekproef van de normale populatie. 
In alle door ons onderzochte relaties hebben we voor confounders gecorrigeerd. Hierdoor zijn de relaties tussen maten van ophoping van AGEs en maten van vaatschade die wij vonden in onze studies zeer waarschijnlijk een juiste weerspiegeling van de relatie in de normale bevolking, met en zonder diabetes. We hebben AGEs gemeten in het bloed en in de huid. De gedachte is dat AGEs schade geven in het vaatweefsel en andere weefsels die worden aangedaan bij mensen met diabetes, zoals de nieren, ogen en zenuwen. We weten niet of de AGEs die wij onderzocht hebben daadwerkelijk een juiste weerspiegeling zijn van de AGEs in weefsels. Ook hebben we in veel van onze studies maten voor vaatschade gebruikt, en niet gekeken naar wie wel of niet een hartinfarct ontwikkelt of eerder dood gaat. Hiervoor is namelijk onderzoek nodig dat mensen veel langer volgt. Desalniettemin vonden we een duidelijke en consistente relatie tussen SAF, een maat voor AGE ophoping in de huid, en maten van vaatschade. Dit maakt dat we sterke aanwijzingen hebben dat AGEs inderdaad betrokken zijn bij het ontwikkelen van vaatschade bij mensen met en zonder diabetes. Uit vervolgonderzoek zal moeten blijken of hogere AGEs ook inderdaad leiden tot meer hartinfarcten, herseninfarcten of overlijden. Middels dit en toekomstig onderzoek krijgen we meer inzicht in het mechanisme achter de relatie tussen diabetes en hart- en vaatziekten, nier-, oogen zenuwschade en dementie. Iets wat in de toekomst hopelijk leidt tot het ontwikkelen van therapieën om diabetes en de daarbij voorkomende vaatschade te voorkomen en te genezen. 

DANKWOORD 


\section{DANKWOORD}

Een tijdje geleden las ik het boek 'Verborgen Gebreken' van Renate Dorrestein. Hierin wordt in een passage beschreven hoe de schoonzussen van de hoofdpersoon, allen weduwe inmiddels, terugkijken op hun huwelijk. Ik heb in deze passage het onderwerp huwelijk vervangen door het onderwerp promotie. Hoewel ik niet zo ver wil gaan dat deze promotie echt tot moordzucht heeft geleid, kom ik toch tot de conclusie dat het huwelijk veel weg moet hebben van een promotietraject.

'En na de verdediging, als het zenuwslopende uur achter de rug is, herschrijven zij hun promotietijd, ze redigeren de rotte plekken er uit weg, ze schrapen de ondragelijke ergernissen, de misverstanden, de momenten van pure frustratie en moordzucht - en wat ze overhouden poetsen ze op totdat er vonken van de hoogglans afspringen en ze zeggen tevreden tegen zichzelf: 'zo volmaakt was het'.' (gebaseerd op 'Verborgen Gebreken' van Renate Dorrestein)

Naast frustraties waren er natuurlijk ook talloze momenten van vreugde, overwinning, trots en samenhorigheid. Dit proefschrift was niet tot stand gekomen zonder de hulp en begeleiding van velen. Naast alle deelnemers aan de studies waarop mijn onderzoek gebaseerd is, zonder wie epidemiologisch onderzoek überhaupt nooit mogelijk zou zijn, wil ik een aantal mensen in het bijzonder bedanken.

Geachte prof. dr. Schalkwijk, beste Casper. Ik wil je bedanken voor de manier waarop je me de afgelopen jaren hebt begeleid. Ik heb zowel op wetenschappelijk als op leidinggevend gebied ontzettend veel van je geleerd. Als ik onzeker was, het ergens niet mee eens was of het even niet meer zag zitten stond je altijd achter me. Ik heb veel bewondering voor jouw manier van het leiden van je onderzoeksgroep. Je bent ontzettend gedreven in wat je doet, maakte altijd tijd voor ons, laat iedereen in zijn of haar waarde, respecteert eigen keuzes, maar zorgt er tegelijkertijd voor dat we open staan voor jouw en elkaars feedback, wat het niveau omhoog tilt. Kortom, je bent net zo geliefd als je gerespecteerd wordt, een bewonderenswaardige combinatie. Ook al word ik straks maar half de collega of baas die jij bent, dan ben ik al dik tevreden.

Geachte dr. Schram, beste Miranda. Jij, als research manager van de Maastricht Studie, en ik, als eerste Maastricht Studie AIO, hebben in het begin van mijn promotietraject meer met elkaar opgetrokken als deel van een 'projectteam' om de Maastricht Studie van de grond te krijgen, dan als begeleider en AIO. Ik ben ontzettend dankbaar voor alle vrijheid, verantwoordelijk en het vertrouwen dat ik in deze periode van je heb gekregen. Dit maakt dat ik enorm veel heb geleerd over het opzetten, de logistiek en het uitvoeren van zo'n grote epidemiologische studie. Toen ik eenmaal 'verlost' was van het uitvoeren van de praktische kant van de studie kwam de schrijfperiode. In deze periode, en in het bijzonder bij de laatste loodjes, stond je altijd voor me klaar en maakte je tijd voor me vrij om ervoor te zorgen dat ik zoveel mogelijk af kon maken voordat ik met mijn opleiding tot huisarts begon. Ik wil je daarvoor bedanken en vind het een mooie beloning voor ons beiden dat de Maastricht Studie zo'n groot succes is geworden. 
Geachte prof. dr. Stehouwer, beste Coen. Hoewel we elkaar niet veel zagen heb je toch op een belangrijk manier bijgedragen aan mijn promotietraject. Jij weet als geen ander de kritieke punten in een manuscript aan te stippen, geduldig advies te geven op basis van je onuitputtelijke kennis, maar ook ogenschijnlijke details te verbeteren met het oog op de belangrijke boodschappen in een manuscript. Ik heb van je geleerd dat het gebruik van de juiste woorden cruciaal is om een boodschap over te brengen, iets wat ik niet alleen heb kunnen gebruiken tijdens mijn promotietraject, maar ook voor mijn vak als huisarts enorm waardevol is. Bedankt daarvoor.

De leden van de leescommissie en corona, Prof. dr. Peter W. de Leeuw, Prof. dr. Ilja Arts, Prof. dr. Henk Bilo, Dr. Esther G. Gerrits en Prof. Dr. Giel Nijpels wil ik bedanken voor de beoordeling van mijn proefschrift en het plaatsnemen in de corona.

Dan in chronologische volgorde, te beginnen degene die aan me voorstelde om te gaan promoveren, Dr. Maya Huijberts. Alhoewel ik in eerste instantie bedankte, haalde jij me over om toch dit traject in te gaan. Had je mij die ene mail niet gestuurd, dan had ik hier nooit gestaan. Ik wil je bedanken voor je openheid, oprechtheid en de warme manier waarop je me destijds begeleid hebt.

Dan mijn allereerste kamergenootjes, Janine en Peter. Bedankt voor alle wijze raad en het helpen met opstarten.

Niet lang daarna kwam Nordin, mijn 'partner in crime' de eerste jaren. Ik heb allereerst inhoudelijk ontzettend veel van je geleerd. Jouw onuitputtelijke kennis over zowel medische zaken als veel daaromheen maakt je een wandelende encyclopedie. Daarnaast vind ik je gedrevenheid, oprechte interesse en enthousiasme bewonderenswaardig. Naast vele andere congressen heb ik met jou en Jürgen naar Chicago mogen afreizen voor het ADA-congres. Wat een lol hebben we gehad met elkaar. We zien elkaar niet veel meer, mede door drukke vervolgopleidingen en de afstand, maar ik hoop je niet uit het oog te verliezen. Heel veel succes met het afronden van je opleiding.

De journal club op dinsdagmiddag, de talloze discussies op vrijdagochtend, maar vaak ook gewoon tussendoor. Ontzettend leerzaam, van hoog niveau, maar altijd respectvol, met oprechte interesse voor de ander. Bedankt Lian, Bas, Roel, Johanna, Marleen, Elisabeth, Katrien, Olaf, Dionne, Yvo, Kristiaan en Jean, en natuurlijk iedereen die hier zijn bijdrage aan leverde en die ik nu vergeet. En ondanks dat ik vrijwel niets in het laboratorium heb gedaan, wil ik ook Vicky, Marjo, Margee en Petra bedanken voor de geduldige uitleg en gezelligheid op de afdeling.

En toen kwam de start van de Maastricht Studie, waarin we met een klein groepje AIO's ineens veel verantwoordelijkheid kregen en mooie en minder leuke momenten deelden. Dennis, ik wil je bedanken voor je nuchterheid, je luisterend oor, je vertrouwen in mij. Ik heb veel aan je gehad in die begin tijd. De andere AIO's van het eerste uur, Thomas, Peggy, Jose, Fleur, Pauline en Stefan. Ik ben er trots op wat wij met zo weinig ervaring voor elkaar hebben gekregen. Maar niet alleen de AIO's hebben deze studie gemaakt tot wat hij is, ook grote dank aan Josephine, Yvette, Karin, Jos, Chantalle, Bernarda en Myriam. Jullie maakten mijn werkplezier compleet. Ook bedankt aan het managementteam van de Maastricht Studie, in het bijzonder Ronald, Simone, Carla en Annemarie voor het neerzetten van een open sfeer, jullie begeleiding en het vertrouwen in ons als AIO's. Teammanagers Rosemarie en Joyce, bedankt voor jullie inzet.

Niet te vergeten prof. dr. Andries Smit en de medewerkers van DiagnOptics, o.a. Jasper Dijkstra en Bart van den Berg, die als 'uitvinders' van de AGE-reader mij hebben begeleid bij het inzetten van de AGE-reader in de Maastricht Studie. Bedankt dat jullie altijd bereid waren om me te helpen waar nodig, zelfs als daarvoor een trip naar Maastricht was vereist. 
Daarna de schrijfperiode, waarin ik weer terug verhuisde naar de UNS 50 en een kamer deelde met Lian en Elisabeth. Lian, bedankt voor je luisterend oor, je geduldige uitleg, je hulp bij analyses of computerproblemen. Het was een intense tijd waarin we veel gedeeld hebben. Ik ben je dankbaar voor je vriendschap in die periode. Elisabeth, dank voor je interesse en de vele kritische discussies. En natuurlijk nog een extra dank aan Bas, die me als zijn paranimf alvast een kijkje liet nemen achter de schermen bij een promotie.

Dan mijn twee paranimfen, Emilie en Astrid. Eem, bedankt voor je bijna levenslange vriendschap. Bij jou voel ik me altijd thuis, als bij een zus. Bij een echte vriendschap is dat niet afhankelijk van veel woorden of tijd. Assie, vriendinnetje van hockey, maar sinds de mannen elkaar hebben leren kennen ook veel daarbuiten. Heerlijk om met jou verhalen uit te wisselen over onze ervaringen met patiënten, zowel de hilarische als de pijnlijke en zware. Ik heb je zelfs even als collega gehad toen je na je Geneeskunde opleiding metingen deed voor de Maastricht Studie. Ik ben dankbaar voor zulke goede vriendinnen en vind het ontzettend mooi dat jullie twee naast me staan bij deze belangrijke mijlpaal.

Mijn familie. Ik heb een ontzettend leuke en warme familie waarbij ik me altijd welkom, geliefd en gewaardeerd voel. In het bijzonder moet ik de zussen van mijn moeder Mieke, Mariëlle en Helga noemen, die ik geen tantes mag noemen omdat dat 'oud' klinkt. Jullie voelen als mijn extra moeders en ik ben mede dankzij jullie geworden wie ik ben, dank daarvoor. Patrick, mijn schoonbroer. Bedankt voor de gezellige familieavonden en natuurlijk de prachtige foto op de kaft van dit proefschrift. En Carla en Werner, mijn 'bijna familie' als schoonouders, bedankt voor jullie steun en trots de afgelopen jaren. Helaas is Werner er niet meer om mijn dank over te brengen, maar dat betekent niet dat hij hier geen plaats verdient.

Mijn twee fantastische ouders. Zonder jullie zou ik natuurlijk niet staan waar ik nu ben. Een prachtige zorgeloze jeugd heb ik gehad. Altijd heb ik het gevoel gekregen dat ik speciaal ben, dat ik alles kan bereiken. Dank voor jullie vertrouwen en jullie liefde voor mij, die is geheel wederzijds.

Birgit, mijn zusje. Tijdens mijn afstudeerfeest als huisarts bekende je dat je naast de trots die je voelde voor mij baalt dat je zelf telkens deze feestjes bent misgelopen. Je afstuderen van de middelbare school werd geen feest, je afstuderen van je opleiding niet gevierd als mijlpaal. Ik wil hierbij duidelijk maken dat ik juist erg trots op je ben, omdat jij iemand bent die niet de begaande paden volgt, maar precies doet wat je hart je ingeeft. Hierdoor loop je misschien meer risico, en zijn er meer hobbels, maar je haalt ook uit het leven wat je er zelf uit wilt halen. Bedankt voor je trots, liefde en steun zusje!

Jürgen, Juppie, mijn grote vriend. Jij weet als geen ander mijn onzekerheid en onrust weg te nemen. Relaxed, relativerend, maar altijd begripvol en lief. Ik ben dankbaar dat we al zo lang samen zijn en nog steeds zo gelukkig met elkaar. Dank voor je liefde voor mij, ik houd ook ontzettend veel van jou. 


\section{CURRICULUM VITAE}





\section{Curriculum vitae}

Marcelle Godefrida Antonia van Eupen was born on January $16^{\text {th }} 1985$ in Gemert, the Netherlands. She graduated from secondary school in 2003 (Commanderij College, Gemert), after which she started her medical training at Maastricht University, Maastricht, the Netherlands. In 2009, she obtained her medical degree and started her $\mathrm{PhD}$ research at the department of Internal Medicine of the Maastricht University Medical Centre, Maastricht, within the CARIM school of Cardiovascular diseases of the same institution. The results of this research are presented in this thesis. Her PhD project was performed under supervision of promotors Prof. dr. Casper Schalkwijk and Prof. dr. Coen Stehouwer, and copromotor Dr. Miranda Schram. In 2013, she obtained a Master of Health Sciences in Clinical Epidemiology at VU University, Amsterdam. In May 2017, she graduated as a general practitioner at the Radboud University Medical Centre. 



\section{LIST OF}

PUBLICATIONS 



\section{List of publications}

van Eupen MG, Schram MT, van Sloten TT, Scheijen J, Sep SJ, van der Kallen CJ, Dagnelie PC, Koster A, Schaper N, Henry RM, Kroon AA, Smit AJ, Stehouwer CD, Schalkwijk CG. Skin Autofluorescence and Pentosidine Are Associated With Aortic Stiffening: The Maastricht Study. Hypertension. 68(4):956-63 (2016)

Spauwen PJ, van Eupen MG, Köhler S, Stehouwer CD, Verhey FR, van der Kallen CJ, Sep SJ, Koster A, Schaper NC, Dagnelie PC, Schalkwijk CG, Schram MT, van Boxtel MP. Associations of advanced glycation end-products with cognitive functions in individuals with and without type 2 diabetes: The Maastricht Study. J Clin Endocrinol Metab. 100(3):951-60 (2015)

van Eupen MG, Schram MT, Colhoun HM, Scheijen JL, Stehouwer CD, Schalkwijk CG. Plasma levels of advanced glycation endproducts are associated with type 1 diabetes and coronary artery calcification. Cardiovascular Diabetology 12:149 (2013)

van Eupen MG, Schram MT, Colhoun HM, Hanssen NM, Niessen HW, Tarnow L, Parving HH, Rossing P, Stehouwer CD, Schalkwijk CG. The methylglyoxal-derived AGE tetrahydropyrimidine is increased in plasma of individuals with type 1 diabetes mellitus and in atherosclerotic lesions and is associated with sVCAM-1. Diabetologia 56 (8):1845-1855 (2013)

Versluis B, Backes WH, van Eupen MG, Jaspers K, Nelemans PJ, Rouwet EV, Teijink JA, Mali WP, Schurink GW, Wildberger JE, Leiner T. Magnetic resonance imaging in peripheral arterial disease: reproducibility of the assessment of morphological and functional vascular status. Investigative Radiology 46(1):11-24 (2011) 
